PUMPED HYDROELECTRICITY AND UTILITY-SCALE BATTERIES FOR RESERVE ELECTRICITY GENERATION IN NEW ZEALAND

by

Gareth Kear

Thesis

ENVIRONMENTAL STUDIES 593

2011

A 90 point thesis submitted to Victoria University of Wellington, as partial fulfilment of requirements for the degree of Master of Environmental Studies

School of Geography, Environment and Earth Sciences

Victoria University of Wellington

March 2011 


\title{
PUMPED HYDROELECTRICITY AND UTILITY-SCALE BATTERIES FOR RESERVE ELECTRICITY GENERATION IN NEW ZEALAND
}

\author{
Gareth Kear
}

\begin{abstract}
Non-pumped hydroelectricity-based energy storage in New Zealand has only limited potential to expand to meet projected growth in electricity demand. Seasonal variations of hydro inflows have also led to several 'dry-year' events over the last decade and dedicated fast-start 'peaker' capacity may also be required to support wind power as it approaches a $20 \%$ generation share. In this research, the New Zealand electricity industry has been surveyed in regard to the feasibility of reducing $\mathrm{CO}_{2}$-e emissions through the introduction of pumped hydroelectricity and utility-scale batteries by 2025. A desk-based review of the economic costs of these technologies has also been performed and their drivers and barriers critically assessed.
\end{abstract}

Most respondents to the survey projected that peak power demand will continue to increase and this will result in new-build centralised $(\sim 150 \mathrm{MW})$ thermal reserve power sources. In New Zealand, the costs of pumped hydro and batteries are seen to be prohibitive to their introduction, even though they are almost universally assumed to be technically capable of providing renewables support and peak power adequacy. The perception of the poor economic viability of pumped hydro may, in part, be due to the relatively high capital cost estimate associated with the Manorburn-Onslow proposal ( NZ\$3 billion). This research has shown, however, that smaller, 'more-internationally-representative' pumped hydro schemes, if available in NZ with low associated environmental impact, are cost-competitive with thermal peakers, especially diesel peakers. Conversely, utility-scale batteries have very high storage costs per kWh and are most likely to be used only for very high value applications where there is a strong technical advantage, such as the six-second fast instantaneous reserve.

Keywords: New Zealand; energy storage; cost of storage; reserve generation; renewable electricity generation; electricity demand; energy policy; pumped hydropower; utility-scale batteries; dry-year generation; hydro spillage; wind spillage. 


\section{Acknowledgements}

This work was funded by a Victoria University of Wellington Masters by Thesis Scholarship.

The author would like to thank his supervisor Associate Professor Ralph Chapman. Considerable thanks are also given to Dr. Mike Gavin and Ms. Suzanne Weaver (Victoria University of Wellington) and all those who responded to the Energy Storage Survey. 
Abstract $\quad$ ii

Acknowledgements $\quad$ iii

Contents iv

List of figures $\quad$ vi

List of tables $\quad$ vii

\section{Introduction}

1.1 Green-house gas emissions and thermal electricity generation in New Zealand 1

1.2 The New Zealand electricity market 3

1.3 Reserve generation 4

1.4 Thermal generation in New Zealand 6

1.5 Introduction to pumped hydroelectricity and battery-based energy storage $\quad 15$

1.6 Aims

1.6.1 The potential of introduced forms of energy storage 19

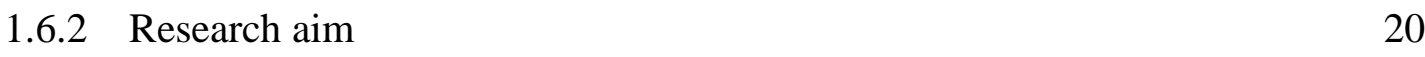

$\begin{array}{ll}\text { 1.6.3 Research questions } & 20\end{array}$

$\begin{array}{lll}\text { 1.6.4 Assumptions } & 21\end{array}$

$\begin{array}{lll}\text { 1.6.5 Positionality statement } & 22\end{array}$

\section{Experimental method}

2.1 Desk-based literature review 23

2.2 Calculation of the cost of storage 23

2.3 Survey 25

2.3.1 Introduction and list of respondents 25

2.3.2 Victoria University of Wellington ethics approval 28

$\begin{array}{lll}2.3 .3 & \text { Questionnaire } 28\end{array}$

$\begin{array}{lll}\text { 2.3.4 Semi-structured interview } & 30\end{array}$

3 Results

3.1 Desk-based analysis 34

3.1.1 Electricity demand, supply-side bias and centralised generation 34

3.1.2 Dry-year security of supply 38

3.1.3 GHG emissions reduction and the price of carbon 39

3.1.4 Policy measures complementary to the NZ ETS 42

3.1.5 Support of variable-output renewables 44

3.1.6 Wind-spillage mitigation 46

$\begin{array}{lll}3.1 .7 & \text { Hydro-spillage mitigation } & 47\end{array}$ 
$\begin{array}{lll}3.1 .8 & \text { Cost-analysis } & 49\end{array}$

3.1.9 The Manorburn-Onslow pumped hydroelectricity proposal 65

3.2 Questionnaire 68

3.3 Semi-structured interview 84

3.3.1 Framework of themes and responses 85

$\begin{array}{lll}3.3 .2 & \text { Emergent themes } & 93\end{array}$

\section{Discussion}

4.1 Introduction 96

4.2 Perceived drivers 96

4.3 Perceived barriers 104

4.4 Limitations of the research 110

4.5 Further work 111

5 Conclusions 112

6 References $\quad 115$

7 Appendices

Appendix A Method of calculation of cost of energy storage per kWh 132

Appendix B Survey information sheet 134

Appendix C Consent to participation forms 136

$\begin{array}{lll}\text { Appendix D Survey ethics approval } & 138\end{array}$

$\begin{array}{lll}\text { Appendix E Questionnaire } & 139\end{array}$

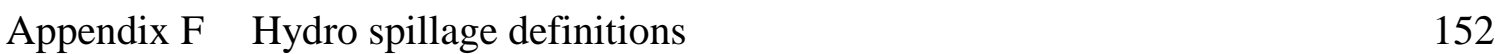

Appendix G Tabulated summaries of interview responses 153

Appendix H Thermal reserve capacity under EC and MED scenarios to 2040 163 


\section{List of figures (captions abbreviated)}

Figure 1.1. Trends in electricity generation from renewable flows and thermal generation.

Figure 1.2. Electricity generation emissions by fuel type.

Figure 1.3. $\quad$ Energy-derived GHG emissions from NZ by sector during 2008.

Figure 1.5. Projected sum of installed capacity of dedicated diesel and gas peaking power stations.

Figure 1.6. Generation rates and capacity factor for the Whirinaki Power Station.

Figure 1.7. Generation rates from the Huntly site.

Figure 1.8. Annual rates and May-October rates of generation from thermal power stations.

Figure 1.9. Estimated values of additional generation during dry years.

Figure 1.10. Annual and May-October rates of generation from thermal power stations.

Figure 1.11. Estimated values of additional normalised generation rates from thermal power stations.

Figure 1.12. The total monthly sum of the output from the primary dry-year reserve generators.

Figure 1.13. Generalised capital cost comparison per installed kW of electrical power generation capacity.

Figure 1.14. The concepts of load levelling and peak shaving in relation to energy storage.

Figure 2.1. Typical examples of the Likert scale-based response scales.

Figure 2.2. A generalised technology comparison of per cycle cost of energy storage.

Figure 3.1. Historic hydro flow rates into NZ's main hydroelectric systems prior to 2008.

Figure 3.2. Trends in New Zealand's sectoral and total $\mathrm{CO}_{2}$-e emissions from 1990.

Figure 3.3. Framework for the integration of renewables into a hypothetical electricity network.

Figure 3.4. $\quad$ Energy spilled from high inflow and cost during 2008.

Figure 3.5. Long-run marginal cost of new electricity generation projects from various generation sources.

Figure 3.6. $\quad$ EC- and MED-derived projected long-run marginal costs of generation in NZ.

Figure 3.7. A generalised technology comparison of efficiency and time to end of life of energy storage.

Figure 3.8. A generalised technology comparison of capital cost per unit energy output of energy storage.

Figure 3.9. Cost of storage $(S)$ per kWh $v s$. time of discharge from $10 \mathrm{MW}, 80 \mathrm{MWh}(8 \mathrm{~h})$ systems.

Figure 3.10. The energy storage capacity available within the lakes at the Manorburn-Onslow depression.

Figure 3.11. Simulated energy storage data for the proposed Manorburn-Onslow depression PH scheme.

Figure 3.12. Response to Questions $1 \& 3$.

Figure 3.13. Response to Question 2.

Figure 3.14. Response to Question 4.

Figure 3.15. Response to Questions 5 \& 6.

Figure 3.16. Response to Question 7.

Figure 3.17. Response to Question 8.

Figure 3.18. Response to Question 9.

Figure 3.19. Response to Question 10.

Figure 3.20. Response to Question 11.

Figure 3.21. Responses to Questions 12-15.

Figure 3.22. Response to Question 16.

Figure 3.23. Response to Question 16.

Figure 3.24. Response to Question 16.

Figure 3.25. Response to Question 17.

Figure 3.26. Response to Question 18.

Figure 3.27. Response to Question 19.

Figure 4.1. Trend in hydroelectricity-based capacity in NZ. 


\section{List of tables (captions abbreviated)}

Table 1.1. Reserve power definitions (USA).

Table 1.2. New Zealand's thermal power stations.

Table 1.3. Primary dry-year reserve thermal power stations operating in NZ.

Table 1.4. Historical values of total generation from all grid-connected power stations in NZ.

Table 1.5. Review of utility-scale applications of grid-connected energy storage technologies.

Table 1.6. Comparison of utility-scale PH- and battery-based energy storage technologies.

Table 1.7. Summary of typical parameters associated with peaking/spinning reserve and wind adequacy.

Table 2.1. List of informants to which a request for participation was submitted.

Table 3.1. Review of projected annual electricity demand growth rates for New Zealand.

Table 3.2. Governance based demand-side management measures assessed for application to NZ.

Table 3.3. Values of EC-derived annual $\mathrm{CO}_{2}$-e emissions projections for peaking and coal-based reserves.

Table 3.4. Economic assessment of the Huxley Hill Wind Farm battery system on King Island, Australia.

Table 3.5. $\quad$ EC-derived LRMC and SRMC of generation from thermal reserve power stations in NZ.

Table 3.6. MED-derived (2010) LRMC of new generation from thermal power within the NZ context.

Table 3.7. Review of the relative merits the redox flow battery and enclosed battery types.

Table 3.8. Parameters and values used to derive cost-of-storage data.

Table 3.9. Costs of storage per kWh of all-vanadium, zinc-bromine and sodium-sulfur batteries.

Table 3.10. Estimated capital costs of large-scale all-vanadium batteries of various power ratings.

Table 3.11. Estimated capital costs and power and energy capacities of GW-scale PH facilities.

Table 3.12. Standard values of the parameters used to estimate the cost of storage for PH facilities.

Table 3.13. Estimated costs of storage per $\mathrm{kWh}$ of the $\mathrm{PH}$ facilities.

Table 4.1. A list of primary drivers (perceived) of PH and utility-scale batteries.

Table 4.2. A list of primary barriers (perceived) of PH and utility-scale batteries.

Table 4.3. Comparison of the perceived advantages and disadvantages of PH and utility-scale batteries.

Table 4.4. MED-modelled LRMC costs of generation - thermal peakers and renewables-based generators.

Table AF1. Typical definitions of the terms and categories used to describe hydro spillage in NZ.

Table AG1. Summary of responses obtained during the interview for Question A1.

Table AG2. Summary of responses obtained during the interview for Question A2.

Table AG3. Summary of responses obtained during the interview for Questions B1.

Table AG4. Summary of the perceived negative aspects of increasing the capacity of thermal generation.

Table AG5. Summary of responses obtained during the interview for Questions B2.

Table AG6. Summary of responses obtained during the semi-structured interview for Questions C1.

Table AG7. Summary of responses obtained during the semi-structured interview for Questions C2.

Table AG8. Summary of responses obtained during the semi-structured interview for Questions D1.

Table AG9. Summary of responses obtained during the semi-structured interview for Questions E1.

Table AG10. “Do NZ-new types of utility-scale energy storage technologies have a future in NZ?”

Table AG11. Summary of responses obtained during the semi-structured interview for Questions E2.

Table AH1. Review of EC-derived, 2008 SOO-projected new-build schedule of reserve plant.

Table AH2. EC-derived cumulative sums of peaking and Huntly dry-year reserve power capacity.

Table AH3. Review of MED-derived projections of new-build schedule of reserve plant.

Table AH4. Summary of MED-derived sums of peaking and Huntly Units 1-4 dry-year reserve capacity. 



\section{Introduction}

1.1 Green-house gas emissions and thermal electricity generation in New Zealand

The work of the Intergovernmental Panel on Climate Change [1] has led the United Nations Framework Convention on Climate Change Conference (UNFCCC) Parties to continue to call for Annex 1 countries to adopt national targets of $25 \%$ to $40 \%$ greenhouse gas (GHG) emissions abatement vs. 1990 levels by 2020 [2,3]. The historic legacy of emissions and the high average rate of current emissions from developed world nations $\left(\sim 12\right.$ tonnes $\left[\mathrm{CO}_{2}\right.$-e] capita $\left.{ }^{-1} \mathrm{y}^{-1}[4]\right)$, has led the UNFCCC to note that primary responsibility for $\mathrm{CO}_{2}$-e mitigation should be accepted by these countries, including New Zealand (NZ).

However, total emissions from the NZ energy sector have increased 22.7\% since 1990 [5-7] reflecting a general trend in increasing electricity generation from thermal-based sources (Figure 1.1). In 2007 and 2008, for example, NZ's $\mathrm{CO}_{2}$-e energy-derived emission rates were 33,056 and 34,262 ktonne $\mathrm{y}^{-1}$, respectively, and electricity generation contributed 6,675 and 7,686 ktonne $\mathrm{y}^{-1}$ in each case $[8,9]$. The electricity industry has also contributed the largest percentage increase in GHGs of any sector since 1990.

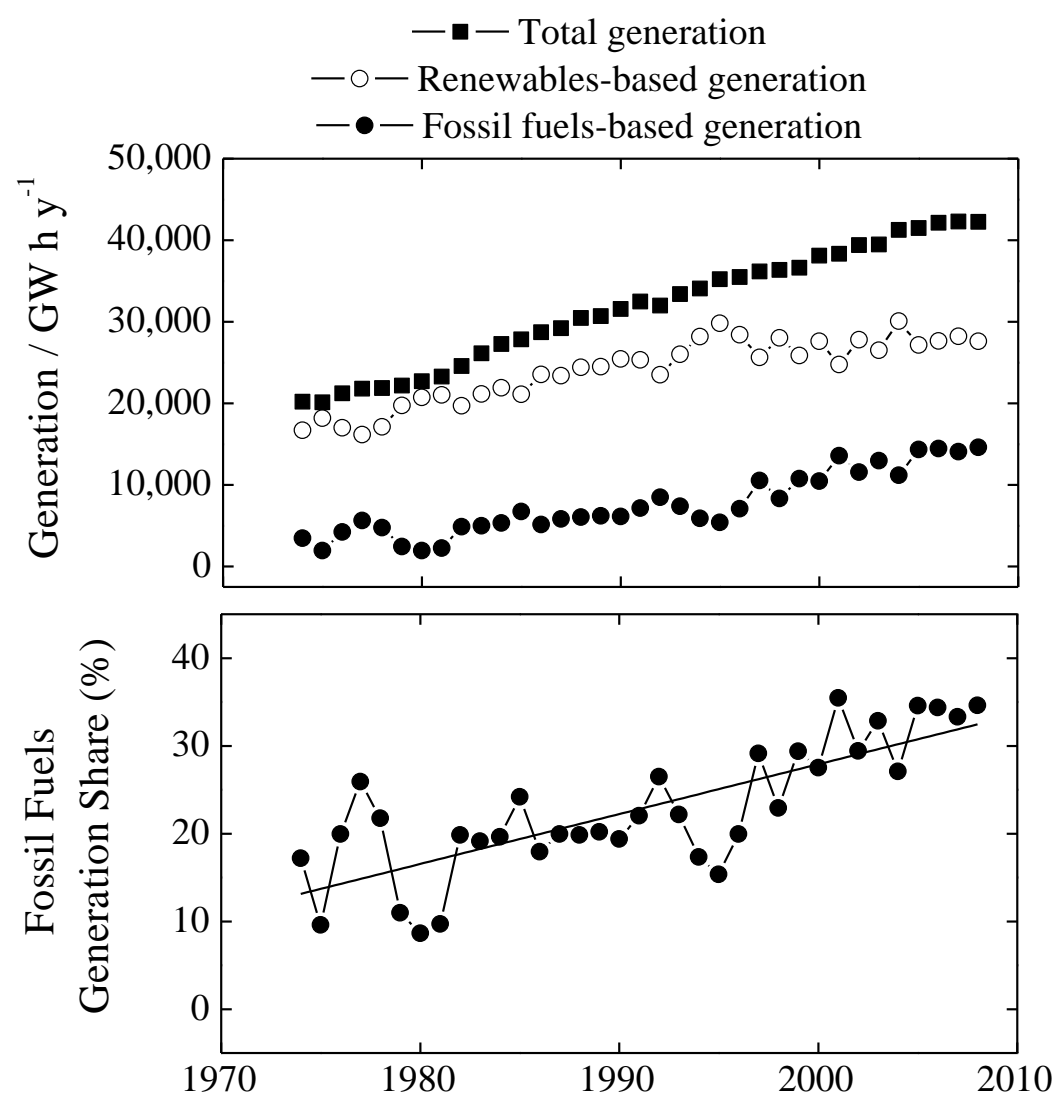

Figure 1.1. Trends in the proportion of total electricity generation from renewable flows and thermal generation in NZ from 1974 to 2008. Plots were created from data presented within the NZ Energy Data File [10]. 
In part, this trend is due to the increased use of coal for baseload generation (Figure 1.2) and dry-year reserve [9]. Indeed, the reduced availability of hydro-based storage during dry years [11] has increased the sectors average after-oxidation emission factor (EF) [10] through the added use of natural gas $\left(\mathrm{EF}=52-54\right.$ ktonne $\left.\left[\mathrm{CO}_{2}\right] \mathrm{PJ}^{-1}\right)$, coal $\left(87-93\right.$ ktonne $\left.\left[\mathrm{CO}_{2}\right] \mathrm{PJ}^{-1}\right)$ and, to a much lesser extent, diesel (69 ktonne $\left[\mathrm{CO}_{2}\right] \mathrm{PJ}^{-1}$ ) [12]. During 2008 (the last recorded dry year), the sector contributed $22 \%$ of all energy-derived GHG emissions (Figure 1.3 [7]).

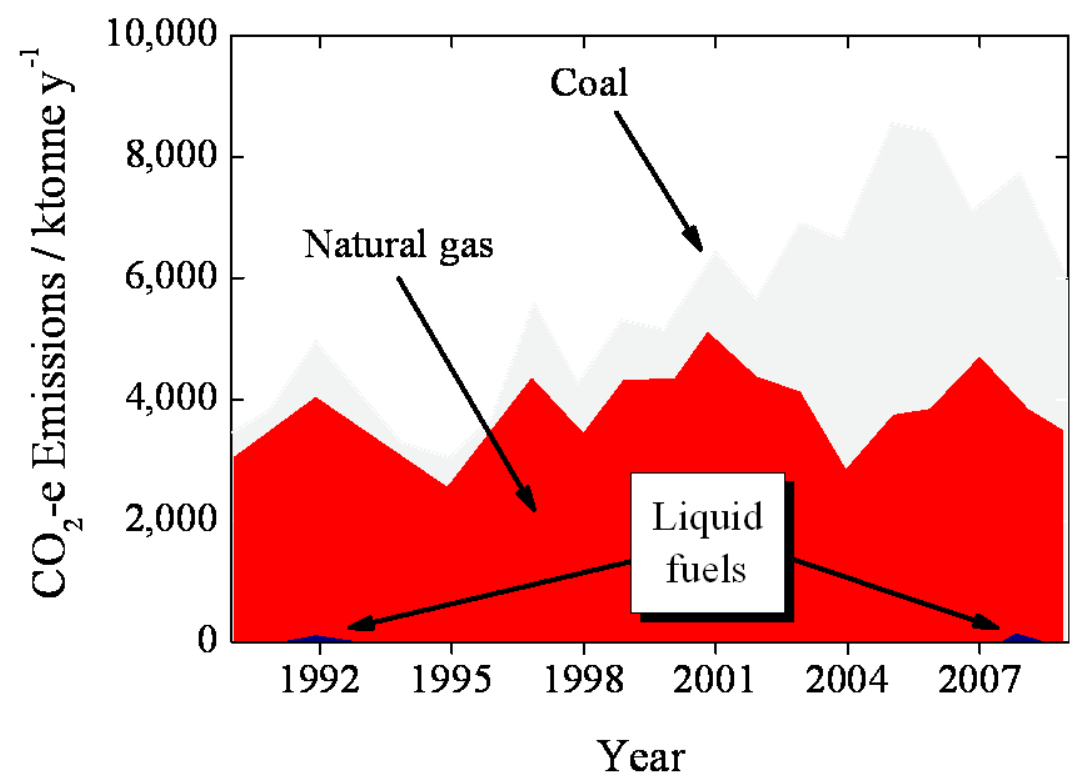

Figure 1.2. Electricity generation emissions by fuel type (stackplot), redrawn after the Ministry of Economic Development (MED) [12].

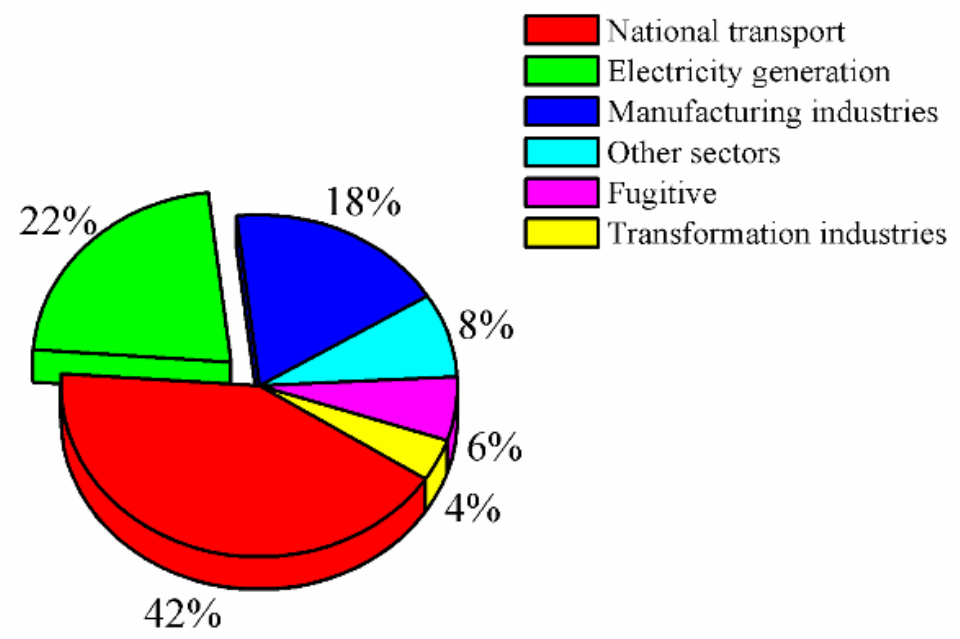

Figure 1.3. Energy-derived GHG emissions from NZ by sector during 2008, redrawn after the MED [7].

Although a conditional 2020 emissions abatement target range of between 10-20\% vs. 1990 levels by 2020 has been offered by the NZ Government in regard to a post Kyoto Protocol agreement [13-16], the 10-year restriction on the construction of new fossil-fuel-based 
electricity generation capacity [17] was repealed by the National-led Government in December 2008 [18]. The NZ Government appears to assume that development of dispatchable (firm) thermal capacity based on centralised thermal power stations will be essential $[19,20]$ in order to maintain security of supply and to achieve an aspirational goal of $90 \%$ renewables in NZ [21].

\subsection{The NZ electricity market}

After the break-up of the Electricity Corporation of NZ in 1998, three generation/retail (gentailer) companies were retained as the state owned enterprises (SOEs) [22] (Genesis Power Ltd. [Genesis], Meridian Energy Ltd. [Meridian] and Mighty River Power Ltd. [MRP]). Contact Energy Ltd. (Contact) and TrustPower Ltd. (TrustPower) are currently listed as private companies. The local, low-voltage distribution networks are managed by around twenty eight lines companies (at 2010), most of which are publicly owned [23]. The high voltage (HV) transmission grid includes a HVDC (HV direct current) $350 \mathrm{kV}$ line that runs via the Cook Strait submarine cables from the Benmore power station in the South Island to Haywards substation in the North Island [24]. SOE Transpower NZ Ltd. (Transpower) is the Systems Operator and owns, maintains and invests in the transmission system and associated infrastructure. Transmission energy losses can be $\sim 3 \%$ on average, but up to $7 \%$ for some South Island transmission routes. Some local 'embedded' generation capacity is also connected directly to the distribution networks [24].

The NZ electricity market consists of both (1) a continuous wholesale market and (2) a retail electricity market $[24,25]$. The wholesale component includes both individual fixed price contracts, known as hedging agreements and a spot price market. Hedging reduces the risk associated with short and medium term price fluctuations. Within the spot market, competitive trading occurs between twelve retailers and a number of large industrial users. Electricity is bought and sold on a half-hourly basis and priority generation is given to the generator with the lowest priced offer. The spot price of electricity is generally dependent on the availably of power capacity and a long-term trend in increasing prices can indicate a requirement for additional generation capacity to be included in the system. Generator submissions are rated in order of increasing price and the highest price for generation required to meet the projected demand dictates the spot price for all electricity that is traded within that trading period.

Generators are also required to provide ancillary services including 'reserves' for 'frequency keeping' (50 \pm 2 Hz.) and 'voltage support'. Reserve markets include: fast instantaneous reserve (FIR; $\leq 6$ seconds response over 60 seconds) and slow instantaneous reserve (SIR; $\leq$ 
$60 \mathrm{~s}$ response over 15 minutes) [24]. The reserve must be at least equal to the largest operating generator unit. The industry response to power drop-off can also include interruptible load (e.g., controllable water heating and distribution). Some large commercial grid-connected customers also have access to technology that can shut down plant on site when the spot price becomes uneconomical [25]. The electricity market is driven by centralised generation and there are no feed-in tariffs or net metering schemes for the support of renewables in general or micro- to mini-scale distributed generation. Moreover, only generators with > $30 \mathrm{MW}$ installed capacity can compete in the spot market [24].

The NZ electricity sector is unusual in that the government, through SOEs and crown entities, acts as a generator, retailer, regulator, HV transmitter and Systems Operator within a 'competitive' market system. Privatisation was also not included in the terms of reference that guided the 2010 Ministerial Review of Electricity Market Performance [26]. In January 2010, however, the National-led government indicated that it may partially sell-down the state-owned generators if it secures a second term in government after the November 2011 election [27].

\subsection{Reserve generation}

The various types of reserve power (excluding seasonal reserve) are shown in Table 1.1, as defined by the Electric Power Research Institute (EPRI) [28]. In NZ, 'peaker' capacity has been used as a descriptor for power sources that meet either (1) diurnal demand and (2) compensate for sudden grid-connected generation drop off $[29,30]$. Peaker is a term also used interchangeably with the terms 'peaking capacity' and 'spinning reserve'. The latter, however, most correctly refers to 'fast-start' capability that is waiting online to increase power output. The time to start-up of fast-start thermal sources is limited to minutes. Contact's newly commissioned $200 \mathrm{MW}$ peaker at Stratford, for example, was designed to ramp from a cold start to full power within ten minutes [31].

Table 1.1. Reserve power definitions (USA), after EPRI [28].

\begin{tabular}{ll}
\hline Regulation reserves & Generation that is continuously online and available to maintain frequency \\
\hline Spinning reserves & Generation online and 'spinning' with reserve $(<10$ min response time; operation $>2 \mathrm{~h})$ \\
\hline Non-spinning reserves & Generation that is available but not online $(<10$ min response time; operation $>2 \mathrm{~h})$ \\
\hline Replacement reserves & Generation that is capable of a $<1 \mathrm{~h}$ response time for $>2 \mathrm{~h}$ \\
\hline
\end{tabular}


The relationship between growth in mean time-averaged demand, mean peak demand and mean peak capacity over time is illustrated in Figure 1.4(a). The total capacity required during peak periods is significantly greater than actual peak demand to ensure peak adequacy. This value sets the minimum capacity of most systems [20]. A typical diurnal trend in electricity demand (a generic load curve) is also shown in Figure 1.4(b). Note that base load supply operates almost continuously [32], and comprises high capital cost, low operating cost infrastructure with a typical capacity factor $(\mathrm{CF})$ of $\geq 80-90 \%$. In NZ, base load has been traditionally supplied by hydroelectricity and, over the last decades, gas [33]. Forecast peaking events are met initially by a relatively large reserve of intermediate load-following capacity, which is more efficient than fast-start power sources.

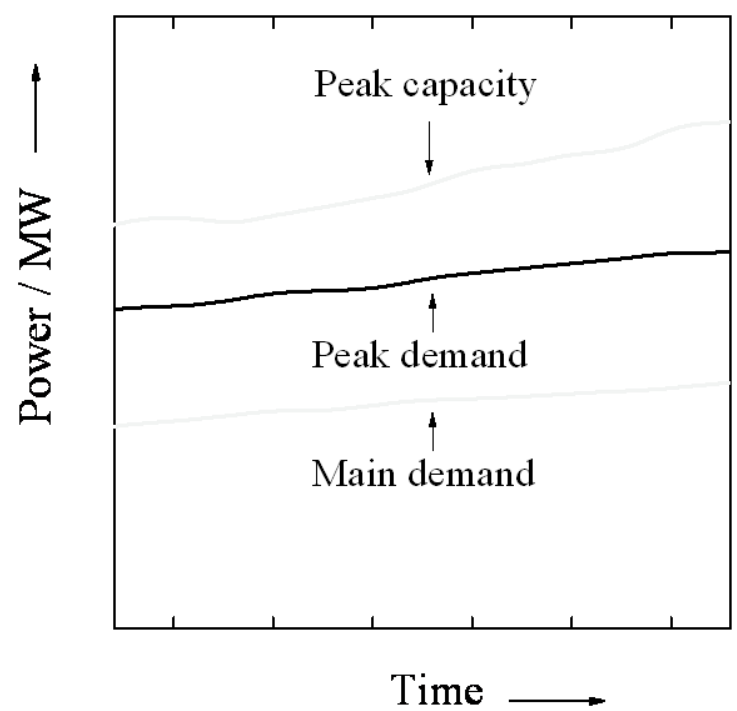

(a)

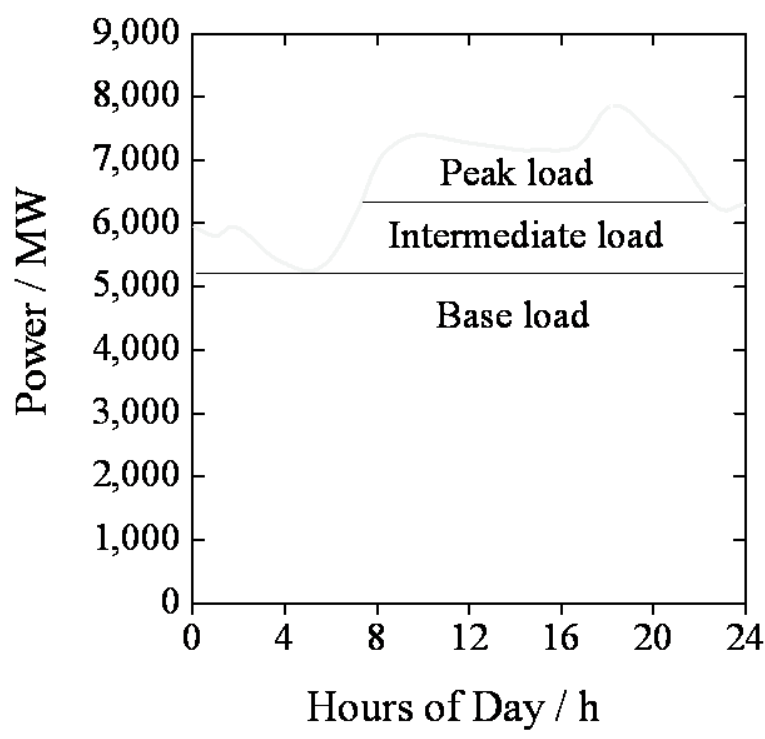

(b)

Figure 1.4. (a) The relationship between the power required to meet mean demand, mean peak demand and to ensure peak adequacy and security of supply, redrawn from IPENZ [19]. The time scale of growth, as shown, is of the order of years or decades. (b) Generic winter demand load profile. An almost continuous base load is indicated, with a diurnal requirement for peaking generation during the hours 8 am to $10 \mathrm{pm}$, redrawn from [34].

In NZ, thermal reserve generation has also been adopted for (1) seasonal security of supply during dry-years and (2) the future support of wind power [35,36]. The Electricity Commission's (EC's) 2008 Statement of Opportunities summarised the latter as follows:

"Thermal peakers are able to start relatively quickly from cold, but the ability of mid-order thermal plant to ramp up in time may be limited. The implication is that with increased amounts of wind generation, variability may require relatively expensive peaking generation to be dispatched, which could increase system costs. Further, if wind output is low when demand is near annual peak, then some form of peaking generation will certainly be required." [20]. 
However, this outlook is somewhat limited and pumped hydroelectricity or batteries were not considered in detail, although both of these technologies (and other forms of storage) have fast-start capability [37]. Moreover, unlike gas peaking turbines, which are relatively inefficient and can emit a considerable amount of nitrogen-based oxides when ramped [38], storage will emit negligible levels of GHGs when charged via renewable power sources [39].

Bertram and Clover have considered that, with fuel- and $\mathrm{CO}_{2}$-e-price increases the primary role of fossil fuel-based electricity generation will be "limited to specialist roles", including dry-year reserve and the support of variable-output renewables [33]. However, policy conditions change and a legacy of investment in thermal reserves now will impede the development of a 100\% renewables-based sector without an additional financial penalty [40]. Locking into a paradigm that relies on thermal backup will not enable the complete mitigation of emissions from the sector, or long-term energy independence in times of fuel price uncertainty.

\subsection{Thermal generation in New Zealand}

Table 1.2 presents a summary of the transmission-grid-connected thermal power stations operating in $\mathrm{NZ}$ ( $\geq 50 \mathrm{MW}$ ). Also included is plant that, although not operating at full capacity, has been used for backup over the previous decade. A number of these stations have multiple roles, such as Huntly (base load and dry-year reserve) and Otahuhu A (reactive power stability and reserve). As they approach end-of-life condition, the older, less efficient installations are reserved for higher-value backup applications. For example, New Plymouth (closed) and Otahuhu A were used when high spot prices triggered dry-year operation.

The majority of peaking generation is currently derived from hydroelectricity and, other than the Whirinaki (155 MW) and Huntly p40 (50 MW) open cycle gas turbines (OCGTs), there has been little dedicated fast-start thermal peaking capacity available since the four $50 \mathrm{MW}$ gas-fired, Pratt and Whitney FT4 turbines at Stratford Power Station were decommissioned in 2001.

Indeed, in 2008, the Electricity Commission's Statement of Opportunities (SOO) estimated (Figure 1.5) that the combined gas and diesel-based peaking capacity was around $200 \mathrm{MW}$ (prior to commissioning of the Stratford peaker). Even though the long-run marginal costs (LRMCs) of generation of peakers are already two-five times greater than the LRMCs of new base load generation [41], the EC considered that growth in this area is likely to be significant (for example, a further 650 MW by 2025 under the SOO's 'Demand-Side Participation' scenario). 
Table 1.2. New Zealand's thermal power stations that are currently operating, or have been recently closed/decommissioned ( $\geq 45 \mathrm{MW}$ ) [42-45]. All data have been derived from the open literature. The primary characteristics of each station are given.

\begin{tabular}{|c|c|c|c|c|c|}
\hline $\begin{array}{l}\text { Power station } \\
\text { (date commissioned) }\end{array}$ & Primary fuel & $\begin{array}{l}\text { Installed } \\
\text { power / MW }\end{array}$ & Primary role/s & $\begin{array}{l}\text { Owner \& } \\
\text { operator }\end{array}$ & $\begin{array}{l}\text { Typical gen. / } \\
\text { GWh y } \mathbf{y}^{-1}\end{array}$ \\
\hline \multicolumn{6}{|l|}{ Operating } \\
\hline Huntly (1983) & Units 1-4 Coal/gas & 1,000 & $\begin{array}{l}\text { Baseload \& dry- } \\
\text { year reserve }\end{array}$ & Genesis & 5,695 \\
\hline Huntly e3p (2006) & Unit 5 natural gas & 385 & Baseload & Genesis & 2,410 \\
\hline Huntly p40 (2004) & Unit 6 natural gas & 50 & Peaking (OCGT) & Genesis & 335 \\
\hline Otahuhu A (1968) & Natural gas & 55 & $\begin{array}{l}\text { Reactive power } \\
\text { stability \& reserve }\end{array}$ & Contact & - \\
\hline Otahuhu B (2000) & Natural gas & 400 & Baseload & Contact & 2,380 \\
\hline Southdown (1996) & $\begin{array}{l}\text { Natural gas } \\
\text { (cogeneration) }\end{array}$ & 175 & $\begin{array}{l}\text { Baseload, peaking } \\
\& \text { voltage support }\end{array}$ & $\begin{array}{l}\text { Mighty River } \\
\text { Power }\end{array}$ & 850 \\
\hline $\begin{array}{l}\text { Taranaki combined } \\
\text { cycle* (1998) }\end{array}$ & Natural gas & 385 & Baseload & Contact & 3,350 \\
\hline Whirinaki (2004) & Diesel & 155 & $\begin{array}{l}\text { Dry-year reserve \& } \\
\text { peaking (OCGT) }\end{array}$ & Meridian & 9 \\
\hline \multicolumn{6}{|c|}{ Recently closed (not officially decommissioned) } \\
\hline $\begin{array}{l}\text { New Plymouth } \\
\text { (1974) Closed Dec. } \\
2007 \dagger\end{array}$ & Natural gas & 360 & $\begin{array}{l}\text { Baseload \& dry- } \\
\text { year reserve } \\
\text { towards end of life }\end{array}$ & Contact & - \\
\hline \multicolumn{6}{|c|}{$\begin{array}{l}\text { * Abbreviated to Taranaki CC or TCC. The new Stratford } 200 \text { MW peaking plant is due to be commissioned on the same } \\
\text { site as the existing Taranaki CC Power Station. }\end{array}$} \\
\hline \multicolumn{6}{|c|}{$\begin{array}{l}\dagger \text { The power plant decreased in use from } 2000 \text { and was closed in December } 2007 \text {. But this plant has seen some use after this } \\
\text { phase out period as a dry-year reserve generator. For example, a } 100 \mathrm{MW} \text { unit of this plant was temporary used in May } \\
2008 \text { to compensate for dry-year hydroelectricity shortfalls and to reduce the associated increases in wholesale electricity } \\
\text { prices [46]. The New Plymouth Power Station, however, is unlikely to contribute to dry-year generation into the medium } \\
\text { term. }\end{array}$} \\
\hline
\end{tabular}

Whirinaki Power Station was commissioned (2003) as a dry-year reserve and has operated at an extremely low capacity factor (CF), Figure 1.6, which would have had a significant impact on the cost-effectiveness of this plant. During non-dry years the monthly CF has been negligible. The overall average monthly CF from 2003 to 2010 was only 0.02 . The averaged CF over 2009 (a non-dry year) was $<0.01$. Dry year spikes in generation $(2003,2005$ and 2008 [11,47], Figure 1.6[a]), however, have produced CFs of 0.1 to 0.4 . Using a higher temporal resolution (Figure 1.6[b]), it can also be shown that Whirinaki has not operated on a regular diurnal basis, i.e., as a peaker. ${ }^{1}$ There were no generation data available for the Stratford peaker at the time of publication. Conversely, the mean diurnal generation rate data

\footnotetext{
${ }^{1}$ The OCGT technology could allow Whirinaki to operate as a fast-start generator. The gas turbine components of the Whirinaki Power Station could also be converted to gas combustion and could, for example, be transferred to a location closer to the North Island's west-coast gas fields.
} 
for all six Huntly units (Figure 1.7[a]) indicate that, when considered as a single facility, Huntly does have a load-following role. Peaks are observed at around seven to eight a.m. and seven p.m. Generation during peak times is, on average, double the generation rate during off-peak. The p40 unit is a load follower, but was relatively inactive during 2009 and it did not then appear to have had a significant dry-year role (Figure 1.7[b]). The Huntly e3p unit also appears only to have operated for base load supply with a relatively constant monthly output of $\sim 200 \mathrm{GWh}$.

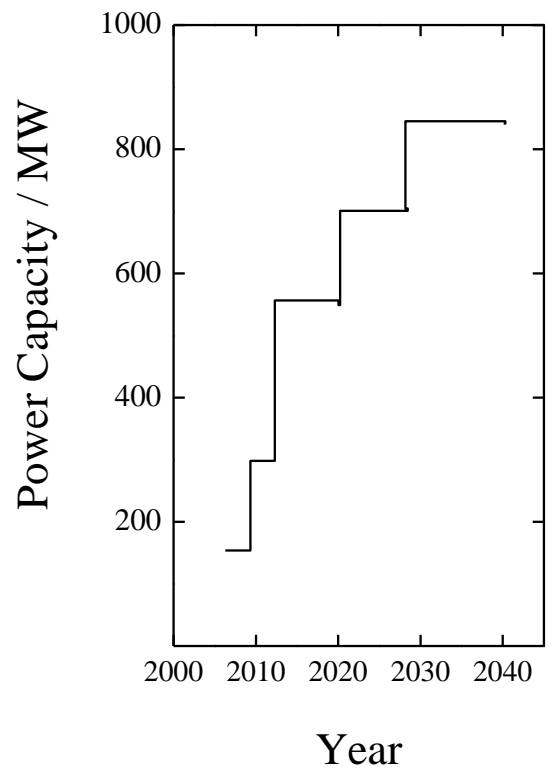

Figure 1.5. Projected sum of installed capacity of dedicated diesel and gas peaking power stations, source the EC [20]. (Post-2008 data are EC-modelled projections). NB: dedicated power capacity of total peaking plant was less than $200 \mathrm{MW}$ in 2008 but grows to more than $800 \mathrm{MW}$ by 2030 under the 'Demand-side Participation' scenario.

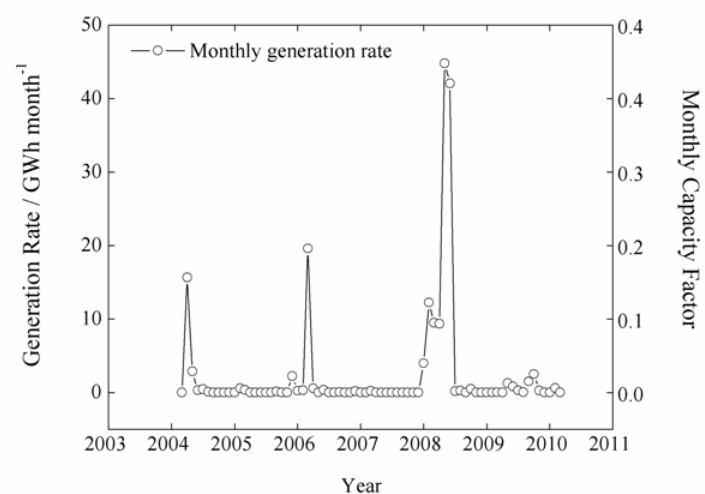

(a)

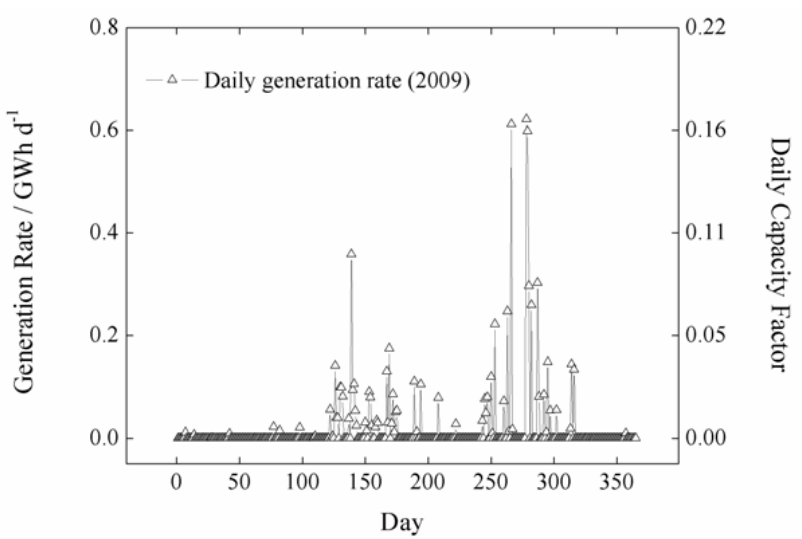

(b)

Figure 1.6. (a) Monthly Generation rate and capacity factor for the Whirinaki Power Station since commissioning. (b) Daily generation rate and capacity factor for the Whirinaki Power Station during 2009. The plots were derived from data given within the EC's 'Generation by Plant' online database (now EA website) [43]. 


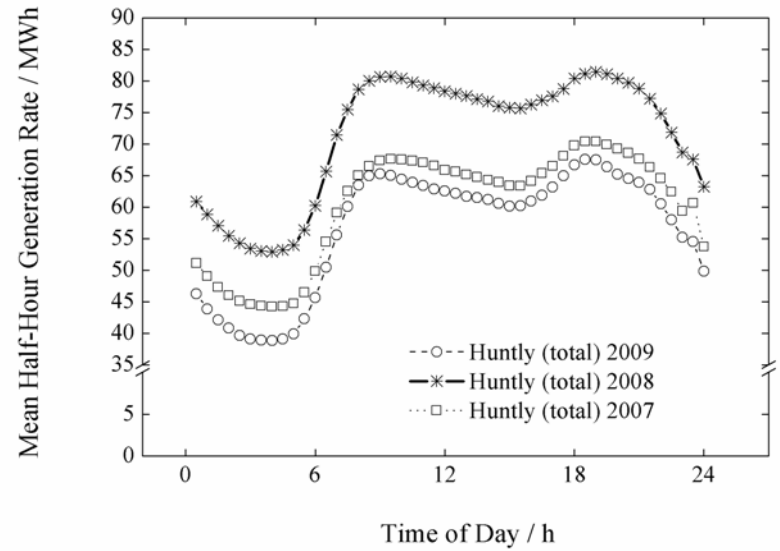

(a)

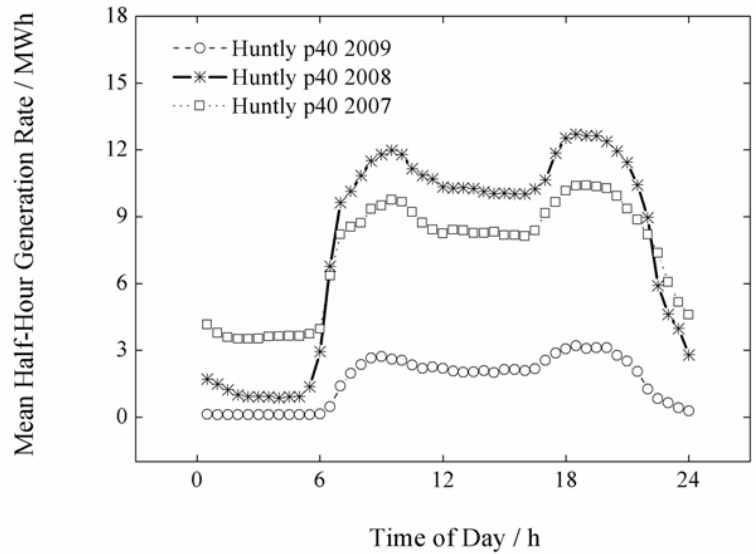

(b)

Figure 1.7. (a) Annual mean half-hourly generation rate from the Huntly site (sum of energy production from Units 1-4, p40 and e3p) for 2007, 2008 and 2009. (b) Annual mean half-hourly generation rate from the Huntly p40 gas-fired generator site 2007, 2008 and 2009. The data were extracted from information given within the EC's Centralised Dataset [44].

Regardless, Huntly has made the largest contribution to reserve generation (both coal and gas) and has added the majority of additional $\mathrm{CO}_{2}$-e emissions from the electricity sector during dry-year events.

In this research, the ep3 and p40 generation data were extracted from the EC's Centralised Data Set [44] for all of the power sources listed in Table 1.2 and the following variables were calculated:

- absolute value of thermal energy generation from individual stations, $E_{\mathrm{i}}^{\text {Station }}$,

- absolute value of total thermal energy generation of all stations is examined, $E_{\mathrm{i}}^{\text {Thermal }}$,

- the additional energy generation that is estimated to have occurred during a dry year (relative to a baseline drawn between the preceding and subsequent years), $E_{\mathrm{i}}^{\text {Dry year }}$,

- the fraction of energy generation derived from station $\mathrm{i}, E_{\mathrm{i}}^{\text {Station }}$ normalised by dividing by total national generation, $E_{\mathrm{F}}^{\text {Station, }}$

- $E_{\mathrm{i}}^{\text {Thermal }}$ normalised by dividing by total national generation, $E_{\mathrm{F}}^{\text {Thermal }}$, and

- normalised energy generation estimated to have occurred during a dry year relative to the normalised rate of generation estimated for the preceding and subsequent years, $E_{\mathrm{F}}^{\text {Dry year }}$. 
The trends in annual $E_{\mathrm{i}}^{\text {Station }}$ and annual $E_{\mathrm{i}}^{\text {Thermal }}$ are shown in Figure 1.8(a). Since 2003 the absolute value of total annual thermal generation has fluctuated somewhat, but thermal generation rates during the $2003^{2}, 2005$ and 2008 dry-years were usually higher than non-dry years. The peak in total thermal generation at 2005 can be resolved more effectively if only the sum of generation during the winter period is considered (Figure 1.8[b]).

The annual generation rate from the Huntly coal units has consistently been at least double that of any other power station (Otahuhu B/Huntly e3p and Taranaki CC having the second and third highest rates, respectively). Figure 1.8 also shows that Huntly is NZ's primary dryyear thermal reserve. For comparison, Whirinaki only generated $123 \mathrm{GWh}^{-1}$ compared to Huntly's 7,534 GWh $\mathrm{y}^{-1}$ in 2008, thus indicating that the pre-Ministerial Review dry year emergency response plan of the EC [48] was not implemented to any great extent.

Overall, there has been a high rate of base load generation from the introduced Huntly e3p (2007 onwards) and there has been an increasing dependence on combustion via Huntly Units 1-4. Combustion at some of the natural gas-based sites, however, has deceased. In 2008, for example, the values of $E_{\mathrm{i}}^{\text {Dry year }}$ from New Plymouth, Southdown and Taranaki CC were of the same order as that of Whirinaki ( $E_{\mathrm{i}}^{\text {Dry year }} \sim 100 \mathrm{GWh}$ for May to October inclusive).

The corresponding values of $E_{\mathrm{i}}^{\text {Dry year }}$ are presented in Figures 1.9 and the characteristics of generation from the power sources during winter events are summarised in Table 1.3. ${ }^{3}$ The estimated values of $E_{\mathrm{i}}^{\text {Station }}$ (annual) and $E_{\mathrm{i}}^{\text {Dry year }}$ are also shown in the latter.

These data indicate that the generation rate of the majority of the thermal power stations did peak relative to the adjacent non-dry years and again that the use of thermal power is increasing. The 2005 dry year illustrates an intermediate state of fuel selection with the absolute annual rate of energy transformation from coal-gas combustion at Huntly's Units 1-4 $\left(E_{\mathrm{i}}^{\text {Station }}\right)$, increasing from $4,820 \mathrm{GWh}^{-1}$ in 2003 to $6,047 \mathrm{GWh}^{-1}$ in 2005. This had increased to $7,534 \mathrm{GWh} \mathrm{y}^{-1}$ by 2008 .

However, negative values of $E_{\mathrm{i}}^{\text {Dry year }}$ (annual) were derived for Otahuhu B in 2005 and Taranaki CC in 2008 (the latter being unavailable for eight weeks from February 2008 due to an extended maintenance outage [11]).

\footnotetext{
${ }^{2}$ Generation data for 2002 was not available from the EC online database at the time of the analysis.

${ }^{3}$ The analysis of the thermal generation during the 2008 dry year is also complicated by the fact that the generators did not introduce all of the available thermal plant, in what has been described as, a 'timely manner. This resulted in the hydro resource being significantly over utilitised during the first six months of 2008. This resulted in Whirinaki being brought online for a limited time period 11. Review of the 2008 Winter and the period leading into winter. 2009, Electricity Commission: Wellington, NZ..
} 


\section{Gareth Kear (garethkear@hotmail.com)}

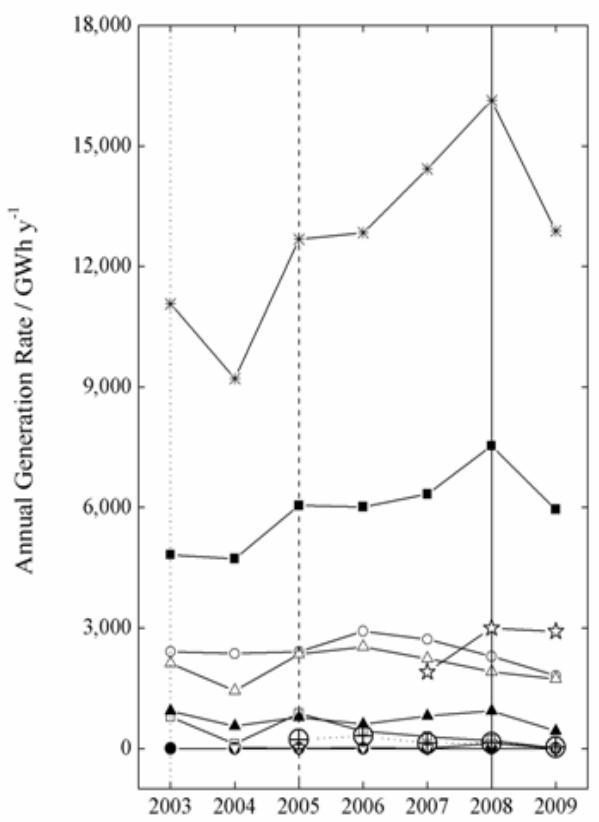

(a)

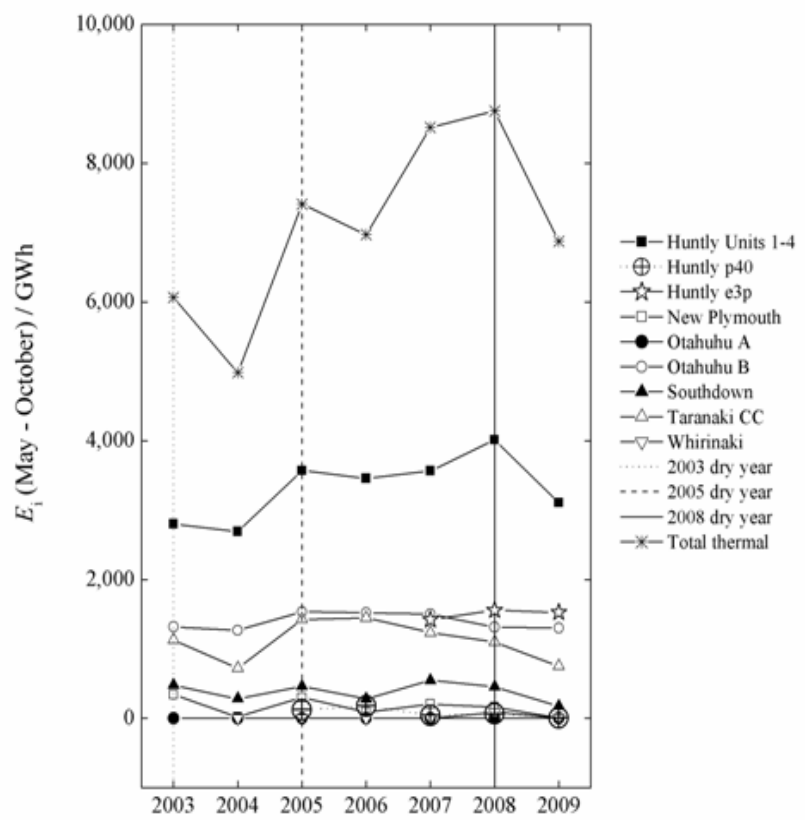

(b)

Figure 1.8. (a) Annual rates and (b) sum of May-October rates of electricity generation from the main thermal power stations connected to the NZ transmission grid for the period 2003 to 2009. Total generation is given with respect to the power stations as shown. Data were derived from the generation rates supplied by the EC's 2009 'Generation by Plant' web-based tool [43] and the Centralised dataset April 2010 [44].

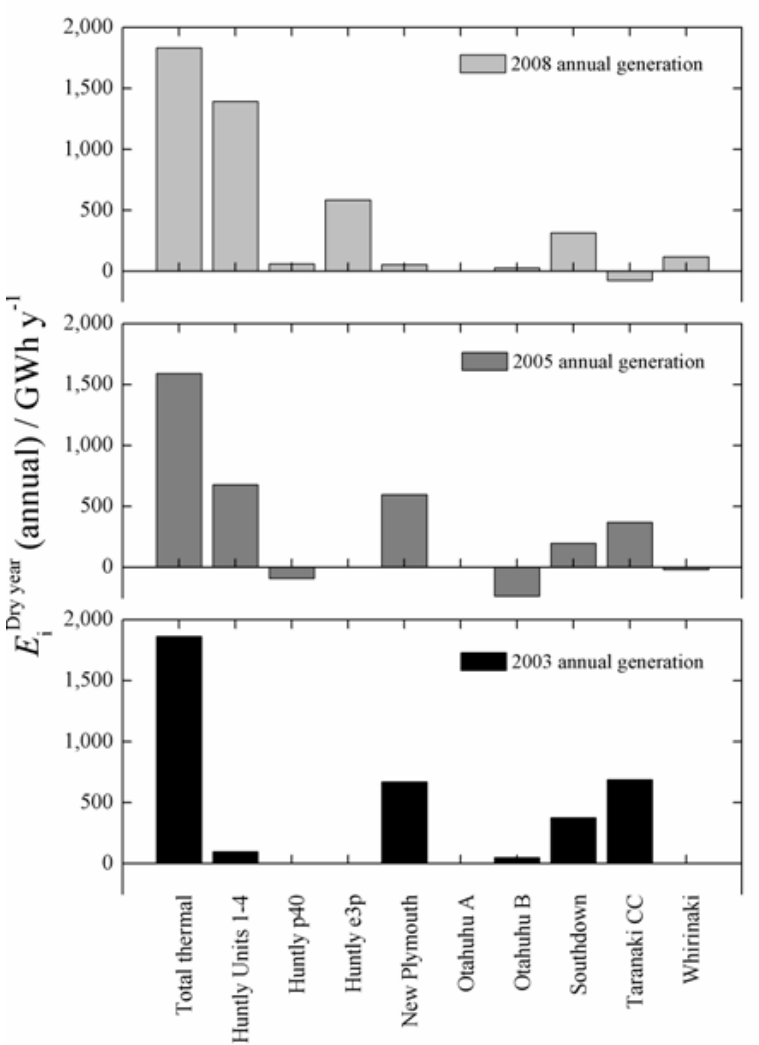

(a)

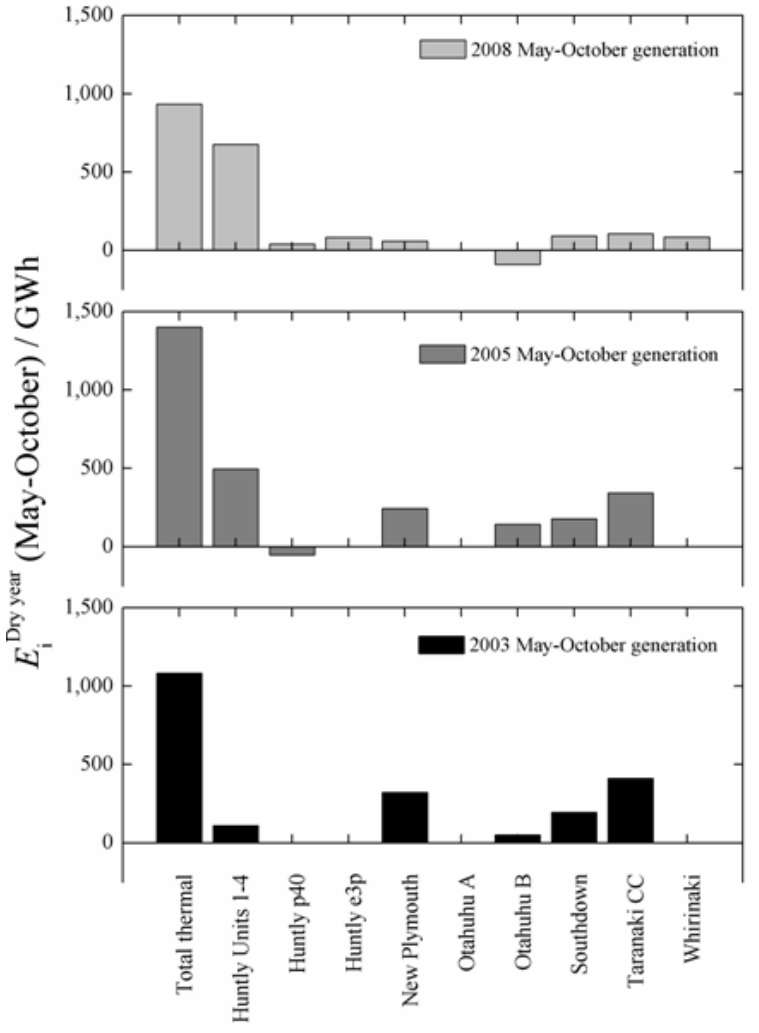

(b)

Figure 1.9. Estimated values of additional (a) annual thermal generation ( $\left.E_{\mathrm{i}}^{\text {Dry year }}\right)$ and (b) sum of May-October rates of generation supplied by each power station during dry-years (2003, 2005 and 2008) relative to non-dry years $(2004,2006,2007$ and 2009). 
Table 1.3. Primary dry-year reserve thermal power stations operating in NZ over the 2003, 2005 and 2008 dry years (selected on the basis of the outputs of the data presented in Figure 1.9).

\begin{tabular}{|c|c|c|c|c|c|}
\hline Power Station & $\begin{array}{l}\text { Total annual } \\
\text { generation rate / } \\
\text { GWh } \mathbf{y}^{-1}\end{array}$ & $\begin{array}{l}\text { Winter generation } \\
\text { rate (May-October) / } \\
\text { GWh }\end{array}$ & $\begin{array}{l}\text { Percentage of } \\
\text { total annual } \\
\text { generation }(\%)\end{array}$ & $\begin{array}{l}\text { Annual } \\
\boldsymbol{E}_{\mathrm{i}}^{\text {Dry year }} / \\
\mathbf{G W h ~ y}^{-1} *\end{array}$ & $\begin{array}{l}\text { May-October } \\
\boldsymbol{E}_{\mathrm{i}}^{\text {Dry year }} \\
\text { / GWh } *\end{array}$ \\
\hline \multicolumn{6}{|l|}{2008} \\
\hline Huntly Units $1-4$ & 7,534 & 4,013 & 18.38 & 1393 & 677 \\
\hline Huntly e $3 p \dagger$ & 2995 & 1557 & 6.79 & 585 & 84 \\
\hline New Plymouth $\nleftarrow$ & 201 & 1,61 & 0.49 & 54 & 60 \\
\hline Southdown & 936 & 454 & 2.28 & 314 & 93 \\
\hline Taranaki CC & 1,911 & 1,099 & 4.66 & -75 & 106 \\
\hline Whirinaki & 123 & 88 & 0.30 & 119 & 85 \\
\hline Totals & 13,839 & 7,438 & 31.37 & 2450 & 1146 \\
\hline \multicolumn{6}{|l|}{2005} \\
\hline Huntly Units $1-4$ & 6,047 & 3,570 & 14.90 & 679 & 496 \\
\hline New Plymouth $\ddagger$ & 873 & 298 & 2.15 & 597 & 245 \\
\hline Otahuhu B & 2,406 & 1,535 & 5.93 & -236 & 141 \\
\hline Southdown & 777 & 459 & 1.91 & 198 & 178 \\
\hline Taranaki CC & 2349 & 1,425 & 5.79 & 368 & 342 \\
\hline Totals & 12,673 & 7,411 & 31.07 & 1671 & 1437 \\
\hline \multicolumn{6}{|l|}{2003} \\
\hline Huntly Units $1-4$ & 4,820 & 2,799 & 12.49 & 97 & 109 \\
\hline New Plymouth $\ddagger$ & 785 & 340 & 2.03 & 670 & 322 \\
\hline Otahuhu B & 2,410 & 1,318 & 6.25 & 50 & 51 \\
\hline Southdown* & 933 & 477 & 2.42 & 377 & 195 \\
\hline Taranaki CC & 2,123 & 1,130 & 5.50 & 688 & 410 \\
\hline Totals & 11,070 & 6,064 & 28.69 & 1,882 & 1,087 \\
\hline
\end{tabular}

* Estimated for the purposes of this research.

$\uparrow$ Generally operates for baseload and the value of energy generated is consistent between years. Did contribute to total thermal generation during the 2008 dry year.

$\$$ New Plymouth Power station was closed prior to 2008, although reopened for the 2008 dry year and is thus unlikely to contribute to medium to long-term future of dry-year reserve generation.

Identical trends were observed when the above results were normalised for total annual generation, $E_{\mathrm{T}}$, (Figures 1.10 and 1.11 and Table 1.4). In this case, values of $E_{\mathrm{T}}$ were calculated using the historical rates of total generation from all grid-connected power stations in NZ (2003-2009) [43]. ${ }^{4}$ For example, it can again be noted that after the 2005 dry year the rate of generation from Huntly remained relatively high through 2006 and 2007 even though

\footnotetext{
${ }^{4}$ This approach again involved the setting of a short-term, wet-year generation baseline, but is does not guarantee the accuracy of dry-year reserve generation measurement as plant may have been operated for applications other than dry-year backup. It is also acknowledged that these data may not accurately reproduce the actual reserve potential of many power stations, especially those that were non-operative during dry periods as a result of down time due to maintenance. In the absence of actual dry-year plant generation data from sources such as the gentailers and the EC/EA, however, this analysis does enable an order of magnitude estimate of the addition generation supplied by all of NZ's thermal power stations during dry years.
} 
these years were not 'dry'. The normalised data indicate, therefore, that the proportion of generation from renewable sources relative to thermal sources, other than hydroelectricity and the main thermal reserve plant, has also remained relatively constant from 2003 to 2009.

Table 1.4. Historical values of total generation from all grid-connected power stations in NZ (thermal- and renewables-based). The data shown were derived from the annual generation rate information available through access of the EC's 2009 'Generation by Plant' database (the sum of all generators published) [43] and the total generation rates of the Huntly p40 and Huntly e3p units as published in the Centralised Dataset [44].

\begin{tabular}{llll}
\hline Year & Annual generation / GWh $\mathbf{~}^{-1}$ & $\begin{array}{l}\text { Sum of May through October / } \\
\text { GWh }\end{array}$ & $\begin{array}{l}\text { Sum of July through September / } \\
\text { GWh }\end{array}$ \\
\hline 2003 & 38,581 & 20,050 & 10,452 \\
2004 & 40,555 & 21,410 & 9,281 \\
2005 & 40,795 & 21,460 & 10,870 \\
2006 & 41,412 & 22,034 & 11,167 \\
2007 & 43,532 & 23,335 & 12,005 \\
2008 & 44,116 & 23,184 & 11,748 \\
2009 & 42,995 & 22,769 & 11,400 \\
\hline
\end{tabular}

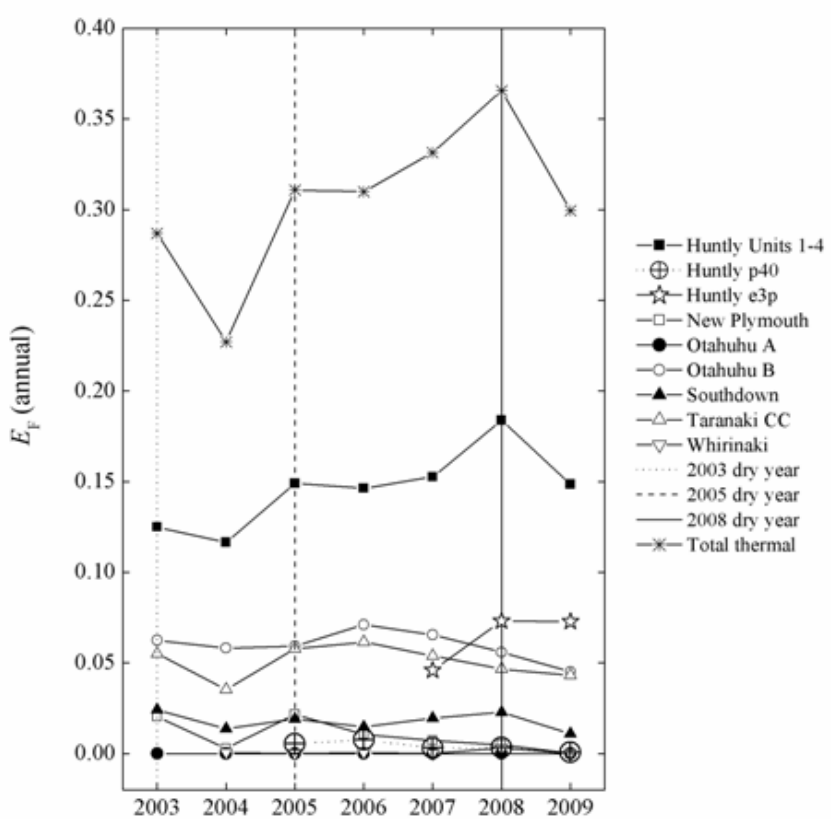

(a)

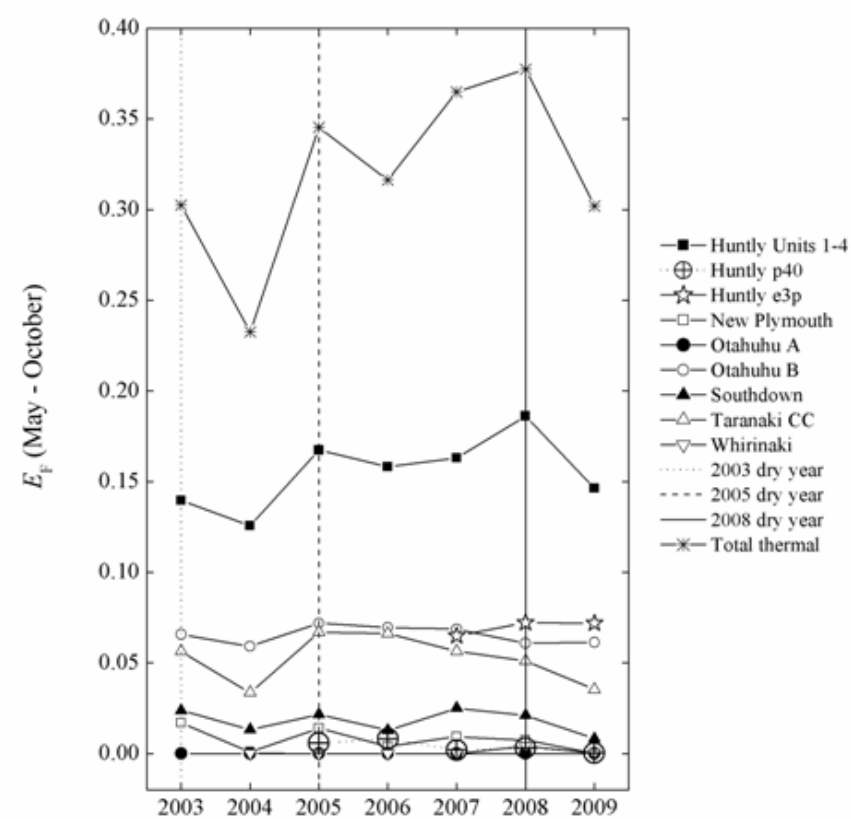

(b)

Figure 1.10. (a) Annual rates and (b) sum of May-October rates of electricity generation from the main thermal power stations connected to the NZ transmission grid normalised against the total generation supplied to the transmission grid for the period 2003 to 2009. Total generation is given with respect to the power stations as shown. Data were derived from the generation rates supplied by the EC's 2009 'Generation by Plant' webbased tool [43] and the Centralised dataset April 2010 [44]. 
A summary of monthly generation rates from the main dry-year reserves is shown in Figure 1.12 (2007, 2008 and 2009). Thermal generation during January 2008 was almost twice that of 2007 and 2009 and a peak in reserve plant generation can be noted in June 2008 (400-500 GWh per month greater than 2007/2009; Figure 1.12[a]).

The additional energy generated by Huntly (along with some additional contributions from Taranaki CC and Southdown relative to 2007 and 2009) provided all of the required additional 2008 dry-year generation during the month of January (Figure 1.12[b]). Huntly also compensated for the extended loss of Taranaki CC due to maintenance during February and March of 2008.

Of significance, however, is that the decreasing cost-efficiency of the Huntly Units 1-4 [49] has already indicated to the industry that a phasing out of coal combustion will also be likely by 2025 [50] and, from the above data, it is very clear that an alternative solution to dry-year hydro-generation shortfalls will be required.

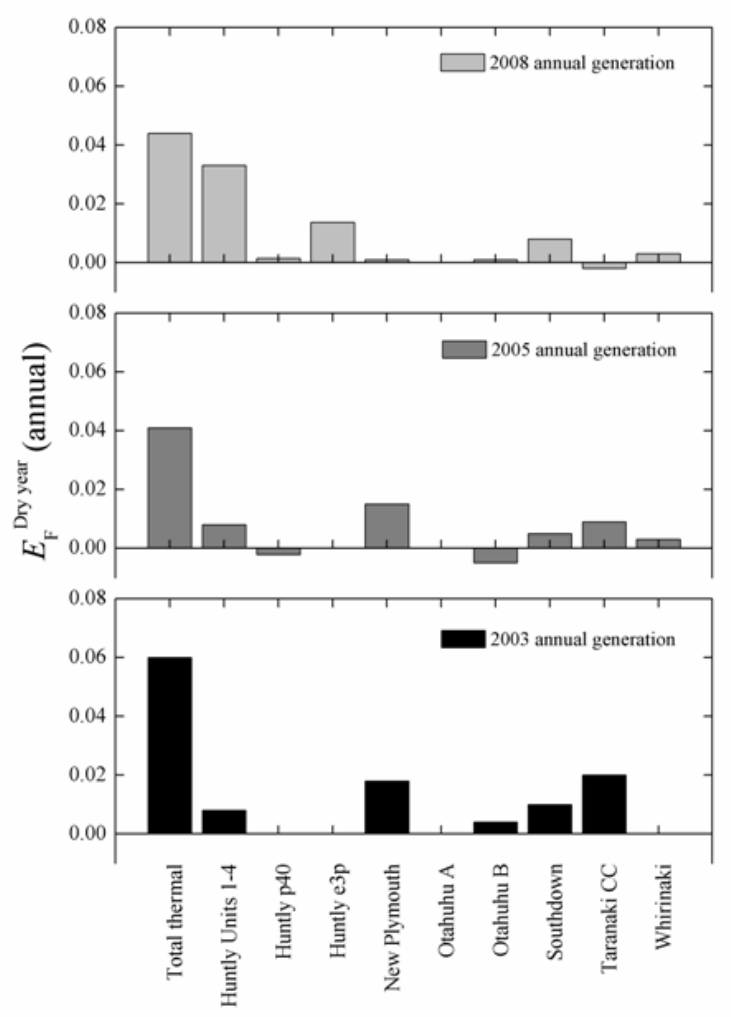

(a)

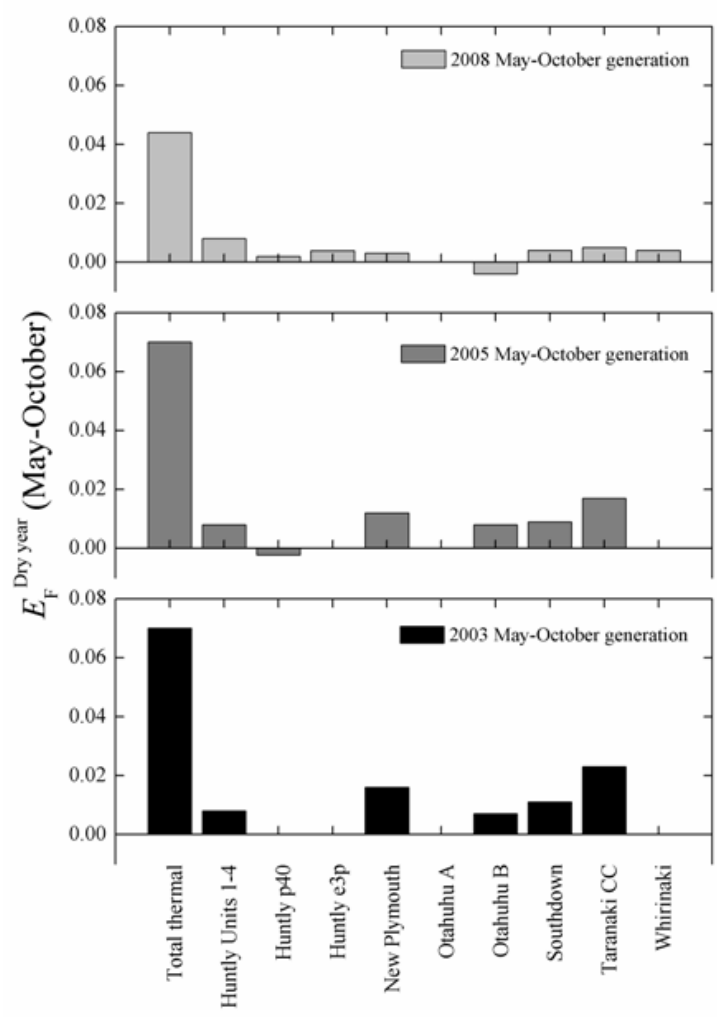

(b)

Figure 1.11. Estimated values of additional normalised (a) annual thermal generation and (b) sum of MayOctober rates $v s$. total generation $\left(E_{\mathrm{F}}^{\text {Dry year }}\right)$ for the dry-years $(2003,2005$ and 2008) relative to the years 2004 , 2006, 2007 and 2009. 


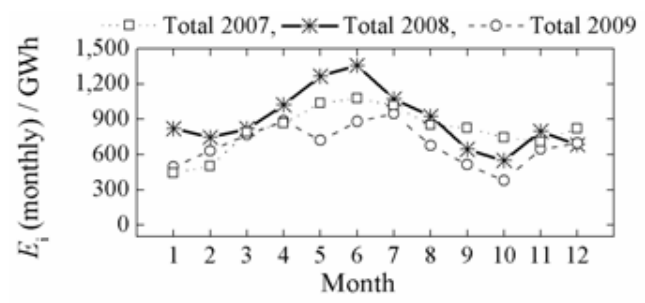

(a)

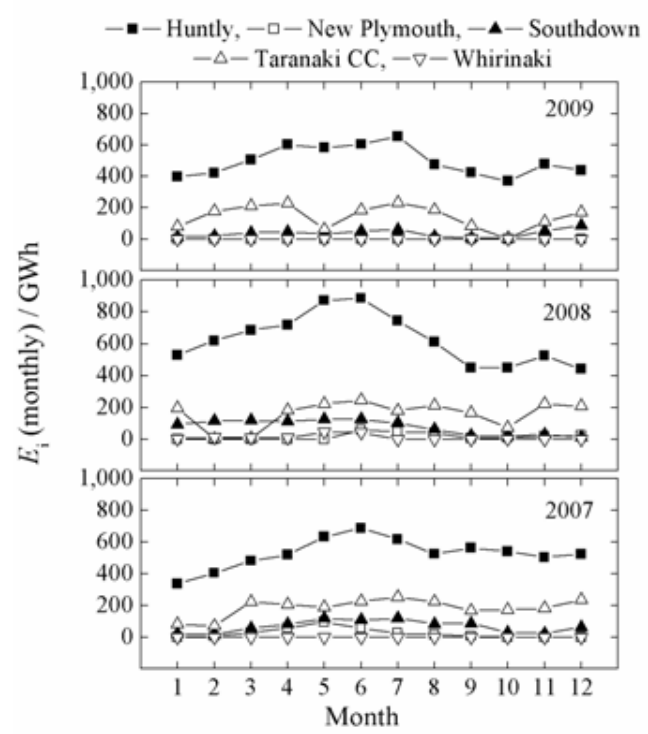

(b)
Figure 1.12. (a) The total monthly sum of the output from the primary dry-year reserve generators for 2007, 2008 and 2009 and (b) the individual monthly rates of dry-year reserve electricity production from each primary generator for 2007, 2008 and 2009.

\subsection{Introduction to pumped hydroelectricity- and battery-based energy storage}

Utility-scale energy storage technologies that are either being applied or have been considered for application to centralised electricity-based systems include non-pumped, lake-based hydroelectricity, pumped hydroelectricity $(\mathrm{PH})$, batteries (redox flow batteries [RFBs] and conventional enclosed batteries such as sodium-sulfur $[\mathrm{NaS}]$ ), compressed air energy storage (CAES), thermal heating, flywheels, supercapacitors and hydrogen-based approaches (Figure 1.13) $[51-58] .{ }^{5}$ All these technologies store energy for release under dispatchable conditions. As 'firm' sources of power supply they have a wide variety of actual and potential applications (Table 1.5), such as load levelling, seasonal reserve, grid design and the support of intermittent/variable power sources. Excluding non-PH, the least-cost forms currently appear to be CAES, lithium ion and flywheel technologies. Cost-effectiveness, however, is dependent on the application, location, environmental impact, power and energy requirements, operation and maintenance costs and the expected capacity factor. Globally, $\mathrm{PH}$ and batteries are the most commonly applied utility-scale technologies (excluding nonstandard-hydro and fuel stockpiles).

\footnotetext{
${ }^{5}$ Distributed vehicle-to-grid technologies are considered separately in this report, see Section 2.
} 
Batteries tend to have low energy capacity relative to hydro-storage systems (Table 1.6), but with a geographical footprint that is of a similar to a thermal power station. Batteries are also generally independent of the site specific factors that limit the nationwide introduction of large hydroelectric systems. Both batteries and $\mathrm{PH}$, however, have low operational GHG emissions [39].

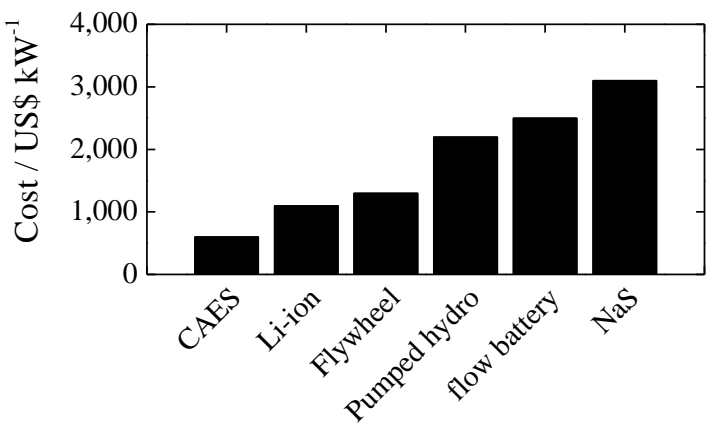

Figure 1.13. Generalised capital cost comparison per installed $\mathrm{kW}$ of electrical power generation capacity (2008), after The Electricity Advisory Committee, USA [57].

Table 1.5. Review of utility-scale applications of grid-connected energy storage technologies, after the Electricity Advisory Committee (EAC, USA) [57]. Further details of the correlation between power and duration for these applications are also available from the Energy Storage Association (ESA, USA) [67].

\begin{tabular}{|c|c|c|}
\hline Application & Definition & Duration \\
\hline Governor response & Generator autonomous dynamic response to frequency & $1 \mathrm{~ms}-1 \mathrm{~s}$ \\
\hline Regulation & Second-by-second adjustment of power production & $15-30 \mathrm{~min}$ \\
\hline $\begin{array}{l}\text { Balancing energy/real-time } \\
\text { dispatch }\end{array}$ & $\begin{array}{l}\text { Managing market 'spikes' balancing requirements and prices. } \\
\text { Mitigation of renewable-derived volatility }\end{array}$ & $>1 \mathrm{~h}$ \\
\hline Reserve augmentation & Spinning and operating reserve as back-up for generation drop-off & $>15-30 \mathrm{~min}$ \\
\hline Intra-day production shifting & $\begin{array}{l}\text { Some renewable have intra-day behaviour [output variation]. Energy } \\
\text { storage can mitigate scheduling and load-matching issues }\end{array}$ & $>1 \mathrm{~h}$ \\
\hline Diurnal renewable levelising & $\begin{array}{l}\text { Stores renewable energy resources from peak production for use at } \\
\text { peak load hours }\end{array}$ & $6-12 \mathrm{~h}$ \\
\hline Weekly production levelising & Storage of production from weekends for peak weekday discharge & $48 \mathrm{~h}$ \\
\hline Seasonal production levelising & Storage of seasonal resources for use in peak load seasons & Months \\
\hline $\begin{array}{l}\text { Transmission capacity factor for } \\
\text { renewable sources }\end{array}$ & $\begin{array}{l}\text { Storage of renewable production for delivery when transmission } \\
\text { capacity is available }\end{array}$ & $6-12 \mathrm{~h}$ \\
\hline Transmission congestion relief & Generalised application of the above & $>1 \mathrm{~h}$ \\
\hline $\begin{array}{l}\text { Transmission reliability } \\
\text { relaxation limit }\end{array}$ & Specialised version of relief (above) - fast response & $1 \mathrm{~s}-15 \mathrm{~min}$ \\
\hline Transmission capital deferral & Relieve short-term deferral & $>1 \mathrm{~h}$ \\
\hline Substation peak load/backup & Defer transformer upgrades due to peak load and growth & $>1 \mathrm{~h}$ \\
\hline Voltage support & Storage can provide local real power at high power factor & Variable \\
\hline Reliability enhancement & Provide down circuit supply while outages are restored & $>1 \mathrm{~h}$ \\
\hline
\end{tabular}


Table 1.6. Comparison of the primary characteristics of utility-scale PH- and battery-based energy storage technologies [53,55,68-70]. See Sections 2 and 4 for further details.

\begin{tabular}{lll}
\hline Characteristic & Batteries & PH \\
\hline Energy storage capacity & $\begin{array}{l}\text { Low (typically, 1 to 8 h generation periods are } \\
\text { utilized) }\end{array}$ & Medium to very high \\
Power density & Low to medium & High to very high \\
Commercial development & Emerging (RFBs); established (NaS) & Established century of application \\
Local environmental impact & Very low to medium (potentially reversible) & High to very high (irreversible) \\
$\begin{array}{l}\text { Site specificity } \\
\text { Capital cost relative to other } \\
\text { energy storage technologies }\end{array}$ & Very low & Very high \\
Longevity (cycles) & Medium to high & Medium \\
\hline
\end{tabular}

PH is an established technology, but the recent development and uptake of utility-scale batteries has also been strong in Peoples Republic of China, Japan, the USA, the European Union, Thailand and the United Kingdom [53,59-64]. GTM research (USA) have estimated (2009) that manufacturers of energy storage for grid stabilisation could be competing for a US $\$ 2.5$ billion world market share by 2015 and that global installed power capacity for load shifting and power quality could be 450,000 MW and 38,000 MW, respectively [65].

Effective government regulation, however, was noted to be critical to the success of future grid management, which may be reflected in the outcome of the California Energy Storage Bill AB 2514, which was signed into law in September 2010. This law requires utilities to adopt minimum levels of energy storage capacity [66] (procurements targets will be set in 2013 which must be achieved by 2015 and 2020).

Although NZ has a considerable amount of lake-based hydroelectric storage already in place, further development is likely to be limited [19,20,71-73] and an added capacity based on batteries (low to medium energy capacity, low to medium power density) and/or PH-storage (high energy density, high power density) could provide a benefits to the sector, including (1) displacement of $\mathrm{CO}_{2}$-e emissions, (2) improved security of supply, (3) fossil fuel independence, (4) mitigation of wind excess losses, (5) reduction of hydro spillage and (6) improved system flexibility through diversification of supply options in NZ. All these factors would most likely increase electricity sector resilience. Technical services could also include: peak shaving/load levelling (Figure 1.14), spinning reserve, ancillary services and dry-year reserve $[28,55,57,58,62,67,68]$. Table 1.7 presents a list of parameters associated with backup power control used in the USA [28]. All of these characteristics can be matched by either batteries or $\mathrm{PH}$. 


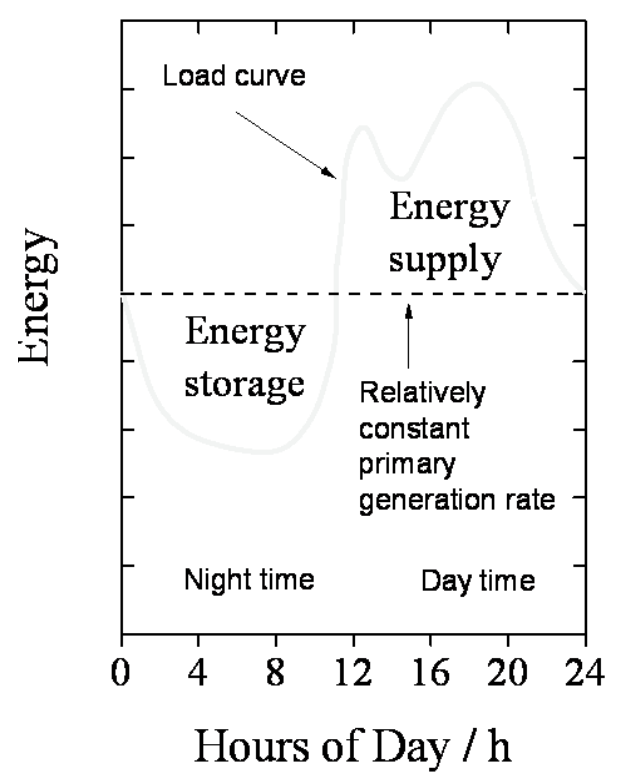

(a)

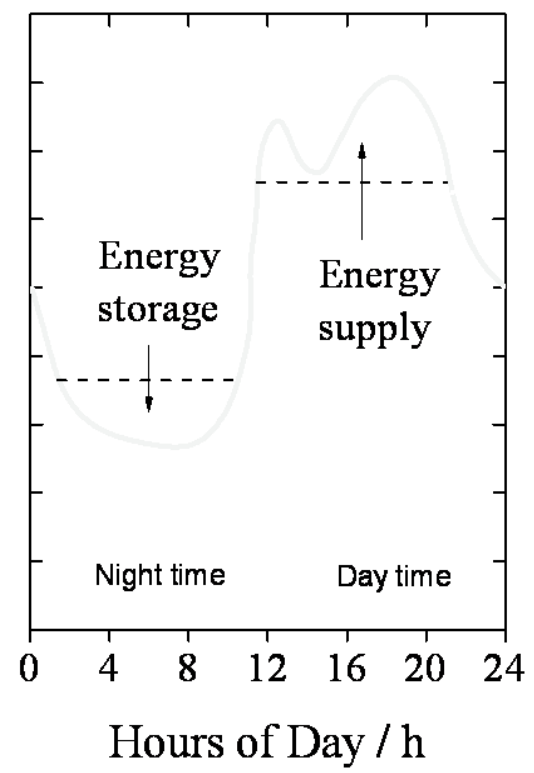

(b)
Figure 1.14. The concepts of (a) load levelling and (b) peak shaving in relation to energy storage, redrawn from [74]. In both cases, release of energy occurs during peak hours when the value of this energy to the system is high.

Table 1.7. Summary of typical parameters associated with peaking/spinning reserve and wind adequacy/power stabilisation collated by EPRI in the USA [28].

\begin{tabular}{llllll}
\hline Application & Power / MW & Duration / h & Energy / MWh & Response time / s & Duty cycle / $\mathbf{y}^{-1}$ \\
\hline Peak shaving & 0.5 to 25 MW & 4 to 8 & 1 to 100 & 60 to 600 & 20 to 50 \\
Spinning reserve & 1 to 1,000 & 2 & 2 to 2,000 & 600 & 5 to 60 \\
$\begin{array}{l}\text { Wind farm stabilisation } \\
\text { \& dispatch }\end{array}$ & $\begin{array}{l}100 \mathrm{~kW} \text { to } 100 \\
\text { MW }\end{array}$ & 4 to 8 & 0.5 to 800 & $\begin{array}{l}1 \text { (stability } \\
\text { control) }\end{array}$ & $\begin{array}{l}\text { Continuous for } \\
\text { stability; } 10 \text { to } 50 \\
\text { for dispatch }\end{array}$ \\
\hline
\end{tabular}

In NZ, the charging of storage systems could occur during periods of high rates of renewable flows (hydro and wind), and/or during off-peak times when the spot price is low. The energy could be subsequently discharged during periods of low renewable-based capacity factor, and/or when the price of electricity is high $[55,62,68,75,76] .{ }^{6}$ For example, under conditions of excess wind-derived generation (or a built-in excess of wind capacity) this unwanted power of exceptionally low value could be used to pump excess lake inflows to adjacent reservoirs and thus avoid energy loss through spillage [77-81].

As will be confirmed in this research, however, $\mathrm{PH}$ and batteries are generally perceived in NZ to be capital-cost intensive $[57,58,82-84]$. This is due to the 'added cost' of storage $(S)-$

\footnotetext{
${ }^{6}$ It must be noted, however, that a significant increase in renewables-derived baseload generation (e.g., geothermal and wind) could also be used to displace hydro-based resources currently used extensively for baseload generation in NZ. This will increase the flexibility of fast-start backup already in place.
} 
in the simplest case, equal to the sum of the capital-, storage system transmission/distribution-, standby-, operational-, maintenance- and efficiency-based costs.

Thus, the value of the electricity being used to charge the storage system must be small relative to the value of this energy when discharged and the difference must be greater than $S$. Regardless, $S$ is likely to decrease as battery technologies develop. Moreover, any increases in diurnal/seasonal price variation/spikes, reduced access to fuels and the internalisation of GHG-based environmental costs will favour the cost effectiveness of energy storage when charged by renewable power sources.

Currently (2011), there are no utility-scale, PH- or grid-connected battery-based storage installations either operating or under development in NZ. In 2010, the Institution of Professional Engineers New Zealand (IPENZ) noted that the potential of storage should be examined, although the option reviewed was firmly based on thermal backup generation. This capacity has been referred to as "incompressible" [33] and, when modelled under NZ conditions, it is usually not less than $5-10 \%$ of total generation $[20,85,86]{ }^{7}$ In regard to the new gas storage facility constructed by Contact in Taranaki [87], IPENZ considered that:

"[f]or thermal generation, gas storage facilities may be of greater importance in the future as a buffer against supply uncertainties" [19].

This facility, which is based on gas-combustion, is certainly a form of energy storage, albeit a likely environmentally unsustainable one. Although the costs are commercially sensitive [88], such schemes are currently likely to be economically viable if energy (gas) is available and purchased when wholesale prices are low. The construction of this facility also clearly indicates that minimisation of the impacts of gas-price volatility through energy storage is a significant priority for Contact.

\subsection{Aims}

\subsubsection{The potential of introduced forms of energy storage}

To date, there have been no investigations into MW-scale utility-scale batteries in NZ. PH studies have been limited to a single scheme (see Sections 3 and 4). It is understood that a desk-based, introduced energy storage study has been funded by Meridian in the USA, but the results of this study are commercially sensitive and have not been released to the public [88].

Nevertheless, at least five of the issues listed in the introduction have the potential to be solved with the development of NZ's storage capacity beyond that possible with non-PH: (a) dry-year reserve, (b) hydro/wind spillage mitigation, (c) support of variable-output

\footnotetext{
${ }^{7}$ The absolute proportion of this generation could be considerably lower under optimum weather conditions.
} 
renewables, (d) peaking generation and (e) supply of ancillary services (for example, sixsecond fast instantaneous response [FIR], frequency control and moderation of voltage sag). ${ }^{8}$ With the exception of (b), thermal generation is used in NZ to partially satisfy all of the above; the displacement of thermal could exclude a considerable proportion of the $\mathrm{CO}_{2}$-e emissions, especially if renewables-based primary generators are increasingly favoured by the NZ electricity sector. ${ }^{9}$ This approach could also enable NZ to achieve $100 \%$ renewablesbased electricity generation. The following factors, which may have some influence on the relative favorability of energy storage vs. thermal generation, have been considered: (1) fundamental economic costs of the technologies, (2) environmental impact, (3) technological effectiveness, (4) the price of $\mathrm{CO}_{2}-\mathrm{e},(5)$ the prices of fossil fuels (including oil and gas price uncertainties), (6) consumer demand growth rates, (7) congruence with existing infrastructure and (8) the framework of the electricity market.

\subsubsection{Research aim}

The determination of the feasibility of introducing utility-scale pumped hydroelectricity- and battery-based energy storage to the New Zealand electricity sector for enhanced (a) dry-year security of supply, (b) hydroelectricity/wind spillage mitigation, (c) support of intermittent/variable-output renewables-based generation (d) non-thermal, peak demandbased generation and (e) six-second fast instantaneous reserve.

Specifically, using (i) a desk- based review and (ii) an electricity sector perceptions survey, the case is examined for utility-scale energy storage to displace the requirement for growth in thermal backup power capacity based on natural gas, coal and diesel fuels. These have been achieved through the application of a literature review, a critical analysis and assessment of sector documents, a questionnaire and a semi-structured interview. The work includes both an analysis of the economic costs of these technologies and a comprehensive review of their drivers and barriers within the NZ context.

\subsubsection{Research questions}

- Is a business as usual approach to reserve generation in New Zealand likely to lead to increased levels of thermal backup power sources?

\footnotetext{
${ }^{8}$ There is considerable overlap between operation and role of generation plant associated with ensuring security of supply associated with Points a), c) and d). For example, the Whirinaki reserve power station is also used for general peaking plant operation as circumstance dictate.

${ }^{9}$ The potential for satisfaction of Points e) and f) using energy storage are related, in many respects, to the outcomes of this analysis of Points b) to d), particularly at the utility scale. It is likely that these opportunities will be explored in further work related to this current report and, therefore, are considered to be beyond the scope of the analysis presented in this report.
} 
- Have the institutional arrangements for ensuring security of supply been overly narrow in considering alternatives to thermal backup capacity?

- Do pumped hydro and/or batteries forms have a potential to contribute to:

- dry-year reserves,

- management of hydroelectricity/wind spillage,

- grid integration of variable-output renewables,

- meeting peak demand, and

- $\quad$ six-second fast instantaneous reserve?

- What are the most significant drivers and barriers to investment in pumped hydro and utility-scale batteries in NZ?

- Under what economic conditions could pumped hydro and batteries be considered for reserve applications in NZ?

- How feasible are pumped hydro and batteries as alternatives to thermal backup generation?

- Are global trends in energy storage reflected in local assessments, i.e., is there a knowledge gap in NZ?

\subsubsection{Assumptions}

- Environmental impact is one of the primary factors influencing the consenting of new utilities and the re-consenting of existing plant. Environmental parameters are thus included in this research, albeit at a qualitative level. This reflects the approach under the RMA and the NZ Environment Court.

- When comparing the business-as-usual development of the electricity sector, middleof-the-road, NZ government-derived projections (EC/EA or MED) are adopted for all parameters, except where otherwise stated.

- The date of introduction of electric vehicles is uncertain (most respondents to the survey, when asked, assumed that electric vehicles [EVs] will not make a shortmedium-term contribution to grid-based storage in NZ, Sections 3.2 and 3.3). The intelligent-electric-vehicle-to-grid-network concept [56,83,89-92], therefore, is not examined in detail.

- It is assumed that the 'centralised' nature of generation will continue to dominate small scale distributed generation and demand-side management (DSM). (This was 
also indicated by all respondents to the survey, Section 3.) The construction of new utility-scale reserves, therefore, is likely to continue.

- For the purposes of this research, stock piles of coal and diesel are not considered to be a form of renewables-based energy storage.

- To the author's knowledge, Contact's gas-storage facility was not functional at the time of the survey.

\subsubsection{Positionality statement}

I am personally oriented towards outcomes that support the long-term sustainability of the NZ electricity sector. For the purposes of this research, I have attempted to reduce this potential for bias by undertaking an objective 'Energy Storage Survey', in which a range of potential informants, including industry stakeholders, analysts and NGOs, were invited to contribute to the survey. Those generators who were invited were selected from a population that had both (1) a majority share of thermal capacity within their portfolio (e.g., Genesis) and (2) a majority share of renewables (e.g., Meridian). Moreover, individuals were invited from a range of organisations and backgrounds, including those who have publicly questioned the validity of anthropogenic climate change. An independent approach to the analysis of the literature has also been attempted and the responses of each informant have been reported as accurately as possible. The survey informants were also presented with at least two opportunities to express additional comment. 


\section{Experimental method}

\subsection{Desk-based literature review}

Data on the cost, impacts and feasibility of battery and pumped hydro-based utility-scale energy storage was collected from technical publications (e.g., journal and conference papers), industry reports, manufacturer and generator websites, non-governmental organisations (e.g., NZ Wind Energy Association and the Electricity Storage Association) and both journalistic- and technology-based websites (e.g. Reuters.com). A general statement regarding the environmental impact of the proposed Manorburn-Onslow PH facility was also received from Forest and Bird $(\mathrm{F} \& \mathrm{~B}), \mathrm{NZ}$. The method used to calculate storage costs is given below and a summary of the results is given in Section 3.1.

\subsection{Calculation of the cost of energy storage}

Unlike generation costs, energy storage costs are usually expressed either in terms of capital cost per (1) unit of power or (2) unit of energy capacity, and are given as a function of total number of expected cycles, or time to end of life (for example, see Figure 2.1). Energy conversion efficiency is also included to account for energy purchase costs from 'primary generation'.

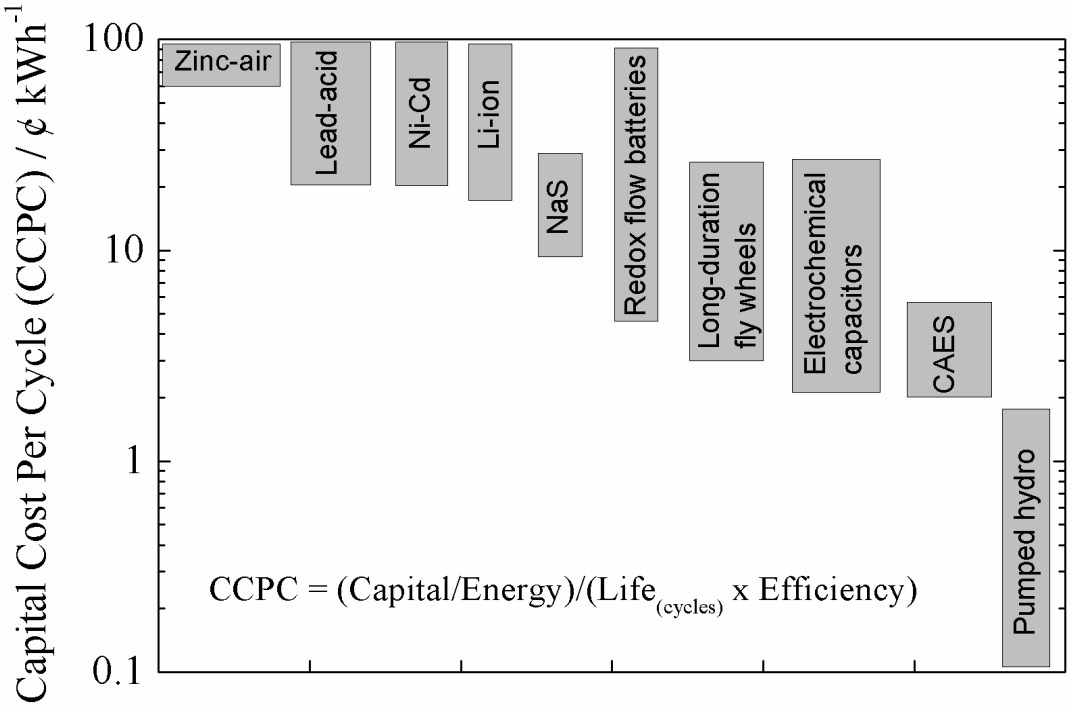

Figure 2.1. A generalised technology comparison of per cycle cost of energy storage published by the Electricity Storage Association in 2010 (costs given in US\$ and exclude carrying charges, O\&M and replacement costs), redrawn from [70].

While this, and similar approaches are ideal for inter-storage technology comparisons, it is not ideal for comparing integrated costs of charge and discharge with the cost of generation per unit of energy supplied from a primary generator, such as a diesel peaker. In this research, therefore, the overall cost of integrated generation from energy storage technologies has also 
been assessed in terms of the units $\$ \mathrm{kWh}^{-1}$ and an approach has been developed, which is based on the calculation of the total cost of electricity $\left(C_{\text {total }}\right)$ from an integrated primary generator/energy storage/generator system, where:

$$
C_{\text {total }}=G+T_{\mathrm{L}}+S \text {. }
$$

$C_{\text {total }}$ excludes national transmission costs, but, unless stated to the contrary, will include all onsite auxiliary, primary-generator-to-storage transmission, power quality management and ac-dc transformation costs.

$G$ is the effective cost of electrical energy supplied to charge the storage unit and has units of $\$ \mathrm{kWh}^{-1}$. When charging occurs during times of off-peak demand, for example, $G$ can be small because the value of the energy to the national electricity system can be relatively low.

$T_{\mathrm{L}}$, is the location-specific cost of on-site/off-site transmission of the energy from the primary generator to the storage system (for example, at a wind turbine to battery facility). $T_{\mathrm{L}}$ also has units of $\$ \mathrm{kWh}^{-1}$. When both units are on the same site $\mathrm{T}_{\mathrm{L}}$ is extremely small and can be excluded. $S$ is the cost of storage and, in this research, the sum of $T_{\mathrm{L}}$ and $S$ is known as the storage cost premium, or the added cost of storing electricity $\left(\$ \mathrm{kWh}^{-1}\right)$.

The total amount of required energy input $\left(E_{\text {in }}\right)$ to the energy storage system that is required to achieve a given output from the energy storage system $\left(E_{\text {out }}\right)$ is a function of the overall efficiency of the storage facility. In this case, $\mathrm{E}_{\mathrm{in}}$ can be represented by:

$$
E_{\text {in }}=E_{\text {out }}\left(1+\left[1-\eta_{\text {ac-ac }}\right]\right)
$$

where, $\eta_{\text {ac-ac }}$ is the sum of the total ac-to-ac (round-trip) energy efficiency of the storage facility, which is expressed as a fraction of total energy imported, i.e.:

$$
\eta_{\mathrm{ac}-\mathrm{ac}}=\text { energy out of the facility }(\mathrm{kWh}) / \text { energy into the facility }(\mathrm{kWh}) .
$$

For example, many batteries will operate at an $\eta_{\mathrm{ac}-\mathrm{ac}}$ of $0.70(70 \%)$. The effective cost of the charging energy, $G$ can be expressed as:

$$
G=g\left(1+\left[1-\eta_{\mathrm{ac}-\mathrm{ac}}\right]\right) \text {. }
$$

Here, $g$ is the market value (or spot price) of generation from the primary charging generator. In this research, $S$ was calculated using a life-cycle cost analysis (LCCA) and literature derived estimates of capital cost $\left(\$ \mathrm{~kW}^{-1}\right.$ or $\left.\$ \mathrm{kWh}^{-1}\right)$, operation and maintenance (O\&M) costs $\left(\$ \mathrm{kWh}^{-1} \mathrm{y}^{-1}\right)$, life expectancy, or number of cycles), etc. Values of $g$ and $\eta_{\mathrm{ac}-\mathrm{ac}}$ have also been adopted from the literature wherever possible (although this information has not been published for NZ conditions). 
The LCCA model used in this research to estimate $S$ is based, in the most part, on the approach applied by Poonpun and Jewell [93] (described in Appendix A). Using this work, the total annual energy production $(A E P)$ can be calculated using:

$$
A E P=P \cap H_{0} D
$$

where $P$ is the power rating $(\mathrm{kW}), n$ is the designed number of charge/discharge cycles per day, $H_{0}$ is the designed length of the discharge cycle used and $D$ is the designed number of operating days per year. However, in NZ CF is most commonly quoted by the MED and EC/EA to describe the expected output rate of NZ-based thermal plant, where reserve plant is usually assumed to have mean annual CF ratings of $0.05,0.20$ and $0.26[20,85]$. In this research, therefore, $\mathrm{CF}$ is also used to estimate the annual energy output of an energy storage facility (the rated power of the energy storage system is multiplied by the required CF and the number of hours in a year to give the annual energy output in $\mathrm{kWh}, \mathrm{MWh}$ or $\mathrm{GWh}$ ). For example, a CF of 0.26 would imply an average rate of discharge of around $6.2 \mathrm{~h} \mathrm{~d}^{-1}$.

But, since capital cost data is only available for systems designed to operate at specific CF values, only the use of Equation (2.6) will gives the maximum capital cost efficiency for the system under examination. If the same capital costs are used with lower nominal CF values than the system was designed for, such as $0.05,0.20$, etc., this is likely to result in non-ideal cost-effectiveness.

Regardless, all of the storage technologies examined in this research are capable of achieving CF ratings of 0.05-0.26 (although low values will reduce cost-effectiveness, Section 4.3). Most, utility-scale, battery-based energy storage facilities can operate at full power for 4-8 hours per day without re-recharging. A $1 \mathrm{MW}$ battery will thus have around 4-8 MWh of storage capacity $[28,93]$. It is also possible to cycle an energy storage system a number of times during a single day and batteries are modular. Practical examples show that pumped hydro-based systems can supply bulk energy at the GW scale and have full-power discharge times ranging from $5 \mathrm{~h}$ (a small energy storage system operating at a high power output of 1.9 GW) to 153 hours (for a larger capacity system operating at 1.2 GW) [94].

\subsection{Survey}

\subsubsection{Introduction and list of respondents}

The energy storage survey was developed to determine both the perceptions of the industry in regard to energy storage (batteries and PH) and to identify gaps in existing data. The collection of data on the potential characteristics of reserve capacity at 2025 was also of 
interest. The survey was derived and largely completed prior to the issue of the various 2010 Energy Outlook publications (15 December 2010).

The survey used a mixed method approach; a questionnaire and a semi-structured interview. The latter was presented as being 'optional' due to the varying time constraints of the targeted respondent group. Although there is an undeniable component of the elicitation of opinion associated with the questioning, the survey was not purposefully written to elicit responses that engage personal preferences or an attitudinal or behavioural component. The analysis was focused on factual and technical detail. Regardless, due to the commercialised and, thus, competitive nature of the electricity sector, it was considered likely that stakeholder bias could be significant across the spectrum of informants. Such bias was only noted when a significant pattern could be observed within the population of responses. Regardless, none of the respondents were asked to provide, or appeared to provide an answer that was not based on logical consideration of a question.

The list of organisations that were contacted and the response rate is given in Table 2.1. ${ }^{10}$ At the time of the survey, all potential respondents were active in the development, the management, the operation and/or independent commentary on the New Zealand electricity sector. All of the 'individual' respondents were employed as electricity sector analysts, consultants or policy advisors.

All participants were advised that they were selected on the understanding that they have good working knowledge of policy and/or technical aspects of the NZ electricity sector. Although, individuals were contacted directly by the author and invited to participate, the following step-by-step procedure was used to invite organisations to respond:

Week 1. Formal hardcopy request to participate was addressed and posted to the manager of the relevant department/group within the organisation,

Week 1-2. Follow-up telephone/email to parties in receipt of the hardcopy request,

Week 2-3. Direct contact with alternative individuals within the same organisation, if required.

If at any point a member of the organisation declined to participate the organisation was classed as providing 'no official response' (Table 2.1).

In a number of instances the contacted member of a particular organisation offered to respond to the survey, but only as an individual. These offers were universally accepted, on the condition that their opinion does not reflect that of their employers. In this report, the

\footnotetext{
10 'Individuals' that were contacted, but did not respond are not listed.
} 
identities of all respondents have been encoded and are not correlated with the answers provided.

Table 2.1. List of informants to whom a request for participation was submitted. The survey response rate is also indicated (for organisations only). The identities of those individuals who declined to participate are not shown.

\begin{tabular}{|c|c|c|}
\hline Organisation & Respondent name & Response \\
\hline \multicolumn{3}{|c|}{ Publically traded generator/retailer companies (Code GR\#) } \\
\hline Contact Energy Ltd. & - & No official response \\
\hline TrustPower Ltd. & - & No official response \\
\hline \multicolumn{3}{|c|}{ Governmental organisations and State-owned enterprises (Code: GO\#) } \\
\hline Genesis Power Ltd. & Mr Richard Pearce & Responded \\
\hline Meridian Energy Ltd. & Mr. Ray Brown & Responded \\
\hline Mighty River Power Ltd. & - & No official response \\
\hline Electricity Authority & Mr. Bruce Smith & Responded \\
\hline Transpower NZ Ltd. & Dr. Nikki Newham & Responded \\
\hline $\begin{array}{l}\text { Energy Efficiency and Conservation } \\
\text { Authority }\end{array}$ & - & No official response \\
\hline Ministry of Economic Development & - & No official response \\
\hline Ministry for the Environment & - & Statement of Interest received \\
\hline \multicolumn{3}{|c|}{ Non-governmental organisations (Code NGO\#) } \\
\hline NZ Wind Energy Association & Mr. Fraser Clark & Responded \\
\hline Energy Federation of NZ & - & No official response \\
\hline Sustainable Energy Forum (SEF) & - & Statement of Interest received* \\
\hline Greenpeace New Zealand (GPNZ) & Confidential analyst & Responded \\
\hline International Hydropower Association & - & Statement of Interest received \\
\hline \multicolumn{3}{|l|}{ University (Code: U\#) } \\
\hline University of Waikato & - & No official response \\
\hline \multicolumn{3}{|c|}{ Individual energy analysts (Code INDIV\#) } \\
\hline- & Mr. Murray J Ellis & Responded \\
\hline- & Mr. Bryan Leyland & Responded \\
\hline- & Dr. Alastair Barnett & Responded \\
\hline- & Dr. Geoff Bertram & Responded \\
\hline- & Mr. Martin Brown-Santirso & Responded \\
\hline- & Mr. Gareth Wilson & Responded \\
\hline- & Confidential analyst I & Responded \\
\hline- & Confidential analyst II & Responded \\
\hline Number of completed questionnaires & & \\
\hline Number of interview frameworks cor & & \\
\hline
\end{tabular}

*At the time of the survey two individual respondents were members of the SEF and were happy to be recognised as such. 


\subsubsection{Victoria University of Wellington ethics approval}

Prior to being surveyed, all potential respondents were provided with project 'information' sheets (Appendix B) and a 'consent to participation' form (Appendix C). The questionnaire, the interview framework and the associated 'Information to Participants' letter and 'Consent Forms were all submitted to the VUW Human Ethics Committee for assessment against the VUW Human Ethics Policy. Approval was issued 30 November 2010 (Appendix D).

Individual respondents were provided with a 'consent to participation form' distinct from that given to organisations. Both forms, however, covered issues associated with the collection of data, the attribution of opinions and information that could be published in a journal, at a conference or within a report or thesis. If the informant was an employee of a company, the informant was given the opportunity to check an option that ensures that the research is attributed only to their organisation and not themselves as individuals. Individuals were also given the option of ensuring that their information remains completely confidential.

Access to the raw research data is restricted to the author and Associate Professor Ralph Chapman and all questionnaires, interview notes and similar materials will be destroyed prior to December 2015. There was no conflict of interest in regard to the funding of this research or the programme of the research.

\subsubsection{Questionnaire}

The questionnaire (Appendix E) was the primary quantitative instrument of the survey [95] and was designed to be completed in less than 30 minutes (prior to the semi-structured interview). The topics covered included the economic, environmental and technical issues and the order of questioning flowed from least 'sensitive' to the most sensitive. For example, general issues, such as likely electricity demand growth rates, were examined prior to more complex questions relating to energy storage.

The questionnaire included three types of closed-end response interface:

1 Likert scale-based interfaces [95] (bounded/continuous response scale), where respondents were asked to present either the (1) orientation (polarity) of the response and extent of polarisation or (2) an absolute value, or range of values, from a limited scale of values (for example, refer to Figures 2.2(a) and (b), respectively),

2 relative order of importance-based interfaces, where respondents were asked to rate the relative likelihood a number of a fixed number of options (' 1 ' being most likely), and

3 ordinal-polytomous response scale of five ordered options-based interfaces, where the ordered options were $-2,-1,0,+1$ and +2 . Here, ' -2 ' represented the most negative, or 
unfavourable, unit and ' +2 ' the most positive or most favourable unit. ' 0 ' was presented as being neutral.

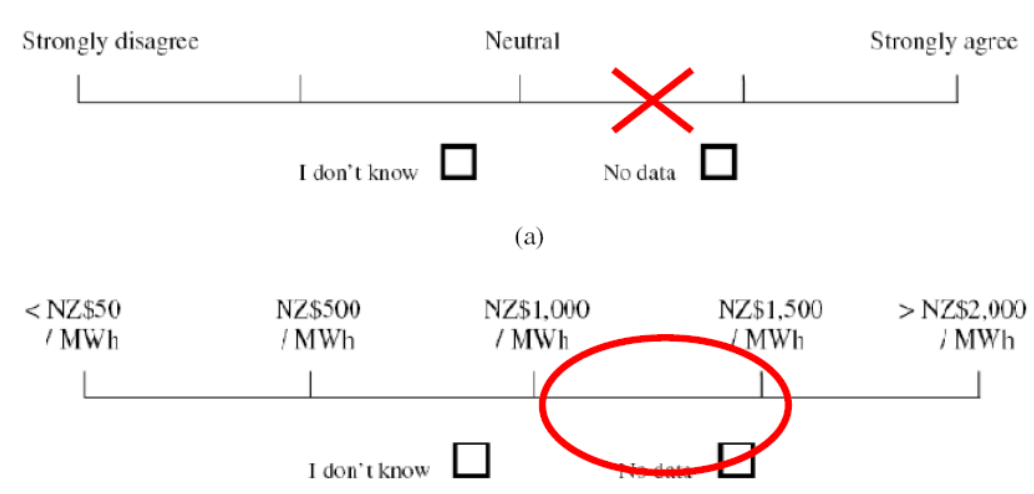

(b)
Figure 2.2. Typical examples of the Likert scale-based response scales where respondents are asked to present either (a) the polarity and the extent of polarisation of their response or (b) an absolute value, or a range of values, from a limited range of options. Note also the option to acknowledge that 'I don't know' or there is 'no data' available. Respondents were also offered the opportunity to present either an absolute value or a range of values, as illustrated in the figure.

Both the questionnaire and the semi-structured interview asked questions that were either factual in nature, or were based on logical, albeit totally hypothetical, projections to 2025 . The respondents were asked to make judgements based on what they would consider to be the 'most likely' outcome of various scenarios. All questions given in the questionnaire were closed-ended, with the exception of the last two questions. For the latter, the respondent was asked to (1) specify any other forms of energy storage technologies that could be examined for application to the New Zealand electricity sector and (2) to make 'additional comment' if necessary. For all the closed-ended questions the respondent was given the opportunity to either check an 'I don't know' box (I am personally unaware of the answer), or to leave the response section blank (Figure 2.1). Also included in all the Likert scale-based response panels was the opportunity for the respondent to note that it was their understanding that 'no data' was available to answer the question.

Electricity sector development models are complex and, boundary limits were introduced in order to frame each scenario that the respondent was asked to consider. Complexity of the questioning was also minimised wherever possible, although it is understood that the projection of future events is highly uncertain and only the general perceptions of the respondents were of interest.

By way of example, the respondents were asked to consider most-likely developmental pathways, while adopting fundamental assumptions such as: “"Backup electricity generators' is a term for plant applied to (1) peak adequacy, (2) intermittency adequacy and (3) dry-year security of supply under emergency conditions", and "unless directed by the questioning, there will be no new discoveries of large-scale and easily accessible natural gas fields in New 
Zealand prior to 2025." Further details, such as the price of $\mathrm{CO}_{2}$-e per tonne ${ }^{-1}$, were specified within each question. All values were selected to be unambiguous (to the initiated) in regard to their potential impact on sectoral development. The aims and background to the individual questions are given in Section 3.

In regard to data analysis, the hardcopy responses to the Likert scale-based questions were translated to graphical form by physically measuring the range, or encircled limits, of the informants responses on hardcopy and converting, via a conversion factor $(k)$, to numerical data, where:

$$
k=\frac{\text { Total numerical limit represented by Likert scale (various units) }}{\text { Total phyical distance of scale on hardcopy }(\mathrm{mm})}
$$

Where no numerical limits were shown in the Likert scale (e.g., Figure 2.2[a]), a scale of 1 to 100(\%), was assumed, where 50\% was taken to be 'neutral'.

When respondents indicated values on a Likert scale using ' $\mathrm{X}$ ', this was assumed to indicate a relatively low level of perceived uncertainty. When a range of values was 'encircled' along the scale provided in the questionnaire, the uncertainty was characterised as the maximum deviation either side of the central point of each encircled response. Averaging was occasionally used to provide a broad indication of the general weight of opinion received from those respondents who broadly agreed upon a particular polarity of the response (for example, in the case of Question $1(\mathrm{Q} 1)$ and Q3, thirteen of the fourteen respondents agreed that annual electricity demand will increase and only these thirteen values have been averaged). Averaging was not used where there was a broad spread of opinion or where there were exceptionally large values of uncertainty.

\subsubsection{Semi-structured interview}

A total of ten of the fourteen respondents participated via both questionnaire and the interview framework. The interview was developed to enable the respondents to provide additional comment on a number of the topics covered by the questionnaire and also to allow a platform from which specific issues could be raised by the respondent and addressed, if required. Although the respondents were encouraged to respond in the affirmative or the negative to a question (if applicable) prior to continuing with a general discussion of that question, the majority of the data gathered was qualitative in nature. 
The interview was designed to be completed in less than 30 minutes $^{11}$ and the interview agenda was standardised to minimise errors and to increase the likelihood of consistency in the output [95]. Many questions were open-ended; an alternative approach to the closedended questions of the questionnaire. The author proceeded by asking each question and allowing the informant to respond and explain their deductive reasoning without further direction (excluding time constraints). When the initial monologue was completed additional questioning or 'prompts', were then applied, if necessary.

In terms of analysis, a framework of themes was imposed by the author (see below) and thematic analysis [96] was also used to identify any additional themes within the responses of the informants that emerged during the interview. For the latter, broad themes or topics were identified from the content and patterns of the completed response of the informant. Such 'emergent themes' dominated the data when the respondent was asked for additional comment at the end of the interview.

The framework of 'imposed themes' that were systematically explored during each interview were presented in the respondents in the form of requests and questions, as follows:

\section{A. The value of renewables-based energy storage to the NZ electricity system:}

1. Please describe 2 or 3 of the main benefits that renewables-based utility-scale energy storage currently provides to the electricity system.

2. If the capacity of renewables-based energy storage could be greatly expanded to meet all of the needs of the system, what could be the main benefits to the electricity sector?

\section{B. The likely proportion of thermal generation used for backup by 2025}

1. Do you respond in the questionnaire that more thermal backup power (such as peaker capacity) is more likely to be to be introduced than new forms of renewable energy storage such as pumped hydro? If so, why. Or if not, why not?

2. Do you think that the price of $\mathrm{CO}_{2}$-e and oil-price uncertainty have the potential to stop investment in thermal backup generation by 2025 ?

\section{The management of dry-year events using pumped hydroelectricity}

1. In the past, have the institutional arrangements for security of supply during extremely dry years been wholly adequate?

2. Do you think that most, if not all, of the negative aspects of dry year events could be mitigated through the use of large-scale pumped hydro, for example?

\footnotetext{
${ }^{11}$ A number of respondents chose to extend the total period of the interview after the completion of the formal questioning. In most cases this was undertaken in order to provide further information and/or to receive additional data regarding the project.
} 


\section{The potential energy savings from the reduction of hydro spillage}

1. Is hydro spillage a serious issue in terms of energy losses from the system?

2. How much money (or energy) can be saved from the sector (or individual hydro lakes) through spillage mitigation?

\section{E. The state of development of introduced forms of energy storage in NZ}

1 Do you know if your organization/the electricity sector has considered introducing renewable energy storage such as pumped hydro and batteries?

2 If the long run marginal cost of electricity from pumped hydro or batteries can be proven (by a number of sources) to be similar to thermal backup, would your organization/the sector consider investigating further?

\section{F Any other comments?}

If the following issues were not raised by the respondent, a series of prompts were provided:

\section{With respect to question $B 1$ :}

- What are the benefits and the negative aspects of a greatly expanded capacity of thermal backup?

\section{With respect to question $B 2$ :}

- $\quad$ Are both gas and diesel peakers likely to be equally affected?

- $\quad$ Are diesel peakers closely linked to the price of oil (consider the low capacity factor)?

- How high would a price on $\mathrm{CO}_{2}$-e have to be for change to occur?

- Is your organisation, or the sector, planning for change?

- How could significant new natural gas discoveries influence your response?

\section{With respect to question $C 1$ :}

- $\quad$ Either: how could the management of the system be improved in regard to dry year events, or

- $\quad$ will an increase in electricity demand still make the situation more difficult to manage?

\section{With respect to question $\mathrm{C2}$ :}

- What is stopping the electricity sector from doing this?

- What can be done to make energy storage more attractive for dry year management?

- Could this be a free market problem? Does the government need to act?

\section{With respect to question D2:}

- $\quad$ Could these savings be used to pay for the costs of storage? 


\section{With respect to question E1:}

- What was the result?

- Do NZ-new types of utility-scale energy storage technologies have a future in NZ?

The selection of each prompt from the list given above was entirely dependent on the orientation of the informant's responses to the preceding questions.

In regard to the analysis of the data, a grounded theory [97] approach, but one that recognised the theoretical constructs of the disciplines at play, was used to code and organise the higher resolution responses of the informants into simple concepts and categories for tabulation. These data were then used in the final derivation of the conclusions of the research. Indeed, as the research proceeded, it was noted that the responses to the deliberately open-ended questions could be very easily coded, as they were clearly stated by the informant in simple terms and were unambiguously defined. In disciplinary terms, either economics, engineering or physical science dominated the backgrounds of every respondent and their responses always fell 'naturally' into simple categories. For example, discussions relating to the potential barriers to energy storage were presented in a step-by-step fashion and each step could be clearly identified as being (for example) 'economic', 'local environmental' or 'technical' in nature. 


\section{Results}

\subsection{Desk-based analysis}

\subsubsection{Electricity demand, supply-side bias and centralised generation}

A summary of demand projections for $\mathrm{NZ}$ is provided in Table 3.1, where growth rate estimates over the last five years have ranged from at least 200 to $1,500 \mathrm{GWh}^{-1}$. Only half of the projections examined assume that demand growth rate is 'likely' to slow during the medium to long term relative to the recent historical growth rate value of $1.8 \% \mathrm{y}^{-1}$ [71]. However, only the later projections consider the impact of the recent economic downturn $[71,98,99]$.

Table 3.1. Review of projected annual electricity demand growth rates for New Zealand to 2025 and 2030. Only projections published after 2005 have been considered.

\begin{tabular}{|c|c|c|c|c|c|c|c|c|c|c|}
\hline & $\begin{array}{l}\text { EC } \\
\text { demand } \\
\text { 'base-line' } \\
\text { projection } \\
{[20]}\end{array}$ & $\begin{array}{l}\text { EC } \\
\text { 'sustainable } \\
\text { path' } \\
\text { scenario [20] }\end{array}$ & $\begin{array}{l}\text { MED } \\
\text { energy } \\
\text { outlook } \\
2006 \\
{[100]}\end{array}$ & $\begin{array}{l}\text { MED } \\
\text { 'low } \\
\text { carbon } \\
\text { future' } \\
\text { scenario } \\
{[101]}\end{array}$ & $\begin{array}{l}\text { MED } \\
\text { energy } \\
\text { outlook } \\
2009 \\
{[71]^{*}}\end{array}$ & $\begin{array}{l}\text { MED } \\
\text { energy } \\
\text { outlook } \\
2010 \\
{[99]^{*}}\end{array}$ & $\begin{array}{l}\text { Mighty } \\
\text { River } \\
\text { Power } \\
{[102] \dagger}\end{array}$ & $\begin{array}{l}\text { Genesis } \\
{[103]}\end{array}$ & $\begin{array}{l}\text { Contact } \\
{[104] \ddagger}\end{array}$ & $\begin{array}{l}\text { Bertram } \\
\text { \& Clover } \\
{[33] \S}\end{array}$ \\
\hline \multicolumn{11}{|c|}{ Energy / GWh } \\
\hline $2009 / /$ & 38,600 & & & & & & & & & \\
\hline 2025 & 49,100 & $\sim 53,000 / / /$ & 47,480 & 41,800 & 49,400 & 47,700 & 62,000 & $\sim 53,000$ & 55,000 & 42,100 \\
\hline 2030 & 52,100 & $\sim 57,000 / / / /$ & 50,600 & 42,900 & 51,900 & 52,700 & 71,800 & $\sim 58,500$ & 61,000 & 43,300 \\
\hline \multicolumn{11}{|c|}{ Additional demand vs. 2009} \\
\hline 2025 & 10,500 & $\sim 14,400$ & 8,860 & 3,200 & 10,800 & 9,100 & 23,300 & $\sim 14,400$ & 16,000 & 3,500 \\
\hline 2030 & 13,500 & $\sim 18,400$ & 12,000 & 4,300 & 13,000 & 14,100 & 33,200 & $\sim 19,900$ & 22,000 & 4,700 \\
\hline \multicolumn{11}{|c|}{ Percentage change during 2009 through to 2025} \\
\hline$\%$ total & 27.2 & $\sim 37.3$ & 23.0 & 8.2 & 27.9 & 23.6 & 60.6 & $\sim 37.3$ & 41.5 & 9.1 \\
\hline \multicolumn{11}{|c|}{ Percentage change during 2009 through to 2030} \\
\hline$\%$ total & 35.0 & $\sim 47.7$ & 31.1 & 11.1 & 33.7 & 36.5 & 86.6 & 51.6 & 57.0 & 12.2 \\
\hline \multicolumn{11}{|c|}{ Percentage change to $2025 \mathrm{y}^{-1}$} \\
\hline$\%$ & $\sim 1.5$ & $\sim 2.0$ & $\sim 1.3$ & $\sim 0.5$ & $\sim 1.5$ & $\sim 1.4$ & $\sim 3.0$ & $\sim 2.0$ & $\sim 2.2$ & $\sim 0.5$ \\
\hline
\end{tabular}

* Reference scenario.

$\dagger$ Including $\sim 2 \pm 0.5 \%$ base-case growth with an additional $1 \%$ from a transition to electric vehicles and some substitution of fossil fuel-based stationary energy to electricity consumption (i.e., $\sim 2 \%+1 \% \cong 3 \%$ ).

+ Conservative demand assumption.

$\S$ Assuming the implementation of major efficiency measures.

II Interpolated to 2025 using MED data [105].

// Demand at 2009 as noted by the EC [20].

/// Data from [33] 
Most recently, the MED's Energy Outlook 2010 'reference scenario'12 [99] assumed a somewhat slowed rate of increase in demand of $\sim 1.4 \% \mathrm{y}^{-1}$, where renewable-based generation would have only a $78 \%$ and $84 \%$ representation by 2025 and 2030, respectively. A carbon price (real) of NZ\$50 $\left(\mathrm{CO}_{2}\right.$-e) tonne ${ }^{-1}$ from 2013 was adopted in this case and a long-term rate of GDP growth of $1.5 \% \mathrm{y}^{-1}$ was assumed [106]. By comparison, the 2009 MED reference scenario [71] projected electricity demand to 2025 as $1.6 \% \mathrm{y}^{-1}$ (or $1.5 \% \mathrm{y}^{-1}$ to 2030) with electricity demand values $\sim 49,400 \mathrm{GWh}^{-1}$ at 2025 and $\sim 51,900 \mathrm{GWh} \mathrm{y}^{-1}$ by 2030. In general, these rates of growth are of a similar size to the average value for electricity demand growth given by the respondents (as described in Section 3.2), although it should be noted that the survey was initiated prior to the release of the 2010 Outlook.

In regard to small-scale power sources, it has been noted that the supply-side dominates the market and "domestic-scale renewable electricity production [in NZ] is virtually nonexistent" [107]. Demand-side Management (DSM; Table 3.2), energy efficiency and conservation have received relatively limited attention [19,33]. This supply-side bias is likely to act as a driver of further investment in utility-scale capacity and (in the absence of a costeffective alternative) utility-scale energy storage. Nevertheless, there is considerable scope for energy savings, especially as energy efficiency and conservation initiatives can be more cost-effective than building centralised capacity [33,108-110]. KEMA's New Zealand Electric Energy-Efficiency Potential Study, for example, quantified the potential of the demand-side and found that economically feasible savings from efficiency could amount to $\sim 6,500 \mathrm{GWh} \mathrm{y}^{-1}$ by 2016 [108] ( 14\% of projected electricity sector energy use). The savings potential from peaking capacity was $\sim 1,700 \mathrm{MW}$ by 2016 ( $21 \%$ of projected peak demand).

Table 3.2. Governance based demand-side management measures assessed for application to NZ by the Treasury [111].

\begin{tabular}{lll}
\hline Contractual tools & Energy efficiency tools & Financial incentives and price-based measures \\
\hline Ripple control & Smart metering & Subsidies and loans \\
Call options & Regulation & Taxes \\
Demand exchanges & Education/information & \\
Spot market buying & & \\
Contract for difference & & \\
\hline
\end{tabular}

\footnotetext{
${ }^{12}$ MED caveat: does not represent the most-likely scenario.
} 
IPENZ have also considered that increased levels of DSM could significantly improve the management of electricity supply in NZ [19] and the 2007 NZEECS stated that $160 \mathrm{MW}$ of peaking capacity and network constraints could be off-set via demand shifting for the NZ business sector alone [112]. More effective DSM could also defer new transmission and network infrastructure and reduce the need for maintenance and upgrades and reduce dry-year and peak demand $[33,108,113,114]$. Small-scale distributed generation (DG), at $1 \mathrm{~kW}$ to $>1$ MW [115], should also be capable of reducing total grid connected load in addition to the introduction of a quantifiable level of benefits to the local network [114] and resilience through diversity of supply [101]. Clearly, a reduced rate of growth in centralised plant could also defer the exploitation of marginally viable (economic and environmental) energy sources. In 2010 EECA estimated that its programmes were delivering savings at a cost of NZ\$62 $\mathrm{MWh}^{-1}$ [116]. During 2008, 2009 and 2010 spot wholesale prices were generally of the order $\mathrm{NZ} \$ 175 \mathrm{MWh}^{-1}, \mathrm{NZ} \$ 50 \mathrm{MWh}^{-1}$ and NZ\$125 $\mathrm{MWh}^{-1}$, respectively. The 2008 dry year winter period produced prices consistently greater than NZ\$200 $\mathrm{MWh}^{-1}$ [117]. However, even though these prices are typically higher than the cost of EECA savings, the more relevant price of consumer savings is the retail price to the consumer. The consumer could benefit significantly from energy savings since the retailer-averaged retail price of electricity at 15 February for Wellington during 2008, 2009 and 2010, for example, were NZ\$216 $\mathrm{MWh}^{-1}$, $\mathrm{NZ} \$ 231 \mathrm{MWh}^{-1}$ and NZ\$229 $\mathrm{MWh}^{-1}$, respectively [118].

Regardless, rates of uptake of efficiency measures in NZ have decreased relative to developed world standards [119], despite the fact that the NZ Government has recognised the importance of DSM and [21]:

"[s]uch programmes should be implemented where they provide a more cost-

effective option than the long run marginal cost of new electricity supply."

The lack of widespread DSM, including DG, may indicate that these measures are not attractive under current market and regulatory conditions. It may also be interpreted as an indicator of the conservatism of the electricity market participants, which may also have an impact on the rate of uptake of new-to-NZ storage options.

Bertram and Clover have also specifically noted [33] that the limitations and complexity of the current regulation of the centralised market continue to favour the large-scale generators and exclude medium- to small-scale DG. It is probable that government funding has also not been sufficient to enable the maximum benefit to be realised from the available options [120].

Recent IPENZ recommendations included: "time-of-use tariffs, smart meters, smart appliances and wider use of load control/interruptible supplies" [19] and Poletti has proposed 
that real-time retail pricing plans are more likely to be effective for the management of peak demand than flat-rate plans [121]. Moreover, although ripple/load control of consumer hot water heating is widespread in NZ, the efficacy of this technology may have degraded due to a lack of maintenance [111]. In addition, in order to reduce demand by only $2 \%$ per day nationwide cuts in heating may have to be applied over 16-18 hours per day [122]. Extended cuts under long term restrictions could also induce end-users to reject controllable load regimes. Extended, mandatory nationwide ripple control, therefore, is most likely acceptable only under extreme risk of rolling blackouts.

Smart metering is also viewed by many to have been poorly regulated in NZ $[123,124]$ and may favour commercial interests over consumer empowerment [124]. The relatively low penetration rate of solar hot water heating under the grant system also indicates that direct intervention by the government may be required to reduce capital and maintenance costs.

Both DSM, conservation and efficiency were subject to the scrutiny of the 2010 Ministerial Review of Electricity Sector Performance [26] and were included in three of the main decisions subsequently adopted within the Electricity Industry Act 2010 [26]. ${ }^{13}$ Now the sector must:

- facilitate more demand-side participation in the wholesale market,

- ensuring that smart meters provide for (or allow upgrades for) energy efficiency capability, open access, customer switching and the development of smart networks, and

- provide incentives to better manage electricity consumption.

However, the primary objectives of the review were overwhelmingly focused upon centralised perceptions of [125]:

- governance,

- inter-gentailer competition and the moderation of retail electricity prices, and

- $\quad$ security of supply.

Moderation of prices is unlikely to stimulate conservation/efficiency. Demand-side signals, including representative electricity prices, was considered by the previous government to be central to the support of conservation and efficiency [112].

\footnotetext{
${ }^{13}$ (The Electricity Industry Bill 2010 replaced subpart 2 of Part 14 of the Electricity Act 1992 and the Electricity Industry Reform Act 1998 and introduced minor amendments to Part 4 of the Commerce Act 1986 and associated amendments to the Gas Act 1992 among other Acts.)
} 
Conversely, the MED now also proposes that electricity prices will have to increase by $29 \%$ by 2030 in order to support investment new and more expensive forms of centralised generation absence of 'cheap' gas and the Huntly coal/gas units [99].

\subsubsection{Dry-year security of supply}

Expected economic growth in NZ is linked to hydro-based security of supply $[11,126]$ and the economic impact of dry years is significant. For example, the NZ Treasury estimated that annual GDP in 2001 fell by NZ\$200 million as a result of conservation measures during that year [126]. Both IPENZ and the EC have recently concluded that, as security is climatemoderated in NZ, it is the lack of energy storage in NZ that is the main factor influencing sectoral vulnerability $[19,127-129]$, although it is very clear that the management of dry-year response through failure to maintain hydro reserves leading into winter, which was also a primary factor that increased the impacts of the 2008 dry-year [11].

The extent of lake-based storage is seasonal and usually approaches 3,000 GWh (energy equivalent) during February/March (maximum 3,600 GWh) and around 2,000 GWh during August/October [127]. Most of this storage ( 3,000 GWh) is located in the South Island. The total annual hydro inflows for the main hydro schemes over the years 1999-2007 are presented in Figure 3.1.

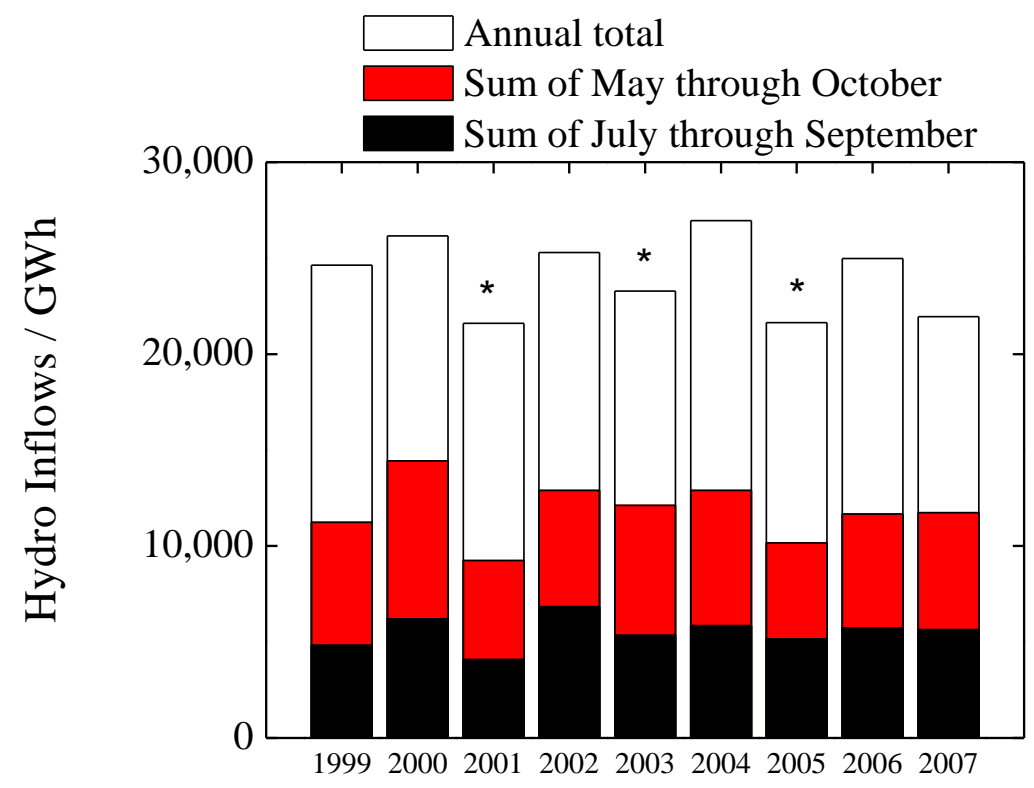

Figure 3.1. Historic hydro flow rates into NZ's main hydroelectric systems prior to 2008. The plots were summarised from monthly hydro inflow data reported by the EC for seventeen river systems up to June 2008 [130]. The dry-year electricity-supply conservation events (1999-2007, but excluding 2008) are indicated with an asterix $[11,47]$.

The 2008 winter [11] experienced the seventh lowest national shortfall in hydro energy since 1931. During November 2007 up to June 2008 only 12,758 GWh of inflows were recorded 
for the main hydroelectric systems [130] $(14,667 \mathrm{GWh}$ and $15,437 \mathrm{GWh}$ were recorded during 2006 and 2007, respectively).

On the advice of the Ministerial Review [131] (see also Section 4), The Reserve Energy Scheme was abolished in 2010. One of the driving factors was that:

"[i]n dry years, there are incentives for some market participants to seek to shift increased costs to consumers through public conservation campaigns, rather than manage the risks themselves" [132].

IPENZ [11] considered that the future success of the Electricity Industry Act (2010) (and the resulting Security and Reliability Council [133]) in this respect will be dependent on Transpower and/or the generators effectively (1) maintaining and monitoring 'security margins' (2) investing in new power sources (3) maintaining high wholesale prices during dry year events to increase the cost-effectiveness of the application of high value reserves and to initiate new investments. The latter could include the application of alternative forms of energy storage.

Regardless, under BAU conditions it is likely that NZ's vulnerability cannot be completely mitigated in a sustainable manner, i.e., without building new thermal reserves. Indeed, the IPENZ report focused on the latter as hydroelectric plant in NZ has limited energy storage capability [26,33]. However, plant selection for security of supply is considerably more complex than simply choosing the least-cost generating option and The Act equally includes the possible expansion of energy storage capacity.

\subsubsection{GHG emissions reduction and the price of carbon}

It has been estimated that, under the current policy settings, the cost of meeting NZ's legally binding Kyoto Protocol [134] obligations could be of the order of NZ\$1 billion in tax payer contributions [135-137], although this estimate has fluctuated greatly. Energy-derived GHG emissions have increased significantly since 1990 (Figure 3.2), and if NZ is to maintain its international credibility, its economic stability and its 'clean-green' image [21] (based on the ' $100 \%$ pure New Zealand' brand [138-141]), this country needs to make a real contribution towards $\mathrm{CO}_{2}$-e mitigation $[142,143]$. 


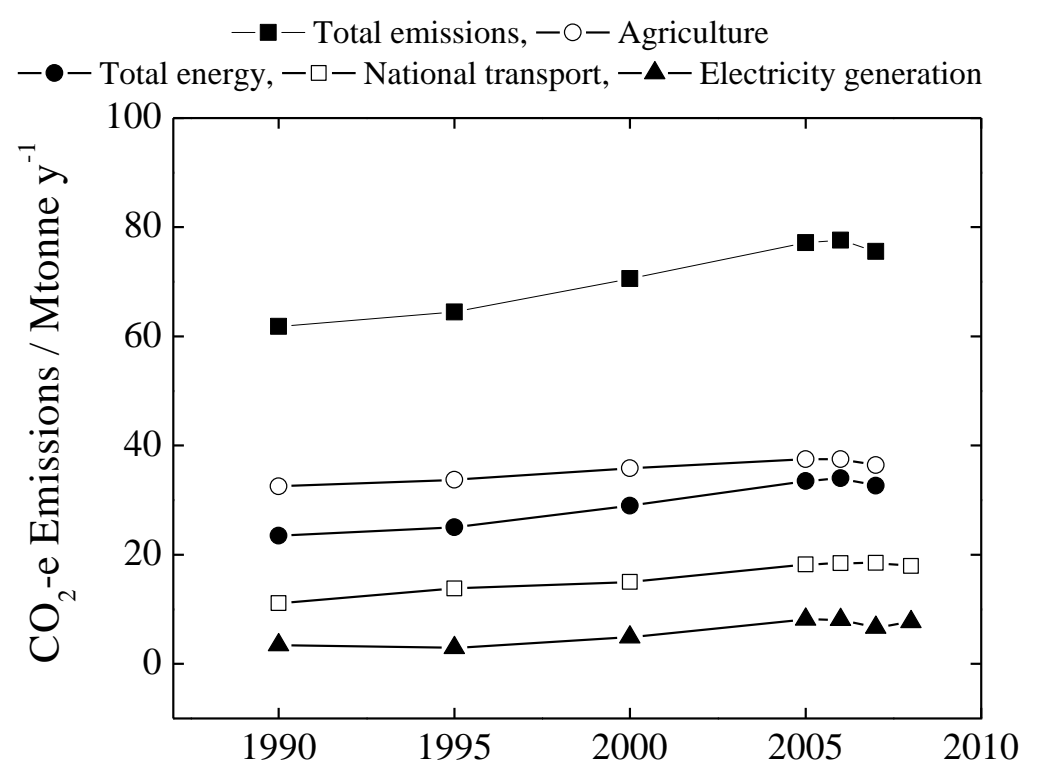

Figure 3.2. Trends in New Zealand's sectoral and total $\mathrm{CO}_{2}$-e emissions from 1990, drawn using MED data [9].

Real advances in NZ-based climate change mitigation technologies and services could increase export competitiveness [144] and present NZ with a tangible economic advantage over local trading partners, especially those that defer action to reduce $\mathrm{CO}_{2}$-e emissions [145]. However, there is a strong case for the fragile international consumer illusion of NZ's progressive environmental responsibility [138-141] being transformed into verifiable fact as rapidly as possible by reducing the number of thermal power sources.

Although the MED's 2010 Energy Outlook reference scenario suggests that it is possible that electricity sector GHG emissions could decrease relative to 2009 levels (5,955 ktonne $\mathrm{y}^{-1}$ ) through to 2025 (4,585 ktonne $\left.\mathrm{y}^{-1}\right)$ and 2030 (3,839 ktonne $\left.\mathrm{y}^{-1}\right)$ under BAU conditions [99], there will be strong pressure on New Zealand to reduce these emissions where possible. Also, a considerable amount of emissions would still be expected from reserve generation. There are no 'peaker' emissions data available for this scenario, but an indication of the quantity of emissions expected from these 'peakers' can be estimated (Table 3.3) from the GHG stackplots of the 2008 SOO published by the Electricity Commission.

For the MDS1 scenario, there appears to be around 400-500 ktonne $\mathrm{y}^{-1}$ of $\mathrm{CO}_{2}$-e emissions saving potential available by 2025 and 2030, respectively, if the gas- and diesel-based peaking capacity is replaced with renewables-based reserve capacity $(11-14 \%$ of the projected total 
sectoral emissions for 2025/2030 of $\sim 3,500$ ktonnes $\mathrm{y}^{-1}$ ). Under the MDS2 and MDS3 scenarios the equivalent emissions saving potential could be around 5\% and 8\% at 2025

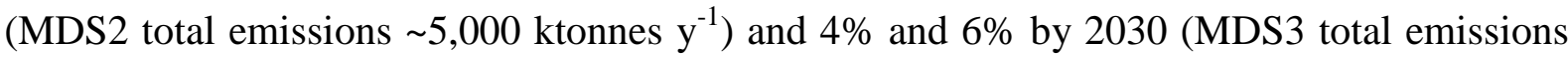
$\sim 6,000$ ktonnes $\mathrm{y}^{-1}$ ). The equivalent emissions saving potential from thermal peaking plant

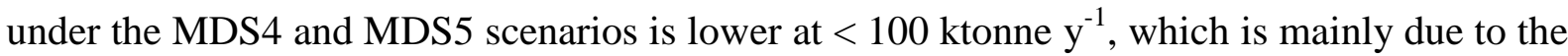
lack of requirement for variable-output renewables support. But, in the place of sustainable forms of generation, coal alone is projected to have a very large contribution towards overall emissions under these EC-derived scenarios (7,000 ktonne $\mathrm{y}^{-1}$ and 2,000 ktonne $\mathrm{y}^{-1}$, respectively, by 2025).

Table 3.3. Values of EC-derived annual $\mathrm{CO}_{2}$-e emissions rate projections for natural gas- and diesel-based peaking and coal-based dry-year reserve generation taken from data presented with the 2008 SOO [20]. For details of scenarios MDS1 through to MDS5, please refer to the original SOO documentation.

\begin{tabular}{|c|c|c|c|c|c|}
\hline & \multicolumn{5}{|c|}{ Greenhouse gas emissions $\left(\mathrm{CO}_{2}\right.$-e) / ktonne $\mathrm{y}^{-1}$ (approximate) } \\
\hline & MDS1 & MDS2 & MDS3 & MDS4 & MDS5 \\
\hline & Sustainable path & $\begin{array}{l}\text { South Island } \\
\text { surplus }\end{array}$ & $\begin{array}{l}\text { Medium } \\
\text { renewables }\end{array}$ & $\begin{array}{l}\text { Demand-side } \\
\text { participation }\end{array}$ & $\begin{array}{l}\text { High gas } \\
\text { discovery }\end{array}$ \\
\hline \multicolumn{6}{|c|}{ Peaker, fast start gas-fired } \\
\hline 2025: & $\sim 370$ & $\sim 220$ & $\sim 210$ & $<10$ & $\sim 40$ \\
\hline 2030: & $\sim 330$ & $\sim 230$ & $\sim 310$ & $<10$ & $\sim 90$ \\
\hline \multicolumn{6}{|c|}{ Peaker, diesel-fired OCGT } \\
\hline 2025: & $\sim 100$ & $\sim 30$ & $<10$ & $<10$ & $<10$ \\
\hline 2030: & $\sim 100$ & $\sim 160$ & $\sim 40$ & $<10$ & $\sim 130$ \\
\hline \multicolumn{6}{|c|}{ Total peaking } \\
\hline 2025 & $\sim 470$ & $\sim 250$ & $\sim 210$ & $<10$ & $\sim 40$ \\
\hline 2030 & $\sim 430$ & $\sim 390$ & $\sim 350$ & $<10$ & $\sim 220$ \\
\hline
\end{tabular}

The EC's also noted [20] that 'the effect of the price of carbon will "...disincentivise base load and mid-order thermal generation-especially coal-fired, but also gas-fired-and to encourage renewable development." This summary is also reflected in the MEDs Energy Outlook 2009, emissions pricing sensitivity scenarios [146], where any emissions price [147] $\geq \mathrm{NZ} \$ 25\left(\mathrm{CO}_{2}\right.$-e) per tonne ${ }^{-1}$ would be capable of completely phasing out coal combustion for electricity generation by 2030 [146]. The quantity of emissions produced by Huntly Units 1-4 during dry years is insignificant (Section 1). For example, the calculated rate of generation of

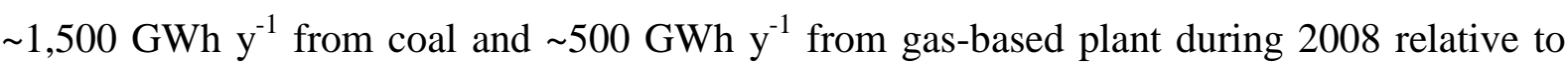
2007 and 2009 (Section 1) is roughly equivalent to $\mathrm{CO}_{2}$ emissions of approximately 450 and 100 ktonne $\mathrm{y}^{-1}$, respectively (assuming: $\sim 0.3 \mathrm{~kg}\left[\mathrm{CO}_{2}\right] \mathrm{kWh}^{-1}$ and $0.2 \mathrm{~kg}\left[\mathrm{CO}_{2}\right] \mathrm{kWh}^{-1}$ [148]). 
This may be a moderate estimate, as reported emissions during $2008\left(7,687\right.$ ktonne $\left.\mathrm{y}^{-1}\right)$ were $15.2 \%$ higher than that of $2007\left(6,675 \mathrm{ktonne}^{-1}\right)$ [9].

Although the economic impact of the price of carbon in NZ has been debated $[149,150]$, the cost of emitting $\mathrm{CO}_{2}$-e will most likely increase over time [151,152]. In an apparent effort to minimise short-term impact on the economy, therefore, the NZ ETS [135,153-155] was extensively modified by the government to the point where it currently does not operate as a cap and trade system [154]. In effect, there is no limit on emissions and sectors, including agriculture, are 'subsidised' by the tax payer through late entry.

In regard to electricity generation, the current, short-term 'transitional' settings of the first commitment period of the NZ ETS (1 July 2010 to 31 December 2012 [153]) include [155157]:

- stationary energy sector participants must self report and surrender New Zealand Units (NZUs),

- petroleum importers and NZ-based mining companies are included (which affects diesel as a 'liquid fossil fuel' and natural gas),

- costs are passed to consumers, and

- emission units are bought from the NZ Government at a capped price of NZ\$25 tonne ${ }^{-1}$, but only one emission unit has to be surrendered for every two tonnes of GHG production. $^{14}$

Thus, only a capped price of NZ\$12.50 $\left(\mathrm{CO}_{2}-\mathrm{e}\right)$ tonne ${ }^{-1}$ currently affects the generators [156]. Renewable energy generators, however, are likely to receive only an additional NZ\$1.8 million in benefits [154]. The ETS, therefore, is unlikely to have a significant impact over the short term (perhaps a $2 \%$ reduction in GHGs [154]). Regardless, the settings of the NZ ETS will be reviewed every five years, with the next re-assessment being due in 2011, and the settings could be modified considerably [153].

\subsubsection{Policy measures complementary to the NZ ETS}

There is an apparent lack of political motivation to introduce measures that are complementary to the NZ ETS, the latter being seen as the primary instrument of government GHG mitigation policy [143]. The NZ Government currently does not intend to introduce market-based instruments such as feed-in tariffs or portfolio standards for sustainable forms of electricity generation. Moreover, there are no grants, deployments funds or obligations in action in NZ that directly promote the development of sustainable reserve power sources. It

\footnotetext{
${ }^{14}$ Recommended for electricity generation by the Technical Advisory Group for the Stationary Energy and Industrial Process component of the New Zealand Emissions Trading Scheme.
} 
has been noted, therefore, that the Government's current approach to climate change mitigation policy may not be capable of directing NZ towards a truly sustainable, lowemissions electricity sector by 2025 [143].

In 2007, targets of $80 \%, 90 \%$ and $95 \%$ renewables by 2030 were modelled by the MED, the EC and the EECA, both with and without a price on carbon of NZ\$25 tonne ${ }^{-1}$ [158]. A "no [increase in] renewable electricity target' was also examined. It was concluded in this work that an increased market share of renewables could only be achieved through both a price on carbon and through the use of an absolute renewables target. Even if MED projections are considered, an approach of simply relying on the price on $\mathrm{CO}_{2}$-e to reach even $\mathrm{NZ} \$ 100$ tonne ${ }^{1}$ would not result in a $90 \%$ renewables share by 2025 (the value could be closer to $84 \%$ at NZ\$100 tonne $\left.{ }^{-1}[8]\right)$.

In 2010 The MED released the combined draft New Zealand Energy Strategy and draft NZ Energy Efficiency and Conservation Strategy [21] for comment (submission period: 22 July 2010 to 2 September 2010). The document focused on an "overarching goal" of economic growth through non-renewable resources extraction (i.e., mining of natural gas and petroleum were part of a "desirable future"). However, the expansion of both thermal- and renewablesbased power and an "innovative" electricity market was promoted as essential for this growth to occur. The draft document notes that [21]:

"as New Zealanders, we pride ourselves on being nimble and quick to adopt new technologies and to develop leading technologies" and that NZ becomes "a smart niche player in new energy technologies both through international partnerships and the development of local companies. New Zealand quickly adopts innovative energy efficient and low emissions technologies".

The draft energy conservation and efficiency strategy also noted:

"[t]he Government expects the regulator, system operator, and lines companies to minimise lines losses and make efficiency gains in the operation of the system, and plan ahead to ensure the system can securely support a greater proportion of renewable generation in the future."

Politically at least, these comments may leave the door open to the adoption of storage technologies, that may include overseas battery-based systems and also the 'in-house' development of PH. It is clear, however that the present government supports the continued introduction of thermal reserves as [21]:

"New Zealand will improve its resilience to disruptions in energy supply through utilising a wider range of energy resources and by replacing oil with local 
energy sources", but "[f] or the foreseeable future some fossil fuel generation will be required to support supply security."

Gas and electricity supply were noted to be "interdependent" and future discoveries of the former were seen as an extremely important for (1) security of supply, (2) the reduction of electricity prices and (3) the development of a gas export market.

The target of 50\% reduction in net $\mathrm{CO}_{2}$-e net emissions by 2050 (vs. 1990 levels) was restated by the National-led government, was an "aspirational" 90\% renewables target by 2025 [21], with the caveat: "providing supply security is maintained". The draft also does not specifically consider a $100 \%$ renewables-based supply system as being a desirable long-term outcome.

With reference to the proposed National Policy Statement on Renewable Electricity Generation (NPSREG) [159], the draft Energy Strategy stated that [21]:

"A National Policy Statement on Renewable Electricity Generation is being developed to assist RMA decision makers weigh up the benefits of renewable generation with local environmental effects."

When in force, it is envisioned that the NPSREG will add clarity and consistency to the RMA [160] process through the directing of regional and district planning in regard to energy-based consent processes. The NPSREG, therefore, could act to support the introduction of sustainable technologies by mitigating some of the concerns raised by the respondents in regard to consent complexity and timescales, especially that likely to be associated with pumped hydro. For example, Contact notes that the higher costs, declined consents and delays $d o$ influence to some extent the choice of investments by the industry $[73,104]$. Contact proposed, therefore, that an NPSREG that effectively supports renewable electricity generation is critically important for the uptake of sustainable technologies.

However, it is likely that even with an NPSREG in conjunction with the RMA; there will continue to be tensions between lowering barriers to renewable-based power stations (thus reducing global environmental impact) and minimisation of the local impacts of these developments.

\subsubsection{Support of variable-output renewables}

A major perceived drawback to the use of wind power is the possibility of electricity grid instability at levels $>15-20 \%$ wind-derived contribution $[20,92,161,162]$, especially for small, geographically isolated nations. Indeed in NZ, 'variability' (or more incorrectly 
'intermittency') is most often cited as the most significant factor limiting universal acceptance of utility-scale, wind-derived energy generation for base-load demand [19,20,92,163-165].

The Electricity Commission (EC) noted, for example, that "the unpredictably of wind generation output on pre-dispatch processes ${ }^{15}$ is the issue that should be accorded the highest priority" and considered that weather forecast error could exceed load forecast error, even at low levels of installed wind capacity $[6,166,167]$.

Regardless, variability is not a fatal technical limitation of wind power. In Europe, wind contributes to $20 \%$ of total annual generation in Denmark and in Spain wind can contribute up to a third of total instantaneous generation during conditions of peak wind energy flow [168]. However, this success is likely to be supported at least in part by the transcontinental electricity transmission grid $[33,163]$ and large quantities of nuclear base load and/or thermal peaking capacity. For interconnected geographically distributed sources of wind power in the USA, Jacobson [35] reports that up to twenty wind farms distributed over $850 \mathrm{~km}$ x $850 \mathrm{~km}$ in the Midwest region of the USA results in an average 33\% combined generation capacity which could be considered for base load supply at a reliability that has been estimated to be equivalent to that of coal-fired plant [169]. In addition, the long-range interconnection of intra-regionally distributed wind farms significantly reduce transmission energy losses (to $1.6 \%$ from $9.8 \%$ ).

In NZ, a widely distributed network of variable-output generators could include the future marriage of wind-, hydro-, marine- and introduced-energy-storage-based power sources at locations situated over both the South and North Islands [35]. Indeed, increasing the diversity of renewable energy sources is likely to both reduce the impact of variability and improve strategic security of supply $[33,101,159,170]$. New Zealand will also benefit from its high associated wind-based capacity factor (0.30 to 0.45 [33]) and hydro resources that may be able to be freed up to support 2,000 MW of wind-based capacity [35,36,171,172], even without introduced forms of energy storage. The NZWEA, also projects a scenario where total wind power capacity could be 2,500 to 3,000 MW by 2035 [173] (calculated to be $~ 15$ $20 \%$ of total generation at this time), while still maintaining security of supply [174].

Bertram and Clover have examined the economic feasibility of renewables-derived variability and an increased renewables share of generation by examining various levels of confidence in the security of supply (reliability) as a function of the share of renewables connected to the grid (Figure 3.3) [33]. Of importance is that the reliability cost rises almost exponentially because the capacity of fast-start reserves (which could, in theory, include introduced forms of

\footnotetext{
${ }^{15}$ Forecasting/wind capacity data gathering.
} 
energy storage) increases rapidly with linear increases in the share of variable-output renewables. These levels of dispatchable power are seen as having higher cost per MW vs. other forms of generation (see latter in this section) and costs increase rapidly with the reliability expectation factor. As the figure illustrates, the authors conclude that a $100 \%$ reliability factor may be economically feasible at a $90 \%$ renewables share, but not $95 \%$. (Note, however, the exact shape of the reliability curves is more likely to be conjectural than empirically established.)

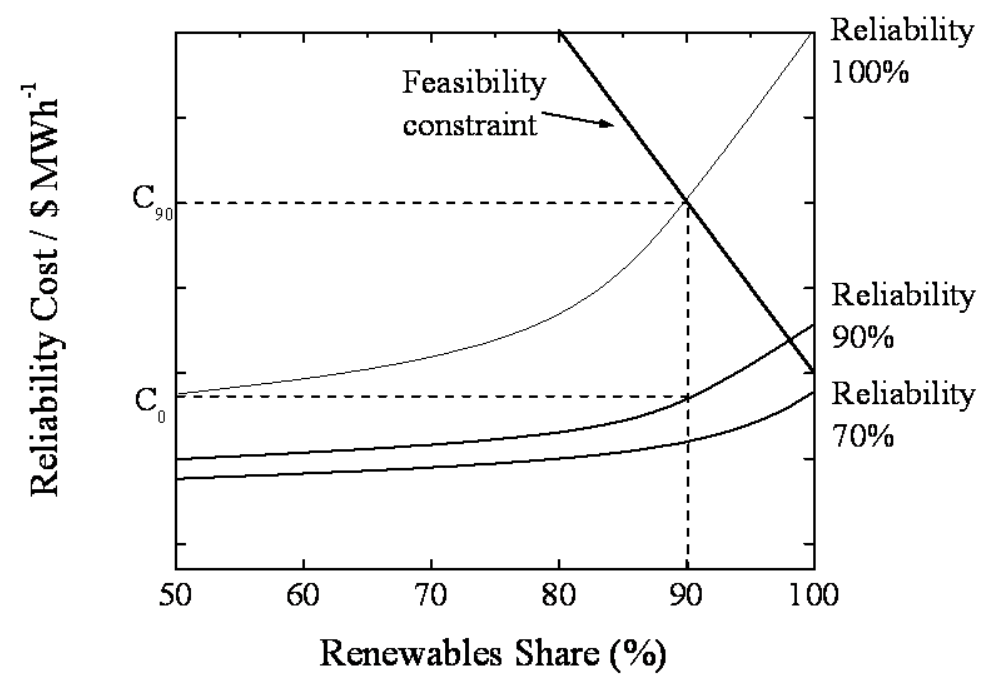

Figure 3.3. Schematic framework for the integration of variable-output renewables into a hypothetical electricity network, after Bertram and Clover [33].

\subsubsection{Wind-spillage mitigation}

Although, there is little-to-no data available in NZ regarding the extent of wind spillage to 2025, theoretically, wind spillage could be reduced via the application of either $\mathrm{PH}$ [79] or batteries [28]. Utility-scale batteries facilities are commonly built on wind farms in order to capture spillage and regulate output $[75,76,163,175-182]$. This includes the $34 \mathrm{MW}$ NaS battery system in Rokkasho, Northern Japan, which has a 245 MWh ( 7 h) energy capacity $[76,163,182]$. This installation supports a $51 \mathrm{MW}$ collection of turbines operated by Japan Wind Development Co. Ltd. Here, the wind energy (including spillage when available) is used to charge the battery system during off-peak hours. During these times the energy is first stored prior to the excess being released to the transmission grid. Unless firming capacity is specifically required during off-peak periods, the batteries are only discharged during periods of peak demand. The power output quality of the turbines is also regulated by the batteries at all times. The potential economic and environmental benefits of an all-vanadium battery installed at the King Island, Australia in 2003 were estimated by VRB Power (Table 3.4). This simple, analysis estimated a 3.5-year payback period through the reduction of 
operational costs relative to the continuous operation of a diesel-fuelled generator. Wind spillage mitigation was estimated to provide a saving of US\$51,200 $\mathrm{y}^{-1}$. Some 4 ktonnes $\mathrm{y}^{-1}$ of GHG emissions were also avoided [179] (NZ\$100,000 $\mathrm{y}^{-1}$, assuming NZ\$25 $\left[\mathrm{CO}_{2}\right]$ tonne ${ }^{1}$ ). There is also the potential for generators, such as Meridian to install an overcapacity of wind for the provision of 'firm power capacity' for ancillary services, or, perhaps, as a reserve for periods of reduced hydo inflows. Clearly, rather than spill this potential energy generation when offline this potential could be stored for release at peak times. The stored energy could also be used to provide additional high-value ancillary services, including six-second FIR.

Table 3.4. Economic assessment of the all-vanadium Huxley Hill Wind Farm battery system on King Island, Australia. The battery system consists of a $200 \mathrm{~kW}, 800 \mathrm{kWh}$ all-vanadium flow battery system (augmenting a $6,000 \mathrm{~kW}$ diesel engine generator) [179].

\begin{tabular}{|c|c|c|}
\hline Operational factor & Quantity & Annual value / US\$ \\
\hline \multicolumn{3}{|l|}{ Cost reductions } \\
\hline $\begin{array}{l}\text { Reduction of diesel spinning reserve operational } \\
\text { time }\end{array}$ & $8 \mathrm{~h} \mathrm{~d}^{-1}$ & 91,500 \\
\hline Improved operational efficiency & $25 \mathrm{dm}^{3} \mathrm{~h}^{-1}$ (spinning reserve) & 83,200 \\
\hline Capture of 'spilled' wind power & $1,100 \mathrm{kWh} \mathrm{d}^{-1}$ & 51,200 \\
\hline \multirow[t]{2}{*}{ Maintenance reduction } & 12 fewer generator set run-hours $\mathrm{d}^{-1}$ & 23,000 \\
\hline & Total & 248,900 \\
\hline \multicolumn{3}{|l|}{ Emissions reductions } \\
\hline $\mathrm{CO}_{2}$ & 4 ktonne $\mathrm{y}^{-1}$ & - \\
\hline $\mathrm{NO}_{\mathrm{x}}$ & 99 tonne $\mathrm{y}^{-1}$ & - \\
\hline Unburned hydrocarbon & 75 tonne $\mathrm{y}^{-1}$ & - \\
\hline
\end{tabular}

\subsubsection{Hydro-spillage mitigation}

As noted in Table AF1 (Appendix F) [183], the reasons for hydro spillage are varied, although, in general, most spills are the result of excess inflows to the storage system during the wet season. Regardless, the value of the water spilled is effectively zero and this would be reflected in the cost per kWh of generation from 're-directed' spillage (Section 2.2 and Appendix A). Although spillage has rarely been an issue in NZ, the rate of spillage from the Waitaki system during late December 2008 and the first quarter of 2009 was noted by one commentator to be such that "if harnessed for generation, [it would] be enough to power half the households in New Zealand in summer" [184]. This excess spillage resulted from a damaged transformer at the Rio-Tinto-owned Tiwai aluminium smelter ( $180 \mathrm{MW}$ of reduced 
demand) [185]. When combined with high inflows during early 2009 the overall drop in demand resulted in a significant drop in wholesale electricity prices and a 30-33\% loss in underlying earnings (after tax) for Contact in 2009 relative to 2008 [186]. In this present research, the spillage from each generator during this period (2008-2010) has been collated from each of the generator web-sites (Figure 3.4, at 29 November 2010). Only the spills due to 'high inflows' and 'costs' (low value of generation) are considered (Appendix F). The energy lost from Contact's lakes was $415 \mathrm{GWh}$ of the total of $534 \mathrm{GWh}$ spilled by this company during this period [187]. Contact also experienced relatively high cost-derived spills during 2008, 2009 and the first half of 2010 and a total of $359 \mathrm{GWh}$ was spilled because of the low storage capacity of the Clyde and Roxburgh stations. This was more than twice that spilled as a result of high inflows (184 GWh).

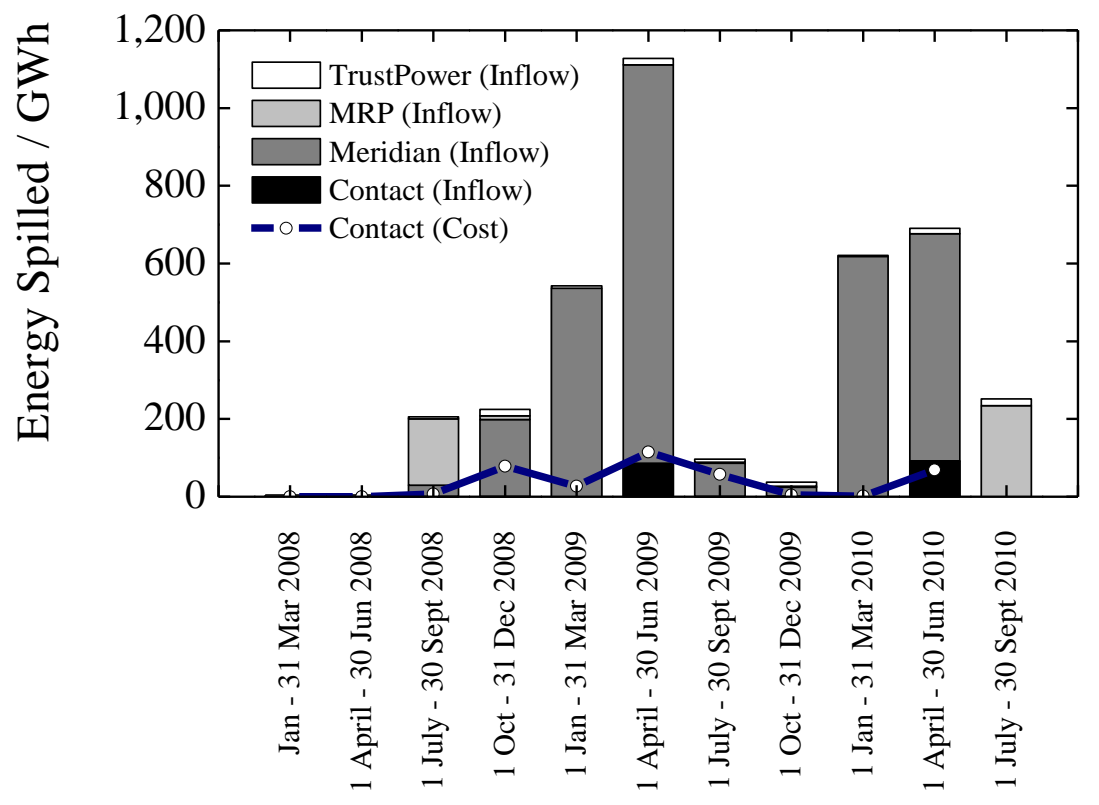

Figure 3.4. Energy spilled from high inflow (histogram) and cost (line and symbol Contact only) during 2008 to the end of September 2010. All raw data were downloaded as quarterly reports from the respective generation company websites. Contact had not made the July/Sept 2010 hydro spill data available by the time of the analysis.

The total of high inflow spillage lost by Meridian was considerable at 3,096 GWh over the period, comprising $225 \mathrm{GWh}$ during the 2008 dry year, 1,668 GWh during 2009 and 1,202 during 2010 to the end of September. By comparison, the total cumulative losses through TrustPower and MRP installations over these years were only $105 \mathrm{GWh}$ and $420 \mathrm{GWh}$, respectively. The total combined hydro spillage losses affecting all four generators from Jan 2008 to the end of June 2010 was 3,900 GWh. The 2,007 GWh $\mathrm{y}^{-1}$ lost during 2009 represents $4.8 \%$ of the total amount of energy generated in $2009\left(\sim 42,000 \mathrm{GWh} \mathrm{y}^{-1}\right)$, all of 
which could have been used to charge a network of energy storage systems, had they been available. Moreover, many of the respondents projected that such events may increase if a paradigm of 'security of supply' (and not 'efficiency') is indeed adopted by the sector.

\subsubsection{Cost-analysis}

\section{Thermal reserve generation costs}

The long run marginal costs (LRMC) ${ }^{16}$ and short run marginal costs (SRMC) ${ }^{17}$ of reserve generation from the EC's SOO [20] are reproduced in Table 3.5 as a function of the price of gas and $\mathrm{CO}_{2}$-e. Projected LRMCs are also available from the MED [85] (Table 3.6 and Figure 3.5). Figure 3.5(a), for example, shows the relative order of LRMCs that can be calculated using the MED's interactive cost of generation spreadsheet (2010) [85]. ${ }^{18}$ for a 'high' price of gas $\left(\mathrm{NZ} \$ 13 \mathrm{GJ}^{-1}\right)$ and a 'low' price on $\mathrm{CO}_{2}-\mathrm{e}\left(\mathrm{NZ} \$ 25.00\left[\mathrm{CO}_{2}-\mathrm{e}\right]\right.$ tonne $\left.{ }^{-1}\right)$.

Table 3.5. EC-derived LRMC and SRMC of generation from thermal reserve power stations within the NZ context (North Island only) [20]. These data exclude connection costs and the expected error is $\pm N Z \$ 0.020$ $\mathrm{kWh}^{-1}$

\begin{tabular}{|c|c|c|c|c|}
\hline Classification & $\begin{array}{l}\text { Capacity } \\
\text { factor }\end{array}$ & 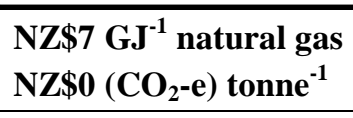 & $\begin{array}{l}\text { NZ\$10 GJ } \mathbf{J}^{-1} \text { natural gas } \\
\mathrm{NZ \$ 30}\left(\mathrm{CO}_{2}-\mathrm{e}\right) \text { tonne }^{-1}\end{array}$ & 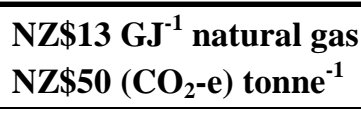 \\
\hline & & \multicolumn{3}{|l|}{ LRMC / NZ\$ kWh } \\
\hline $\begin{array}{l}\text { Diesel-fired } \\
\text { peaking plant }\end{array}$ & 0.05 & 0.620 & 0.640 & 0.656 \\
\hline \multirow{3}{*}{$\begin{array}{l}\text { Natural gas-fired } \\
\text { peaking plant }\end{array}$} & 0.05 & 0.545 & 0.591 & 0.632 \\
\hline & 0.20 & 0.215 & 0.261 & 0.302 \\
\hline & & \multicolumn{3}{|l|}{ SRMC/ NZ\$ kWh } \\
\hline Taranaki CC & - & 0.056 & 0.090 & 0.119 \\
\hline Whirinaki & - & 0.280 & 0.304 & 0.320 \\
\hline $\begin{array}{l}\text { Huntly units } 1-4 \\
\text { on coal }\end{array}$ & - & 0.052 & 0.081 & 0.100 \\
\hline
\end{tabular}

\footnotetext{
${ }^{16}$ LRMC is defined in the SOO as "the mean price (at the relevant GIP) that is sufficient to cover all plant costs (in this context, including capital financing costs, carbon costs, fuel costs, operation and maintenance and transmission charges but excluding network losses).". A real pre-tax discount rate of eight percent was assumed and the assumed depreciation rates may also have varied between technologies.

17 SRMC is defined in the SOO as "the marginal cost, at the relevant GIP, of producing the next unit of electricity (in this context, including carbon costs, fuel costs and variable operation and maintenance, but excluding capex, fixed operation and maintenance, transmission charges and network losses).”.

${ }^{18}$ Coal: NZ\$4.5 GJ ${ }^{-1}$, lignite: NZ\$1.8 $\mathrm{GJ}^{-1}$, diesel (moderately priced): NZ\$35.0 $\mathrm{GJ}^{-1}, \mathrm{NZ} / \mathrm{US} \$ / \$$ exchange rate: $0.60, \mathrm{NZ} \$$ /Euro exchange rate: 0.48 , discount rate: $8.0 \% \mathrm{y}^{-1}$ and $0 \% \mathrm{y}^{-1}$ increase in costs.
} 
Table 3.6. Output of the MED-derived (2010), approximate LRMC of proposed new generation from thermal power stations within the NZ context. These data were derived from the MED's Interactive Generation Cos Model [85] and exclye

\begin{tabular}{|c|c|c|c|c|c|c|c|c|c|c|}
\hline $\begin{array}{l}\text { Classification and } \\
\text { project name }\end{array}$ & $\begin{array}{l}\text { MED- } \\
\text { assumed } \\
\text { capacity } \\
\text { factor }\end{array}$ & $\begin{array}{l}\text { Status } \\
\text { (April } \\
\text { 2010) }\end{array}$ & $\begin{array}{l}\text { Power } \\
\text { / MW }\end{array}$ & $\begin{array}{l}\text { Energy } \\
/ \text { GWh } \\
\mathbf{y}^{-1}\end{array}$ & $\begin{array}{l}\text { Capital } \\
\text { cost / } \\
\text { NZ\$ } \\
\text { million }\end{array}$ & $\begin{array}{l}\text { Variable } \\
\text { operation \& } \\
\text { maintenance } \\
\text { costs / NZ\$ } \\
\mathbf{k W h}^{-1}\end{array}$ & $\begin{array}{l}\text { Fixed } \\
\text { operation \& } \\
\text { maintenance } \\
\text { costs / NZ\$ } \\
\text { kWh }^{-1}\end{array}$ & 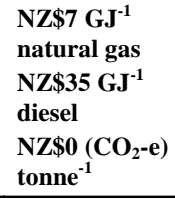 & 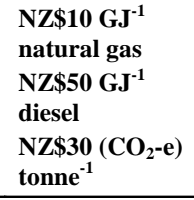 & 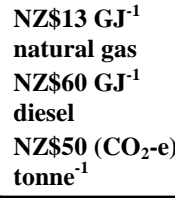 \\
\hline \multicolumn{8}{|c|}{ Combined cycle natural gas turbine } & \multicolumn{3}{|c|}{ Long-run marginal costs of generation / $\mathrm{NZ} \$ \mathrm{kWh}^{-1}$} \\
\hline \multicolumn{11}{|c|}{ Diesel-fired peaking plant } \\
\hline Generic OCGT NI 1 & 0.05 & Possible & 150 & 66 & 151 & 0.004 & 0.040 & 0.649 & 0.808 & 0.914 \\
\hline Generic OCGT NI 2 & 0.05 & Possible & 150 & 66 & 153 & 0.004 & 0.040 & 0.652 & 0.811 & 0.917 \\
\hline Generic OCGT NI 3 & 0.05 & Possible & 150 & 66 & 155 & 0.004 & 0.040 & 0.654 & 0.813 & 0.920 \\
\hline Generic OCGT NI 4 & 0.05 & Possible & 150 & 66 & 156 & 0.004 & 0.040 & 0.657 & 0.816 & 0.922 \\
\hline Generic OCGT NI 5 & 0.05 & Possible & 150 & 66 & 158 & 0.004 & 0.040 & 0.660 & 0.819 & 0.925 \\
\hline Generic OCGT SI 1 & 0.05 & Possible & 150 & 66 & 159 & 0.004 & 0.040 & 0.735 & 0.899 & 0.1008 \\
\hline Generic OCGT SI 2 & 0.05 & Possible & 150 & 66 & 161 & 0.004 & 0.040 & 0.738 & 0.902 & 0.1011 \\
\hline \multicolumn{11}{|c|}{ Natural gas-fired peaking plant } \\
\hline Gas fired OCGT 2 & 0.26 & Possible & 200 & 438 & 245 & 0.025 & 0.050 & 0.192 & 0.236 & 0.275 \\
\hline Gas fired OCGT 4 & 0.26 & Possible & 200 & 438 & 253 & 0.025 & 0.050 & 0.194 & 0.238 & 0.277 \\
\hline Stratford peaker & 0.26 & Complete & 200 & 438 & 241 & 0.025 & 0.050 & 0.199 & 0.245 & 0.285 \\
\hline Gas fired OCGT 3 & 0.26 & Possible & 200 & 438 & 249 & 0.025 & 0.050 & 0.201 & 0.247 & 0.287 \\
\hline
\end{tabular}




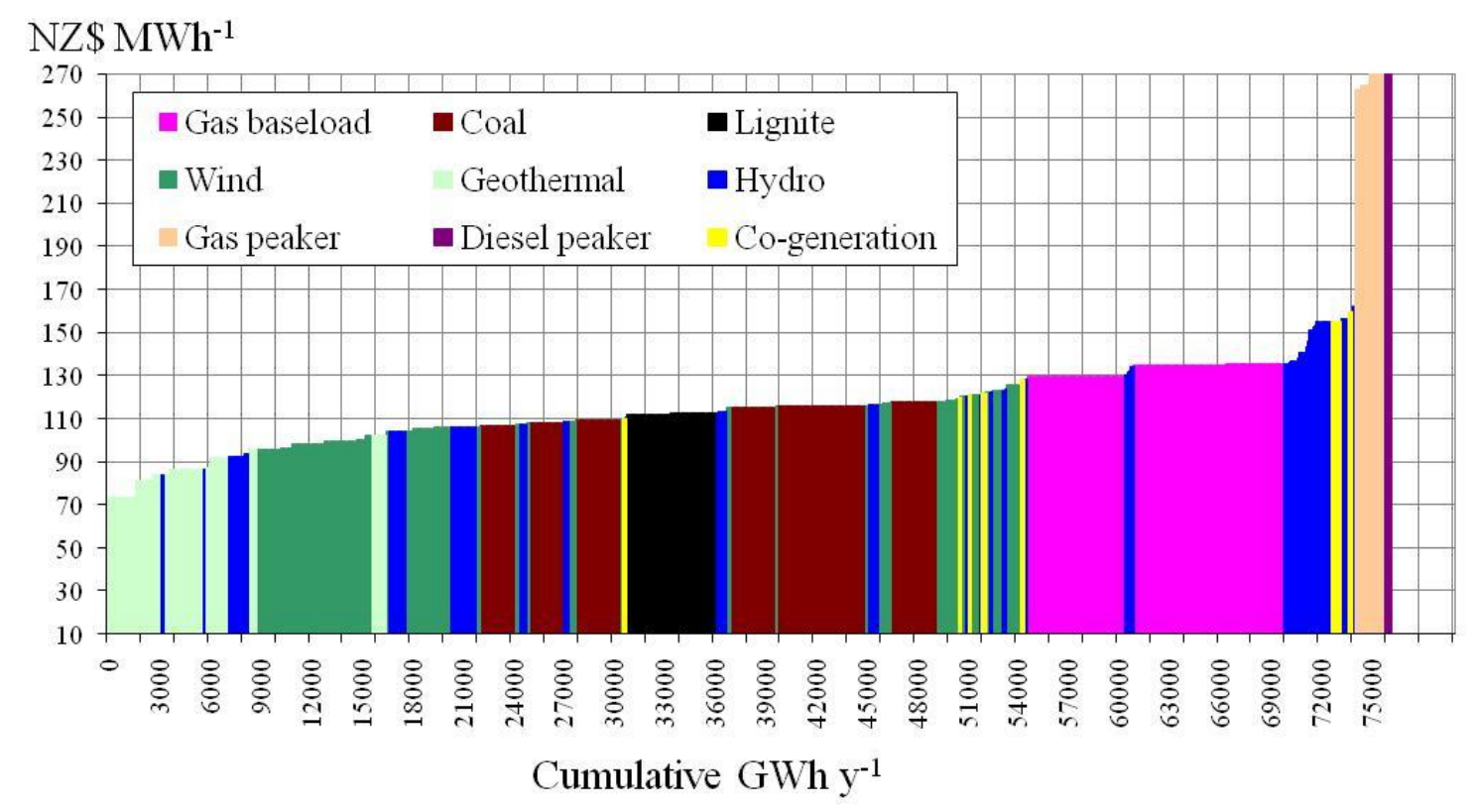

(a)

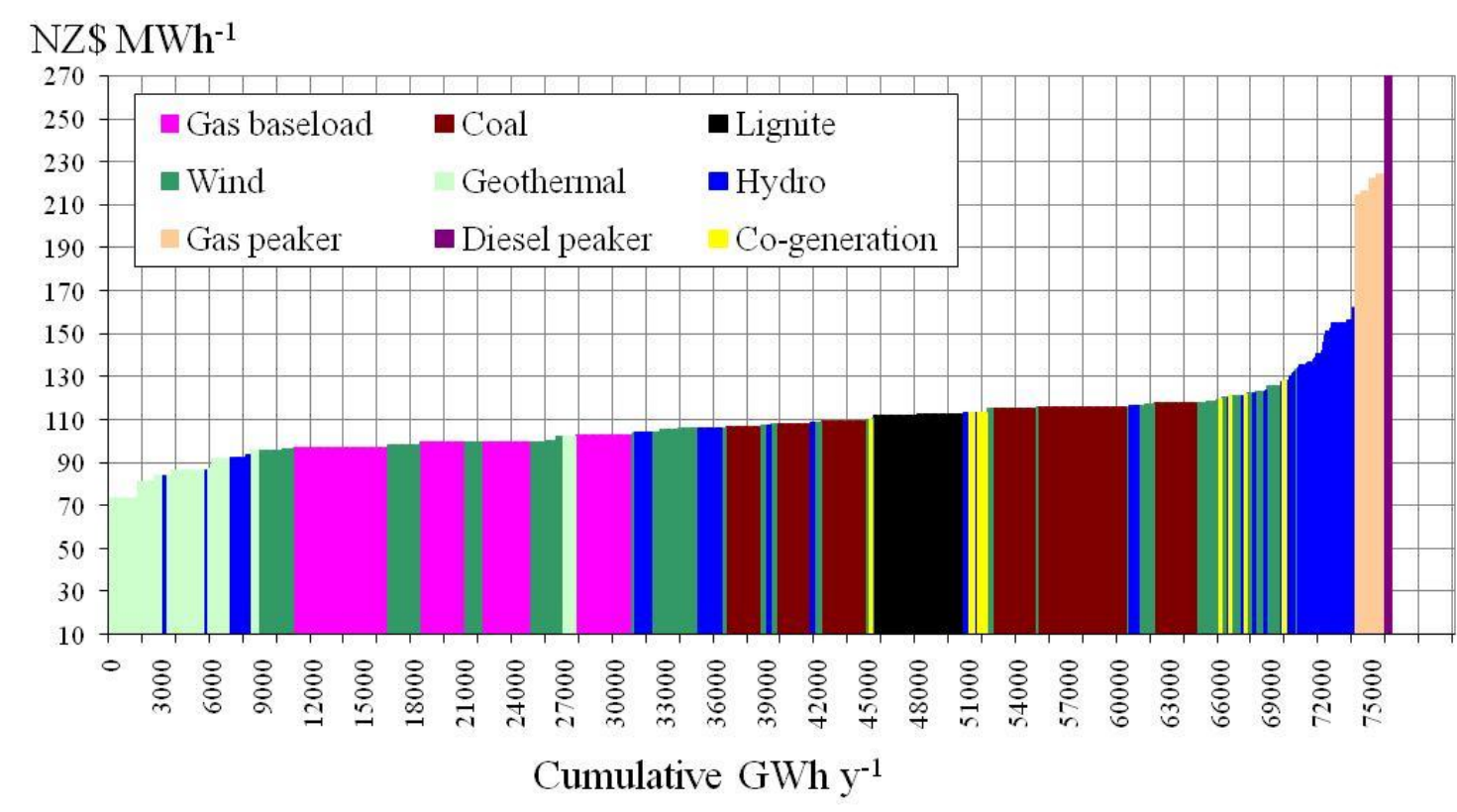

(b)

Figure 3.5. Long-run marginal cost of new electricity generation projects from various generation sources as modelled by the MED's Energy Modelling Group [85]. Assumptions: (a) Price of natural gas NZ $\$ 13 \mathrm{GJ}^{-1}$ and $\mathrm{NZ} \$ 25.00\left(\mathrm{CO}_{2}-\mathrm{e}\right)$ tonne ${ }^{-1}$, (b) price of natural gas NZ\$8 GJ${ }^{-1}$ and $\mathrm{NZ} \$ 25.00\left(\mathrm{CO}_{2}-\mathrm{e}\right)$ tonne ${ }^{-1}$.

From these data, it is clear that peaking gas- and diesel-based reserves are likely to be the most expensive form of new thermal-derived centralised electricity production that could be introduced to NZ. Peaking generation from diesel is also likely to be exceptionally expensive. There is a significant difference in costs, however, between technologies. The MED-derived LRMCs of generation from a generic $200 \mathrm{MW}$ natural-gas-based peaking plant, for example, 
could be $\sim \mathrm{NZ} \$ 0.192-0.201 \mathrm{kWh}^{-1}$ (at CF: 0.26). This estimate rises to NZ\$0.649-0.738 $\mathrm{kWh}^{-1}$ from diesel reserves (CF of 0.05). The equivalent EC values were NZ\$0.215 (CF: 0.20) and $\mathrm{NZ} \$ 0.620 \mathrm{kWh}^{-1}$ (CF: 0.05), respectively. Furthermore, if the prices of gas and $\mathrm{CO}_{2}-\mathrm{e}$ increase to NZ\$10 GJ $\mathrm{J}^{-1}$ and NZ\$30 tonne ${ }^{-1}$ and subsequently NZ\$13 $\mathrm{GJ}^{-1}$ and NZ\$50 tonne ${ }^{-1}$ the resulting LRMCs from gas could be NZ\$0.236-0.247 and NZ\$0.275-0.289 $\mathrm{kWh}^{-1}$, respectively (CF: 0.26) and NZ\$0.261 $\mathrm{kWh}^{-1}$ and $\mathrm{NZ} \$ 0.302 \mathrm{kWh}^{-1}(\mathrm{CF}: 20)$. At CF: 0.05, these values double to NZ\$0.591 and NZ\$0.632 $\mathrm{kWh}^{-1}$.

The costs of diesel-based peaking increase to extraordinary levels as the cost of this fuel increases from NZ\$50 $\mathrm{GJ}^{-1}$ to $\mathrm{NZ \$ 60} \mathrm{GJ} \mathrm{G}^{-1}$ (at $\mathrm{NZ \$ 30}$ and $\mathrm{NZ \$ 50}\left[\mathrm{CO}_{2}-\mathrm{e}\right]$ tonne ${ }^{-1}$, respectively). The costs of generation are then projected to be: NZ\$0.808-0.902 $\mathrm{kWh}^{-1}$ and NZ\$0.914-1.011 $\mathrm{kWh}^{-1}$, respectively (CF: 0.05). This is not surprising, as the wholesale price of diesel per GJ is more than four times that of gas (2008 values) [10].

Indeed, the EC considered that the high price of electricity generation from Whirinaki was the key factor that influenced the Reserve Energy Dispatch Guidelines (the SRMC of generation [Table 3.5] was optimistically assumed to be $\sim \mathrm{NZ} \$ 0.300 \mathrm{kWh}^{-1}$ in 2008). Prior to the Electricity Industry Act (2010), dry-year reserve generation from Whirinaki Power Station was based on the trigger of an elevated spot price of hydroelectricity. The "value of the water" [188] that would trigger generation tended to vary throughout the year and was equal to the offer price of this reserve.

The market-based approach to the sector should, in theory, negate government subsidy. But, being owned by the government, Whirinaki was able to receive tax-payer-derived support when:

"the Electricity Commission decided to hold the Whirinaki offer price at $\$ 289 / M W h$ despite rising fuel costs in an effort to increase non-hydro generation, and greater conservation of hydro storage." [11].

Whirinaki is now up for sale [26] and the non-subsidised cost of generation will be paid by the highest bidder, should they choose to continue its operation.

\section{Plant capacity factor}

The CF of a power source will have considerable influence over the cost-efficiency of generation and low $\mathrm{CF}$ values can be an economic barrier to the introduction of any power source. This is illustrated in Figure 3.6. Thus, in addition to the previous availability of flexible lake-based hydro, these high costs at low CF values may also partly explain why there has been a limited capacity of dedicated thermal peaking plant in NZ prior to 2010. 


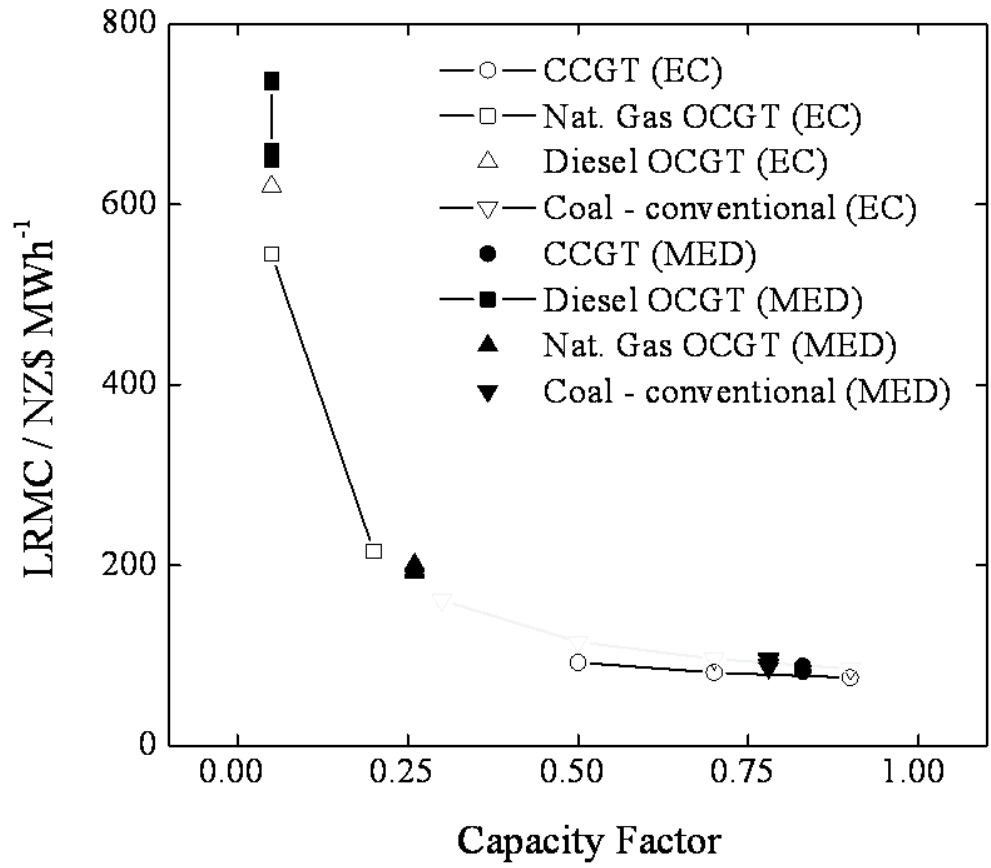

Figure 3.6. Electricity Commission(EC) and Ministry of Economic Development- (MED) derived projected long-run marginal costs of generation in NZ [20,85] plotted against capacity factor $(\mathrm{CF})$.

Combined cycle gas turbine is abbreviated to CCGT and open cycle gas turbine (for peaking) to OCGT. Conditions assumed include natural gas at $\mathrm{NZ} \$ 7 \mathrm{GJ}^{-1}$, diesel at $\mathrm{NZ} \$ 7 \mathrm{GJ}^{-1}$ (excluding EC data) and $\mathrm{CO}_{2}$-e at NZ\$0 tonne ${ }^{-1}$.

\section{Capital and operational cost comparison of batteries and pumped hydroelectricity}

As will be seen, the results of the survey indicate that there is some considerable uncertainty regarding the LRMCs of generation from batteries, although these estimates were almost universally assumed to be greater than PH. Because of the large initial investment (and no fuel requirements/low charging costs) both the capital cost and plant longevity (number of cycles) of energy storage are primary indicators of cost-effectiveness. For example, from Figures 2.1, 3.7 and 3.8 [189] it can be seen that PH may be more cost-effective, per kWh of output, than batteries, as the ESA considers the capital cost per cycle of $\mathrm{PH}$ in terms of energy generated to be $\sim \mathrm{US} \$ 0.001-0.01 \mathrm{kWh}^{-1}$ cycle $^{-1}$ (Figure 2.1). RFBs have equivalent costs of $\sim$ US\$0.01-1.00 $\mathrm{kWh}^{-1}$ cycle $^{-1}$ and NaS batteries $\sim \mathrm{US} \$ 0.10 \mathrm{kWh}^{-1}$ cycle $^{-1}$. (The primary differences between RFBs and enclosed batteries, such as the NaS system, are reviewed in Table 3.7)

Other estimates for batteries, such as those provided by the Electricity Advisory Committee, USA (2008) assume capital costs of $\sim \mathrm{US} \$ 2,500 \mathrm{~kW}^{-1}$ (RFBs) and US $\$ 3,100 \mathrm{~kW}^{-1}$ (NaS) with $\mathrm{PH}$ at $\sim \mathrm{US} \$ 2,250 \mathrm{~kW}^{-1}$ [57]. These figures however, do not consider energy capacity, which is equally as influential as power-based costs. 
Table 3.7. Review of the relative merits of the redox flow battery (for example, all vanadium) and enclosed (for example $\mathrm{NaS}$ ) battery types for $\mathrm{kW}$ to MW stationary applications. This table was derived using data from Ponce-de-Leon, et al. [53], EPRI [28], Hall and Bain [55,68] and the various sources discussed in the text.

\begin{tabular}{|c|c|c|}
\hline \multirow[b]{2}{*}{ Parameter } & \multicolumn{2}{|l|}{ Performance characteristic } \\
\hline & Redox Flow batteries & Conventional enclosed batteries \\
\hline Commercial examples & All-vanadium, zinc/bromine & $\begin{array}{l}\text { Lead/acid, valve-regulated } \\
\text { lead/acid (VRLA), sodium/sulfur }\end{array}$ \\
\hline Energy storage capacity & High potential & High (when used cumulatively) \\
\hline Power capacity & High potential & High (when used cumulatively) \\
\hline Power density (to weight) & Low to medium & High \\
\hline Stage of commercial development & $\begin{array}{l}\text { Established with potential for } \\
\text { further development at }>1 \mathrm{MW}\end{array}$ & $\begin{array}{l}\text { Established for power capacities } \\
\text { up to } 34 \mathrm{MW}\end{array}$ \\
\hline Local environmental impact & Very low & Very low \\
\hline Site specificity & Very low & Very low \\
\hline Capital cost & High & High \\
\hline Longevity (number of cycles) & $\begin{array}{l}>10 \text { years, or }>1,000 \text { cycles (for } \\
\text { all-vanadium only) }\end{array}$ & $\begin{array}{l}>10 \text { years, or > 1,500 (for } \mathrm{NaS} \\
\text { only) }\end{array}$ \\
\hline Level of O\&M required & Medium to high & Low to medium \\
\hline dc-dc round-trip efficiency & High (70-85\%, variable reports) & High (70-89\%, variable reports) \\
\hline $\begin{array}{l}\text { Complexity in design/auxiliary } \\
\text { equipment losses }\end{array}$ & Medium to high & Low to medium \\
\hline $\begin{array}{l}\text { Depth of discharge (efficiency of } \\
\text { use of total energy capacity) }\end{array}$ & Deep (100\%) & Deep (approaching 100\%) \\
\hline Thermal management & $\begin{array}{l}\text { Active control via external } \\
\text { management of electrolyte }\end{array}$ & Passive \\
\hline $\begin{array}{l}\text { Ongoing operational management } \\
\text { of electrolyte }\end{array}$ & At the scale of the system & At the scale of individual cell \\
\hline Modularity & Very high & Very high \\
\hline $\begin{array}{l}\text { Auxillary energy losses (e.g., via } \\
\text { pumping, heating/cooling) }\end{array}$ & Medium & Low \\
\hline
\end{tabular}

PH's apparent cost-advantage is due to both the maturity of the technology, lower materials costs per kWh and the capacity for tens of thousands of cycles ( $v s$. thousands of cycles for batteries, Figure 3.7). The energy storage potential of PH has also not yet been matched by batteries.

PH may also have an advantage in terms of capital cost per unit of energy generated (Figures 3.8). The deviation in capital cost per unit of power is less significant. For $\mathrm{PH}$, the median capital cost of energy and power is $\sim \mathrm{US} \$ 100 \mathrm{kWh}^{-1}$ and $\sim \mathrm{US} \$ 1,000 \mathrm{MW}^{-1}$, respectively. The values for RFBs/NaS are $\sim 400 \mathrm{kWh}^{-1}$ and $\sim \mathrm{US} \$ 1,100 \mathrm{MW}^{-1} .19$

\footnotetext{
${ }^{19}$ Such capital cost estimates, however, do not include primary generator, operational and maintenance (O\&M) and replacement costs and cannot simply be applied to a thermal generator comparison.
} 


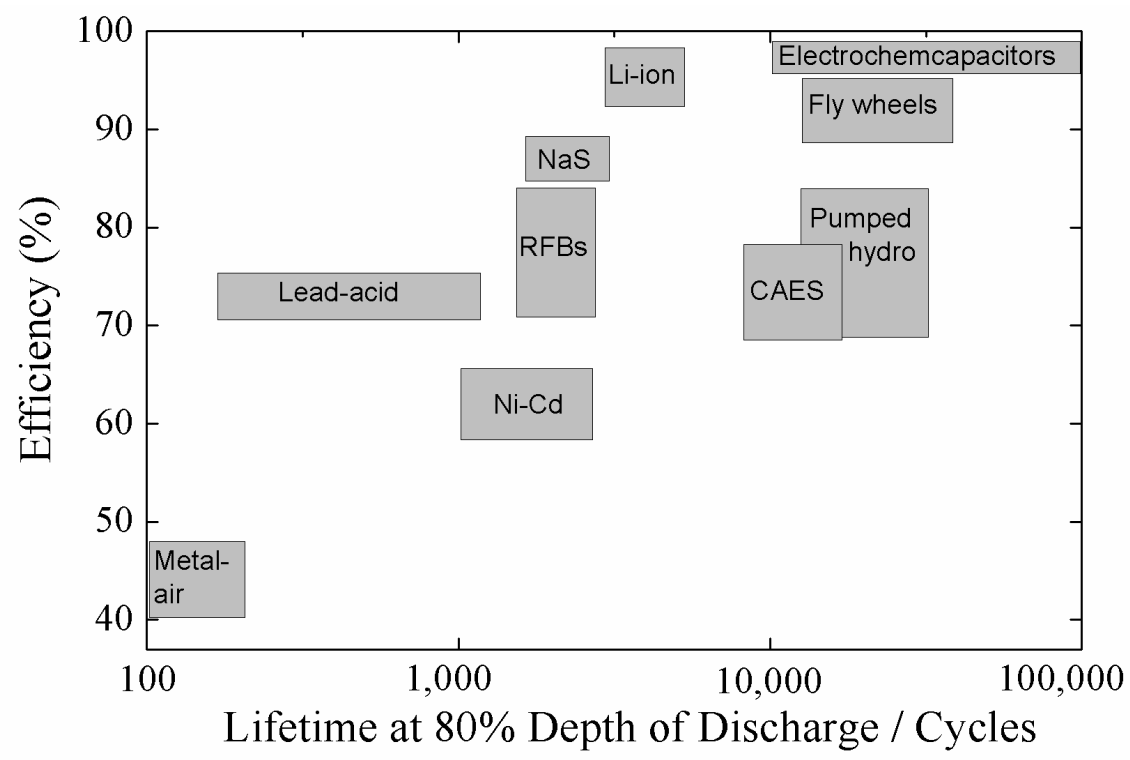

Figure 3.7. A generalised technology comparison of efficiency and time to end of life of energy storage, redrawn after the Electricity Storage Association [190]. Efficiencies exclude auxiliary power conversion losses such as those incurred during ac-dc transformation and power quality management. These costs, however, are likely to be relatively consistent between technologies.

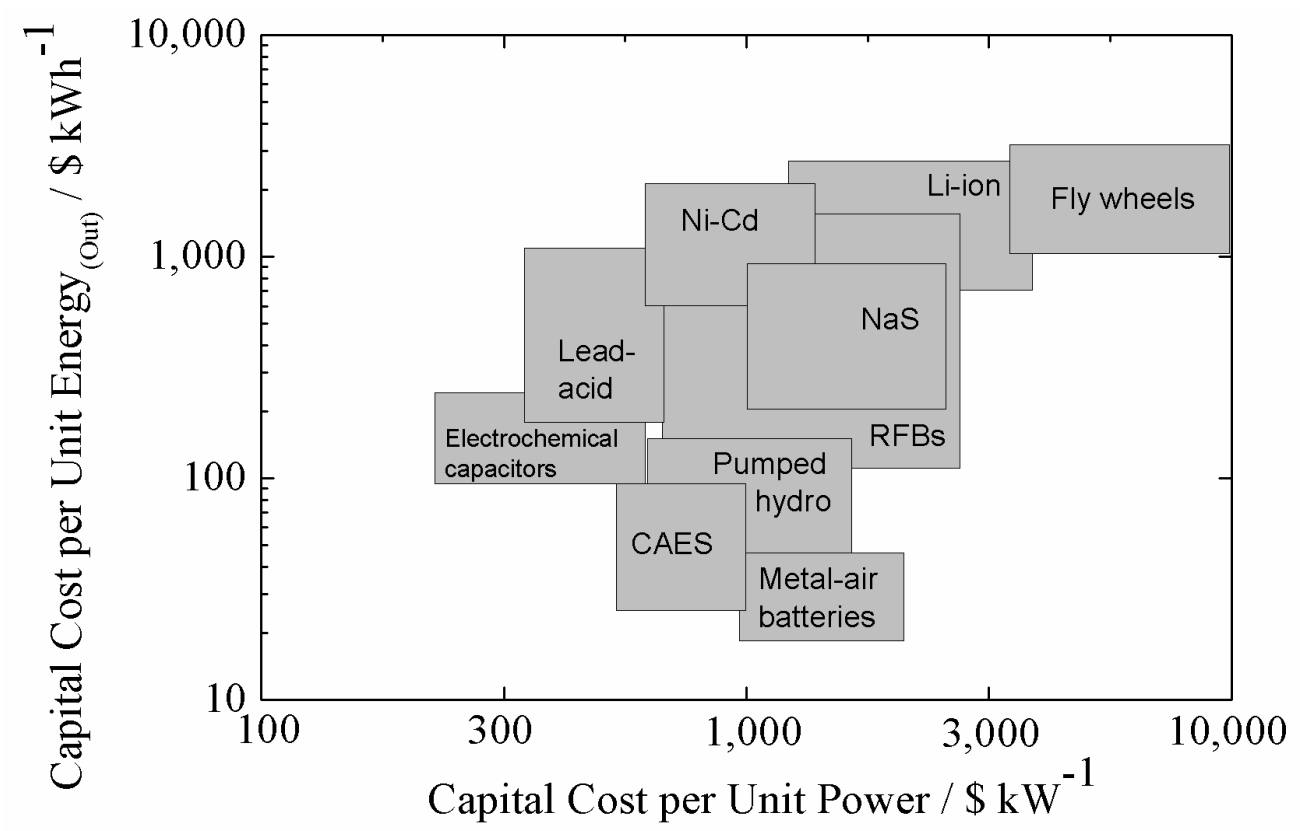

Figure 3.8. A generalised technology comparison of capital cost per unit energy output of energy storage, redrawn after the Electricity Storage Association (costs given in US\$) [189]. The estimates include energy conversion efficiencies, but excludes operational and maintenance costs, time to end of life and onsite power conversion and auxiliary costs.

Although access to commercial costs of utility-scale batteries is limited, it is understood that both materials and manufacturing costs are key limiters. For example, the highly volatile materials costs and manufacturing technicalities associated with the electrolyte (conductive solution) currently limit the cost-effectiveness of the all-vanadium battery [28,83,191-198]. 
EPRI have reported that the electrolyte represents $\sim 35 \%$ of the capital costs of these systems; $91 \%$ of which is associated with the vanadium pentoxide feedstock [28]. Moreover, life expectancy is currently limited by the membrane technology [199-205] (>10 years or $>1,000$ cycles $[28,62])$ and operation and maintenance costs can range from US\$0.008-0.010 $\mathrm{kWh}^{-1}$ [206]).

The $100 \%$ depth of discharge of these batteries, however, is a distinct advantage over hydro lakes, which could have associated depth-based resource consent limitations and can take a decade to fill (see next section). With deep-discharging technologies less onsite energy capacity is required, which increases the rate of return on the capital investment.

The magnitude of energy losses also defines the overall efficiency, which, in turn, influences operational cost-effectiveness. PH plant have been stated to typically operate at an ac-ac round-trip efficiency of 70-85\% [52,94,207-209]. The round-trip efficiency of vanadium and $\mathrm{NaS}$ batteries is now likely to be of the order $70-75 \%$, or higher $[28,62]$.

\section{Literature estimates of costs per kilowatt hour to store electricity}

The work of Poonpun and Jewell in 2008 [93] directly compared to the cost per kWh to store electricity $(S)$ of various $10 \mathrm{MW}$ PH and battery based systems (Table 3.8 and Figure 3.9). Ac-ac roundtrip efficiencies of 0.70-0.77 were assumed with total discharge times of $8 \mathrm{~h}$ (i.e., $\sim 80 \mathrm{MWh}$ storage capacity). ${ }^{20}$ For PH, storage costs ranged from US $\$ 0.05-0.40 \mathrm{kWh}^{-1}$ when designed to operate at discharge times of $8 \mathrm{~h}$ to $1 \mathrm{~h}$ for $250 \mathrm{~d} \mathrm{y}^{-1}$. These costs increased to around US\$0.10-0.90 $\mathrm{kWh}^{-1}$ when operating at only $100 \mathrm{~d} \mathrm{y}^{-1}$.

The range of values for the NaS battery was higher at US\$0.20-0.50 $\mathrm{kWh}^{-1}$ and US\$0.40-1.20 $\mathrm{kWh}^{-1}$ for 250 and $100 \mathrm{~d} \mathrm{y}^{-1}$ utility, respectively. The all-vanadium battery costs were US\$0.30-0.35 $\mathrm{kWh}^{-1}$ and US\$0.65-0.90 $\mathrm{kWh}^{-1}$. Although the capital cost range quoted in the literature for $\mathrm{PH}$ is extremely broad, $\mathrm{PH}$ provided the least-cost solution by a significant margin and the value regulated lead-acid (VRLA) battery was the highest-cost solution.

Increasing the rate of utility from $100 \mathrm{~d} \mathrm{y}^{-1}$ to $250 \mathrm{~d} \mathrm{y}^{-1}$ (i.e., increasing the $\mathrm{CF}$ ) was found to reduce the cost of storage by around half (excluding the VRLA). The relatively low cost of hydro storage was the result of low O\&M costs, low cost of stored energy and a high longevity/cycle lifetime. Moreover, increasing the discharge time from 1 to $8 \mathrm{~h}$ produces an obvious positive result in terms of generating revenue from the entire installed energy capacity of the system).

\footnotetext{
${ }^{20}$ The capital cost associated with pumped hydro is extremely variable and the single set of values given by Poonpun and Jewell should only be taken as indicative of one particular system, and not a range of installations.
} 


\section{Calculated battery costs per kilowatt hour to store electricity}

In addition to the data of Poonpun and Jewell, the costs of storage per $\mathrm{kWh}$ of various other large-scale batteries have been calculated in this research using literature-derived capital cost and O\&M data (Table 3.9). When O\&M costs were not available, a value of US\$0.008 $\mathrm{kW}^{-1}$ $\mathrm{h}^{-1}$ was assumed. The cost of grid connection and transmission is excluded. Replacement costs are also not considered and a range of CFs has been adopted in addition to standard operation at $8 \mathrm{~h} \mathrm{~d}^{-1}$ over $250 \mathrm{~d} \mathrm{y}^{-1}$. Most of the batteries were modelled at $70 \%$ total ac-acroundtrip efficiency $[28,62]$. To date, the most comprehensive capital cost assessment of an all-vanadium battery system (250 kW to $10 \mathrm{MW}$ and $1 \mathrm{MWh}$ to $80 \mathrm{MWh}$ ) was performed by EPRI in 2007 [28]. Cost estimates and projections were reported at both 2007 and projected to 2013 and included balance of plant, but excluded and off-site transmission. The rather large range of capital costs (Table 3.10) was the result of numerous, significant short-term unknowns associated with future costs of components, level of manufacturing automation and volatility of the vanadium feedstock market. The installation of a $10 \mathrm{MW}, 8 \mathrm{~h}$ system could cost anywhere between US\$29-46 million ( NZ\$37-59 million; 2013-2007) with an uncertainty range of $\sim \mathrm{US} \$ 21-40$ million (NZ\$27-54 million).

Table 3.8. Parameters and values used to derive the cost-of-storage data shown in Figure 3.9 [93]. The data assume utility for general grid management applications, such as load levelling and peaking, but not power quality control.

\begin{tabular}{llllll}
\hline Parameter & $\begin{array}{l}\text { Lead-acid } \\
\text { battery }\end{array}$ & $\begin{array}{l}\text { Valve regulated } \\
\text { lead-acid battery }\end{array}$ & $\begin{array}{l}\text { NaS } \\
\text { battery }\end{array}$ & Pumped hydro & $\begin{array}{l}\text { All-vanadium } \\
\text { battery }\end{array}$ \\
\hline Power rating / MW & 10 & 10 & 10 & 10 & 10 \\
$\begin{array}{l}\text { Efficiency } \\
\begin{array}{l}\text { Unit cost of power } \\
\text { electronic / US\$ kW }\end{array}\end{array}$ & 0.75 & 0.75 & 0.77 & 0.75 & 0.70 \\
$\begin{array}{l}\text { Unit cost of storage / US\$ } \\
\mathrm{kWh}^{-1}\end{array}$ & 125 & 125 & 833 & 1,000 & $\begin{array}{l}\text { See unit cost of } \\
\text { storage* }\end{array}$ \\
$\begin{array}{l}\text { Unit cost for balance of } \\
\text { plant / US } \mathrm{kWh}^{-1}\end{array}$ & 150 & 150 & 208 & 10 & $500^{*}$ \\
$\begin{array}{l}\text { Unit fixed O\&M cost / US\$ } \\
\mathrm{kW}^{-1}\end{array}$ & 15 & 5 & 0 & 4 & 30 \\
$\begin{array}{l}\text { Future amount of } \\
\text { replacement costs / } \$ \mathrm{kWh}^{-1}\end{array}$ & 305 & 360 & 20 & 2.5 & 20 \\
Cycle lifetime & 3,200 & 1,000 & 208 & 0 & 150 \\
\hline
\end{tabular}

\footnotetext{
* The manufacturer-supplied unit cost of power electronic is included in the unit cost of the storage units.
} 


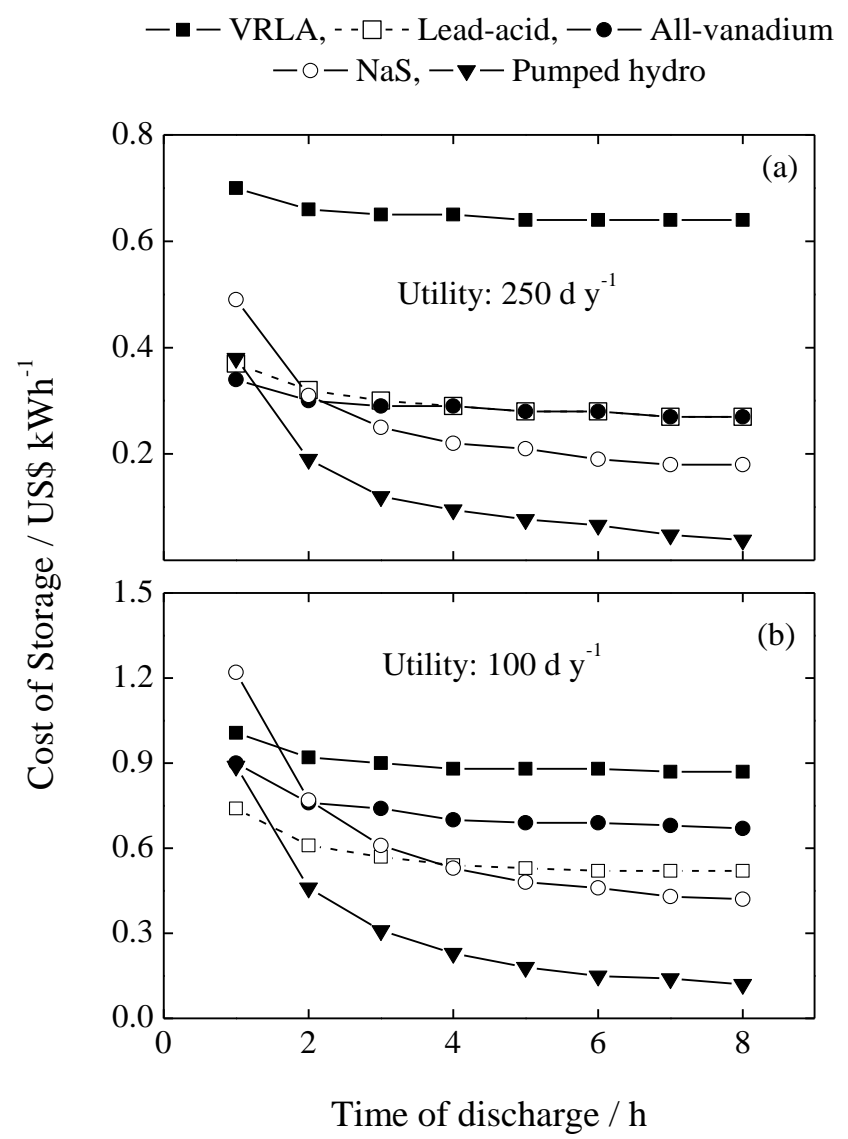

Figure 3.9. Cost of storage $(S)$ per $\mathrm{kWh} v s$. time of discharge from $10 \mathrm{MW}, 80 \mathrm{MWh}(8 \mathrm{~h})$ storage systems based on various battery types and a hypothetical $\mathrm{PH}$ installation [93]. 2006 prices are given for utility at (a) $250 \mathrm{~d} \mathrm{y}^{-1}$ and (b) $100 \mathrm{~d} \mathrm{y}^{-1}$. The data and the method used to calculate the data are given in Table 3.8 and Section 2, respectively.

An estimated cost range of storage per kWh was not given, but it can be estimated that for the $10 \mathrm{MW}$ system (5\% annual interest rate), values of $S$ could be NZ\$0.21-0.45 $\mathrm{kWh}^{-1}$ at a CF 0.26 and up to NZ\$1.05-2.28 $\mathrm{kWh}^{-1}$ (CF: 0.05). At $8 \%$ annual interest rate the equivalent values are NZ\$0.24-0.52 $\mathrm{kWh}^{-1}$ (CF: 0.26) to NZ\$1.21-2.63 $\mathrm{kWh}^{-1}$ (CF: 0.05). When operating at $8 \mathrm{~h} \mathrm{~d}^{-1}$ over $250 \mathrm{~d} \mathrm{y}^{-1} S$ was NZ $\$ 0.24-0.51 \mathrm{kWh}^{-1}$ and NZ\$0.27-0.59 $\mathrm{kWh}^{-1}$ at $5 \%$ and $8 \%$ annual interest rates, respectively.

The Corey et al. Boulder City battery feasibility study [62] compared the capital and O\&M costs of three $2.5 \mathrm{MW}, 4 \mathrm{~h}$ battery systems for city-scale, load levelling (Table 3.9). Off-peak charging, at a cost of US $\$ 0.02 \mathrm{kWh}^{-1}$, was assumed along with O\&M costs of US $\$ 35,000 \mathrm{y}^{-1}$ (with 3\% $\mathrm{y}^{-1}$ inflation), 15-year life expectancies, $300 \mathrm{MWh}$ energy output $\mathrm{month}^{-1}$ and 100 cycles $\mathrm{y}^{-1}$. The overall aim was to replace peak power imports at $\sim \mathrm{US} \$ 0.10-0.20 \mathrm{kWh}^{-1}(2001$ prices). 
All Intellectual Property Rights Owned by Gareth Kear (garethkear@hotmail.com)

Table 3.9. Costs of storage per $\mathrm{kWh}(S)$ of all-vanadium (vanadium), zinc-bromine $(\mathrm{ZnBr})$ and sodium-sulfur (NaS) batteries. The calculations were performed according to the methodology set out in Section 2 . Where a range of capital costs are given by the original source, both the lower and upper limits are shown and have been used to derive

\begin{tabular}{|c|c|c|c|c|c|c|c|c|c|c|}
\hline \multirow[b]{2}{*}{ Storage system } & \multirow{2}{*}{$\begin{array}{l}\text { Units } \\
-\end{array}$} & \multirow{2}{*}{\begin{tabular}{|l|l|} 
Jossen \& \\
Sauer [83]
\end{tabular}} & \multirow{2}{*}{$\begin{array}{l}\text { EPRI [28] } \\
\text { Vanadium } \\
\text { low limit } \\
\end{array}$} & \multirow[b]{2}{*}{$\begin{array}{l}\text { Vanadium } \\
\text { high limit }\end{array}$} & \multicolumn{4}{|c|}{ Corey et al. (Boulder City) [62] } & \multicolumn{2}{|c|}{$\begin{array}{l}\text { Carnegie Mellon Uni } \\
{[58,210]}\end{array}$} \\
\hline & & & & & All-vanadium & $\begin{array}{l}\mathrm{ZnBr} \\
\text { low limit }\end{array}$ & $\begin{array}{l}\mathrm{ZnBr} \\
\text { high limit }\end{array}$ & $\mathrm{NaS}$ & $\begin{array}{l}\text { NaS } \\
\text { low limit }\end{array}$ & $\begin{array}{l}\text { NaS } \\
\text { high limit }\end{array}$ \\
\hline Life time & $\mathrm{y}$ & 10 & 10 & 10 & 10 & 15 & 10 & 15 & 12 & 12 \\
\hline Power capacity & $\mathrm{kW}$ & 2 & 10,000 & 10,000 & 2,500 & 2,500 & 2,500 & 2,500 & 1,000 & 1,000 \\
\hline Energy capacity & $\mathrm{kWh}$ & 30 & 80,000 & 80,000 & 10,000 & 10,000 & 10,000 & 10,000 & 10,000 & 10,000 \\
\hline Max. Possible time of discharge & $\mathrm{h}$ & 15 & 8 & 8 & 4 & 4 & 4 & 4 & 10 & 10 \\
\hline Time of discharge at $250 \mathrm{~d}^{-1}$ & $h d^{-1}$ & 8 & 8 & 8 & 4 & 4 & 4 & 4 & 8 & 8 \\
\hline Number of cycles & $\mathrm{d}^{-1}$ & 1 & 1 & 1 & 1 & 1 & 1 & 1 & 1 & 1 \\
\hline Max. number of Days & $y^{-1}$ & 250 & 250 & 250 & 250 & 250 & 250 & 250 & 250 & 250 \\
\hline ac-ac round-trip efficiency & - & 0.70 & 0.70 & 0.70 & 0.70 & 0.70 & 0.70 & 0.70 & 0.70 & 0.75 \\
\hline Total capital cost (TCC) & US\$ & 6,531 & $21,000,000$ & $46,000,000$ & $11,000,000$ & $5,800,000$ & $8,000,000$ & $12,000,000$ & $1,500,000$ & $3,000,000$ \\
\hline Interest/discount rate (IEA [211]) & $(\% / 100) y^{-1}$ & 0.05 & 0.05 & 0.05 & 0.05 & 0.05 & 0.05 & 0.05 & 0.05 & 0.05 \\
\hline Interest/discount rate (MED [85]) & $(\% / 100) \mathrm{y}^{-1}$ & 0.08 & 0.08 & 0.08 & 0.08 & 0.08 & 0.08 & 0.08 & 0.08 & 0.08 \\
\hline $\begin{array}{l}\mathrm{O} \& \mathrm{M}_{\mathrm{fE}} \text { (based on energy } \\
\text { discharged) }\end{array}$ & US\$ $\mathrm{kWh}^{-1}$ & 0.008 & 0.008 & 0.008 & - & - & - & - & - & - \\
\hline $\mathrm{O} \& \mathrm{M}_{\mathrm{fy}}($ based on installed power) & US\$ $\mathrm{kW}^{-1} \mathrm{y}^{-1}$ & - & - & - & 20 & 12 & 60 & 13 & 15 & 90 \\
\hline Total annual $\mathrm{O} \& \mathrm{M}$ costs & US\$ $y^{-1}$ & - & - & - & 50,000 & 30,500 & 150,000 & 32,500 & 15,000 & 90,000 \\
\hline $\begin{array}{l}\text { Annual energy (at } 250 \mathrm{~d} \mathrm{y}^{-1}, 4 \text { or } 8 \\
\text { h discharge, } 1 \text { cycle } \mathrm{d}^{-1} \text { ) }\end{array}$ & $\mathrm{kWh} \mathrm{y}^{-1}$ & 4000 & $20,000,000$ & $20,000,000$ & $2,500,000$ & $2,500,000$ & $2,500,000$ & $2,500,000$ & $2,000,000$ & $2,000,000$ \\
\hline Capital recovery factor (CRF) $(5 \%)$ & US\$ $\mathrm{y}^{-1}$ & 0.13 & 0.13 & 0.13 & 0.13 & 0.10 & 0.13 & 0.10 & 0.11 & 0.11 \\
\hline Amortised capital cost (AC) (5\%) & US\$ $\mathrm{y}^{-1}$ & 846 & $2,719,596$ & $5,957,210$ & $1,424,550$ & 558,785 & $1,036,037$ & $1,156,107$ & 169,238 & 338,476 \\
\hline Capital recovery factor (CRF) $(8 \%)$ & US\$ $\mathrm{y}^{-1}$ & 0.15 & 0.15 & 0.15 & 0.15 & 0.12 & 0.15 & 0.12 & 0.13 & 0.13 \\
\hline Amortised capital cost (AC) (8\%) & US $\$ y^{-1}$ & 973 & $3,129,619$ & $6,855,356$ & $1,639,324$ & 677,611 & $1,192,236$ & $1,401,955$ & 199,043 & 398,085 \\
\hline
\end{tabular}


All Intellectual Property Rights Owned by Gareth Kear (garethkear@hotmail.com)

\begin{tabular}{|c|c|c|c|c|c|c|c|c|c|c|}
\hline \multicolumn{11}{|l|}{ Table 3.9 continued } \\
\hline & Units & $\begin{array}{l}\text { Jossen \& } \\
\text { Sauer } \\
\text { [83] }\end{array}$ & EPRI [28] & & Corey et a & (Boulder & ty) [62] & & \begin{tabular}{|l|} 
Carnegie \\
{$[58,210]$}
\end{tabular} & Mellon Uni \\
\hline \multicolumn{2}{|l|}{ Cost of storage (S) } & Vanadium & $\begin{array}{l}\text { Vanadium } \\
\text { low limit }\end{array}$ & $\begin{array}{l}\text { Vanadium } \\
\text { high limit }\end{array}$ & \begin{tabular}{|l|}
$\begin{array}{l}\text { All- } \\
\text { vanadium }\end{array}$ \\
\end{tabular} & $\begin{array}{l}\mathrm{ZnBr} \\
\text { low limit }\end{array}$ & $\begin{array}{l}\mathrm{ZnBr} \\
\text { high limit }\end{array}$ & $\mathrm{NaS}$ & \begin{tabular}{|l|} 
NaS \\
low limit
\end{tabular} & $\begin{array}{l}\text { NaS } \\
\text { high limit }\end{array}$ \\
\hline \multicolumn{11}{|c|}{ United States dollars kWh $^{-1}$} \\
\hline \multicolumn{11}{|c|}{ At $5 \%$ annual interest/discount rate (IEA [211]) } \\
\hline At $250 \mathrm{~d} \mathrm{y}^{-1}, 1{\text { cycle } \mathrm{d}^{-1}}^{-1}$ & US\$ kWh ${ }^{-1}$ & 0.22 & 0.14 & 0.31 & 0.59 & 0.24 & 0.47 & 0.48 & 0.09 & 0.21 \\
\hline Mean annual $\mathrm{CF}=0.05$ & US\$ $\mathrm{kWh}^{-1}$ & 0.97 & 0.63 & 1.37 & 1.35 & 0.54 & 1.08 & 1.09 & 0.42 & 0.98 \\
\hline Mean annual $\mathrm{CF}=0.20$ & US\$ $\mathrm{kWh}^{-1}$ & 0.25 & 0.16 & 0.35 & 0.34 & 0.13 & 0.27 & 0.27 & 0.11 & 0.24 \\
\hline Mean annual $\mathrm{CF}=0.26$ & US\$ $\mathrm{kWh}^{-1}$ & 0.19 & 0.13 & 0.27 & 0.26 & 0.10 & 0.21 & 0.21 & 0.08 & 0.19 \\
\hline \multicolumn{11}{|c|}{ At $8 \%$ annual interest/discount rate (MED [85]) } \\
\hline At $250 \mathrm{~d} \mathrm{y}^{-1}, 1$ cycle $^{-1}$ & US\$ $\mathrm{kWh}^{-1}$ & 0.25 & 0.16 & 0.35 & 0.68 & 0.28 & 0.54 & 0.57 & 0.11 & 0.24 \\
\hline Mean annual $\mathrm{CF}=0.05$ & US\$ $\mathrm{kWh}^{-1}$ & 1.12 & 0.72 & 1.57 & 1.54 & 0.66 & 1.13 & 1.33 & 0.57 & 1.02 \\
\hline Mean annual $\mathrm{CF}=0.20$ & US\$ $\mathrm{kWh}^{-1}$ & 0.29 & 0.19 & 0.40 & 0.39 & 0.17 & 0.28 & 0.33 & 0.14 & 0.26 \\
\hline Mean annual $\mathrm{CF}=0.26$ & $\mathrm{US} \$ \mathrm{kWh}^{-1}$ & 0.22 & 0.15 & 0.31 & 0.30 & 0.13 & 0.22 & 0.25 & 0.11 & 0.20 \\
\hline \multicolumn{11}{|c|}{ New Zealand Dollars kWh $\mathbf{k}^{-1} \quad(1 \mathrm{US} \$=\mathrm{NZ} \$ 1.67)$} \\
\hline \multicolumn{11}{|c|}{ At $5 \%$ annual interest/discount rate (IEA [211]) } \\
\hline At $250 \mathrm{~d} \mathrm{y}^{-1}, 1$ cycle $^{-1}$ & $\mathrm{NZ} \$ \mathrm{kWh}^{-1}$ & 0.37 & 0.24 & 0.51 & 0.98 & 0.39 & 0.79 & 0.79 & 0.15 & 0.36 \\
\hline Mean annual $\mathrm{CF}=0.05$ & $\mathrm{NZ} \$ \mathrm{kWh}^{-1}$ & 1.63 & 1.05 & 2.28 & 2.25 & 0.90 & 1.81 & 1.81 & 0.70 & 1.63 \\
\hline Mean annual $\mathrm{CF}=0.20$ & $\mathrm{NZ} \$ \mathrm{kWh}^{-1}$ & 0.42 & 0.27 & 0.58 & 0.56 & 0.22 & 0.45 & 0.45 & 0.18 & 0.41 \\
\hline Mean annual $\mathrm{CF}=0.26$ & $\mathrm{NZ} \$ \mathrm{kWh}^{-1}$ & 0.32 & 0.21 & 0.45 & 0.43 & 0.17 & 0.35 & 0.35 & 0.14 & 0.31 \\
\hline \multicolumn{11}{|c|}{ At $8 \%$ annual interest/discount rate (MED [85]) } \\
\hline At $250 \mathrm{~d} \mathrm{y}^{-1}, 1$ cycle $^{-1}$ & $\mathrm{NZ} \$ \mathrm{kWh}^{-1}$ & 0.42 & 0.27 & 0.59 & 1.13 & 0.47 & 0.90 & 0.96 & 0.18 & 0.41 \\
\hline Mean annual $\mathrm{CF}=0.05$ & $\mathrm{NZ} \$ \mathrm{kWh}^{-1}$ & 1.87 & 1.21 & 2.63 & 2.58 & 1.11 & 1.89 & 2.21 & 0.95 & 1.71 \\
\hline Mean annual $\mathrm{CF}=0.20$ & $\mathrm{NZ} \$ \mathrm{kWh}^{-1}$ & 0.48 & 0.31 & 0.67 & 0.64 & 0.28 & 0.47 & 0.55 & 0.24 & 0.43 \\
\hline Mean annual $\mathrm{CF}=0.26$ & $\mathrm{NZ} \$ \mathrm{kWh}^{-1}$ & 0.37 & 0.24 & 0.52 & 0.50 & 0.21 & 0.36 & 0.43 & 0.18 & 0.33 \\
\hline
\end{tabular}


Table 3.10. Estimated capital costs of relatively large-scale all-vanadium batteries of various power ratings from $250 \mathrm{~kW}$ to $10 \mathrm{MW}$ and energy storage capacity $1 \mathrm{MWh}$ to $80 \mathrm{MWh}$. The data presented were derived by EPRI in 2007 [28].

\begin{tabular}{|c|c|c|c|c|}
\hline \multirow[t]{2}{*}{$\begin{array}{l}\text { Power rating / } \\
\text { MW }\end{array}$} & \multirow[t]{2}{*}{$\begin{array}{l}\text { Time of discharge } \\
\text { at full power / } h\end{array}$} & \multirow[t]{2}{*}{$\begin{array}{l}\text { Energy capacity / } \\
\text { MWh }\end{array}$} & \multicolumn{2}{|c|}{ Capital cost / US\$ [NZ\$] (millions)] } \\
\hline & & & Mean & Range indicated \\
\hline \multicolumn{5}{|l|}{2007 estimates } \\
\hline 0.25 & 4 & 1 & $1.1[1.4]$ & 0.9 to 2.9 [1.2 to 3.7$]$ \\
\hline 0.25 & 8 & 2 & $1.4[1.8]$ & 1.0 to $2.2[1.3$ to 2.8$]$ \\
\hline 1 & 4 & 4 & $3.8[4.9]$ & 2.7 to $5.9[3.5$ to 7.6$]$ \\
\hline 1 & 8 & 8 & $4.9[6.3]$ & 3.6 to 7.6 [4.6 to 9.8$]$ \\
\hline 10 & 4 & 40 & $35[45]$ & - \\
\hline 10 & 8 & 80 & $46[59]$ & - \\
\hline \multicolumn{5}{|l|}{2013 projections } \\
\hline 0.25 & 4 & 1 & $0.8[1.0]$ & 0.6 to $1.1[0.8$ to 1.4$]$ \\
\hline 0.25 & 8 & 2 & $1.0[1.3]$ & 0.8 to $1.4[1.0$ to 1.8$]$ \\
\hline 1 & 4 & 4 & $2.3[3.0]$ & 1.7 to $3.4[2.2$ to 4.4$]$ \\
\hline 1 & 8 & 8 & $3.2[4.1]$ & 2.3 to 4.5 [3.0 to 5.8$]$ \\
\hline 10 & 4 & 40 & $21[2.7]$ & 15 to 30 [19 to 39$]$ \\
\hline 10 & 8 & 80 & 29 [37] & 21 to 42 [27 to 54$]$ \\
\hline
\end{tabular}

The results indicated that the NaS battery had the highest capital costs (US\$12 million, or $\sim \mathrm{NZ} \$ 15$ million), but a 33\% greater life expectancy than the vanadium system. The report concluded that all the batteries could provide a net benefit to the city, with a net present value (at 2004) of around $\$ 400,000$ over 15 years. Again, costs $\mathrm{kWh}^{-1}$ were not given, but can be estimated to range from NZ\$0.17-0.36 $\mathrm{kWh}^{-1}$ (CF: 0.26) to NZ\$0.90-1.89 $\mathrm{kWh}^{-1}$ (CF: 0.05) for the zinc bromide battery (interest rate $5-8 \% \mathrm{y}^{-1}$ ). The NaS battery was intermediately

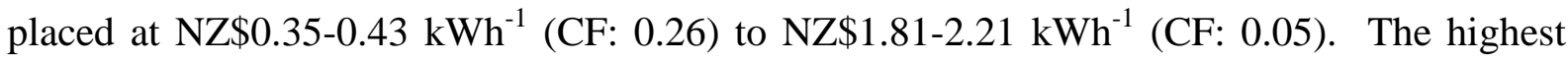
costs were calculated for the all-vanadium battery at $\mathrm{NZ} \$ 0.43-0.50 \mathrm{kWh}^{-1}(\mathrm{CP}: 0.26)$ to NZ\$2.25-2.58 $\mathrm{kWh}^{-1}$ (CP: 0.05). It must be noted, however, that CFs of 0.20 and 0.26 are not likely in this case, as this would require multiple cycles per day due to the nominal $4 \mathrm{~h}$ storage capacity assumed for the systems.

When operating at maximum capacity at a single cycle $\mathrm{d}^{-1}$ over $250 \mathrm{~d} \mathrm{y}^{-1}$ (calculated at an annual interest rate range of 5-8\%), the equivalent range of costs were $\mathrm{NZ} \$ 0.43-0.50 \mathrm{kWh}^{-1}$ $(\mathrm{ZnBr}) \mathrm{NZ} \$ 0.79-0.96 \mathrm{kWh}^{-1}(\mathrm{NaS})$ and NZ\$0.98-1.13 $\mathrm{kWh}^{-1}$ (all-vanadium). The cost of storage was again mainly associated with the extent of the initial capital investment and plant longevity. 
The equivalent 2008 Carnegie Mellon University [58] results for a $1 \mathrm{MW}, 10 \mathrm{MWh} \mathrm{NaS}$ system assumed capital costs of US\$1,500,000-3,000,000 (median US\$2,500,000) with O\&M costs of US\$15,000-90,000 $\mathrm{y}^{-1}$ (median: US\$37.5 $\mathrm{kW}^{-1} \mathrm{y}^{-1}$, or US\$15-90 $\mathrm{kW}^{-1} \mathrm{y}^{-1}$ ). $S$ values of NZ\$0.15-0.36 kWh${ }^{-1}$ have been calculated in this research for operation at $8 \mathrm{~h} \mathrm{~d}^{-1}$ and $250 \mathrm{~d}$ $\mathrm{y}^{-1}$ at $5 \% \mathrm{y}^{-1}$ interest and $\mathrm{NZ} \$ 0.18-41 \mathrm{kWh}^{-1}$ at $8 \% \mathrm{y}^{-1}$ (Table 3.10). At a 5\% annual interest rate $S$ values ranged from NZ\$0.14-1.63 $\mathrm{kWh}^{-1}$ for $\mathrm{CF}: 0.26$ to 0.05 . At $8 \%$ these values increased to NZ\$0.18-1.71 $\mathrm{kWh}^{-1}$. In general, all the the $S$-values given above are likely to improve significantly to 2025, as experience curves [212] indicate that, post acceptance of the technology, capital and O\&M costs will decrease over time. Batteries operating at $<75 \%$ efficiency are also likely to be superseded.

\section{Calculated pumped hydro costs per kilowatt hour to store electricity}

Table 3.11 presents the capital costs of power and energy capacity from thirteen $\mathrm{PH}$ installations [94] (including a correction for inflation). The range of costs is extremely wide with no clear dependence on year of installation or capacity. This variation is due to contrasting site availability and the physical characteristics of those sites. Distance to the main demand centres and water-based resources are also an issue when operating [94,213].

The costs range from US\$0.15-2.00 million $\mathrm{MW}^{-1}$ (2010: US\$0.34-3.12 million $\mathrm{MW}^{-1}$ ) and US\$2.0-240 million $\mathrm{GWh}^{-1}$ (2010: US\$4.7-312 million $\mathrm{GWh}^{-1}$ ), respectively. The median and mean values (2010) are US\$0.87 and US\$1.2 million $\mathrm{MW}^{-1}$, respectively. The equivalent energy costs are US\$72.5 million $\mathrm{GWh}^{-1}$ (median) and US\$114.0 million $\mathrm{GWh}^{-1}$ (mean). The mean costs are higher than the median values due to the bias introduced by installations such as the Kazunogowa hydroelectric power plant [214], which provides a graphic demonstration of how much Japanese electricity consumers will pay to receive peaking power.

O\&M costs of hydro schemes can be of the order of $1.5-2.5 \%$ of the capital costs per year [215], or around US\$0.005-0.020 $\mathrm{kWh}^{-1}$ [216]. The median of US\$0.0125 $\mathrm{kWh}^{-1}$ from the latter is assumed for calculations used in this research.

A 100-year lifetime is noted by the IEA for hydropower plant [215,216] and the ESA note a cycle life of around 10,000 to 30,000 (Figure 3.7) [189,190], which at 1 cycle $\mathrm{d}^{-1}$ for $250 \mathrm{~d} \mathrm{y}^{-1}$ corresponds to 40-120 y. The lowest value in this range (40-year lifetime), is assumed in this research (Table 3.12). The calculated values of $S$ (Table 3.13) vary considerably, from 0.04 $\mathrm{NZ} \$ \mathrm{kWh}^{-1}$ (Dinorwig) to NZ\$0.19 $\mathrm{kWh}^{-1}$ for Northfield Mt. (CF: 0.20 and $5 \% \mathrm{y}^{-1}$ interest). With an $8 \%$ interest rate these values increased to $N Z \$ 0.05 \mathrm{kWh}^{-1}$ and $\mathrm{NZ} \$ 0.27 \mathrm{kWh}^{-1}$, respectively. 
Table 3.11. Estimated capital costs and power and energy capacities of GW-scale PH facilities. The data were calculated from capital cost and time of discharge data made available via the ESA [94]. Prices were adjusted to 2010 using the US Inflation Calculator [217].

\begin{tabular}{llllllll}
\hline Date & Plant and location & $\begin{array}{l}\text { Power } \\
\text { / MW }\end{array}$ & $\begin{array}{l}\text { Energy } \\
\text { storage } \\
\text { / GWh }\end{array}$ & $\begin{array}{l}\text { Capital costs / } \\
\text { US\$ (million, at } \\
\text { construction) }\end{array}$ & $\begin{array}{l}\text { Capital costs / US\$ } \\
\text { (million, adjusted to 2010) }\end{array}$ \\
\hline \multirow{2}{*}{2002} & Goldisthal (Germany) & 1,060 & - & 700 & 851 & 0.80 & - \\
2001 & Tianhuangping (PRoC) & 1,800 & - & 1080 & 1,335 & 0.74 & - \\
2001 & Kazunogowa (Japan) & 1,600 & 13.12 & 3200 & 3,954 & 2.47 & 301.37 \\
1994 & Mingtan (Taiwan) & 1,620 & - & 1338 & 1,975 & 1.22 & - \\
1991 & Bad Creek (USA/SC) & 1,065 & 25.56 & 652 & 1,047 & 0.98 & 40.96 \\
1985 & Bath County (USA/VA) & 2,700 & 29.70 & 1,650 & 3,354 & 1.24 & 112.93 \\
1985 & Minghu (Taiwan) & 1,008 & - & 866 & 1,760 & 1.75 & \\
1984 & Dinorwig (UK/Wales) & 1,890 & 9.45 & 310 & 652 & 0.34 & 68.99 \\
1984 & Helms (USA/CA) & 1,212 & 185.44 & 416 & 876 & 0.72 & 4.72 \\
1979 & Racoon Mt (USA/TN) & 1,900 & 39.90 & 288 & 868 & 0.46 & 21.75 \\
1973 & Ludington (USA/MI) & 1,980 & 17.82 & 327 & 1,611 & 0.81 & 90.40 \\
1973 & Blenheim-Gilboa & 1,200 & 14.40 & 212 & 1,044 & 0.87 & 72.50 \\
& (USA/NY) & & & & & & \\
1973 & Northfield Mt & 1,080 & 10.80 & 685 & 3,374 & 3.12 & 312.41 \\
& (USA/MA) & & & & & & USW \\
\hline
\end{tabular}

Table 3.12. Standard values of the parameters used to estimate the cost of storage for the various pumped hydro facilities as shown in Table 3.13. The various values of capital cost data (at 2010), power capacity and installed energy used in the calculation were taken from Table 3.11 [94]. Note that calculations were performed for both cycling at $8 \mathrm{~h} \mathrm{~d}-1,250 \mathrm{~d} \mathrm{y}^{-1}, 1$ cycle $\mathrm{d}^{-1}$ and at annual capacity factors of $0.05,0.20$ and 0.26 .

\begin{tabular}{|c|c|}
\hline Parameter & Value \\
\hline Life time & $40 \mathrm{y}$ \\
\hline Assumed time of discharge (at $250 \mathrm{~d} \mathrm{y}^{-1}, 1$ cycle $\mathrm{d}^{-1}$ ) & $8 \mathrm{~h} \mathrm{~d}^{-1}$ \\
\hline Number of cycles (at $250 \mathrm{~d} \mathrm{y}^{-1}, 1$ cycle $^{-1}$ ) & $1 \mathrm{~d}^{-1}$ \\
\hline Maximum number of days (at $250 \mathrm{~d} \mathrm{y}^{-1}, 1$ cycle $\mathrm{d}^{-1}$ ) & $250 \mathrm{~d}$ \\
\hline ac-ac round-trip efficiency & $70 \%$ \\
\hline Interest rate/discount rate (IEA [211]) & 0.05 \\
\hline Interest/discount rate (MED [85]) & 0.08 \\
\hline $\mathrm{O} \& \mathrm{M}_{\mathrm{fE}}$ (based on energy discharged) & $0.0125 \mathrm{US} \$ \mathrm{kWh}^{-1}$ \\
\hline Annual energy (at $250 \mathrm{~d} \mathrm{y}^{-1}, 1$ cycle $^{-1}$ ) & $3,800,000,000 \mathrm{kWh} \mathrm{y}^{-1}$ \\
\hline Capital recovery factor ( $5 \%$ interest rate) & 0.06 \\
\hline Capital recovery factor ( $8 \%$ interest rate) & 0.08 \\
\hline
\end{tabular}


Table 4.13. Estimated costs of storage per $\mathrm{kWh}\left(S\right.$ at US\$/NZ\$ $\left.\mathrm{kWh}^{-1}\right)$ of the PH facilities described in Table 3.11. The calculation of $S$ was performed according to the methodology set out in Section 2 using the capital cost data corrected to 2010. Mean annual $\mathrm{CF}$ values are shown.

\begin{tabular}{|c|c|c|c|c|c|c|c|c|c|c|c|c|c|}
\hline & $\begin{array}{l}\text { Racoon } \\
\text { Mt }\end{array}$ & Dinorwig & $\begin{array}{l}\text { Luding- } \\
\text { ton }\end{array}$ & $\begin{array}{l}\text { Blenheim- } \\
\text { Gilboa }\end{array}$ & Helms & $\begin{array}{l}\text { Tian- } \\
\text { huang- } \\
\text { ping }\end{array}$ & $\begin{array}{l}\text { Bath } \\
\text { County }\end{array}$ & $\begin{array}{l}\text { Bad } \\
\text { Creek }\end{array}$ & $\begin{array}{l}\text { Northfield } \\
\text { Mt }\end{array}$ & Goldisthal & Mingtan & Minghu & $\begin{array}{l}\text { Kaz- } \\
\text { uno- } \\
\text { gowa }\end{array}$ \\
\hline \multicolumn{14}{|c|}{ Cost of storage $(S) / \mathrm{US} \$ \mathrm{kWh}^{-1}$} \\
\hline \multicolumn{14}{|c|}{ At 5\% interest/discount rate (IEA [211]) } \\
\hline $250 \mathrm{~d} \mathrm{y}^{-1}, 1$ cycle $^{-1}$ & 0.026 & 0.023 & 0.036 & 0.038 & 0.034 & 0.034 & 0.049 & 0.041 & 0.104 & 0.036 & 0.048 & 0.063 & 0.085 \\
\hline Mean $\mathrm{CF}=0.05$ & 0.073 & 0.058 & 0.121 & 0.128 & 0.109 & 0.111 & 0.178 & 0.143 & 0.428 & 0.119 & 0.175 & 0.245 & 0.341 \\
\hline Mean $\mathrm{CF}=0.20$ & 0.028 & 0.024 & 0.040 & 0.041 & 0.037 & 0.037 & 0.054 & 0.045 & 0.116 & 0.039 & 0.053 & 0.071 & 0.095 \\
\hline Mean $\mathrm{CF}=0.26$ & 0.024 & 0.021 & 0.033 & 0.035 & 0.031 & 0.031 & 0.044 & 0.038 & 0.092 & 0.033 & 0.044 & 0.057 & 0.076 \\
\hline \multicolumn{14}{|c|}{ At $8 \%$ interest/discount rate (MED [85]) } \\
\hline $\begin{array}{l}\text { At } 250 \mathrm{~d} \mathrm{y}^{-1}, 1 \text { cycle } \\
d^{-1}\end{array}$ & 0.032 & 0.027 & 0.047 & 0.049 & 0.043 & 0.044 & 0.065 & 0.054 & 0.143 & 0.046 & 0.064 & 0.086 & 0.116 \\
\hline Mean $\mathrm{CF}=0.05$ & 0.100 & 0.079 & 0.168 & 0.179 & 0.151 & 0.155 & 0.250 & 0.201 & 0.611 & 0.166 & 0.246 & 0.347 & 0.486 \\
\hline Mean $\mathrm{CF}=0.20$ & 0.034 & 0.029 & 0.051 & 0.054 & 0.047 & 0.048 & 0.072 & 0.060 & 0.162 & 0.051 & 0.071 & 0.096 & 0.131 \\
\hline Mean $\mathrm{CF}=0.26$ & 0.029 & 0.025 & 0.042 & 0.045 & 0.039 & 0.040 & 0.058 & 0.049 & 0.128 & 0.042 & 0.057 & 0.077 & 0.103 \\
\hline \multicolumn{14}{|c|}{ Cost of storage $(S) / \mathrm{NZ} \$ \mathrm{kWh}^{-1}$ (at US\$1 = NZ\$1.67) } \\
\hline \multicolumn{14}{|c|}{ At 5\% interest/discount rate (IEA [211]) } \\
\hline $250 \mathrm{~d} \mathrm{y}^{-1}, 1$ cycle d $^{-1}$ & 0.043 & 0.038 & 0.060 & 0.063 & 0.056 & 0.057 & 0.081 & 0.069 & 0.173 & 0.060 & 0.080 & 0.106 & 0.141 \\
\hline Mean $\mathrm{CF}=0.05$ & 0.122 & 0.098 & 0.202 & 0.214 & 0.181 & 0.186 & 0.297 & 0.239 & 0.715 & 0.199 & 0.292 & 0.409 & 0.570 \\
\hline Mean $\mathrm{CF}=0.20$ & 0.046 & 0.040 & 0.066 & 0.069 & 0.061 & 0.062 & 0.090 & 0.075 & 0.194 & 0.065 & 0.089 & 0.118 & 0.158 \\
\hline Mean $\mathrm{CF}=0.26$ & 0.040 & 0.036 & 0.056 & 0.058 & 0.052 & 0.053 & 0.074 & 0.063 & 0.154 & 0.055 & 0.073 & 0.095 & 0.126 \\
\hline \multicolumn{14}{|c|}{ At $8 \%$ interest/discount rate (MED [85]) } \\
\hline $250 \mathrm{~d} \mathrm{y}^{-1}, 1$ cycle d $^{-1}$ & 0.053 & 0.045 & 0.078 & 0.082 & 0.071 & 0.073 & 0.108 & 0.090 & 0.240 & 0.077 & 0.106 & 0.143 & 0.194 \\
\hline Mean $\mathrm{CF}=0.05$ & 0.167 & 0.131 & 0.281 & 0.299 & 0.252 & 0.258 & 0.418 & 0.335 & 1.020 & 0.278 & 0.411 & 0.579 & 0.811 \\
\hline Mean $\mathrm{CF}=0.20$ & 0.057 & 0.048 & 0.086 & 0.090 & 0.079 & 0.080 & 0.120 & 0.099 & 0.271 & 0.085 & 0.118 & 0.160 & 0.218 \\
\hline Mean $C F=0.26$ & 0.049 & 0.042 & 0.071 & 0.074 & 0.065 & 0.066 & 0.097 & 0.081 & 0.213 & 0.070 & 0.096 & 0.128 & 0.173 \\
\hline
\end{tabular}


The overall median and mean estimated costs of storage at a utility of $250 \mathrm{~d} \mathrm{y}^{-1}, 1$ cycle $\mathrm{d}^{-1}$ were NZ\$0.06 $\mathrm{kWh}^{-1}$ and NZ\$0.08 $\mathrm{kWh}^{-1}\left(5 \% \mathrm{y}^{-1}\right.$ interest) and $\mathrm{NZ} \$ 0.08 \mathrm{kWh}^{-1}$ and $\mathrm{NZ} \$ 0.10$ $\mathrm{kWh}^{-1}\left(8 \% \mathrm{y}^{-1}\right)$. When used at annual capacity factors ranging from 0.26 to 0.05 the equivalent range of median and mean values were NZ\$0.06-0.21 $\mathrm{kWh}^{-1}$ (median) and $\mathrm{NZ} \$ 0.07-0.29 \mathrm{kWh}^{-1}$ (mean), at 5\% $\mathrm{y}^{-1}$ interest and NZ\$0.07-0.30 $\mathrm{kWh}^{-1}$ and NZ\$0.09-0.40 $\mathrm{kWh}^{-1}$ at $8 \% \mathrm{y}^{-1}$ interest, respectively. It should be noted, however, that the capital cost and $S$-value estimates given above have limited value in regard to the accurate prediction of the cost-effectiveness of any particular PH system in NZ, which may not be internationally representative'. This is due to the site-specific nature of $\mathrm{PH}$ cost-effectiveness [93,94,176,207,215,218-221]. The costs of generation from thermal- and energy storagebased generators are compared in Section 4.2.

\subsubsection{The Manorburn-Onslow pumped electricity proposal}

The most recent, publicly available study of PH power in NZ was performed by Bardsley, Bear and Leyland [77-81,222-224]. The proposal illustrated the potential of the ManorburnOnslow depression, adjacent to the Clutha River, Central Otago. The proposed PH facility would be situated approximately $20 \mathrm{~km}$ east of the Roxburgh Dam [80] and the possible elevation of the water level would be $\sim 800 \mathrm{~m}$ above sea level. The storage capacity could be distributed over both the Upper Manorburn and Lake Onslow basins. The lowest operating levels of the Onslow and Upper Manorburn lakes would be limited to $720 \mathrm{~m}$ and $760 \mathrm{~m}$, respectively and at least one dam would need to be constructed at the western edge of the Onslow basin (20 to $100 \mathrm{~m})$.

However, a 15-20 km-long tunnel from this dam(s) would be needed in order to connect to the Clutha River ( $\sim 80 \mathrm{~m}$ above sea level). The maximum operating head could be $640-720 \mathrm{~m}$ at a Treviot generator or 580-670 $\mathrm{m}$ at a Roxburgh generator. Charging capacity (including spillage mitigation) would be derived from the Clutha and the Waitaki Rivers.

The energy storage potential of the scheme was calculated to be 10,200-12,000 GWh (Figure 3.10), which is three-to-four times NZ's total hydro-lake-based capacity ( 3,600 GWh [127]) and half of annual hydro-based generation $\left(\sim 24,000 \mathrm{GWh}^{-1}[24,42]\right)$. The proposal, therefore, has the potential to be the "primary seasonal water store for the whole nation" [77]. The authors simulated the operation of the Clutha and Waitaki hydro schemes using historical hydro flows, both with and without a 1 GW hydro facility (Figure 3.11[a)]) [79] and increased generation on the Waitaki to reduce Clutha-derived spillage. 
The modelling appears to illustrate that $11 \mathrm{GWh}$ of energy through avoided spillage could have been stored during 1990-2003 for minimal water level variation (Figure 3.11[b]). The authors propose that the scheme would be energy neutral [79] and services could include dryyear security of supply, integration of wind power [80], displacement of existing and thermal plant [223] and stabilisation of other lakes, such as Pukaki [79]

Contact have stated publicly [219] that "for a variety of reasons", they have not pursued this scheme. Indeed, all generators will be aware of a 2006 study, which examined the economic and technical viability of the scheme (funded by the EC and performed, in part, by Parsons Brinkerhoff Associates Ltd.) [225-227]. The EC reported that the proposal did not appear to be economically viable ( NZ\$3 billion at $75 \%$ efficiency with $\$ 50$ million $\left.\mathrm{y}^{-1} \mathrm{O} \& \mathrm{M}\right)$. Indeed, the capital costs approach those of the Kazunogowa facility, Japan (Table 3.11).

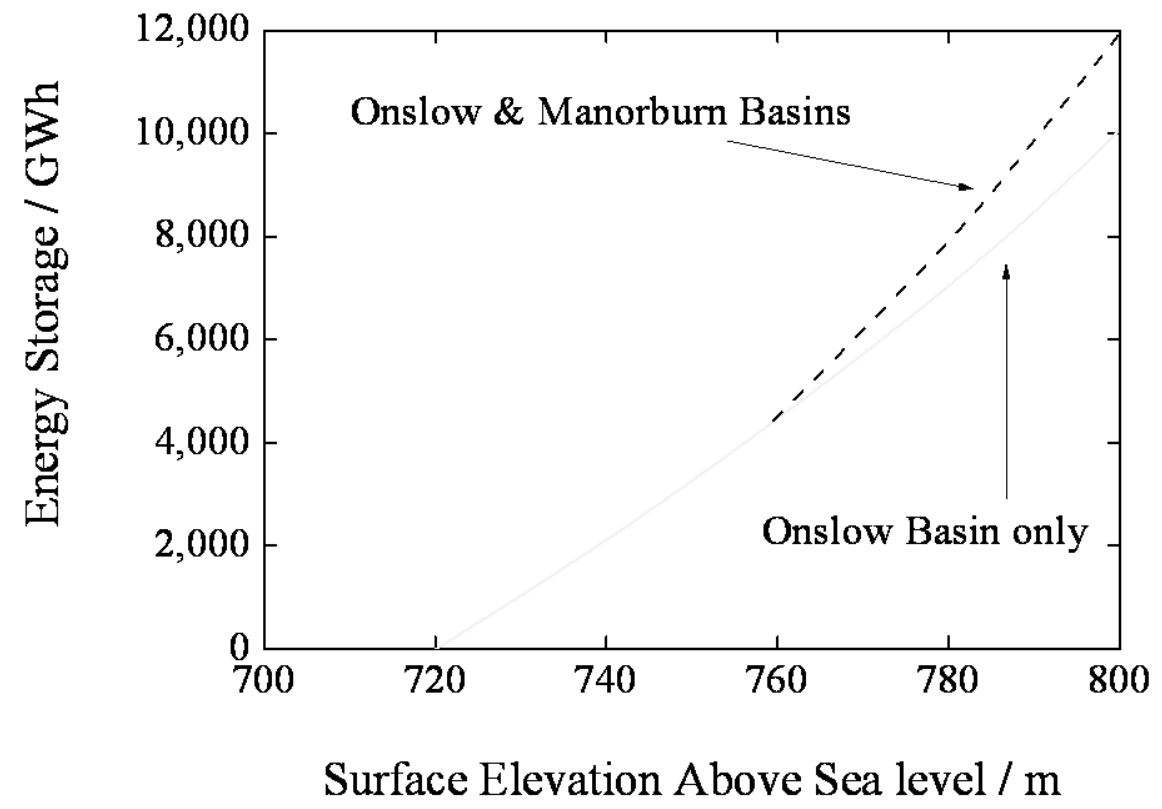

Figure 3.10. The potential energy storage capacity available within the lakes at the proposed Manorburn-Onslow depression PH storage scheme, redrawn from Bardsley [80]. 


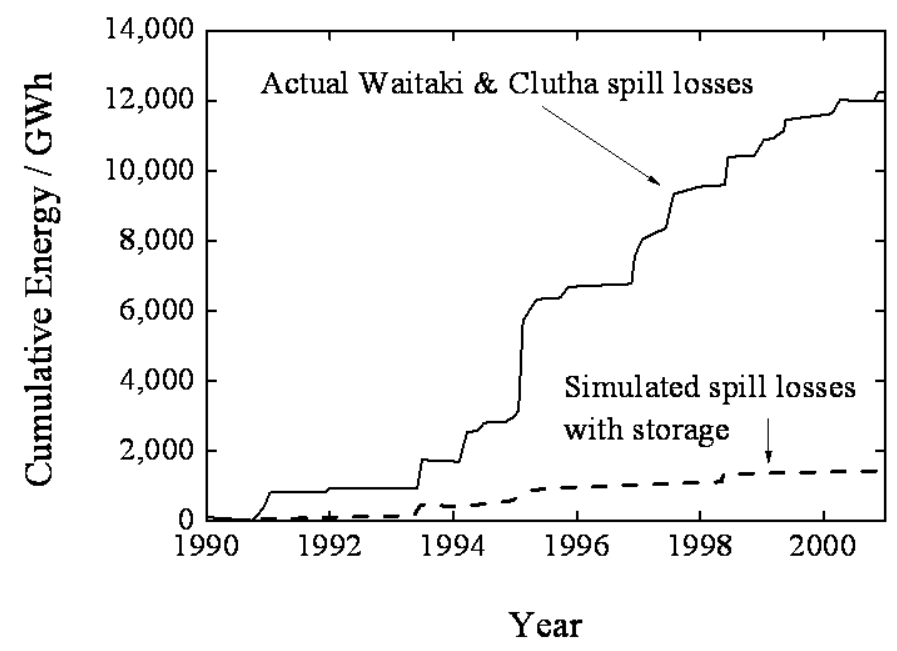

(a)

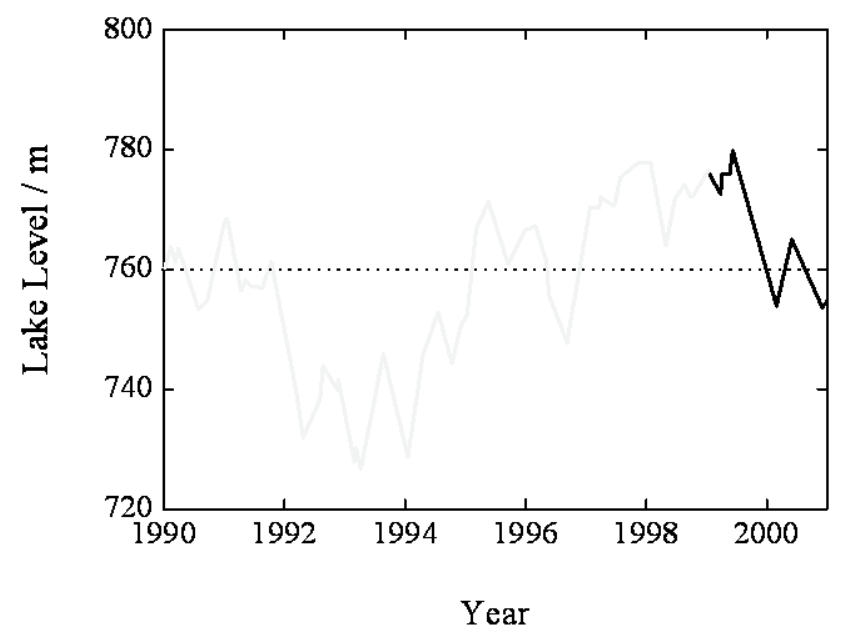

(b)

Figure 3.11. (a) Simulated net accumulation of energy gain (from reduction of spill events) associated with the simulated operation of the proposed Manorburn-Onslow depression PH scheme from 1990 to 2001. (b)

Simulated water level variation of the proposed Manorburn-Onslow depression reservoir calculated for the same period (storage facility in pre-primed condition at $760 \mathrm{~m}$ above sea level). Plots redrawn from Bardsley et al.

[79].

The EC specifically noted that investment in South Island coal and/or lignite would be a more cost-effective option for dry-year reserve. Other barriers included (1) greater energy losses than savings, (2) a net evaporation rate and (3) a lack of investor interest due to intermittent, long-term returns on an extremely large capital investment. The initial 10-year system charge (during which the system would be inoperative) would also require 15,000 GWh of energy, which would be a capital sink of $\sim \mathrm{NZ} \$ 84$ million. The rate of charging via hydro spillage alone $\left(1,000 \mathrm{GWh}^{-1}\right)$ was also noted to be insufficient for dry-year support. This is because of the high frequency of dry years. 
Both Bardsley and the EC noted that, although NZ would benefit from the mitigation of dryyear price spikes, the commercial structure of the market (at that time) would not likely have been capable of supporting the scheme. Indeed, the EC assumed that central-governmentderived intervention and investment would be required, which is clearly at odds with the outcome of the more recent Ministerial Review.

The EC also considered that the barriers associated with obtaining resource consent could be significant. To further examine the latter point, Kevin Hackwell of Forest and Bird was interviewed [228] as a part of this research and was provided with an opportunity to briefly review the Manorburn-Onslow proposal via a hardcopy of the 2006 Bardsley et al. conference paper [81] and maps and images of the location.

Hackwell presented a case that this scheme would most likely not be supported by $\mathrm{F} \& \mathrm{~B}$ and could be actively opposed, mainly because of the irreversible destruction of existing habitats within the landscape. The areas of tussock grassland (which were not likely to have been as intensively modified by pastoral farming as some other areas in Central Otago) and the lakes/wetland areas are likely to have significant intrinsic ecological value.

\subsection{Questionnaire}

\section{Electricity sector development}

The responses to Q1 and Q3 have been collated in Figure 3.12. All but one of the respondents assumed that growth in average and peak electricity demand will occur from now until 2025. The range of values reported was from 0.6-1.9\% $\mathrm{y}^{-1}$ (average demand) and 0.7-2.5\% $\mathrm{y}^{-1}$ (peak demand). The response of NGO1 was remarkably distinct, in that it was assumed in both cases, growth would most likely be negative or zero $\left(-1.0 \pm 1.0 \% \mathrm{y}^{-1}\right.$ and $-0.6 \pm 0.7 \% \mathrm{y}^{-1}$, respectively).

There was variation in the perception of uncertainty associated with the responses (as indicated by the width of the 'confidence intervals') the overall mean values (excluding NGO1) were $1.3+0.3 \% \mathrm{y}^{-1}$ (average) and $1.5+0.4 \% \mathrm{y}^{-1}$ (peak). The mean growth in peak demand appears to be slightly higher than that of the mean growth in average demand, but this is not statistically significant, given the overlap of the uncertainty limits.

All respondents assumed that newly installed power stations to 2025 will most likely comprise installations with capacity greater than $10 \mathrm{MW}$ and less than $400 \mathrm{MW}$ (Figure 3.13). The overall mean value was $147 \pm 50 \mathrm{MW}$, which is also the approximate scale of the Whirinaki Power Station. These data clearly indicate that the respondents assumed that distributed micro- and mini-scale forms of distributed generation will not make a significant 
contribution and most new capacity would be centralised in nature (although potentially embedded in networks).
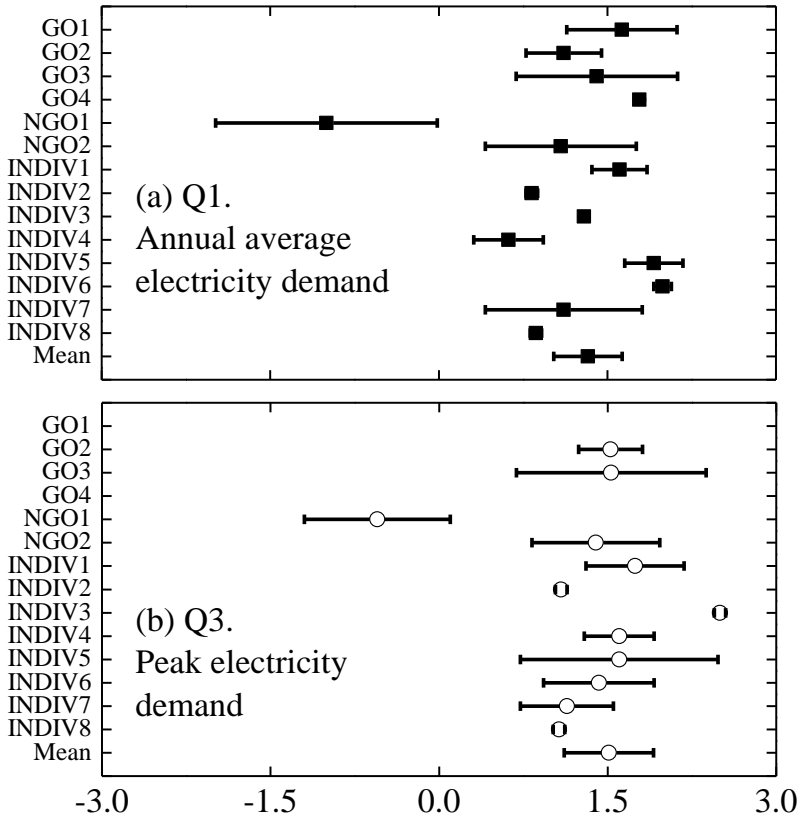

Likely rate of growth $\left(\% \mathrm{y}^{-1}\right)$
Figure 3.12. Response to Questions 1 \& 3:

(a) "What is likely to be the growth rate of average electricity demand from now until 2025?" and

(b) "In approximate terms, what will be the growth rate of peak electricity demand from now until 2025?". As an outlier, NGO1 is excluded from the calculation of both of the mean values.

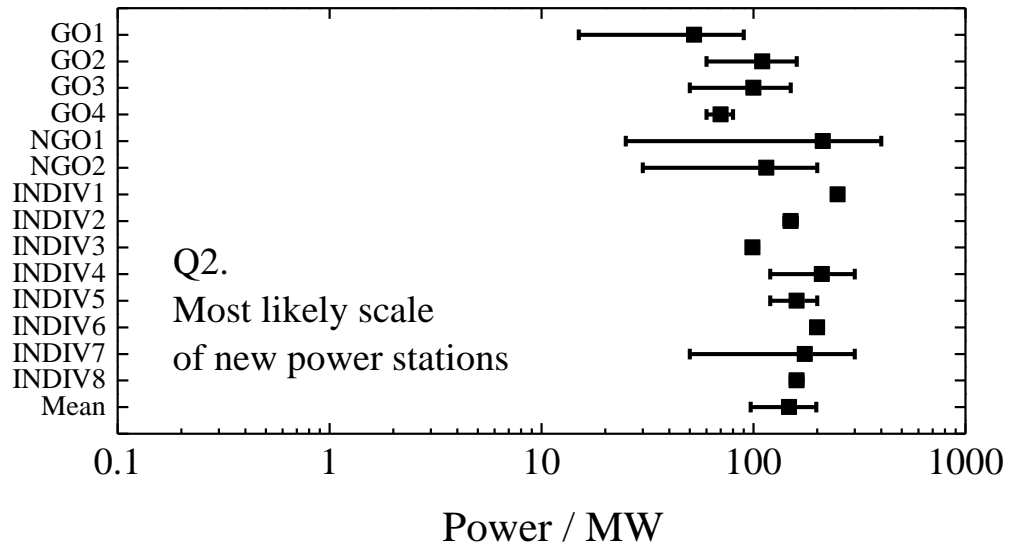

Figure 3.13. Response to Question 2: "If growth in demand does occur, at what scale of individual power station is most of the new supply likely to be realised? (Please note: logarithmic scale.)"

Q4 elicited a much more variable response (Figure 3.14) to the question of how much growth in any peak demand would most likely be supplied by new thermal capacity. Two of the respondents estimated that new thermal would supply approximate half of the required power (NGO2 and INDIV8) and four were oriented in favour of thermal (GO2, GO4, INDIV2 and 
INDIV3). The majority of respondents, however, assumed that a less-than-equal share of new thermal capacity would be built to meet this demand. INDIV4 and INDIV6 assumed zero growth in thermal peakers to 2025. (NGO1 assumed a majority negative growth in peak demand and was excluded from the analysis.) Many respondents (INDIV2, GO2, GO3, INDIVI1, INDVI2 and INDIV6) specifically noted that there is potential for existing hydro to be 'freed-up' for backup applications through the introduction of new base load capacity (wind/geothermal), thus at least partially negating the need for new thermal reserves.

When asked to specifically consider whether fast-start capacity would be required for the introduction of a $20 \%$ share of wind power by 2025 (Q5), the majority of respondents agreed that it would be most likely be necessary (Figure 3.15[a]). However, the question of whether this capacity could be introduced using only of non-pumped hydro capacity (Q6), produced a more evenly spread response (Figure 3.15[b]). Only one respondent (GO3) expressed a neutral stance. (NGO1 was again excluded due to a definitive negative response Q5).

In form, Q6 is similar to Q4 and, in general, the responses to these two questions appear to correlate, i.e., those respondents who assumed that a significant amount of new thermal peaking would be required for peaking also assumed that new thermal fast-start backup of variable wind power would be necessary (exceptions being INDIV1 and INDIV2.) There was again some variability in the responses received in regard to the potential for renewable power alone to replace Huntly Units $1-4$ by 2025 for the prevention of emergency dry-year events (Figure 3.16). However, none of the GOs and most of the individuals assumed that that this was likely. Presumably, therefore, many in the industry consider that new thermal power will be required to mitigate emergency dry-year events if these Huntly units are decommissioned by

2025.

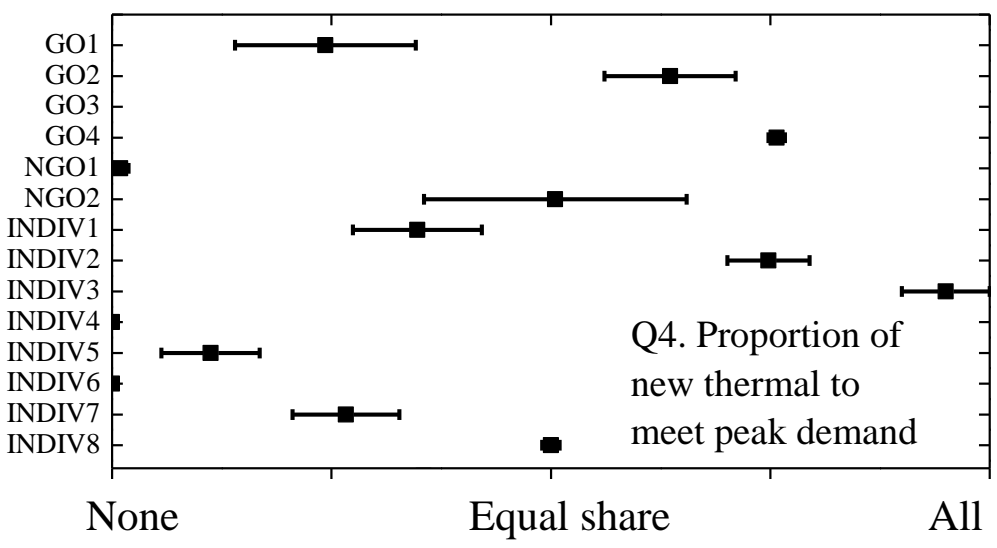

Figure 3.14. Response to Question 4: "How much of any growth in peak demand to 2025 will be met with the construction of thermal capacity based on natural gas and/or diesel fuels?" 


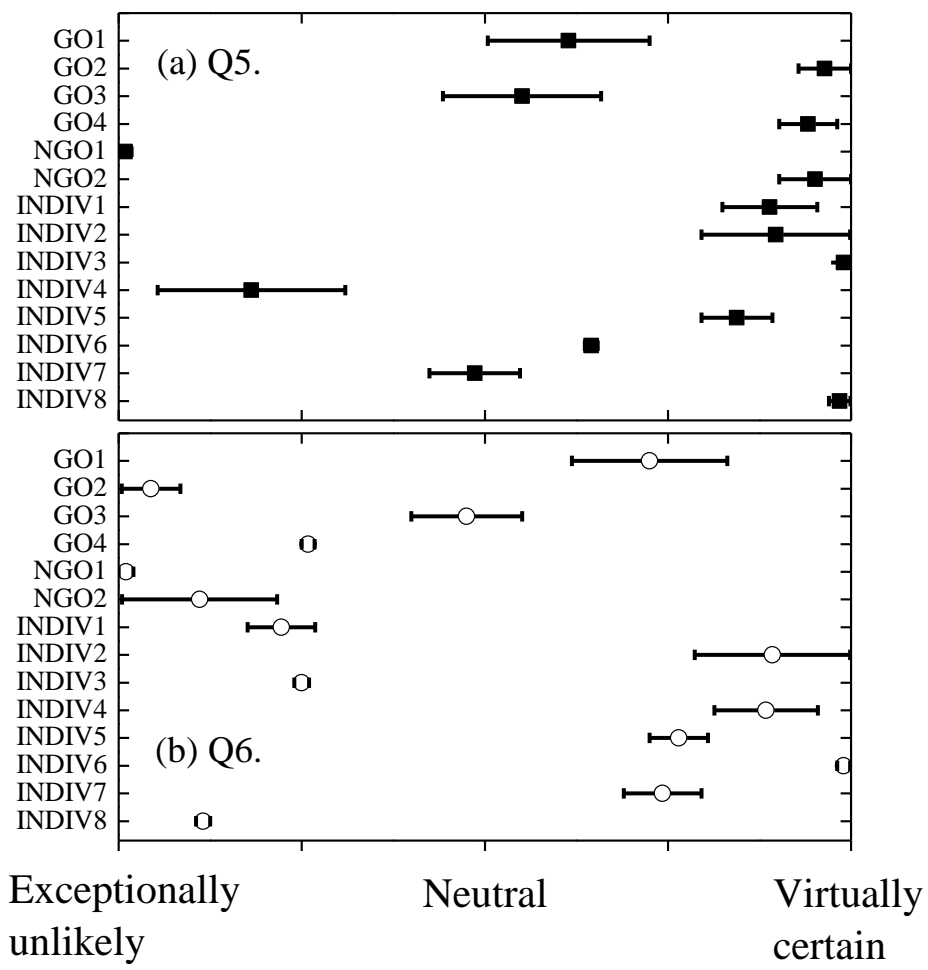

Figure 3.15. Response to Questions $5 \& 6$ :

(a) "Will fast-start backup power capacity be necessary for the successful introduction of a $20 \%$ share of wind power by 2025 ? and

(b) "Is it likely that a $20 \%$ share of intermittent power capacity (wind) can be integrated into the national grid by 2025 using standard, nonpumped hydro storage without the introduction of any new thermal faststart capacity?"

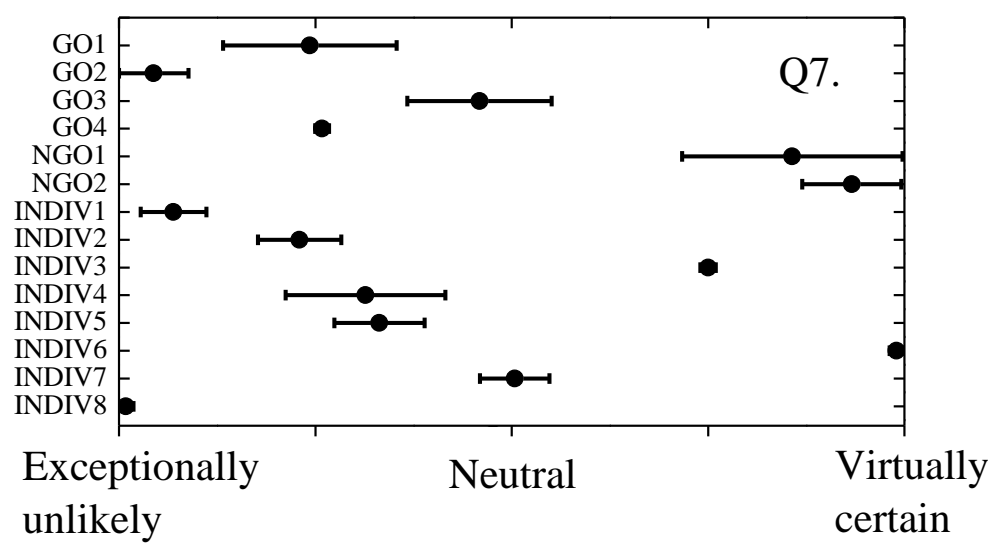

Figure 3.16. Response to Question 7: "If all four coal units at Huntly are decommissioned prior to 2025 and no new thermal is built, do you consider it likely that enough renewables power and standard hydro storage could be consented and built to prevent emergency dry-year events?"

\section{The technical feasibility of pumped hydro and batteries}

Q8 and Q9 (Figures 3.17 and 3.18, respectively) examined the respondents' perceptions in regard to the technical feasibility (theoretically excluding environmental and economic factors) of both pumped hydro and utility-scale batteries for supplying (a) peak demand, (b) grid integration of intermittent (variable) renewable, (c) emergency dry year reserve and (d) 
the mitigation of energy lost through spillage or wind excess. In regard to the answers given in response to Q8 and Q9, a caveat was expressed by multiple informants (via written notes and oral communication) that their responses only apply if sufficient energy and power capacity could be installed.

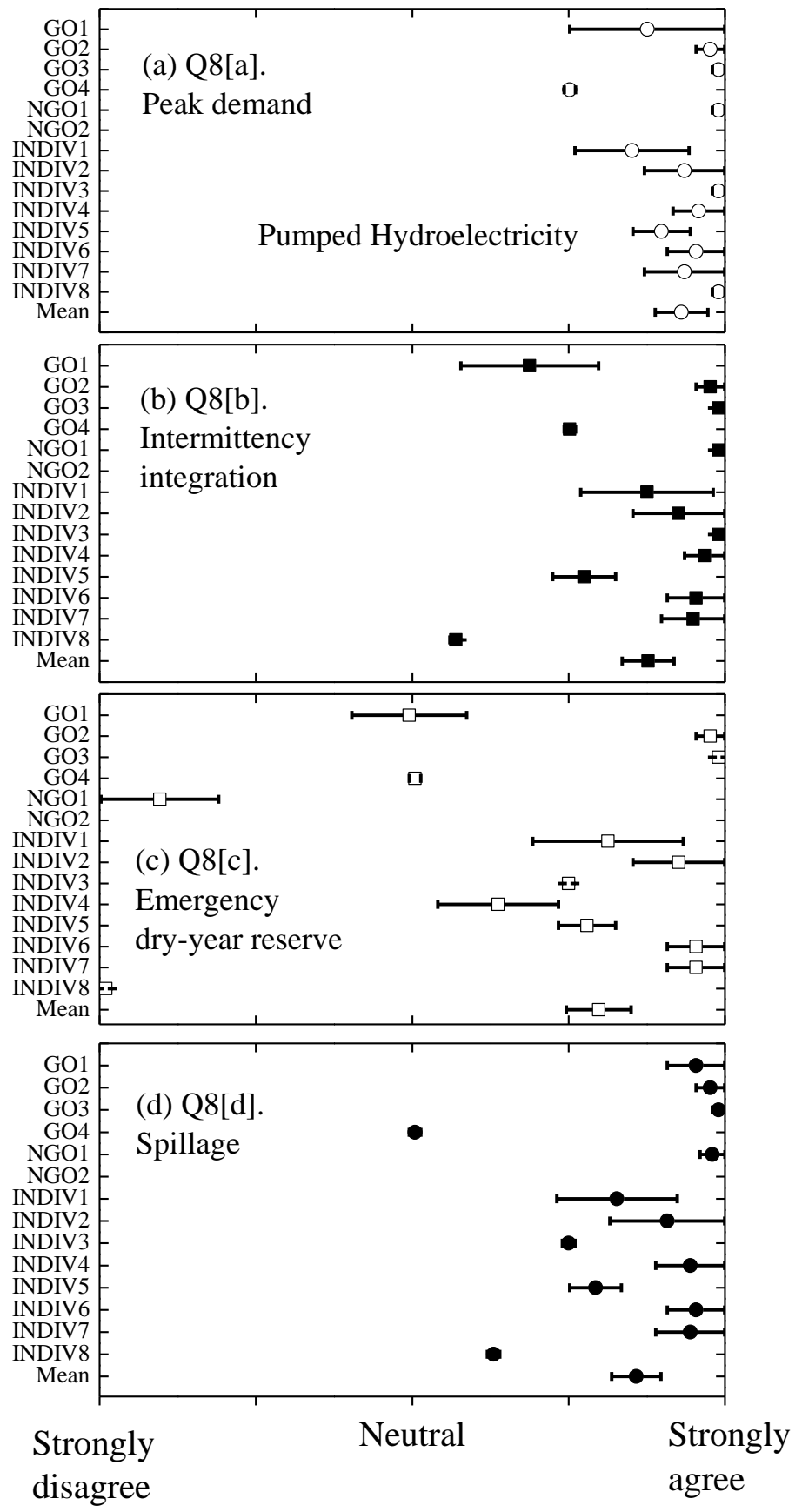

Figure 3.17. Response to Question 8: "Excluding environmental and economic considerations, do you consider that it is technically feasible for pumped hydro-based energy storage systems to be introduced by 2025 for the management of: (a) peak electricity demand, (b) grid integration of intermittent renewables, (c) emergency dry-year reserve generation and (d) Reduction of hydroelectricity spillage losses or wind excess issues?"

Note that, due to polarisation of opinion, the mean value given in Figure 3.6(c) excludes the data of NGO1 and INDIV8.

Other than NGO1 and INDIV8 (Q8[c]), most respondents were either in agreement, or were neutral, in regard to pumped hydro to meet all of the above (although NGO2 gave a 'do not know' response to Q8[a] through [d]). However, there was some uncertainty expressed 
during the interviews (Section 3.3) in regard there being a suitable site available in NZ that could ensure large-scale energy storage for seasonal reserves.

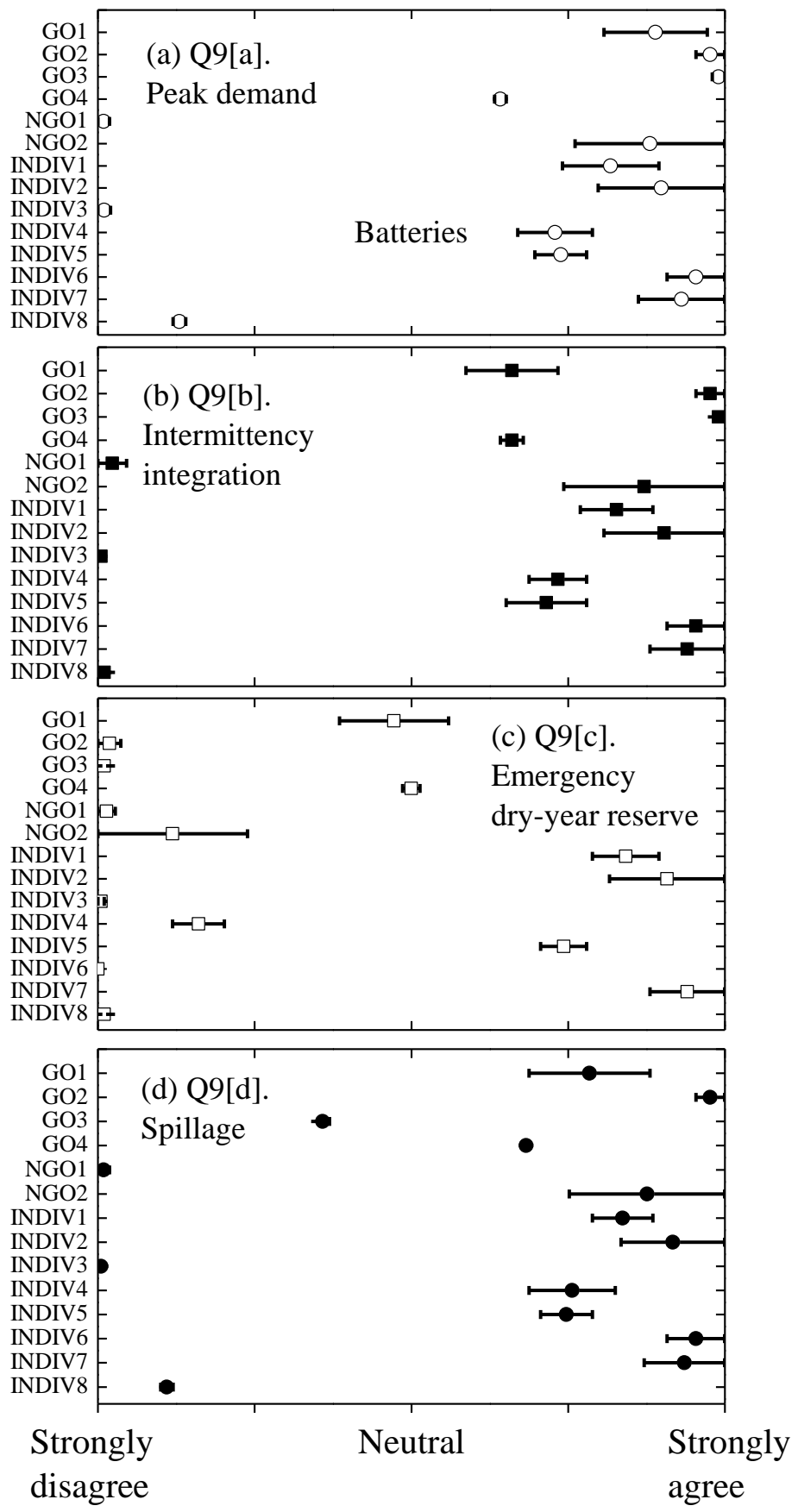

Figure 3.18. Response to Question 9: "Excluding environmental and economic considerations, do you consider that it is technically feasible for battery-based energy storage systems to be introduced by 2025 for the management of: (a) peak electricity demand, (b) grid integration of intermittent renewables, (c) emergency dry-year reserve generation and (d) Reduction of hydroelectricity spillage losses or wind excess issues?"

There was considerably more uncertainty in regard to the technical capacity of batteries to provide these services, although the majority of respondents assumed that this technology would be capable of ensuring peak demand, grid integration of intermittent (variable) renewables and spillage mitigation. Only three informants (NGO1, INDIV3 and INDIV8) assumed that batteries were technically incapable of providing peak adequacy (Figure 3.18[a]) 
and there was an almost identical spread of opinion in regard to the capacity of batteries to support of intermittent renewables (Figure 3.18[b]) and to mitigate spillage. However, there was much less confidence among the respondents that batteries have the technical capacity to supply sufficient power and energy for emergency dry-year reserve, and more respondents were in strong disagreement (GO2, GO3, NGO1, NGO2, INDIV3, INDIV4, INDIV6, INDIV8) than in agreement (INDIV1, INDIV2, INDIV5, INDIV7). During the interview it was noted by most of those who disagreed (and contributed) that the physical energy capacity requirement would technically negate the use of batteries in this case. ${ }^{21}$

\section{The economic costs of generation}

Q10 asked the informants to rate five types of back-up technology in regard to perceptions of relative economic feasibility (Figure 3.19). The following question (Q11) then asked each respondent to define the long-run marginal costs of generation from each of these technology types (Figure 3.20). The data reference points of NZ\$30 $\left(\mathrm{CO}_{2}-\mathrm{e}\right)$ tonne ${ }^{-1}, \mathrm{NZ} \$ 10$ (gas) $\mathrm{GJ}^{-1}$ and NZ\$50 (diesel) $\mathrm{GJ}^{-1}$ were chosen as 'middle-of-the-road' values; somewhat greater than current prices, but not likely to be perceived as excessive, at least by the majority of the respondents.

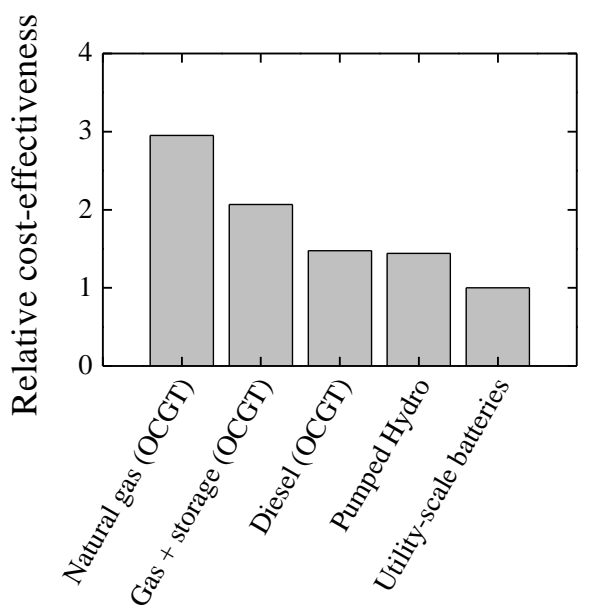

Figure 3.19. Response to Question 10: "Please rank the following in regard to what you would consider to be the most cost-effective investment for fast-start, backup power generation in New Zealand at $\mathrm{NZ} \$ 30\left[\mathrm{CO}_{2}\right.$-e] per tonne, NZ\$10 [gas] per GJ and NZ\$50 [diesel] per GJ. Assume that each power station has a power rating is $200 \mathrm{MW}$ and will operate at a power capacity factor of $0.05(5 \%)$. Please use a scale of 1 to 5 , where 1 is the most cost-effective."

See Equation (3.1) for the definition of 'relative cost-effectiveness'

Non-pumped (i.e., standard) hydro was not offered as an option as only a direct cost comparison with thermal options was sought and the costs of generation of hydro are relatively well known in NZ. (The overall potential of standard hydro is considered, however, in Q18.)

\footnotetext{
${ }^{21}$ Author note: it may be technically possible to charge batteries on a diurnal basis during off-peak times, but only if a considerable excess of wind capacity was available for overnight charging. The cost-effectiveness of this approach, however, is unknown.
} 
The index of 'relative cost-effectiveness' (RCE):

$\mathrm{RCE}=\frac{\text { Sum of the ratings for percieved least cost-effective technology option }}{\text { Sum of the ratings for technology option of interest }}$

of the technologies was calculated to be in the order of: natural gas > gas + storage > diesel/pumped hydro > batteries. The RCE for gas was almost three times greater than that of batteries, which were rated the least cost-effective option a total of ten times. 'Gas + storage' was perceived to have a RCE twice that of batteries. Diesel and pumped hydro had an RCE a factor of 1.5 times greater than batteries.

PH was general assumed to be at least as cost-effective (in relative terms) as diesel generation for the conditions specified and was rated most-cost-effective twice (NGO1 and INDIV3). However, 'natural gas' was usually rated as the most-cost-effective option and gas + storage was generally rated in second place.

From the responses to Q11 it is possible to estimate the level of confidence of each respondent in answering Q10 and whether their responses were based on perceived knowledge of the LRMCs of generation, or simply based on a more qualitative level of understanding.

The results indicate that the latter appeared to be the case in many instances. Although only one respondent did not respond to Q10, five of the fourteen respondents failed to answer any of the sub-questions within Q11. ${ }^{22}$ A total of seven did not respond to the Q11(e) the LRMC of batteries. Moreover, although the range of values presented was somewhat variable for the gas, diesel and pumped hydro options, the uncertainty ranges used in response to Q11(e) for batteries, were extensive ( $\pm \mathrm{NZ} \$ 600 \mathrm{MWh}^{-1}$ in one case $)$ and were, thus, considerably greater than for the other technology types.

This uncertainty, in part, is likely to be due to the fact that the former has never been used in NZ and knowledge of the economics of utility-scale batteries is extremely limited here. Conversely, pumped hydro was regarded by some as having a similar capital costs to nonpumped hydro and it was orally reported to the author on a number of occasions that these costs were apparently used to guide their responses to Q11(d).

However, the costs associated with pumped hydro were usually noted to be highly sitespecific and, therefore, it is rather surprising that pumped hydro was not presented as having a similar level of cost variability as batteries.

\footnotetext{
${ }^{22}$ Number of declined responses for each category associated with Question 11: (a) natural gas $=5$, diesel $=5$, gas + storage $=6$, pumped hydro $=6$ and seven to Q11(e) batteries $=7$.
} 


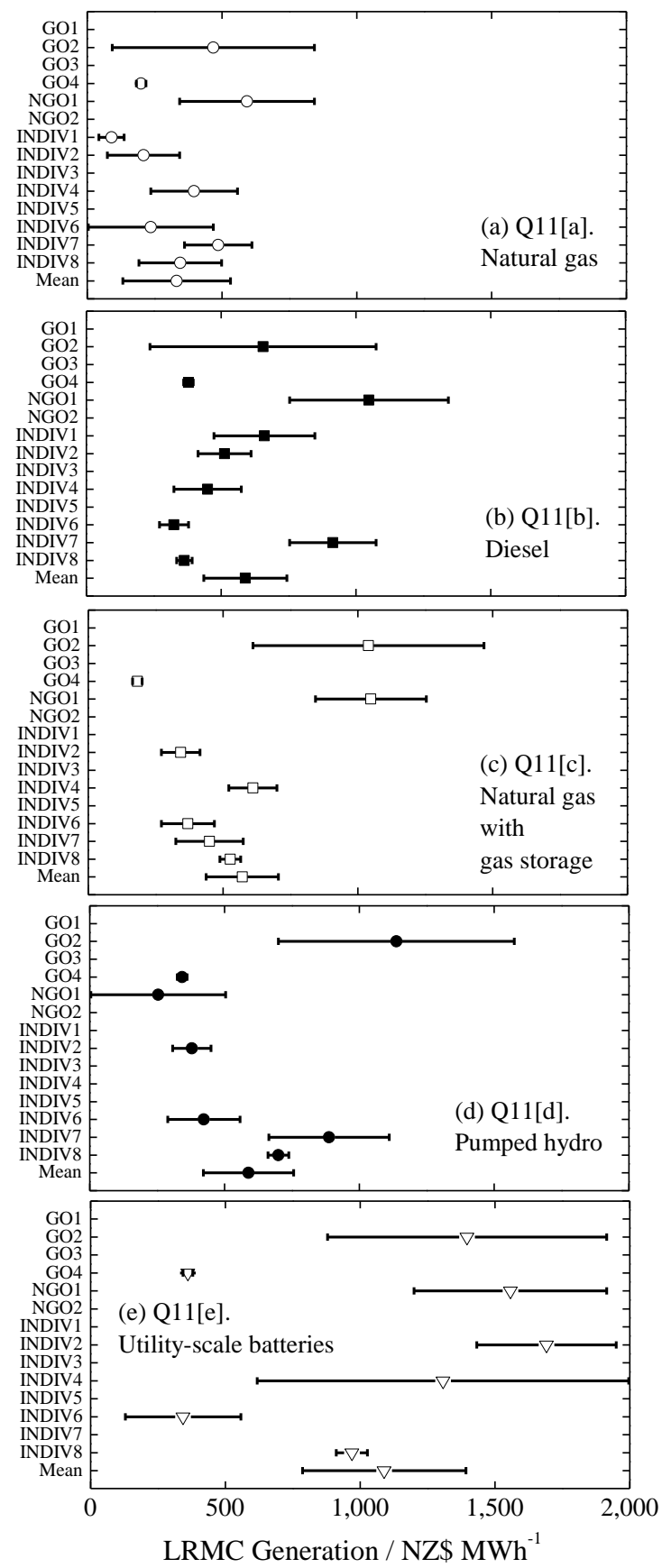

Figure 3.20. Response to Question 11: "Assuming NZ\$30 [ $\mathrm{CO}_{2}$-e] per tonne, NZ\$10 [gas] per GJ and $\mathrm{NZ \$ 50} \mathrm{[diesel]} \mathrm{per} \mathrm{GJ,} \mathrm{what} \mathrm{is} \mathrm{likely}$ to be the approximate long run marginal cost (LRMC) of backup generation from the following? Please assume a power rating of 200 MW operating at a capacity factor of 0.05 (5\%)."

The overall LRMC estimates, for the conditions noted, were NZ\$332 $\pm 200 \mathrm{MWh}^{-1}$ (gas), $\mathrm{NZ} \$ 590 \pm 154 \mathrm{MWh}^{-1}$ (diesel), NZ\$571 $\pm 134 \mathrm{MWh}^{-1}$ (gas + storage), NZ\$590 $\pm 167 \mathrm{MWh}^{-1}$ (pumped hydro) and NZ\$1,089 $\pm 303 \mathrm{MWh}^{-1}$ (batteries). The spread of the data in each case (including the uncertainty limits) was $\mathrm{NZ} \$ 0-850 \mathrm{MWh}^{-1}$ (gas), $\mathrm{NZ} \$ 240-1,340 \mathrm{MWh}^{-1}$

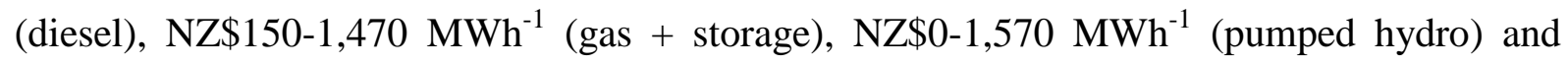
$\mathrm{NZ} \$ 131-2,000 \mathrm{MWh}^{-1}$ (batteries). Thus, on-average, the respondents perceive that the LRMC of pumped hydro used for peaking are likely to be similar to diesel and gas + storage, although, clearly, there is deviation from this assumption at the scale of the individual. 


\section{The impacts of fuel and carbon pricing}

Informant responses to Q12-15 have been collated in Figure 3.21, which reveals that there was clearly no consensus of opinion in regard to the impact of a low to moderate prices on carbon, gas and diesel on the rate of investment in pumped hydro and batteries. Five respondents firmly placed their response as neutral and only the two NGOs firmly agreed that storage could be introduced prior to 2025 under these economic conditions. Five of the respondents also disagreed that these technologies would be introduced under such conditions (GO1, INDIV1, INDIV2, INDIV5 and INDIV7). When asked (Q13) to consider if a price on carbon of NZ $\$ 100$ would improve this outlook (Figure 3.21[b)]), all of the respondents responded that it would (all other economic parameters remaining equal). Five (GO2, GO3, NGO1, NGO2 and INDIV6) assumed a certain improvement.

However, there was again considerable scatter in opinion in response to Q14 and 15 (Figures $3.21[\mathrm{c}]$ and $[\mathrm{d}]$ ). These questions examined the influence of a decrease in gas prices (to NZ\$5 $\mathrm{GJ}^{-1}$ ) and the impacts of a series of international 'oil shocks', respectively. It appears that perceptions of the impact of fuel pricing on the viability of energy storage is also highly varied.

Any analysis of Q14, however, must be considered with the following caveat. Both GO2 and $\mathrm{NGO} 2$ noted that the wholesale price of gas is unlikely to drop to $\mathrm{NZ} \$ 5 \mathrm{GJ}^{-1}$ even if a number of easily accessible new gas fields are found within NZ jurisdiction. Under the current regime of exploration agreements used by the NZ Government, these respondents explained that the exploration/extraction companies would simply immediately export at the international price of liquid petroleum gas. In the opinion of these respondents, therefore, the domestic wholesale price of gas is extremely unlikely to drop significantly relative to current prices.

In answer to Q15, only three respondents appeared to consider that oil price uncertainty would have very little or zero impact on the favourability of pumped hydro and/or batteries and this scenario would most likely or certainly improve the outlook for energy storage. More than one of the respondents noted that the oil-price uncertainty will have a fundamental impact on the NZ economy and, therefore, the energy sector as a whole.

\section{Predisposing conditions}

Q16 was a multi-questioned-examination of a broad range of aspects that may, or may not have some impact on the favourability of pumped hydro- and battery-based energy storage. Respondents were asked to rate each aspect from ' -2 ' to ' +2 ' according to the potential to promote the introduction of ether pumped hydro or batteries. In construction, the questions 
were formulated to consider three broad themes: (1) Market and Commercial Issues, (2) Environmental Issues and (3) Practical Issues (responses are given Figures 3.22, 3.23 and 3.24 , respectively).

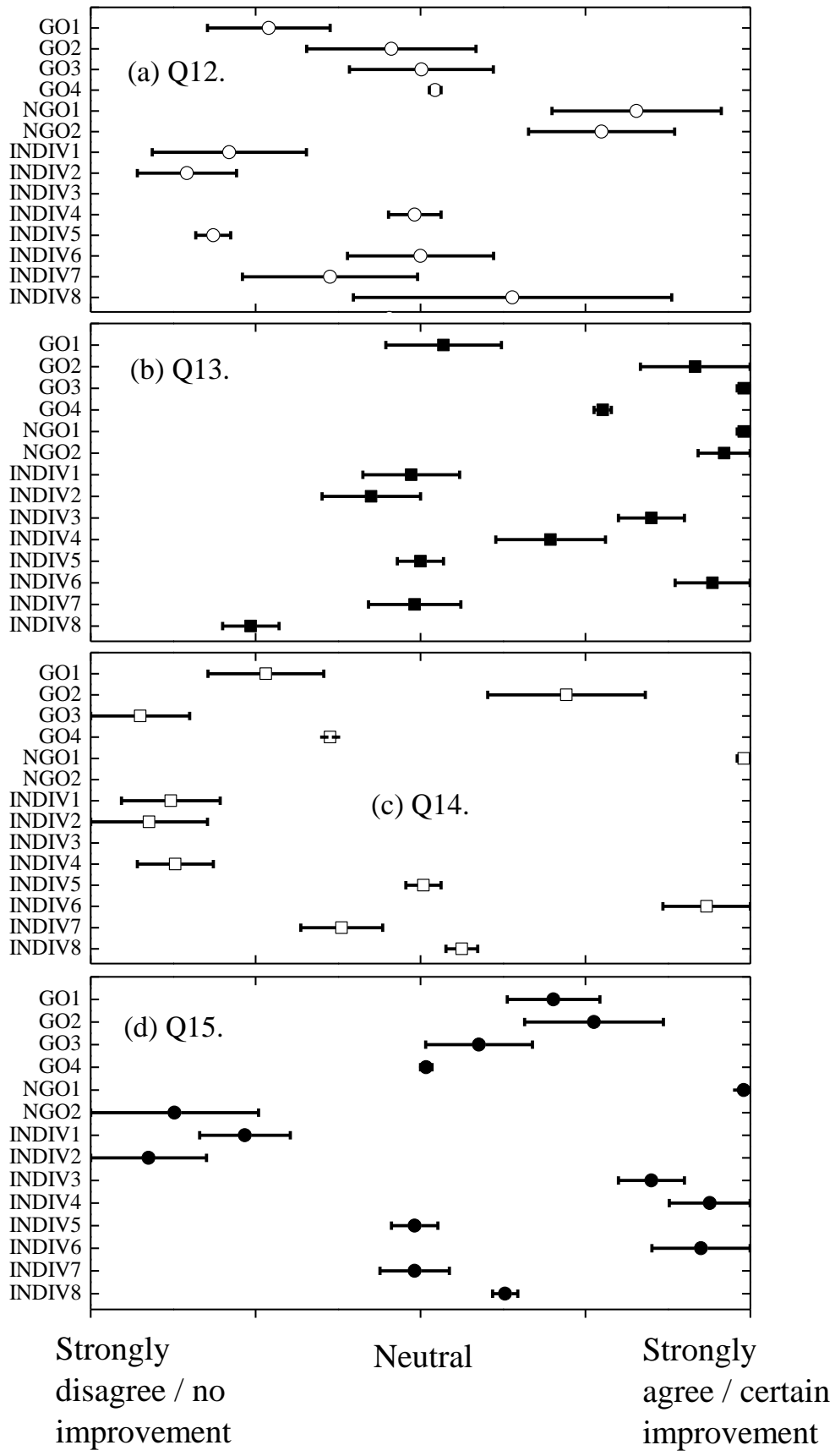

Figure 3.21. Responses to Questions 12-15:

(a) "Do you consider that the introduction of pumped hydro and/or batteries prior to 2025 is likely at $\mathrm{NZ} \$ 30\left[\mathrm{CO}_{2}-\mathrm{e}\right]$ per tonne, NZ\$10 [gas] per GJ and NZ\$50 [diesel] per GJ?”,

(b) "Do you consider that a price on carbon of NZ\$100 $\left(\mathrm{CO}_{2}\right.$-e) per tonne would significantly improve the likelihood of pumped hydro and/or batteries being introduced by 2025 (at NZ\$10 [gas] per GJ and NZ\$50 [diesel] per GJ)?",

(c) If there are discoveries enabling the price of natural gas to limit at $\underline{\text { NZ } \$ 5}$ per GJ by 2025 , would you consider that the introduction of pumped hydro and/or batteries to New Zealand prior to 2025 is likely at NZ\$100 $\left(\mathrm{CO}_{2}-\mathrm{e}\right)$ per tonne?" (note that $\mathrm{GO} 2$ and $\mathrm{NGO} 2$ considered that exports will ensure that gas prices remain above NZ\$5 per GJ), and

(d) If the global economy experiences a series of 'oil shocks' (intermittent periods of high oil prices) prior to 2025 could this significantly improve the likelihood of pumped hydro and/or batteries being introduced by 2025 at NZ\$30 $\left(\mathrm{CO}_{2}\right.$-e) per tonne and NZ\$10 (gas) per GJ?"

\section{Market and Commercial Issues}

Figure 3.22 reports the absolute frequency of responses to Theme (1) (Q16[a], 16[b], 16[f] and 16[j]). There was no marked pattern in the responses to Q16(a), which asked the informants to consider the merits of the current framework of the electricity market and the 
responses were relatively evenly spread between both technology types. It should be noted, however, that $55 \%$ of the respondents represented governmental organisations, SOEs, nonSOE-based generators or were employees of these organisations acting as individuals. Although they would have an 'insider's view' of the market framework, it appears that some bias may have been displayed (these informants are the developers, regulators and the participants within the market). The remainder were commentators participating 'outside' of the market.

None of the 'insiders' indicated that the current market would act as a disadvantage to the promotion of pumped hydro (although two noted that it would disadvantage batteries). Conversely, the 'outsiders' almost universally assumed that the market would most likely not act to promote these technologies.

There was an obvious distinction however, between pumped hydro and batteries when the respondents were asked to consider existing skills and knowledge (Q16[c], Figure 3.22[b]). $62 \%$ responded that batteries could suffer in this regard (response: -2 and -1$)$, while $69 \%(+1$ and +2 ) noted that pumped hydro would be supported.

Q16(f) asked the respondents to consider an investor requirement for a cost-effective solution in regard to the promotion of pumped hydro and batteries (Figure 3.22[c]). The response was almost predominantly negative (-2 and -1$)$.

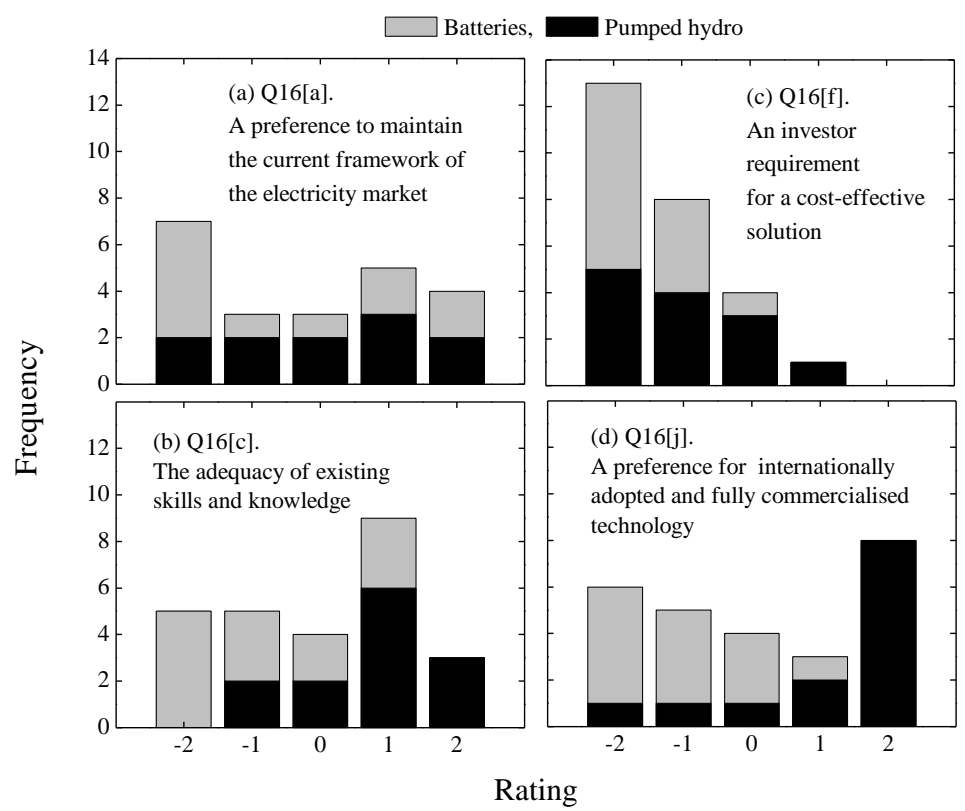

Figure 3.22. Response to Question 16 (Market and Commercial Issues): "While independently considering both pumped hydro- and battery-based energy storage, please rank the following as either a disadvantage (negative) or an advantage (positive) with respect to the promotion of these systems. Please assign any one of the following: $-2,-1,0,+1,+2$. Leave the box blank if you 'don't know'." Note that a total of two respondents (GO3 $\&$ NGO1) recorded that they 'did not know' in response to Q16(a). All data also excludes the response of INVID6, who did not fully complete Q16.

When a preference for an internationally adopted and fully commercialised technology was 
considered (Q16[j]), the informants again made a relatively clear distinction between pumped hydro and batteries (Figure 3.22[d]). Ten positive responses were received for pumped hydro and nine negative responses for batteries, including five at the '-2' grade.

\section{Environmental Issues}

In regard to the environmental issue of local environmental impact (Q16[b]), there was again some considerable distinction perceived between the two technologies (Figure 3.23[a]). Batteries were generally assumed to have low potential for impact, which could be promotional in nature. Pumped hydro, however, was perceived negatively $(69 \%$ of the responses) were negative.

A requirement for future climate change adaptation (Q16[i]) was assumed to most likely have either a neutral or a positive impact on the future promotion of batteries and pumped hydro (75\% of responses noting a positive contribution towards the promotion of batteries; Figure $3.23[\mathrm{~b}])$. However, GO2 orally noted that water would need to be available for the pumping [charging] sequence and regional site selectivity could be an issue for hydro schemes.

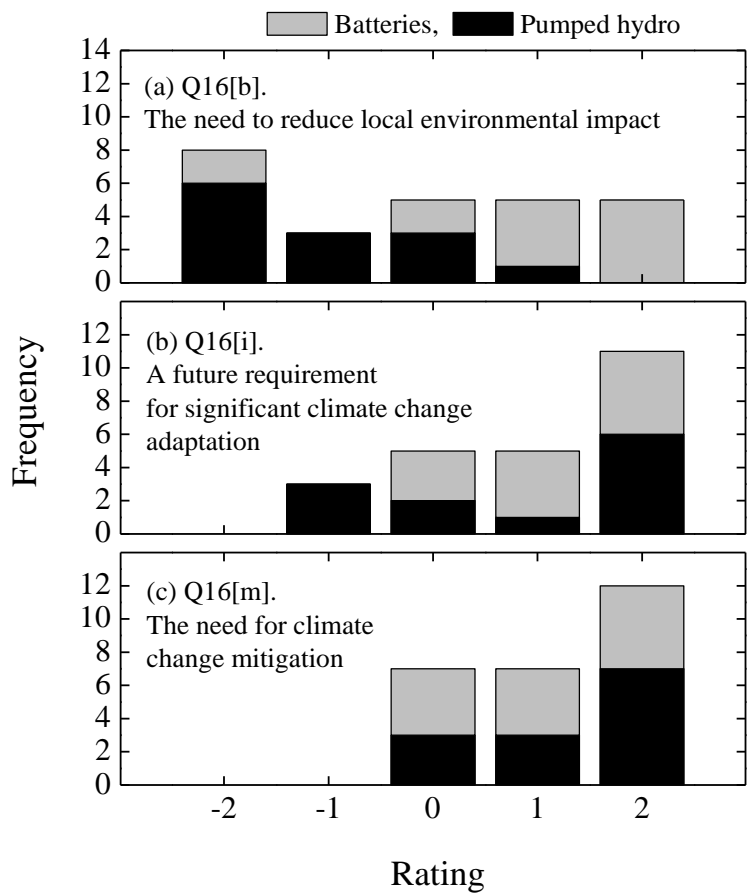

Figure 3.23. Response to Question 16 (Environmental Issues): "While independently considering both pumped hydro- and battery-based energy storage, please rank the following as either a disadvantage (negative) or an advantage (positive) with respect to the promotion of these systems. Please assign any one of the following: $-2,-1,0,+1,+2$. Leave the box blank if you 'don't know'." Data excludes the response of INVID6, who did not complete Q16.

In regard to mitigation of climate change (Q16[m]), 77\% (pumped hydro) and 69\% (batteries) of all participating respondents assumed that consideration of this factor would lead to positive promotion of these technologies. The remainder assumed that a neutral influence 
may prevail (including INDIV8, who noted that climate change, if realised, may not be anthropogenically derived).

\section{Practical Issues}

Figures 3.24(a)-(e) present the data associated with the practical, or technical attributes of pumped hydro and batteries. When asked to consider whether a need for ease of integration with existing infrastructure could be advantageous (Q16[d]) all informants responded either positively $(82 \%)$ or neutrally $(18 \%)$ when considering pumped hydro. Batteries received three '-1' ratings (23\%), four neutral $(31 \%)$ and six positive $(46 \%)$.

Flexibility in site selection (examined in Q16[e]) was another factor that appears to clearly distinguish pumped hydro from batteries. This sub-question produced the most polarised response of the Q16 series. $69 \%$ of respondents assumed that site selectivity could be a significant drawback (rating: -2) to the promotion of pumped hydro in NZ. 62\%, however, proposed that this factor would be a significant benefit (rating: +2 ) in regard to batteries.
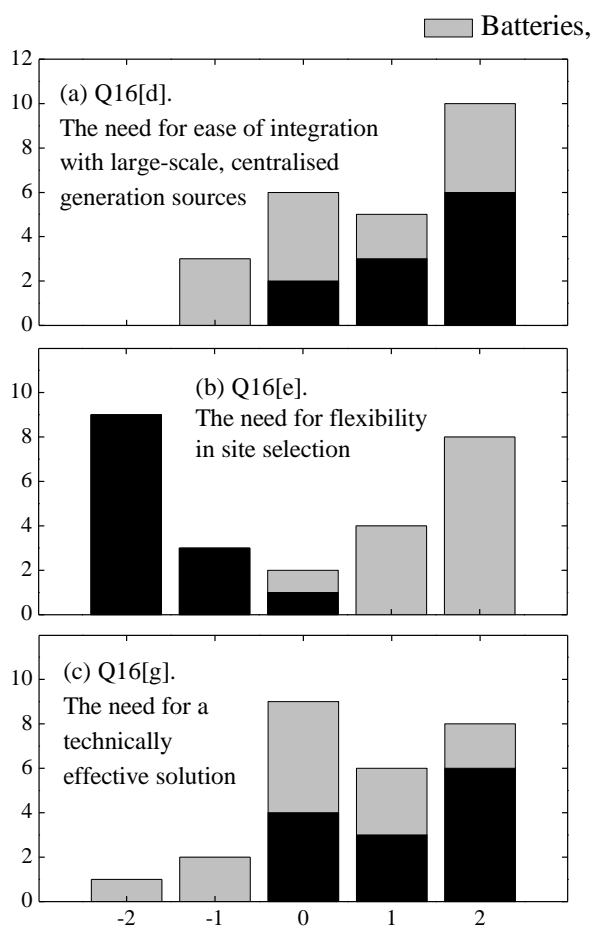
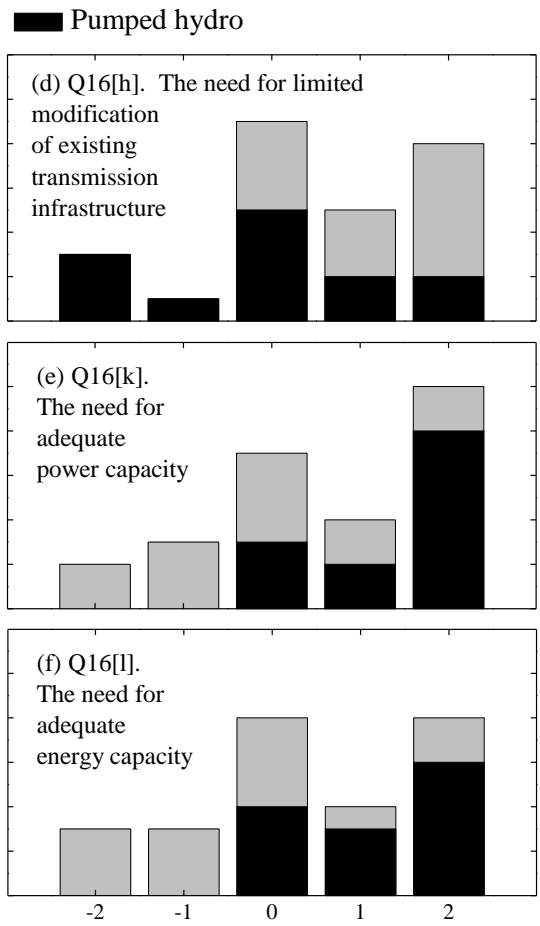

Figure 3.24. Response to Question 16 (Practical Issues): "While independently considering both pumped hydro- and battery-based energy storage, please rank the following as either a disadvantage (negative) or an advantage (positive) with respect to the promotion of these systems. Please assign any one of the following: $-2,-1,0,+1$, +2 . Leave the box blank if you 'don't know'." Data excludes the response of INDIV6, who did not complete the question.

Rating

As illustrated in Figure 3.24(c), most informants in response to Q16(g) responded that pumped hydro would be capable of providing a technically effective solution if this was needed by the sector ( $69 \%$ positive respondent ratings; $31 \%$ neutral). However, there was a slightly more even spread of opinion in regard to the potential effectiveness of utility-scale 
batteries in NZ (23\% negative respondent ratings; 38\% neutral; 38\% positive). NGO1, INDIV3, INDIV8, responded negatively, GO2, GO4, NGO2, INDIV2, INDIV4 responded positively in regard to batteries.

Batteries, however, were perceived to be more favoured in regard to the need for limited modification of existing transmission infrastructure (Q16[h], Figure 3.24[d]), with 69\% positive respondent ratings; $31 \%$ neutral. There was a very even spread of opinion when pumped hydro was examined. Distance to the major demand centres, when was noted, was assumed to be the primary drawback to the latter (Section 3.2).

Questions 16(k) and 16(l) were formulated to gain a general understanding of the perceptions the respondents in regard to the power and energy adequacy of pumped hydro and batteries, in relative terms only. For brevity, the informants were not asked to consider a list of specific applications. Most informants logged positive/neutral ratings in regard to the promotion of pumped hydro (Figures 3.24[f] and [f]). But there was a rather more negative response for batteries (38\% for power adequacy; $46 \%$ for energy adequacy), which indicates mixed perceptions in this regard.

\section{'Policy-related' concerns}

While continuing to investigate the potential of various factors to influence the general promotion of new forms of energy storage (technology not specified), Q17 asked each respondent to rate, from 1 to 5, a number of 'policy-related' concerns including (1) security of supply, (2) $\mathrm{CO}_{2}$-e emissions, (3) fuels-based uncertainty, (4) energy independence an (5) congruence with current investment pathways. The results (Figure 3.25) indicate that policy supporting firstly $\mathrm{CO}_{2}$-e emissions reduction and secondly reliable security of supply would have the most potential (relative to the limited range of options given). Here, 'relative potential' (RP) is defined as:

$\mathrm{RP}=\frac{\text { Sum of the ratings for the 'policy issue' with least potential to promote energy storage }}{\text { Sum of the ratings for the 'policy issue' of interest }}$.

Reduction of $\mathrm{CO}_{2}$-e emissions was graded at an averaged $\mathrm{RF}$ of 1.7 times that of the lowest rated policy incentive (reduction of fossil-fuel uncertainties). Security of supply RF equalled 1.6. Energy independence was rated third $(\mathrm{RP}=1.4)$ and current investment pathway congruence fourth $(\mathrm{RP}=1.3)$.

Of considerable interest is that all the GOs, in addition to NGO2, INDIV6, INDIV5 and INDIV8, selected the reduction of $\mathrm{CO}_{2}$-e emissions as likely to be the most influential policy factor (in relative terms), but a number of the respondents also rated emissions reduction as being a relatively unimportant driver (INDIV1, INDIV2, INDIV3, INDIV4, INDIV7). 


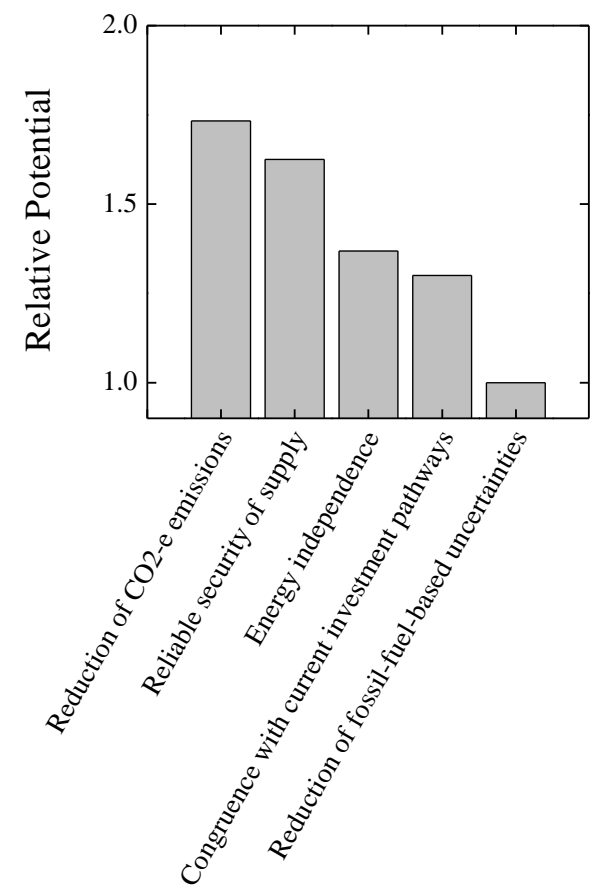

Figure 3.25. Response to Question 17: "Please rank the following with respect to their potential to contribute towards the general promotion of new forms of renewables-based energy storage in NZ. Please use a scale of 1 to 5 , where 1 has the most potential."

\section{Overall potential to contribute}

Lastly, the questionnaire invited respondents to rate the relative likelihood of the following making the greatest contribution towards new-build backup power to 2025: (1) pumped hydro, (2) thermal, (3) battery power and (4) non-pumped (Figure 3.26. Here, 'relative contribution' $(\mathrm{RC})$, is defined as:

$\mathrm{RC}=\frac{\text { Sum of the ratings for the technology with least potential to contribute }}{\text { Sum of the ratings for the technology of interest }}$.

Although, the respondents were asked to continue to assume no new significant natural gas discoveries, thermal backup was still seen as most likely to contribute with an average RC index 2.3 times that of batteries (the latter being the lowest rated option).

Moreover, although many respondents noted that standard hydro has limited potential to increase in regard to new-build capacity, it was still rated with an RC value of 2.0. Twelve of the fourteen respondents concluded that the majority of new-build backup power capacity to 2025 would not be based on pumped hydro or batteries. 


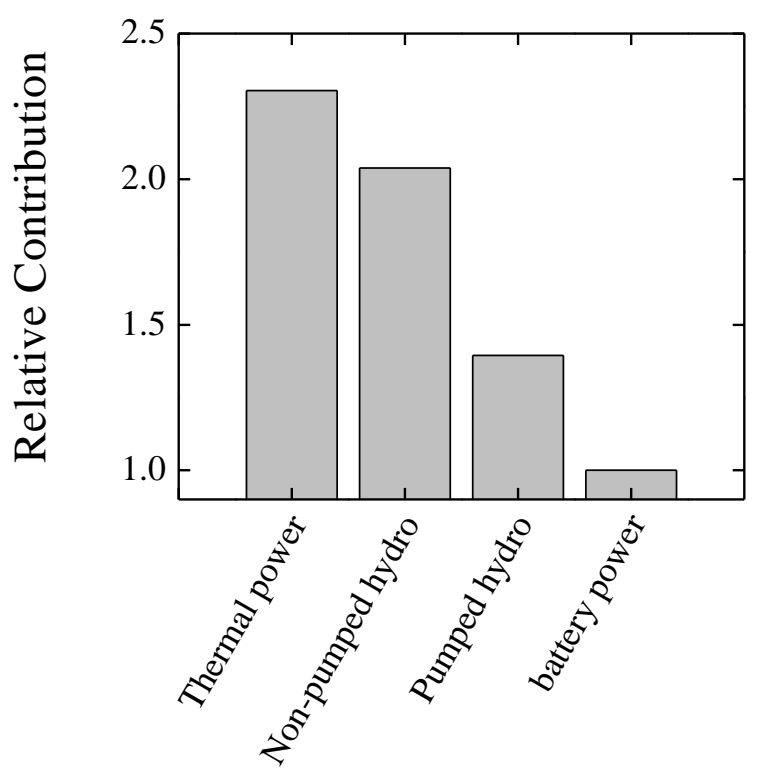

Figure 3.26. Response to Question 18: "Please rank the following in regard to which technology is most likely to make the biggest contribution towards new-build backup power capacity in New Zealand up to 2025 . Please use a scale of 1 to 4 , where 1 has the greatest potential. Please continue to assume that there will be no new discoveries of largescale and easily accessible natural gas fields prior to this date.

GO2 made the distinction, however, between six-minute and six-second FIR and they provided an alternative rating system which considered only the market for six-second FIR. In this case, the order of likelihood to contribute was (1) interruptible load [added by informant - see discussion for details], (2) battery power, (3) pumped hydro electricity, (4) thermal power/non-pumped hydropower. This is clearly the reverse of the trend noted above. Figure 3.27 lists those technologies that were given in response to Question 19 (are there any other energy storage technologies that could be examined) and the frequency of listing. The potential for energy storage via a smart grid and EVs was noted by four of the respondents, although none were able to provide a timeline for its introduction. None specified a date prior to 2025. The use of hot water heaters as an interruptible load heat-storage solution was also noted even though such a system already exists in NZ. (INDIV8 expressed the opinion that this source of interruptible load has been "running down" due to the format of the electricity market.)

\subsection{Semi-structured interview}

Tabulated summaries of the responses of those informants $(n=$ ten $)$ that contributed to the research via interview ${ }^{23}$ are given in Appendix G, where the data are presented in the (numerical) order of presentation by the informant. For brevity, the following sections provide a summary of the details that can be found in Appendix G.

\footnotetext{
${ }^{23}$ INDIV8 chose to respond in writing and did not provide an oral response.
} 


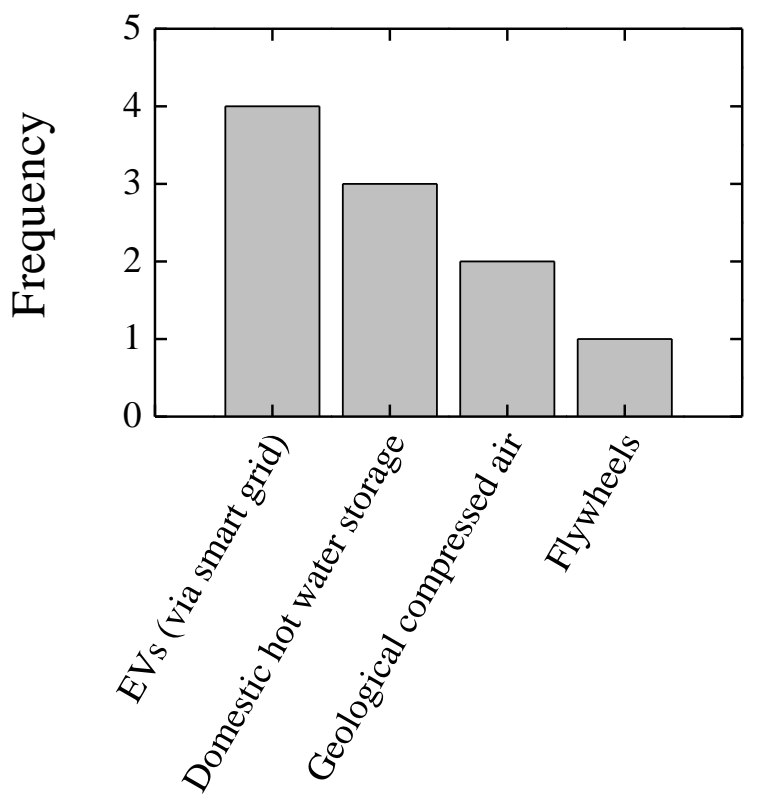

Figure 3.27. Response to Question 19: "Is there another new form of utility-scale energy storage that could be examined for application to the New Zealand electricity sector? If so, please specify."

\subsubsection{Framework of themes and responses}

Theme A: The value of energy storage to the NZ electricity system

Question A1 - Current benefits of energy storage: "Please describe 2 or 3 of the main benefits that renewables-based utility-scale energy storage currently provides to the electricity system."

Every respondent independently noted (Table AG1) security of supply as being one of the primary benefits to the electricity system and security of supply was, with the exception of one respondent, the first benefit to be mentioned. The benefit to the economy was also noted in all but two instances, and was the second most common factor mentioned and was noted by eight of the ten respondents. Many respondents considered that security of supply and economic effectiveness were strongly linked, as economies of developed countries, are fundamentally dependent on electricity supply and the adequate matching of demand with supply was perceived to be essential to the economic well-being of NZ.

Less than half of the respondents cited the $\mathrm{CO}_{2}-$ e emissions-saving benefit of lake-based hydro-storage. The technical benefits associated with ancillary services such as voltage and frequency support and fast-start back-up response capability of existing hydro-based systems were submitted by four of the respondents. 
Question A2 - Future benefits of energy storage: "If the capacity of renewables-based energy storage could be greatly expanded to meet all of the needs of the system, what could be the main benefits to the electricity sector?"

Only six respondents stated that further increasing the level of energy storage would improve upon security of supply, such as improved resilience to dry-year events (Table AG2). When those respondents who had not remarked upon this issue were prompted to comment on it, they generally considered that the existing hydro-storage capacity was physically adequate but inadequately managed.

However, five respondents specifically commented that there would be potential to reduce the need for thermal reserves, and a further two respondents directly illustrated this opportunity by indicating that where would be an opportunity for $\mathrm{CO}_{2}-e$ emissions-saving. Two respondents also directly noted the opportunity to improve the integration of variable renewables up to and beyond a $20 \%$ energy contribution. These three categories are again assumed to be closely linked in regard to the potential of increased level of energy storage capacity to improve the sustainability of the electricity sector.

One respondent (GO3) assumed that an increased capacity of energy storage, would improve the flexibility of the system. This respondent noted that flexibility has significant economic benefit to generators [flexibility will also improve resilience of the system [229,230]]. NGO2 assumed that an elevated capacity of storage would improve reliability, albeit with the caveat that the probable costs of introducing $100 \%$ reliability would be unsupportable.

Other potential benefits that were mentioned included: reduction of fossil fuel price uncertainties, improved plant longevity (pumped hydro only), offsetting of transmission upgrades, local air quality improvements, conservation of petrochemical resources, and moderation of market volatility and electricity price spikes linked to hydro inflow rates.

\section{Theme B: The likely proportion of thermal generation used for backup by 2025}

Question B1 - The likely contribution of future thermal reserves: "Do you respond in the questionnaire that more thermal backup power (such as peaker capacity) is more likely to be to be introduced than new forms of renewable energy storage such as pumped hydro? If so, why. Or if not, why not?"

Again, despite that fact that all informants were reminded to consider a scenario where there were no new large-scale discoveries of easily accessible gas, most (eight of ten) respondents continued to assume that thermal generation would be the primary source of energy for the backup applications considered in this research (Table AG3). Six directly noted that this is 
likely simply as the industry perceives that thermal is most likely to be the more cost-effective option.

Other potential drivers of thermal back-up plant mentioned by one or more of the respondents include: the high value of thermal power for fast-start reserve generation, low visual impact, "trivial" local air-quality issues, flexibility in site section, "well understood and established", ease of RMA processing and political support for thermal generation.

GO3 noted that there is a perception within the industry that thermal is passively supported by public opposition to renewables-based projects, especially as developers can "hide" thermal plant within enclosures. INDIV3 also considered that thermal capacity is often introduced "under the radar" of public opposition, which is supported by the absence of media commentary. Conversely, it was proposed that the media presents hydro in a negative fashion and at such an intensity that politically motivated individuals within central government intervention (which further intensifies negative public perceptions).

GO3 specifically noted that hydro projects can take ten-fifteen years to be completed. This could include ten years for RMA consent followed by four years of construction (The example of the Mokihinui hydropower scheme was used as illustration). In contrast, a typical thermal-based RMA consent process was assumed to average < two years..

One of the respondents who did not assume that thermal capacity would be the main energy source (INDIV2) reasoned that hydro currently used for base load will be displaced by generation from wind and geothermal sources. This would negate the need for new thermal reserves. $^{24}$

In response to the sub-question to B1: "Can you describe what you think are the benefits and the negative aspects of a greatly expanded capacity of thermal backup?", the informants provided a range of answers, some of which have already been discussed (benefits: Table AG3; negative aspects: Table AG4). All informants who responded said that $\mathrm{CO}_{2}$-e emissions is a negative aspect new-build thermal backup. In three instances, this was the only negative aspect provided, despite prompts for further input. Fuel supply/fuel price uncertainties was only noted by four of the respondents to be a drawback and only two individuals noted that petrochemicals currently have intrinsic value as chemical feedstocks and should be reserved for the long term benefit of society.

\footnotetext{
${ }^{24}$ This was a commonly proposed scenario, which is described further in Section 4.
} 
Question B2 - The likely impact of the prices of carbon and petroleum: "Do you think that the price of $\mathrm{CO}_{2}-\mathrm{e}$ and oil-price uncertainty have the potential to stop investment in thermal backup generation by 2025?"

Given the difficulties in projecting physical, political and economic drivers affecting the price of $\mathrm{CO}_{2}$-e and oil up to 2025 , there was understandably some considerable uncertainty associated with the range of responses to this question. Responses of 'I don't know', or 'possible' was expressed by four of the respondents. Regardless, as can be seen in Table AG5, there was some deviation of opinion relating to the current effectiveness of $\mathrm{CO}_{2}-\mathrm{e}$ pricing. For example, GO3 noted that the ETS is currently supporting the potential introduction of energy storage. INDIV4 also noted: "[t]he ETS is useless at the moment."

In regard to the future, only two respondents provided, in strong terms, the opinion that investment in gas-based thermal backup (including peakers) would not likely be affected up to 2025. However, NGO2, INDIV1, INDIV4, INDIV5 and INDIV6 all expressed opinions that diesel combustion is likely to be negatively affected by the international price of oil. NGO2 expressed an 'I don't know' in respect to the impact on gas peakers, but assumed that gas base load would be affected. Indeed, only two respondents reported that gas-based peakers could be significantly affected.

Those who expressed an opinion that the cessation of investment in all forms of thermal backup may be 'possible' noted that relatively high $\mathrm{CO}_{2}$-e prices of INDIV1: NZ\$200-300 (INDIV1) and NZ\$200 tonne ${ }^{-1}$ (INDIV4) would be necessary. Six out of ten assumed that price of $\mathrm{CO}_{2}$-e could have the potential to influence the development of the reserve generators, albeit at $<\mathrm{NZ} \$ 300$ tonne $^{-1}$.

The very low $\mathrm{CF}$ of reserves was assumed by GO2, NGO2 and INDIV2 to indirectly support the introduction of thermal backup plant. Here, the capital costs are the primary consideration (not fuel and emission costs) and the economic value of the service is very high. An unexpectedly rapid introduction of EVs was also noted by INDIV1 to have the potential to encourage the introduction of new thermal backup, especially if the sector is unready to adapt.

\section{Theme C: The management of dry-year events using pumped hydroelectricity}

Question C1 - Past performance in regard to dry-year security of supply: "In the past, have the institutional arrangements for security of supply during extremely dry years been wholly adequate?"

As illustrated in Table AG6, all respondents indicated that the previous arrangements had been inadequate. Moreover, although no "black-outs" (NGO2) or "disasters" (INDIV5) had 
occurred, GO3 and NGO2 assumed that dry-year conservation measures would have negatively impacted upon the NZ economy. The utility of Whirinaki Power Station was also specifically assumed (NGO2 and INDIV4) to have not been ideal and there was lack of incentives for the generators to consider security of supply over economic efficiency [i.e., holding hydro in reserve, at the expenses of spillage mitigation] (GO3, GO2, INDIV1, INDIV3, INDIV6). Other issues included: a lack of effective modelling of the existing hydro schemes and a lack of demand-side planning.

In response to the prompt: "how could the management of the system be improved in regard to dry year events?", most of the Government organisation-based respondents and NGO2 and INDIV2 assumed that the changes that results of the Ministerial Review of Electricity Market Performance (2009) [26] is likely to improve the situation, mostly through incentives favouring less risk-taking and the promotion of 'security of supply' over 'efficiency'. INDIV5 presented a case that the solution could be partly infrastructure (storage/peakers) and improved DSM.

When asked: "will an increase in electricity demand still make the situation more difficult to manage?", GO2 and INDIV5 postulated that demand growth will not increase the problem, as the extent of storage will remain relatively constant. The primary issue was noted to be if enough non- hydro-based capacity can be built to meet this demand (although, there should not be an increased dependency on wind, if the CF of the latter is correlated with former). Conversely, NGO2 promoted additional wind capacity and price signalling to encourage demand shifting. However, INDIV2 and INDIV6 specifically projected that dry-year problems could increase, with a continuation of the trend of dependence of fossil fuels, especially under a weak price on carbon.

Question C2 - Pumped hydro and future dry-year security of supply: "Do you think that most, if not all, of the negative aspects of dry year events could be mitigated through the use of large-scale pumped hydro, for example?"

Although there was unanimous response in regard to the poor performance of the recent history of dry-year security of supply, there was considerable deviation regarding the question of whether introduced forms of energy storage could contribute towards the solution (Table AG7). Although most respondents provided caveats, two replied that it could be feasible in NZ. Three replied that it could not and five replied that it was "possible".

The main barrier that was noted by eight of the ten informants was the perception of unfavourable economics of very large storage systems. INDIV2 and INDIV8, for example, assumed that, although a storage facility of the size of the Manorburn-Onslow proposal would 
be required, this particular proposal would not be cost-effective (note, however, that INDIV2 assumed that an economic assessment was not available for this proposal). Uniquely, INVID8 pointed out that, due to the competitive nature of the market, generators may simply increase the spot price when pumping is known to be occurring.

In response to the prompt: "[w]hat is stopping the electricity sector from doing this?", many again pointed to the economic cost and the lack of market incentives that promote security of supply over economic efficiency. Many others assumed that new wind, geothermal and thermal coupled with the more effective management of existing hydro could to compensate for dry-year events to 2025 .

INDIV4 postulated that "[ $\mathrm{t}]$ he generators and investors are in the business of building new generation" and as long as investors can continue to burn gas, they will not look at alternatives. Indeed, INDIV3 and INDIV6 considered that short-term thinking was a considerable barrier, as long-term thinking is essential for the success of pumped hydro. This is important, as there are short-term uncertainties associated with the attraction of a reasonable rate of return $(\mathrm{GO} 2)$.

The local environmental impact of pumped hydro (assumed to be equivalent to non-pumped hydro) and RMA timescales and uncertainties, were again given as significant drawbacks.

When asked "What can be done to make energy storage more attractive for dry year management?" GO2 noted that an increase in electricity prices (especially diurnal difference between peak and non-peak). GO2 also noted that the cost of storing and generating from coal-based reserves at the aging Huntly units (especially under a significant price on carbon) maybe key to the cost-competiveness of pumped hydro options (although the use of thermal peakers may also be cost-effective for dry-year supply when prices reach extreme levels).

In response to: "Could this be a free market problem? Does the government need to act?" four of the respondents denied that this (GO3, NGO2, INDIV1 and INDIV5). GO2 did not respond. The remaining five (all 'individuals') assumed that the potential of energy storage could be negatively affected if the current structure of the market continues.

\section{Theme D: The potential energy savings from the reduction of hydro spillage}

Question D1 - The extent of hydro spillage in NZ: "Is hydro spillage a serious issue in terms of energy losses from the system?"

Question D2 - The extent of savings from spillage: "How much money (or energy) can be saved from the sector (or individual hydro lakes) through spillage mitigation?" 
The respondents were informed (excluding INDIV8) that only spillage that results from (1) high inflow rates or (2) low wholesale price of electricity should be considered, for example, spillage that forms a component of the resource consent were not included. The majority of the respondents (seven of ten) did not think that hydro spillage is currently a serious issue in NZ (Table AG8). In these instances the respondents assumed that none to very little economic benefit could be gained from redirecting these losses. Moreover, the limited number of who though that the savings could be beneficial could not quantity the relative extent of the savings. Generally, the informants noted that, when averaged over the long term, volumes of spillage are low and short term events are not indicative of long-term trends. Indeed, respondents GO3, INDIV4 and INDIV6 (two of which answered 'no' to QD1) noted that the current trend of maximising efficiency over security of supply has resulted in relatively low spillage rates. Increased incentives for the latter and a requirement for fast-start capacity to support variable output renewables, however, could result in a reduced focus on efficiency and more spillage. ${ }^{25}$

In response to: "[c]ould these savings be used to pay for the costs of storage?", the majority of respondents noted that this would be unlikely at the present time.

Respondents were then reminded of the large amount of spillage that was experienced in NZ during early 2009 (Section 4.2). Six respondents assumed that such events did not occur at a high frequency and that access to this spilled energy would be too uncertain for investors. GO2 and NGO2, for example, explained that these events were an unusual combination of Tiwai Point smelter down-time, high inflows and limited capacity to transfer energy to the northern demand centres. GO2 assumes that the current Pole 3 upgrade of the HVDC link will soon enable excess hydro energy to be redirected, at least over the medium term.

Theme E: The state of development of introduced forms of energy storage in NZ

Question E1 - Current status of introduced energy storage: "Do you know if your organization/the electricity sector has considered introducing renewable energy storage such as pumped hydro and batteries?

When questioned about progress, four of the respondents (GO2, GO3, INDIV2, INDIV3) discussed the Manorburn-Onslow proposal of Bardsley et al. [77-81,223,224] (Table AG9). All noted that the project was curtailed by unfavourable economics. INDIV8 also noted that the pumped hydro project proposals that they had personally contributed to (projects not named) were uneconomical, especially given the current status of the electricity market.

\footnotetext{
${ }^{25}$ Author note: in the future, therefore, lakes could be maintained at higher levels relative to the present day leading to more regular spillage events after occasional, unexpectedly high inflows.
} 
INDIV3 concluded that more attractive alternatives included the use of existing lakes to increase storage capacity (for example, a Tekapo pumped hydro scheme and/or modification of the Lake Hawea consent limits). However, neither had been examined in detail.

GO3 noted that it was their understanding that Meridian had previously funded an energy storage study in 2007/2008 with EPRI (USA). This feasibility study examined options for the $\mathrm{NZ}$ market, including the support of wind variability. Although the report/s associated with this study are not publically available, GO3 noted that Meridian's interpretation was that there are no cost-effective utility-scale applications currently available in NZ. Again, the promotion of a security of supply-based paradigm over efficiency again was considered to be more cost-effective.

Generally, it became clear that detailed knowledge of the actual cost estimates was limited to only three the respondents who were questioned. For example, only two of the respondents appeared to have any knowledge of the fact that the EC had funded an external consultant to estimate the economic cost of the Manorburn-Onslow proposal and that these results are now available from the EA. Most respondents were also not able to provide a recollection of formal investigations into utility-scale batteries in NZ. Moreover, those studies that were mentioned by the respondents had either (1) not been widely circulated and were unavailable or (2) remained confidential.

In response to the sub-question: "Do NZ-new types of utility-scale energy storage technologies have a future in NZ?" (Table AG10), most informants assumed that introduced forms of energy storage currently to not have an immediate role to play in the electricity system. However, seven assumed that the storage would be introduced at some point in the medium to long term (GO3, INDIV6) or only in the long term (NGO2, INDIV1, INDIV2).

GO2 noted that utility-scale batteries may be introduced more quickly than many commentators would expect, simply because six-second FIR market. INDIV3 also argued for an opportunity associated with the use of existing canals as pumping conduits (for example, using Lake Tekapo as a storage facility).

Regardless of the timescales quoted, most assumed that the relative cost-effectiveness of energy storage will have to improve before these technologies are considered. NGO2 summarised their response to this question by noting that introduced energy storage will be the last step in the security of supply risk management plan (after all other options have been exhausted). A point of view shared by the many of the informants.

Question E2 - The potential for rational decision making in the sector: "If the long run marginal cost of electricity from pumped hydro or batteries can be proven (by a number of 
sources) to be similar to thermal backup, would your organization/the sector consider investigating further?"

The majority of responses to this question were in support of investors making a "rational decision" based purely on economic considerations (Table AG11). INDIV1 noted that the generators are likely to be "fuel agnostic", a view apparently shared by GO2, GO3, NGO2, INDIV2 and INDIV5. Regardless, INDIV6 thought that there could be distortion of an objective decision making process as a result of the non-ideal format of the market and the vested interests of some participants, where: "[t]he sector is planning to obstruct change, not to create it". Moreover, INVID3 warned that, given an equal footing, thermal would be favoured through the passive support of the public and, therefore, political motivations. Furthermore, INDIV3, INDIV4 and INDIV6 all assumed that spontaneous innovation would most likely not come easily to most investors and either (1) a number of influential individuals within the industry, or (2) government regulation would be necessary to legitimise the process. INDIV8 concluded that "[t]he current design of the electricity market is the main barrier to pumped storage."

\subsubsection{Emergent themes}

\section{The Manorburn-Onslow proposal is impracticable}

The successful operation of the Manorburn-Onslow pumped hydro scheme would be entirely dependent on the operational characteristics applied by the owners (INDIV6). The owners may not "choose" to manage it to deal with dry year events (for example, the owners may choose to take advantage of intervening price spikes to ensure a profit). The ManorburnOnslow proposal is also expensive (GO2) at "two billion to build it and another billion to fill it up with water". By comparison, a coal plant, for example, was noted to be cheaper and have certain short-term revenue stream.

\section{Huntly Units 1-4 have limited longevity}

The fate of Huntly units was noted to be relatively certain. Huntly Unit 4 is already limited to dry-year generation (GO3) and Genesis have indicated that all four units are becoming less economic and are unlikely contribute to NZ's long-term future (NGO2). NGO2 claimed that an increasing proportion of wind could supply "dry-year assurance" in Huntly's stead, and GO2 stated that the Manorburn-Onslow pumped hydro system would theoretically enable the coal/gas-based units to be decommissioned by 2025 , while maintaining dry-year security of supply. 
Existing hydro can be used for wind integration and peaking adequacy

GO2, GO3, INDIVI1, INDVI2 and INDIV6 all noted that the existing system could manage the integration on up to approximately $20 \%$ wind power and very little new storage would be required. To achieve this, a certain proportion of the existing hydro currently used for 'base load' supply must be displaced by geothermal power, marine power, thermal or wind power. GO3 also indicated that it was their understanding that Meridian is examining a case where an overcapacity of wind capacity is built into the system. Here, the excess can be allowed to spill until compensation for moderate wind variance and/or ancillary services, such as a FIR, is called for. The maintenance of this reserve may be cost-effective if the value (price) of the service is high. ${ }^{26}$

\section{There is a need to consider security of supply over economic efficiency}

GO3 noted that currently the existing hydro resources are used by the generators through "the most efficient means possible", i.e., hydro spillage is reduced to a minimum. Management of the system to ensure security of supply has been a lesser consideration and the maintenance of high lake levels (reserves) has not dominated, as inefficiency (spillage) could result if unexpectedly high inflows occur over the short term. A balance needs to be struck and monetary value should be added to security of supply. This may come to fruition via penalties imposed by the Electricity Industry Act. Moreover, an increasing proportion of must-run renewables (wind, geothermal and run-of-river hydro) would also result in increased spillage as a result of a requirement for a spinning hydro reserve. However, both GO2 and GO3 projected that the volume of spillage will be limited by the Pole 3 HVDC upgrade (as noted above).

When questioned further, GO3 agreed that, technically, all excess spillage could be stored, although "1,000 h per year of spillage" may be required for economic viability. In addition, INDIV1 noted that hydro spillage is also a resource lost to other stakeholders, such as farmers and industry. The value of this resource use, however, would be difficult to quantify.

\section{There are alternative pumped hydro sites and other hydro-based storage options}

INDIV3 noted that the introduction of pumped hydro capacity at existing lakes (for example, pumping from Lake Pukaki via the existing canal to Lake Tekapo (at the top of the Waitaki System) would be more cost-effective. These lakes are already connected and the amendment of existing consent process will incur lower costs and would more timely than introducing a

\footnotetext{
${ }^{26}$ Author note: the spillage from this additional capacity could be stored using batteries and pumped hydro, thus, potentially increasing the economic viability of this concept.
} 
stand-alone facility. However, after the Electricity Industry Act transferred Tekapo A (Lake Tekapo), Tekapo B (Lake Pukaki) and the interconnecting canal to Genesis, the level of cooperation required with Meridian, which operates the downstream power stations, may be now be a considerable barrier to pumped storage at this location. Contact has also presented some interest in examining the economic and physical feasibility of pumping from Lake Wanaka to Lake Hawea [231].

Both INDIV2 and INDIV3 also discussed the potential of Lake Hawea, which already acts as a storage release system for Contact's Clutha hydro scheme [232] and has a consent for a 17 MW power generator [233].) Currently, the storage capacity of this lake is resource-consent limited, which has effectively halved its storage capacity.

\section{The performance characteristics of batteries is uncertain}

The comments received regarding the characteristics of batteries were rather wide ranging in scope and a consensus was not received. For example:

- batteries are likely to be "a last resort" in $\mathrm{NZ}$ and, in terms of potential environmental impact, are a "big, toxic accident waiting to happen" (INDIV5),

- "Battery storage is fundamentally expensive and can only handle short-term demands" (INDIV8),

- the physical footprint and visual impact is likely to be similar to thermal power station, but cannot replace a thermal backup plant for dry-year reserve, such as Whirinaki [in its previous role] (INDIV2).

- batteries have high capital costs, but the service that can be provided in regard to < sixsecond FIR have higher intrinsic value than these costs (GO2).

Low capacity factors may moderate the impact of fuel price uncertainties

Uncertainty associated with gas supply has significance for base load generation, but less for low-CF peakers (NGO2). For example, Contact has had consent to build a new gas-based combined cycle gas turbine (CCGT) at Otahuhu for a number of years, but are not likely to initiate construction until price volatility reduces (NGO2). The CFs of some existing gasbased base load plant are also dropping (NGO2 \& INDIV2). 


\section{Discussion}

\subsection{Introduction}

The discussion reviews the results of the survey and briefly addresses the perceptions of the respondents in regard to energy storage in NZ. Both the perceived drivers (Table 4.1) and barriers (4.2) to the introduction of $\mathrm{PH}$ and batteries are reviewed and critically analysed in Sections 4.2 and 4.3, respectively. The relative advantages and disadvantages of $\mathrm{PH}$ and batteries (as reported by the survey respondents) are also given in Table 4.3. A considerable amount of detail relevant to this discussion is also presented in the results of the desk-based review (Section 3.1).

Although a number of fundamental themes can be drawn from the results of the survey, a complete consensus of opinion was rarely obtained from the respondents. It is recommended, therefore, that the reader continue to refer to Sections 3.2 and 3.3 for details of the individual responses.

\subsection{Perceived drivers}

\section{Electricity demand, supply-side bias and centralised generation}

All but one respondent concluded that large-scale power stations will continue to be built to meet increasing growth in consumer demand (including peak demand). This is also reflected in the NZ-based literature, which almost universally considers that centralised capacity will be necessary for the maintenance of reserves [19,20,33,71,86,234]. Moreover, in regard to electricity supply and demand, NZ does not have a strong recent history of DSM, energy efficiency or conservation, (Section 3.1). Thus, although the sector is currently biased towards large-scale, centralised solutions based on thermal power, the above could also act as a market driver of alternative utility-scale forms of energy storage; especially if shown to be economically viable.

Market volatility, security of supply and the Ministerial review of Electricity Market Performance

Wholesale electricity price volatility was noted to be a significant issue for the electricity sector and the Ministerial Review was quoted on number occasions as the instrument which is most likely capable of moderating future volatility and improving future security of supply (thus negating the need for added energy storage). To date, the dispatch of thermal-based reserves during dry-years has been largely managed through the non-regulated, electricity market response to the fluctuating spot price of hydro power. As noted above there was a 
growing consensus of opinion that gentailers were profiting significantly from the high wholesale spot prices of electricity that can result as direct result of a lack of storage in NZ [11,235], poor management of resources and a lack of investment in reserve capacity $[11,236-$ 238]. A significant increase in the capacity of energy storage in NZ is likely to reduce this market volatility.

Table 4.1. A list of primary drivers (perceived) of PH and utility-scale batteries, as identified from the survey results presented in Section 3. The data are not presented in order of significance.

Economic, market and policy factors

D1 The current supply-side bias of the sector and a sectoral focus on the development of MW-scale, centralised power sources indicates that, given current trends, the industry is most likely to favour MW-scale utility investments over mini- and micro-scale solutions. Coupled to an almost universal perception that there will be continued growth in national electricity demand through to 2025 (and possible restrictions in gas, petroleum and hydro-based resources) it is likely that a variety of different utility-scale energy sources and risk management plans will be considered by the sector.

D2 There are economic benefits to the sector associated with improved dry-year security of supply and reduction of market volatility and flexibility of power sources.

D3 The Ministerial Review of Electricity Market Performance may be effective in leading the market towards a framework that favours 'security of supply' over 'efficiency'. Moreover, in the opinion of GOs and their employees, market participants have a technology-neutral stance in regard to the introduction of cost-effective solutions

D4 The potential for increases in the frequency of global 'oil shocks' may drive sector investments away from diesel generation and towards renewables-based generation and storage (especially if gas supply is also constrained)

D5 On average, at $\mathrm{NZ} \$ 30$ [ $\mathrm{CO}_{2}$-e] per tonne, $\mathrm{NZ} \$ 10$ [gas] per GJ and $\mathrm{NZ} \$ 50$ [diesel] per GJ respondents assumed that PH would most likely be economically competitive with diesel-based reserve power sources by 2025. Moreover, most respondents assumed that a price of $\underline{\mathrm{NZ} \$ 100}\left[\mathrm{CO}_{2}\right.$-e] per tonne would further improve this outlook.

\section{Environmental factors}

D6 There is a political and environmental need to reduce $\mathrm{CO}_{2}$-e emissions from the electricity sector

D7 Energy storage technologies are perceived to be capable of supporting climate change adaptation in NZ

\section{Technical factors}

D8 Batteries can contribute to the supply of the high-value six-second FIR in NZ

D9 There is most likely to be a requirement for fast-start capacity for the support of variable-output renewables

D10 Further business-as-usual development of existing forms of renewables-based generation may not be capable of preventing dry-year events in the absence of Huntly Units 1-4. An alternative large-scale power source(s) will be required to mitigate dry-year events

D11 There may be a potential requirement for wind spillage storage if an over-capacity of wind-based power is built by generators, such as Meridian

D12 If 'security of supply' is favoured over 'efficiency', there is a potential for an increased frequency of hydro spillage events. This may increase the relative cost-effectiveness of $\mathrm{PH}$, for example 
Table 4.2. A list of primary barriers (perceived) of PH and utility-scale batteries, as identified from the survey results presented in Section 3. The data are not presented in order of significance.

\section{Economic, market and policy factors}

B1 There is an almost universal perception that PH and batteries are currently not cost-effective

B2 The Manorburn-Onslow proposal (currently NZ largest-known PH proposal) was not favoured by the majority of respondents

B3 Vested interests of market participants is a potential barrier (variation of opinion received)

B4 There is a current lack of diurnal electricity price variation/price signalling that could increase the costeffectiveness of storage

B5 Short-term thinking by investors, coupled to a potentially unstable rate of return, could be primary factors limiting investment in reserve solutions other than those based on natural gas. Medium to longterm thinking is likely to be essential for the success of PH schemes

B6 There is a current lack of market incentives for the hydro-based generators to consider the promotion of 'security of supply' over 'efficiency'

B7 There is considerable uncertainty regarding the potential of the price of carbon and/or oil and gas to reach adequately high values to render thermal reserve power sources uneconomic

B8 The potential for the discovery of new and easily accessible natural gas fields over the short to medium term may be delaying industry analysis of alternative solutions. There is also uncertainty regarding the timescale of introduction of distributed energy storage via EVs and a smart grid

B9 The low required CFs of reserve power sources in NZ would generally reduce the cost-effectiveness of $\mathrm{PH}$ and batteries

B10 The current format of the NZ electricity market is a barrier to innovation (attributed to non-GOs only), as effective inter-generator co-operation and additional government regulation would most likely be essential for the operation of large-scale energy storage programmes

\section{Environmental factors}

B11 Hydroelectricity facilities are perceived to be associated with significant levels of negative local environmental impact

B12 There some variation of opinion among the respondents in regard to the intensity of the environmental impact of batteries

B13 Renewables-based RMA/Environmental Court consent processes are usually more complex and take longer than thermal projects. The latter, therefore, is favoured in this respect

\section{Technical factors}

B14 Perceptions exists amongst many in the industry that batteries are an emerging technology and not market-ready

B15 There is a strong perception that, over the short to medium term, there will be potential for the existing capacity of hydro storage to be 'freed-up' for reserve applications. In theory, this could be achieved by significantly increasing the share of generation from other baseload sources, such as wind and geothermal

B16 There is currently very little energy saving potential associated with hydro and wind spillage events

B17 Commercially sensitive reports on the potential of energy storage in NZ are not available to the sector at large 
Table 4.3. Comparison of the perceived advantages and disadvantages of PH and utility-scale batteries identified from the responses of the informants to the survey. Only the majority of opinion is shown (for a higher resolution description, see Section 3).

\begin{tabular}{|c|c|c|}
\hline \multirow[t]{2}{*}{ Parameter } & \multicolumn{2}{|l|}{ Majority perceptions } \\
\hline & $\mathbf{P H}$ & Batteries \\
\hline Technical effectiveness & $\begin{array}{l}\text { Effective: peaking, intermittency } \\
\text { support, dry-year reserve \& spillage } \\
\text { mitigation }\end{array}$ & $\begin{array}{l}\text { Effective: peaking, intermittency } \\
\text { support, spillage mitigation \& } 6 \text { s FIR } \\
\text { (excludes dry-year seasonal reserve) }\end{array}$ \\
\hline Mean cost estimate & $\begin{array}{l}\text { Relatively low (comparable with diesel) } \\
\text { Mean estimate: NZ\$590 } \pm 167 \mathrm{MWh}^{-1} *\end{array}$ & $\begin{array}{l}\text { Lowest of the options examined } \\
\text { Mean estimate: NZ\$1,089 } \pm 303 \\
\mathrm{MWh}^{-1} *\end{array}$ \\
\hline Likely contribution by 2025 & Low to nil $\dagger$ & Very low to nil $\dagger$ \\
\hline \multicolumn{3}{|l|}{ Congruence with NZ's: } \\
\hline Electricity market & Varied opinion received & Varied opinion received \\
\hline Skills and knowledge & Advantage & Disadvantage \\
\hline $\begin{array}{l}\text { Transmission } \\
\text { infrastructure }\end{array}$ & Varied opinion received & Advantage \\
\hline $\begin{array}{l}\text { Centralised power } \\
\text { sources }\end{array}$ & Advantage & Advantage \\
\hline Market readiness & Advantage & Disadvantage \\
\hline Local environmental impact & Disadvantage & Advantage \\
\hline $\mathrm{CO}_{2}$-e mitigation & Advantage & Advantage \\
\hline Climate change adaptation & Varied opinion received & Advantage \\
\hline Flexibility of site selection & Disadvantage & Advantage \\
\hline Power capacity potential & Advantage & Varied opinion received \\
\hline Energy capacity potential & Advantage & Varied opinion received \\
\hline
\end{tabular}

* Estimates ranged from: NZ\$0-1,570 $\mathrm{MWh}^{-1}(\mathrm{PH})$ and $\mathrm{NZ} \$ 131-2,000 \mathrm{MWh}^{-1}$ (batteries).

$\uparrow$ Assuming no new discoveries of large-scale and easily accessible natural gas fields prior to 2025 .

The essence of the recommendations of the 'Ministerial Review' [26] passed into law as the Electricity Industry Act 2010 [239] (September 2010). With the resulting dissolution of the EC in favour of the EA (1 November 2010 [240]) and numerous other changes (see below) market incentives are likely to have been modified. However, given that the majority of the changes were adopted after October 2010, and no replacement dry-year reserve emergency plan has ever been implemented, there is very little practical data available for discussion here. Regardless, the EA (and a number of the respondents) currently assume that the Act will support the improved management of the existing energy storage and further investments for the improvement of security of supply [133]. However, as respondent GO3 noted in response to the survey, this is likely to be at the expense of economic 'efficiency', at least in a narrow sense of efficiency. 
The Ministerial Review (2009) was developed by the Minister for Energy and Resources, the MED, an Electricity Technical Advisory Group (E-TAG) and Concept Consulting Group [132]. It suggested twenty nine changes to the sector (some of which required legislation). Reportedly [19,24,132,241,242], it was largely undertaken to:

- reduce electricity prices through increased competition,

- improve security of supply,

- aid investments in transmission, and

- improve electricity market governance.

This included key changes of significance to this research, such as:

- reconfiguration of hydro-based SOE assets,

- abolition of the reserve energy scheme and sale of Whirinaki Power Station

- retailers to make payments to consumers during dry-year conservation or black-out events,

- a floor on spot prices during conservation events (to stimulate operation and investment in high value reserve generation)

- a review of the RMA with regard to significant new generation projects

- promotion of gas-field exploration, and

- introduction of the Security and Reliability Council

The EA will now manage the Security and Reliability Council, which, according to The Act must meet at least once every six months in order to monitor and provide advice to the EA on System Operator and electricity system performance and security of supply in general. The draft Energy Strategy stated that:

"The Government proposes to phase out the reserve energy scheme and ensure that market participants have clear incentives to manage risk" [21].

The Ministerial Review also introduced a liquid hedge market that supports standardised tradable contracts and aims to reduce barriers to more competitive levels of participation [235].

The sale of Whirinaki appears to follow the recommendations of an investigation published by Poletti [121]. Poletti modelled the impact of government-owned peaking capacity within an electricity sector including generators with market power. The results indicated that less peaking-generation capacity would be built by generators if the government continued to own its own reserve plant. It was proposed, therefore, that the costs of reserve generation (which are considerable, Section 4.3) be transferred from government subsidy (the tax payer) to the 
electricity consumer, which, it must be said, is more likely to improve the legitimacy of the payments. However, it is not clear if the proposed solution will lead to optimal levels of provision of energy security.

It is again clear that alternative forms of reserve generation, including introduced forms of energy storage, if cost-effective, could be stimulated by the outcome of the Ministerial Review, even if not directly considered in the output. However, the perceived importance of natural gas discoveries and thermal generation appears to be of primary significance to the government and its agencies, at present.

\section{Flexibility of power sources}

Flexibility of power sources increases system resilience and can reduce risks associated with the management of power production and security of supply [243]. A specific advantage of PH and/or batteries also includes the supply of a number of high value dispatchable services within the market. The use of non-thermal sources also eliminates the economic risk associated with operating thermal resources under the NZ ETS.

\section{Fuel price uncertainty}

Although Parliament has now acknowledged that NZ is likely to continue experiencing both 'oil shocks' and a general increase in oil price as a result of international petroleum supply restrictions [244], the price of oil may only have a small direct impact on electricity generation characteristics. This is because NZ currently only has a single grid-connected diesel reserve generator (Whirinaki) [245]. However, there is a risk of global (and domestic) recession associated with each oil shock [244], which will most likely reduce electricity demand (although the introduction of EVs may moderate this outlook [20,246]). However, the MED assumes that the numbers of $150 \mathrm{MW}$ diesel-fired peaking generators are likely to increase [99].

\section{GHG emissions reduction and the price of carbon}

As noted in detail in Section 3.1, introduced forms of energy storage, such as PH and utilityscale batteries, have relatively low to negligible operational emissions and they are now displacing (at least partially) the requirement for new-build thermal reserves in countries such as Japan and the USA. As also indicated by the results of the desk-based study and the survey, a high price on carbon will certainty act as a driver of these technologies. 
Six-second fast-instantaneous reserve

Batteries are proven sources of FIR reserve/backup services and other ancillary services [74,247,248]. The power response time for the all-vanadium battery in standby mode is relatively instantaneous (for example $350 \mu$ s [247]) and the NaS battery has similar performance characteristics. When not in stand-by mode, most flow batteries can be rapidly primed to achieve complete operational capacity within minutes simply by pumping the precharged electrolyte into the empty cell compartments of each cell stack [28]. Enclosed systems, such as the NaS battery, do not require priming.

\section{Support of variable-output renewables}

Over recent years, the growth in wind generation has actually been noted as a potential driver for increased hydro capacity [249]. Meridian currently assumes that [188]:

"New Zealand's large hydro capacity gives the potential for a significant level of wind penetration at a relatively low cost. The additional generation capacity required to provide back-up generation for when the wind does not blow is low while wind penetration is low".

However, the correlation between wind variability and high hydro inflows needs to be good. The geographic distribution of this correlation has been examined by the EC [250]. The main areas of concern were noted to be:

- hour-to-hour variation and uncertainty,

- frequency and voltage management,

- power system stability, and

- longer-term seasonal and year-to-year variation.

Wind and hydro have considerable short-term and long-term (annual) variability, respectively. Wind in NZ also has a season of low flows between April-July that is regionally variable, which could have significant impact on generation portfolio management. There is also a correlation of low wind flows with low hydro inflows in many regions (from $<0.1$ to a maximum of 0.5), but it was noted that this was not as important a factor as the management of the annual variation in hydro inflows and the seasonality of wind flows (assuming no shortterm changes in the prevailing climate of NZ relative to the last 20 years).

Thus, in the absence of increases in flexible storage such as $\mathrm{PH}$, the continued construction and maintenance of thermal spinning reserves [20,71,72,234], as recently illustrated by the new gas-based peaking plant at Stratford $[73,251]$ is being promoted by the government. The 
cost-effectiveness of this approach will become clear as the prices of $\mathrm{CO}_{2}$-e and natural gas develop over the next decade [85].

\section{Decommissioning of Huntly Units 1-4}

The Huntly coal-gas units currently have an essential dry-year security of supply role and most respondents assumed that if decommissioned, will need to be replaced with another source(s) of firm reserve generation capacity. However, these units are becoming increasingly uneconomic [49,50]. In October 2009 SOE Genesis signed a hedging contract with SOE Meridian to extend the life of the Huntly generators [49] and this power station now operates, in part, to sell electricity to Meridian at a fixed price. Thus, Huntly's life has been extended by Meridian despite (1) the combined coal fired plant at this location being the largest single point source of GHG emissions in the sector when operating at capacity and (2) the coal-based units becoming increasingly uneconomic at an operational level $[49,50]$.

Contact, for example, have assumed that the coal/gas units at Huntly could be decommissioned by 2018 [104]. Moreover, the gradual phasing out of Units 1-4 form a component of many of the scenarios presented in the EC's 2008 SOO [20] (Appendix H) and, more recently, the 2010 MED reference scenario [99].

Alternative dry-year generators will be required in the absence of these units in order to compensate for dry-year conditions, especially if the market response continues to be ineffective in regard to dry-year risk management. The MED [99] now assumes that this reserve could be replaced by seasonal operation of 840 MW of gas- (460 MW) and dieselbased (380 MW) peaking plant. However, this capacity may also be needed to support of 750 MW of wind and to provide peak supply adequacy. But, the primary drawback to this scenario is fuel supply constraints [99,252] and it can be assumed that by 2025, only extremely high, winter-wide, dry-year spot prices will enable these high value peakers to be used for season-long (period of months) backup generation. An alternative could again be seasonal energy storage, such as large-scale PH.

\section{Wind-and hydro-based spillage mitigation}

As discussed in considerable detail in Section 3.1, the potential for an expanded capacity of energy storage to participate in energy savings from wind and hydro spillage could be significant in the future. The availability of spillage that would otherwise be lost should increase (1) as the share of wind power increases (or if an overcapacity of wind power is built into the electricity system) and (2) where hydro-based security of supply is favoured over simply managing hydro resources via an efficiency-based approach. 


\subsection{Perceived barriers}

\section{Cost-effectiveness}

There was an almost universal response from the survey respondents that batteries are prohibitively expensive for applications such as peaking, renewables support and dry-year security of supply. However, many respondents also noted that pumped hydro would be at least as cost effective as diesel peakers, and in some cases, gas peakers. The review given in Section 3.1 certainty indicates that the latter is indeed likely to be the case, especially when relatively small, 'internationally representative' installations are considered. This conclusion, however, excludes the capital-intensive Manorburn-Onslow proposal, which is unlikely to be supported by the current framework of the electricity market and existing patterns of investment.

For comparison purposes, a brief summary of mean LRMCs of thermal peaker generation and the cost of storage from batteries and $\mathrm{PH}$ are given in Table 4.4 (costs of primary generation and transmission excluded.) General estimates of $S$ for PH in the literature include: US\$0.05$0.12 \mathrm{kWh}^{-1}\left(\mathrm{NZ} \$ 0.08-0.15 \mathrm{kWh}^{-1}\right)$ [93], which are very similar to MED-derived LRMCs of generation from new non-PH power in NZ [85]. The overall 'internationally representative' average values of $S$ derived for PH in this work are also of a similar order (Table 4.4) and are $\mathrm{NZ} \$ 0.072 \pm 0.034 \mathrm{kWh}^{-1}$ at a CF of 0.26 . Thus, the 'global average' cost of storage from $\mathrm{PH}$ is likely to be considerably more attractive than batteries (if representative $\mathrm{PH}$ sites are available). At a $\mathrm{CF}$ of 0.05 , for example, the average cost of storage from batteries is six times that of PH and more than twice that of diesel.

As described in Section 2, the overall cost of generation from an energy storage scheme is equal to $S$ plus transmission and charging costs. During off-peak times, the latter is very unlikely to be considerably greater than NZ\$0.100-0.150 $\mathrm{kWh}^{-1}$ (or NZ\$0.075-0.115 $\mathrm{kWh}^{-1}$ when $\eta_{\text {ac-to-ac }}$ is $75 \%$ ). Moreover, this cost can be reduced significantly if spillage becomes available.

Hypothetically, therefore, an idealised peaker-based PH scheme in NZ is likely to be as equally cost-effective as a gas peaker, even if a very conservative 40-year utility is considered (Table 4.4). The life-expectancy of the physical infrastructure is likely to be up to 100 years, which would considerably reduce these costs if a long-term outlook from investors is adopted. Regardless, even over 40 years PH could certainly be more cost-effective than diesel, even at $\mathrm{NZ} \$ 30 \quad\left[\mathrm{CO}_{2}\right.$-e] tonne ${ }^{-1}$. Nevertheless, this outcome is dependent on a 'globally representative' and environmentally responsible $\mathrm{PH}$ facility being sourced in NZ. 
Table 4.4. MED-modelled [85] average LRMC costs of generation from thermal peakers and renewables-based primary generators. The averaged costs of storage that were estimated in this research for $\mathrm{PH}$ and batteries are also given. The storage costs do not include charging and transmission costs and may not be representative of NZ conditions. See Section 4.2 for details of conditions used in the MED model.

\begin{tabular}{|c|c|c|c|}
\hline & $\begin{array}{l}\text { NZ\$10 (gas) GJ } \mathbf{J}^{-1} \\
\text { NZ\$50 (diesel) GJ } \mathbf{G}^{-1} \\
\mathrm{NZ \$ 30}\left(\mathrm{CO}_{2} \text {-e) tonne }{ }^{-1}\right.\end{array}$ & $\begin{array}{l}\text { NZ\$10 (gas) GJ } \mathbf{J}^{-1} \\
\text { NZ\$50 (diesel) GJ } \\
\text { NZ\$100 }\left(\mathrm{CO}_{2}-\mathrm{e}\right) \text { tonne }^{-1}\end{array}$ & $\begin{array}{l}\text { NZ\$15 (gas) GJ } \\
\text { NZ\$75 (diesel) GJ } \\
\text { NZ\$100 }\left(\mathrm{CO}_{2} \text {-e) tonne }\right.\end{array}$ \\
\hline & \multicolumn{3}{|c|}{ LRMC of Generation / NZ\$ kWh $\mathbf{~}^{-1}$} \\
\hline Diesel (CF: 0.05) & $0.838 \pm 0.043$ & $0.885 \pm 0.043$ & $1.119 \pm 0.046$ \\
\hline Gas (CF: 0.26) & $0.242 \pm 0.005$ & $0.278 \pm 0.006$ & $0.327 \pm 0.007$ \\
\hline Wind & $\sim 0.095-0.125$ & $\sim 0.095-0.125$ & $\sim 0.095-0.125$ \\
\hline Geothermal & $\sim 0.070-0.100$ & $\sim 0.080-0.110$ & $\sim 0.070-0.100$ \\
\hline \multirow[t]{2}{*}{ Hydro } & $\sim 0.080-0.155$ & $\sim 0.080-0.155$ & $\sim 0.080-0.155$ \\
\hline & \multicolumn{3}{|c|}{ Cost of storage / NZ\$ kWh ${ }^{-1}$} \\
\hline $\mathrm{PH}$ & $\begin{array}{l}0.286 \pm 0.179(\mathrm{CF}: 0.05) \\
0.072 \pm 0.034(\mathrm{CF}: 0.26) \\
0.079 \pm 0.039\left(250 \mathrm{~d} \mathrm{y}^{-1}\right.\end{array}$ & $\left.\mathrm{le}^{-1}\right)$ & \\
\hline Batteries & $\begin{array}{l}1.800 \pm 0.620(\mathrm{CF}: 0.05) \\
0.349 \pm 0.122(\mathrm{CF}: 0.26) \\
0.592 \pm 0.330\left(250 \mathrm{~d} \mathrm{y}^{-1}\right.\end{array}$ & $\left(e d^{-1}\right)$ & \\
\hline
\end{tabular}

\section{Vested interests and a lack of market incentives for security of supply}

Prior to the Ministerial Review and the introduction of the Electricity Industry Act (2010), there was a general perception within and outside of the industry that there was a lack of incentives for generators to consider 'security of supply' over 'efficiency'. The effectiveness of the measures described in The Review (Section 4.2), however, remains to be seen. In terms of vested interests, most of NZ's hydropower was developed prior to 1990 [101] and the extent of total generation from hydropower since 1986, for example, has reached a plateau (Figure 4.1), even though demand has increased historically at a rate of $\sim 1.8 \% \mathrm{y}^{-1}$ [71]. This is because, thermal plant had been increasingly favoured (Figure 1.1) [6,33]. There may be, therefore, a legacy of vested interests associated with existing, newly commissioned and consented facilities. Indeed, investment in thermal reserves appears to define the future of NZ's electricity sector.

\section{Off-peak and peak electricity prices}

In Japan and the USA, most battery and PH systems are applied to load levelling and peak shaving, as the off-peak/peak price variation is high $[62,93,253]$. The extraordinary high price of residential retail electricity in Japan, which was 3.4 times that of NZ in 2004 [254], 
for example, is also an a driver of alternative sources of reserve power $[57,62,75,93,214,255]$. Although there is certainly a significant amount of seasonal spikes in wholesale electricity prices during dry years and there is a perceived need to reduce this volatility, there is relatively little diurnal wholesale off-peak-to-peak price variation [45].

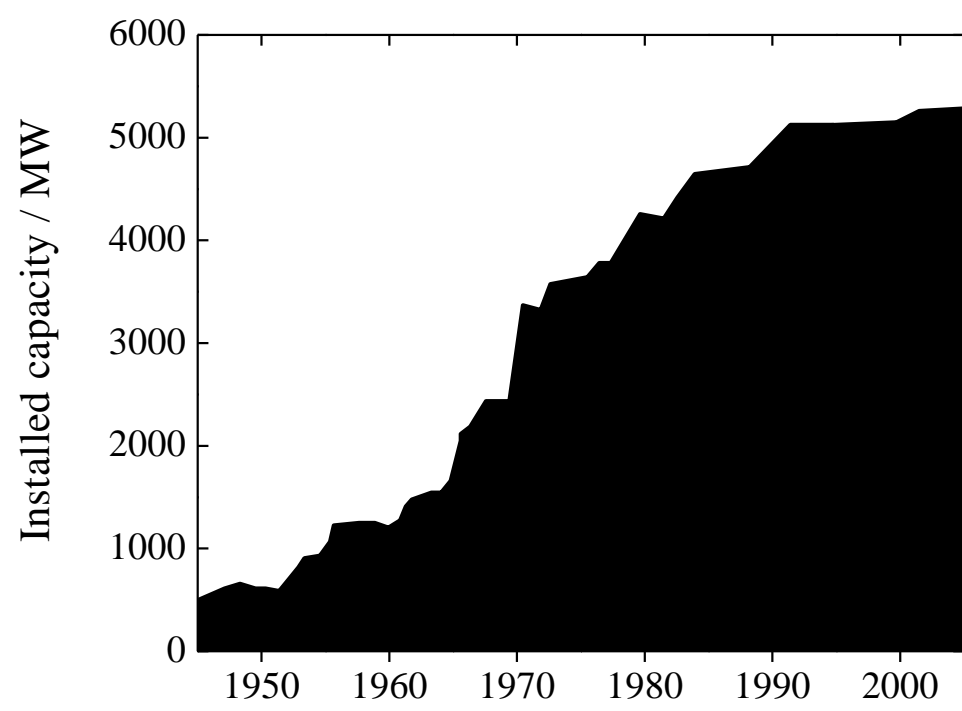

Figure 4.1. Trend in hydroelectricitybased capacity in NZ, re-drawn from Bertram and Clover [33].

\section{Uncertainties associated with the prices of carbon and natural gas}

Today, thermal power is being supported by NZ Government-derived (1) promotion of new discoveries of easily assessable, off-shore domestic natural gas [252] and (2) weak emission trading price signals [136]. The acceptance of this by the industry could have considerable influence over sectoral perceptions and decision making [19,20,33,85,102,252,256]. However, the reduced availability of gas and a high price on carbon are both key to the sustainability of the NZ electricity sector. The MED's 'gas shortage' scenario [252], for example, illustrates that a $90 \%$ renewables share could be realised by 2025 . Conversely, the 'Target Taranaki' scenario results in only a 73\% share [71].

\section{Local environmental impact of hydroelectricity}

As seen in Section 3.1 in regard to the Manorburn-Onslow proposal, the local environmental impact of new-build hydro is likely to be a significant and a contentious barrier to PH. This was also illustrated in the survey responses. Moreover, once commissioned and primed, operational PH lake levels can vary considerably and minimum rates of river discharge have 
to be maintained at the source. Nevertheless, $\mathrm{PH}$ facilities can reduce the potential for acute environmental damage resulting from large-scale spillage events.

$\mathrm{PH}$ is extremely site-specific in nature [57] and, in practice, the perceived intensity of environmental degradation is dependent on the human and ecological values of the available aqueous and terrestrial environments. These values are, thus, reflected in publicly-moderated decision making and the majority of generators have noted the long timescales and the uncertainly of outcome associated with existing RMA processes [73,98,102-104,159,257]. Under the proposed NPSREG (Section 4.2), however, projects of national importance may receive additional support in this regard [159].

There are likely to be environmental cost savings (in relative terms) from the utilisation of existing infrastructure and pre-existing hydro lakes/reservoirs, but this approach may have practical barriers, such as:

- the recent history of splitting hydro schemes between gentailers [26,258] ${ }^{27}$,

- lake recharge will need to occur during dry seasons when the value of water is high,

- river discharge rates and lake levels are resource-consent limited, and

- most existing hydro-lakes in NZ have comparatively low energy capacity.

\section{Local environmental impact of $\underline{\text { batteries }}$}

There was some uncertainty in the responses to the survey in regard to the severity of the local environmental impact of batteries. However, excluding spills (which have not been reported in the open literature for utility-scale systems), the all-vanadium and $\mathrm{NaS}$ systems, have exceptionally low potential local environmental impact relative to hydro-lake-based storage and traditional lead-acid-based batteries [39,253,259]. This is a benefit within sensitive environments [260]. The on-site footprint is small and a 2.5 MW, $10 \mathrm{MWh}$ all-vanadium battery, for example, would require only 1,000-1,500 $\mathrm{m}^{2}(0.10-0.15 \mathrm{ha})$ of floor space [62]. Since these facilities are modular, a $150 \mathrm{MW}, 8 \mathrm{MWh}$ system could require $~ 120,000$ 180,000 $\mathrm{m}^{2}$ (12-18 ha). A $150 \mathrm{MW}, 4 \mathrm{MWh}$ system: 60,000-90,000 m².

The NaS battery design has a higher energy density [75] and a 2.5 MW, $10 \mathrm{MWh}$ NaS system would require considerably less floor space: $\sim 500 \mathrm{~m}^{2}$ (0.005 ha) [62]. A $150 \mathrm{MW} \mathrm{1.2} \mathrm{GWh}$ system could require, perhaps: $60,000 \mathrm{~m}^{2}$ (6 ha). By comparison, Whirinaki covers $\sim 30,000$ $50,000 \mathrm{~m}^{2}$ [ 4 ha].

Batteries are also non-site specific, do not require fuels and, after commissioning and installation, would be independent of the ongoing transport, leakage, infrastructure and health

\footnotetext{
${ }^{27}$ This is also a barrier to the operation of purpose-built pumped hydro lakes.
} 
and safety costs associated with delivery of inflammable and toxic materials to thermal power sources. Batteries are also low-noise and housed in structures no more than two-storeys high. The majority of components and materials are likely to be recycled, especially the vanadium metal [28].

The primary environmental impacts are expected to result from site clearance, construction and the upgrade of existing transmission infrastructure. Accidental spillage of toxic and acidic electrolytes $[28,53,55]$ should be considered. Under chronic, high-level environmental exposure, for example, vanadium compounds can accumulate in animal organs [261] and reduce reproductive health [262]. The NaS battery [263] has a solid electrolyte, but operates at $300-350^{\circ} \mathrm{C}$, which presents an immediate health and safety issue. Liquid sodium also poses an extreme hazard of explosion/fire on exposure to water.

\section{Commercial status and power/energy capacity}

The survey illustrates a perception in NZ that the commercial development of batteries is not complete and this may be a barrier. In contrast, $\mathrm{PH}$ was largely assumed to be a market ready technology, and, with $90 \mathrm{GW}$ of capacity operating globally ( 3\% of global installed power capacity [94]) and GW-scale facilities currently operating in Australia, China, France, Germany, Iran, Italy, Japan, Luxemburg, Russia, South Africa, Taiwan, the United Kingdom and the USA, this is indeed the case $[51,57,84,94,163,264-268]$.

Utility-scale batteries are certainly not ubiquitous, but, in many countries batteries are now operating at the MW and MWh scales [28,53,59-63,263,269,270], which has opened up a number of grid management opportunities. The all-vanadium RFB has been adopted in at least ten countries world-wide and is especially prevalent in Japan [180,181,247,271-290]. In 2008, for example, Sumitomo Electric Industries had at least sixteen all-vanadium RFB installations operating [247,288,289,291-294], including a 4 MW wind-farm-based plant at Sapporo [92]. A 1.5 MW, $12 \mathrm{MWh}(8 \mathrm{~h})$ system was also recently introduced to the Sorne Hill wind farm in Ireland [180,181] and other systems include [83,92,282,295-300]:

- King Island, Australia $(200 \mathrm{~kW}, 800 \mathrm{kWh}$ for $4 \mathrm{~h}$, or $400 \mathrm{~kW}$ for $10 \mathrm{~s} / 300 \mathrm{~kW}$ for 5 $\min$ ) for wind farm/diesel generation support (2003).

- Castle Valley, USA (250 kW, 2 MW h) for load levelling (2004).

The zinc/bromine (ZBB, USA) battery [301] is an alternative RFB that is also attracting attention in regard to utility scale developments [62,302,303].

The enclosed, NaS-based utility-scale battery system, however, is market ready $[175,177,221,253,304]$ and is leading the field [210]. The ESA report an annual global 
Gareth Kear (garethkear@hotmail.com)

production rate of $\sim 90 \mathrm{MW} \mathrm{y}^{-1}$ with Japan supporting at least $270 \mathrm{MW}$ over 190 sites [182]. Currently, the largest battery facility in the world is the $34 \mathrm{MW}, 245 \mathrm{MWh}$ wind-farm-based NaS system in Rokkasho, Japan. The largest system in the USA is a 4 MW, 32 MWh backup system in Presidio, Texas [305,306]. EDF (France) also reportedly has $150 \mathrm{MW}$ and Abu Dhabi Water and Electric Authority 50 MW [307]. To date, NGK Insulators Ltd. (Japan) has been the sole NaS manufacturer [58], although General Electric (USA) has recently started to develop NaS batteries for traction/grid applications [308].

\section{Skills and knowledge}

As noted by the majority of respondents, a lack of technical resources in NZ is likely to present a short-term barrier to utility-scale batteries. The technology and skills will most likely have to be imported at significant cost from China, Japan and/or the USA. The extensive history of hydro development in NZ, however, is likely to present an advantage in regard to $\mathrm{PH}-$ based storage.

\section{Hydro spillage mitigation}

As discussed previously, the energy potential of hydro spillage mitigation in NZ is currently limited due to a focus on the economic efficiency of hydro-based energy use. Spillage mitigation in the short-term, therefore, is currently not likely to be able to provide regular returns on a capital investment.

\section{Re-allocation of existing hydro for reserve applications}

The extent of new-build, large-scale hydro is likely to be capped due to (1) local environmental considerations (2) increasing costs of the existing options and (3) the poor storage capacity of the available catchments. However, new-build geothermal and/or windderived capacity could displace existing hydropower currently used for base load. This may enable this hydro storage to be held in reserve for peaking services/load levelling during intermittent periods of low wind capacity factor [188].

Many of the respondents noted that this potential is a short-to-medium-term alternative to $\mathrm{PH}$ and batteries. However, NZ's new-build hydro and geothermal potential is finite [99] and, once exhausted over the next decade, or so, there is no technical reason why an exceptionally high rate of wind penetration cannot be achieved via a storage option, such as $\mathrm{PH}$. 


\section{Commercial sensitivity of existing data}

Market forces within the sector ensure that most research reports commissioned by generators will not be made available to other participants. This is a significant barrier to the development of new technologies within the industry.

\section{Transmission and congruence with wind power}

The survey respondents tended to associate transmission costs as a barrier to PH. However, this may not always be the case. If built, the Manorburn-Onslow proposal, for example, would certainly be close to existing transmission infrastructure at the Roxburgh hydro facility. This site is not ideally situated, however, in regard to transmission to the North Island demand centres and upgrades would be required.

Utility-scale batteries are most likely to be situated at the locale of the primary generator for which transmission would already be planned or in place, or at the demand centre itself, where transmission costs will be relatively negligible.

In regard to wind-derived charging of the Manorburn-Onslow lakes, there is only one 2.25 MW wind farm (Horseshoe Bend) within the immediate vicinity [309]. Within $\sim 50 \mathrm{~km}$, however, there is the potential 200 MW Mahinerangi wind farm site (consent received) [309]. The $\leq 630 \mathrm{MW}$ Project Hayes, which is currently under appeal at the Environment Court [188,310-312], could present a very significant source of wind power at $\sim 45 \mathrm{~km}$ distance. Other possibilities include the Mount Stuart (6 MW), Kaiwera Downs (240 MW) and Slopedown ( 150 MW) facilities at linear distances of 90, 120 and $140 \mathrm{~km}$, respectively. The extent of inter-generator co-operation required to operate such a scheme, however, may present a barrier.

\subsection{Limitations of the research}

All the respondents to the survey worked in fields such as policy analysis, generation development and energy industry consultancy. They were not NZ-based scientists and research engineers directly involved in the technical development of $\mathrm{PH}$ or batteries. Neither form of MW-GW-scale energy storage has been developed in NZ, so this was not possible. The survey results, therefore, may not be representative of current global scientific and engineering knowledge.

A number of key industry representatives did not provide an official response to the survey. In many cases, only individuals from within these organisations submitted an opinion and at least two key industry stakeholders did neither of the above. This 'self-selection' method of participation may have led to misrepresentation. However, the major geographical centres 
were represented, with respondents residing in cities including Auckland, Christchurch and Wellington. (The majority were based in Wellington, the seat of public policy.)

In regard to the questionnaire, the number of respondents was small at $n=14$ and only ten of these responded to the 'interview' option. Indeed, the low number of respondents who were initially invited to participate $(<20)$ was due to the relatively limited population of stakeholders operating within the small and highly centralised electricity sector. Regardless, the introduction of an element of bias, or relatively random errors of judgement by a small number of individuals could have had a significant impact on the overall output of the survey. The results and conclusions of the research, therefore, are associated with a relatively high level of uncertainty and only a broad interpretation of the data is appropriate.

\subsection{Further work}

The potential for further work related to the output of this research includes:

- analysis of utility-scale energy storage for the supply of ancillary services to the NZ electricity system, in particular, utility-scale batteries for the application to the sixsecond fast instantaneous reserve (FIR) in NZ,

- quantification and comparison of the environmental costs (economic) of both thermal reserve generation and energy storage alternatives.

- evaluation of other forms of sustainable energy storage for application to NZ, and

- evaluation of the total physical potential of PH in NZ. This potential should then be examined for congruence with existing transmission infrastructure and available wind farms (existing and planned). 


\section{Conclusions}

Non-pumped hydroelectricity-based energy storage in New Zealand has only limited potential to expand to meet projected growth in electricity demand and seasonal variations of hydro inflows have also led to numerous 'dry-year' events over the last decade. Moreover, a finite volume of newly dedicated fast-start 'peaker' capacity may also be required to support wind power as it approaches a $20 \%$ generation share. In this research, the New Zealand electricity industry has been surveyed in regard to the feasibility of reducing $\mathrm{CO}_{2}$-e emissions through the introduction of pumped hydroelectricity and utility-scale batteries by 2025. A desk-based review of the economic costs of these technologies has also been performed and their drivers and barriers critically assessed.

The results of the questionnaire survey indicate that there is a general perception within the NZ electricity sector that peak demand will continue to increase to 2025 and a business-asusual approach to investment in reserve-based generation is likely to result in increased levels of centralised ( $150 \mathrm{MW})$ thermal reserve power sources. In particular, reserves based on natural gas and gas-with-storage were favoured, even when it was assumed that domestic gas supply would be constrained. A price of carbon $\geq N Z \$ 100$ tonne $^{-1}$, however, was noted in a number of instances to most likely have some impact on this outlook.

There was also a universal agreement among the respondents that both the institutional arrangements for ensuring security of supply up to 2010 had not been adequate and that pumped hydro does have the technical capacity to contribute towards: (1) dry-year reserve, (2) the management of hydroelectricity/wind spillage, (3) peak adequacy and (4) grid integration of variable-output renewables. In regard to the last, at significantly elevated levels of wind (20\% penetration) wind-energy storage systems were generally seen as technically capable of providing truly dispatchable security of supply via non-thermal reserve-based electricity generation. It was also found that batteries could have a clear technical advantage in regard to the supply of the high-value six-second fast instantaneous reserve.

The primary drivers to introduced forms of energy storage in NZ were reported to be (1) the potential for $\mathrm{CO}_{2}$-e emissions mitigation and (2) the requirement for improved security of supply. When coupled to a significant increase in geothermal and wind power over the medium to long-term, utility-scale energy storage could ensure national security of supply in a sustainable manner by mitigating the impact of uncertainty associated with increasing fuel costs in the face of dwindling petroleum/natural gas production rates and increasing resilience to dry-year events by expanding the physical and market-based flexibility of NZ's lake-based 'storage' capacity. 
The barriers to investment in pumped hydro and utility-scale batteries, however, appear to be considerable and wide-ranging in scope. The survey and the desk-based literature review revealed that primary barriers are likely to include a range of technical, economic, market and environmental factors, such as:

- the poor cost-effectiveness of batteries for peaker applications, and, to a lesser extent, a perception of relatively high economic cost associated with pumped hydro,

- a potential lack of market incentives for improved security of supply,

- a perception that, over the short to medium term, existing hydro capacity currently used for base load in $\mathrm{NZ}$ can be redirected to reserve applications without the need for an expanded capacity of hydro storage,

- inter-generator competition,

- the requirement for long-term investments with potentially variable rates of return,

- limited diurnal variation between off-peak and peak wholesale electricity prices,

- uncertainty associated with the potential for an increased rate of new gas discoveries,

- $\quad$ limited support from the NZ Government's climate change policy,

- the high local environmental impact of hydroelectricity,

- industry perceptions regarding the emerging state of development and limited power/energy capacity of batteries,

- a lack of local skills and knowledge in regard to batteries,

- a limited potential for energy savings from hydro spillage mitigation,

- the commercial sensitivity and confidentiality of existing NZ-specific energy storage data, and

- a perception that there is a high economic cost associated with pumped hydro-based transmission infrastructure.

The primary energy-storage-based alternative to pumped hydro and batteries was seen as electric vehicles coupled to a smart grid. Here it was assumed that a distributed source of traction battery-based energy storage could provide national benefit (although the time-scale for introduction of this capacity could not be defined). A reliance on this form of distributed storage would certainly require a paradigm shift from the current supply-side bias of the sector towards a demand side approach.

Overall, the respondents appeared to provide consistent and internationally representative responses to the technical issues raised by the survey and a good depth of knowledge of the energy storage options was usually exhibited. A number of respondents were able to identify, for example, that the generic LRMCs of generation from pumped hydroelectricity could be of 
a similar order to that of natural gas-based peaking. However, the same respondents generally did not assume that the former would be favoured over the latter even if domestic gas supply is constrained. This skewed perception may, in part, be due to the local environmental impact, the conservative nature of the sector and extremely high projected economic costs of the Manorburn-Onslow proposal ( NZ\$3 billion), which, in effect, has been the only scheme examined in detail in NZ. If built, this project would be close to one of the most capital and time-of-construction intensive pumped hydro schemes yet attempted. It would, therefore, probably require government intervention and a long-term, collaborative approach from the investors. Nevertheless, these costs are not representative of the majority of overseas investments and, therefore, may not be representative of smaller and more-cost effective schemes that may still be available in NZ. 


\section{References}

1. United Nations Intergovernmental Panel on Climate Change (IPCC) fourth assessment report (AR4). Working Group I Report (WGI): Climate change 2007: the physical science basis. 2007, United Nations Intergovernmental Panel on Climate Change: Geneva, Switzerland.

2. Fact sheet: Copenhagen - why is a deal so important? 2009, United Nations Framework Convention on Climate Change: Bonn, Germany.

3. UNFCCC press briefing on the outcome of Copenhagen and the way forward in 2010. 2010, United Nations Framework Convention on Climate Change: Bonn, Germany (Date of access: 3 February 2010), http://unfccc.int/2860.php.

4. $\quad$ Press release. New approach to overcoming the climate policy deadlock: Taking stock before Copenhagen. 2009, German Advisory Council on Global Change: Berlin, Germany.

5. New Zealand's 2020 Emissions Target. 2009, Ministry for the Environment: Wellington, NZ.

6. The first (interim) progress report on the New Zealand Energy Strategy (NZES) including the New Zealand Energy Efficiency and Conservation Strategy (NZEECS) 2008, Ministry of Economic Development: Wellington, NZ.

7. New Zealand energy greenhouse gas emissions (2008 calendar year edition). 2009, Ministry of Economic Development: Wellington, NZ.

8. New Zealand's Energy Outlook 2009 - energy sector greenhouse gas emissions. 2009, Ministry of Economic Development: Wellington, NZ (Date of access: 20 November 2009), http://www.med.govt.nz/templates/MultipageDocumentTOC___41969.aspx.

9. New Zealand energy greenhouse gas emissions (2008 calendar year edition). 2009, Ministry of Economic Development: Wellington, NZ.

10. New Zealand energy data file (2008 calendar year edition). 2009, Ministry of Economic Development: Wellington, NZ.

11. Review of the 2008 Winter and the period leading into winter. 2009, Electricity Commission: Wellington, NZ.

12. New Zealand energy greenhouse gas emissions (2009 calendar year edition). 2010, Ministry of Economic Development: Wellington, NZ.

13. Appendix I- Quantified economy-wide emissions targets for 2020. 2010, United Nations Framework Convention on Climate Change: Bonn, Germany (Date of access: 3 February 2010), http://unfccc.int/home/items/5264.php.

14. 2020 target balances economy \& environment. 2009, New Zealand Government: Wellington, NZ (Date of access: 3 September 2009), http://www.beehive.govt.nz/release/2020+target+balances+economy+amp+environment.

15. Wrap up from Bonn. 2009, Greenpeace New Zealand: Auckland, NZ (Date of access: 4 September 2009), http://www.signon.org.nz/blog/wrap-up-from-bonn.

16. Climate talks undermined by feeble New Zealand target. 2009, EcoFicial (Date of access: 4 September 2009), http://www.ecoficial.com/climate-talks-undermined-by-feeble-new-zealand-target-532/.

17. Electricity (renewable preference) amendment act 2008, section 4, new s.62A of the Electricity Act 1992. 2008, Parliamentary Counsel Office: Wellington, NZ.

18. Thermal ban repeal. 2008, New Zealand Government: Wellington, NZ (Date of access: 19 February 2010), http://www.beehive.govt.nz/release/thermal+ban+repeal. 
19. Electricity generation - achieving New Zealand's objectives. 2010, The Institution of Professional Engineers New Zealand Inc.: Wellington, NZ.

20. 2008 Statement of opportunities. 2008, Electricity Commission: Wellington, New Zealand.

21. Draft New Zealand Energy Strategy and the draft New Zealand energy efficiency and conservation strategy: developing our energy potential. 2010, Ministry of Economic Development: Wellington, NZ.

22. Callow, P., Electricity in limbo. Energy NZ, 2009. Spring (Issue 10): p. 30-31.

23. Electricity Commission. 2009, Electricity Commission: Wellington, NZ (Date of access: 20 December 2009), http://www.electricitycommission.govt.nz/.

24. About the electricity sector. 2009, Electricity Commission: Wellington, NZ.

25. Electricity trading in the New Zealand Electricity Market. 2006, Genesis Energy Limited: Auckland, NZ.

26. Ministerial review of electricity market performance 2009. 2010, Ministry of Economic Development: Wellington, NZ.

27. Key gambles on privatisation. 2011, Fairfax Media Limited: Auckland, NZ (Date of access: 1 February 2011), http://www.stuff.co.nz/dominion-post/news/national/4595769/Key-gambles-on-privatisation.

28. EPRI technical update 1014836. Vanadium redox flow batteries - an in-depth analysis. 2007, Electric Power Research Institute: Palo Alto, USA.

29. Breeze, P., Power generation technologies. 2005, Elsevier: Maryland Heights, USA.

30. Kiameh, P., Power generation handbook. 2002, McGraw-Hill: London, UK.

31. Gas turbine peaking units. 2010, Contact Energy Limited: Wellington, NZ (Date of access: 11 October 2010), http://www.contactenergy.co.nz/web/ourprojects/gasturbinepeakingunits?vert=pr.

32. Hydro risk curves and reserve energy dispatch guidelines 2009, Electricity Commission: Wellington, NZ.

33. Bertram, G. and D. Clover, Kicking the fossil-fuel habit: New Zealand's Ninety Percent Renewable Target for Electricity in Generating electricity in a carbon constrained world, F.P. Sioshansi, Editor. 2009, Elsevier Science Limited: Maryland Heights, USA. p. 369-408.

34. Renewable energy and electricity. 2010, World Nuclear Association: London, UK (Date of access: 13 May 2010), http://www.world-nuclear.org/info/inf10.html.

35. Jacobson, M.Z., Review of solutions to global warming, air pollution, and energy security Energy and Environmental Science 2009. 2(2): p. 148-173.

36. New Zealand wind integration study. 2008, Imperial College London/Meridian Energy Limited: London, UK/Wellington, NZ.

37. Herman, R. and M. Diko, Load profile monitoring and its application to the analysis of a load leveling strategy using a vanadium battery storage system. in 4th IASTED International Conference on Power and Energy Systems. 2004. Rhodes, Greece: International Association of Science and Technology for Development (IASTED).

38. Katzenstein, W. and J. Apt, Air emissions due to wind and solar power. Environmental Science and Technology, 2009. 43(2): p. 253-258.

39. Rydh, C.J., Environmental assessment of vanadium redox and lead-acid batteries for stationary energy storage. Journal of Power Sources, 1999. 80(1-2): p. 21-29. 


\section{Gareth Kear (garethkear@hotmail.com)}

40. The implications of higher proportions of renewable electricity by 2030. 2007, Ministry of Economic Development/Energy Efficiency and Conservation Authority/Electricity Commission: Wellington, NZ.

41. Future costs and efficiencies. Costs of fossil fuel generating plant 2009, Ministry of Economic Development: Wellington, NZ (Date of access: 5 September 2009), http://www.med.govt.nz/templates/MultipageDocumentPage__4121.aspx.

42. Generation station list as at October 2009. 2009, Electricity Commission: Wellington, NZ (Date of access: 15 December 2009), http://www.electricitycommission.govt.nz/opdev/modelling/generation.

43. Generation by plant. 2009, Electricity Commission: Wellington, NZ (Date of access: 11 May 2010), http://www.electricitycommission.govt.nz/opdev/modelling/wip/cdswebinterface/generation-byplant?searchterm=generation.

44. Centralised dataset (DVD: April 2010). 2010, Electricity Commission: Wellington, NZ.

45. Centralised dataset (DVD: November 2010). 2010, Electricity Authority: Wellington, NZ.

46. New Plymouth power station recommissioned. 2008, Mercury Energy Limited: Auckland, NZ (Date of access, http://www.mercury.co.nz/News/news_story.aspx?id=967.

47. Dry-year planning. 2008, Transpower New Zealand Limited: Wellington, NZ (Date of access: 11 May 2010), http://www.systemoperator.co.nz/dry-year-planning-2008.

48. Emergency response plan. 2009, Electricity Commission: Wellington, NZ.

49. The Dominion Post Newspaper. Huntly puts Genesis in red (15 October 2009; p.C1-C1). 2009, Fairfax New Zealand Limited: Wellington, NZ.

50. Open conversations: Genesis Energy annual report 2009. 2009, Genesis Power Limited: Auckland, $\mathrm{NZ}$.

51. Pumped hydro. 2009, Electricity Storage Association: Morgan Hill, USA (Date of access: 9 August 2009), http://www.electricitystorage.org/site/technologies/pumped_hydro/.

52. Buenoa, C. and J.A. Carta, Wind powered pumped hydro storage systems a means of increasing the penetration of renewable energy in the Canary Islands. Renewable and Sustainable Energy Reviews, 2006. 10: p. 312-340.

53. Ponce de León Albarran, C., A. Frías-Ferrer, J. Gonzalez-Garcia, D.A. Szánto, and F.C. Walsh, Redox flow cells for energy conversion. Journal of Power Sources, 2006. 160(1): p. 716-732.

54. Winter, M. and R.J. Brodd, What are batteries, fuel cells, and supercapacitors? Chemical Reviews, 2004. 104(10): p. 4245-4269.

55. Hall, P.J. and E.J. Bain, Energy-storage technologies and electricity generation. Energy Policy, 2008. 36: p. 4352-4355.

56. McDowall, J., Implementation of storage with renewables - industry status. in First International Renewable Energy Storage Conference (IRES I). 2006. Gelsenkirchen, Germany: EUROSOLAR, World Council for Renewable Energy (WCRE).

57. Bottling electricity: storage as a strategic tool for managing variability and capacity concerns in the modern grid. 2008, Electricity Advisory Committee: Washington, D.C., USA.

58. DOE/NETL-2008/1330. Market analysis of emerging energy storage technologies. 2008, Carnegie Mellon University: Pittsburgh, USA.

59. A comparative assessment of flow battery technologies. 2002, The Electricity Storage Association: San Francisco, USA. 
60. Pletcher, D., H. Zhou, G. Kear, C.T.J. Low, F.C. Walsh, and R.G.A. Wills, A novel flow battery - A lead-acid battery based on an electrolyte with soluble lead(II) Part VI. Studies of the lead dioxide positive electrode. Journal of Power Sources, 2008. 180(1): p. 630-634.

61. Pletcher, D., H. Zhou, G. Kear, C.T.J. Low, F.C. Walsh, and R.G.A. Wills, A novel flow battery - A lead-acid battery based on an electrolyte with soluble lead(II) V. Studies of the lead negative electrode. Journal of Power Sources, 2008. 180(1): p. 621-629.

62. Boulder city battery energy storage feasibility study. 2002, Scandia National Laboratories: Albuquerque, USA.

63. An assessment of battery and hydrogen energy storage systems integrated with wind energy resources in California. 2005, University of California, Berkeley: Berkeley, California, USA.

64. Collins, J., G. Kear, X.-H. Li, C.T.J. Low, D. Pletcher, R. Tangirala, D. Stratton-Campbell, F.C. Walsh, and C.-P. Zhang, A novel flow battery - A lead acid battery based on an electrolyte with soluble lead(II): Part VIII. The cycling of a $10 \mathrm{~cm} \times 10 \mathrm{~cm}$ flow cell. Journal of Power Sources, 2010. 195(6): p. $1731-1738$

65. Grid Scale Energy Storage: Technologies and Forecasts Through 2015. 2009, GTM Research: San Francisco, USA (Date of access: 15 November 2010), http://www.gtmresearch.com/report/grid-scaleenergy-storage-technologies-and-forecasts-through-2015.

66. Update: California Energy Storage Bill AB 2514 Signed Into Law by Governor. 2010, GreenTech Media Inc.: Cambridge, USA (Date of access: 15 November 2010), http://www.greentechmedia.com/articles/read/vc-cmeas-gunderson-on-utility-scale-storage/.

67. Applications of energy storage. 2010, Electricity Storage Association Morgan Hill, California, USA (Date of access: 9 November 2010), http://electricitystorage.org/technologies_applications.htm.

68. Hall, P.J., Energy storage: the route to liberation from the fossil fuel economy? Energy Policy, 2008. 36: p. 4363-4367.

69. Ibrahima, H., A. Ilincaa, and J. Perronb, Energy storage systems - characteristics and comparisons Renewable and Sustainable Energy Reviews, 2008. 12(5): p. 1221-1250.

70. Percycle cost. 2010, Electricity Storage Association Morgan Hill, California, USA (Date of access: 9 November 2010), http://electricitystorage.org/tech/technologies_comparisons_percyclecost.htm.

71. New Zealand's energy outlook 2009 - reference scenario. 2009, Ministry of Economic Development: Wellington, NZ.

72. Contact Energy signs peaking plant contracts. 2008, Thomson Reuters: New York, USA (Date of access: 12 July 2009), http://www.reuters.com/article/rbssIndustryMaterialsUtilitiesNews/idUSWLF00082820080415.

73. Statement of evidence of Andrew John Summerville before the Board of Inquiry into the proposed National Policy Statement for Renewable Electricity Generation, Wellington. 2009, Ministry of Economic Development: Wellington, NZ (Date of access: 22 November 2009), http://www.mfe.govt.nz/rma/central/nps/hearing-proceeding/40-2-contact-powerpoint-presentation.pdf.

74. NAS batteries. 2010, NGK Insulators Limited: Japan (Date of access: 9 November 2010), http://www.ngk.co.jp/english/products/power/nas/index.html.

75. Japan installs massive sodium-sulfur wind storage battery. 2008, Next Energy News: International (Date of access: 9 November 2010), http://www.nextenergynews.com/news1/next-energynews4.14.08a.html.

76. Reference installations. 2010, NGK Insulators Limited: Japan (Date of access: 9 November 2010), http://www.ngk.co.jp/english/products/power/nas/installation/index.html. 
77. Bardsley, E., Simulating a possible seasonal pumped storage scheme in New Zealand for enhanced Storage Capacity and Environmental Lake Management. in 2006 Western Pacific Geophysics Meeting. 2006. Beijing, Peoples Republic of China: American Geophysical Union.

78. Bardsley, E., China and New Zealand - large seasonal pumped storage schemes for an electricity future using wind power and small hydro systems. in International East Asia Regional Workshop of InterAcademy Panel (IAP) on the Water Security to Climate Change and Human Activity. 2006. Beijing, Peoples Republic of China: The Association of Academies of Sciences in Asia.

79. Bardsley, E., B. Leyland, and S. Bear, A large pumped storage scheme for seasonal reliability of national power supply. in EEA 2006 Conference: Empowering NZ. 2006. Auckland, NZ: Electricity Engineers Association.

80. Bardsley, W.E., Note on the pumped storage potential of the Onslow-Manorburn depression. Journal of Hydrology (Wellington, NZ), 2005. 44(2): p. 131-135.

81. Bardsley, W.E., A pumped storage scheme for maintaining hydro electricity against climatic variations. in 8th New Zealand Energy Conference. 2006. Wellington, NZ: Energy Federation of New Zealand.

82. Gatzen, C., The economy of electricity storage: applications and strategies for (large scale) power storage technologies. in First International Renewable Energy Storage Conference (IRES I). 2006. Gelsenkirchen, Germany: EUROSOLAR, World Council for Renewable Energy (WCRE).

83. Jossen, A. and D.U. Sauer, Advances in redox-flow batteries. in First International Renewable Energy Storage Conference (IRES I). 2006. Gelsenkirchen, Germany: EUROSOLAR, World Council for Renewable Energy (WCRE).

84. Cost of pumped hydro storage. 2009, National Wind Watch Inc.: Rowe, USA (Date of access: 9 August 2009), http://www.wind-watch.org/documents/cost-of-pumped-hydro-storage/.

85. Interactive Electricity Generation Cost Model. 2010, Ministry of Economic Development: Wellington, NZ (Date of access: 22 March 2010), http://www.med.govt.nz/templates/MultipageDocumentTOC 41972.aspx.

86. Mason, I.G., S.C. Page, and A.G. Williamson, A $100 \%$ renewable electricity generation system for New Zealand utilising hydro, wind, geothermal and biomass resources. Energy Policy, 2010. 38(8): p. 39733984.

87. New Zealand's first underground gas storage facility. 2010, Contact Energy Limited: Wellington, NZ (Date of access: 11 October 2010), http://www.contactenergy.co.nz/web/ourprojects/gasstoragefacility?vert=au.

88. Personal communication with Meridian Energy Limited. 2010, Victoria University of Wellington: Wellington, NZ.

89. Cleveland, C.J. and C. Morris, Dictionary of energy. 2006, Elsevier: Amsterdam, The Netherlands.

90. Re-Fuel ESD - products. 2009, Re-Fuel ESD: Corsham, UK (Date of access: 5 July 2009), http://www.refueltec.com/products.html.

91. The VRB energy storage system (VRB-ESS $\left.{ }^{T M}\right)$ - the multiple benefits of integrating the VRB-ESS with wind energy - case studies in MWH applications. 2007, VRB Power Systems Inc.: Vancouver, Canada.

92. Grimm, V., Energy storage technologies - a way to cope with the intermittent supply of renewable energies. in First International Renewable Energy Storage Conference (IRES I). 2006. Gelsenkirchen, Germany: EUROSOLAR, World Council for Renewable Energy (WCRE).

93. Poonpun, P. and W.T. Jewell, Analysis of the cost per kilowatt hour to store electricity. EEE Transactions on Energy Conversion, 2008. 23(2): p. 529 - 534.

94. Pumped hydro. 2010, Electricity Storage Association: Morgan Hill, USA (Date of access: 9 August 2009), http://www.electricitystorage.org/site/technologies/pumped_hydro/. 
95. Leeuw, E.D.d., J.J. Hox, and D.A. Dillman, International handbook of survey methodology. 2008, Lawrence Erlbaum Associates: New York, USA.

96. Braun, V. and V. Clarke, Using thematic analysis in psychology. Qualitative Research in Psychology, 2006. 3: p. 77-101.

97. Charmaz, K., Constructing grounded theory: a practical guide through qualitative analysis. 2006, Sage Publications: Thousand Oaks, USA.

98. Statement of evidence of James Thomas Truesdale before the Board of Inquiry into the proposed National Policy Statement for Renewable Electricity Generation, Christchurch. 2009, Meridian Energy Limited: Wellington, NZ.

99. New Zealand's energy outlook 2010 - reference scenario. 2010, Ministry of Economic Development: Wellington, NZ.

100. New Zealand's Energy Outlook to 2030: Final Publication. 2006, Ministry of Economic Development: Wellington, NZ.

101. New Zealand Energy Strategy to 2050 - powering our future. 2007, Ministry of Economic Development: Wellington, NZ.

102. Statement of evidence of Robert Graham Hunter before the Board of Inquiry into the proposed National Policy Statement for Renewable Electricity Generation, Hamilton. 2009, Mighty River Power Limited: Auckland, NZ.

103. Legal submissions on behalf of Genesis Energy by Paul Majurey before the Board of Inquiry into the proposed National Policy Statement for Renewable Electricity Generation, Wellington. 2009, Genesis Energy Limited: Auckland, NZ.

104. Contact submission on the National Policy Statement for Renewable Electricity Generation (Powerpoint presentation). 2009, Ministry for Economic Development: Wellington, New Zealand (Date of access: 22 November 2009), http://www.mfe.govt.nz/rma/central/nps/hearing-proceeding/40-2contact-powerpoint-presentation.pdf.

105. New Zealand's Energy Outlook 2009 - summary of 2009 modelling results: energy supply and demand. 2009, Ministry of Economic Development: Wellington, New Zealand (Date of access: 20 November 2009), http://www.med.govt.nz/templates/MultipageDocumentTOC 41969.aspx.

106. New Zealand's energy outlook 2009 - economic growth sensitivity. 2009, Ministry of Economic Development: Wellington, NZ.

107. Grid connected domestic and small scale renewables in New Zealand. BAU uptake projections to 2030. 2007, Hydro Tasmania Consulting: Wellington, NZ.

108. New Zealand electric energy-efficiency potential study. 2007, Electricity Commission: Wellington, NZ.

109. Gunn, C., Energy efficiency vs. economic efficiency? New Zealand electricity sector reform in the context of the national energy policy objective. Energy Policy, 1997. 25(4): p. 445-458.

110. The developing market for energy efficiency in New Zealand. 1992, Electricity Corporation of New Zealand: Wellington, NZ.

111. Electricity demand-side management. 2005, The Treasury: Wellington, NZ.

112. New Zealand energy efficiency and conservation strategy - action plan to maximise energy efficiency and renewable energy. 2007, Energy Efficiency and Conservation Authority: Wellington, NZ.

113. Guiding a least cost grid integration of RES-electricity in an extended Europe. 2006, GreenNet-EU27: Vienna, Austria. 
114. Costs and benefits of connecting distributed generation to local networks. 2008, Maunsell Limited: Auckland, NZ.

115. Domestic-scale distributed generation - guidance for local government. 2009, Energy Efficiency and Conservation Authority: Wellington, NZ.

116. Programmes and funding. 2010, Energy Efficiency and Conservation Authority: Wellington, NZ (Date of access: 5 May 2010), http://www.eeca.govt.nz/programmes-and-funding.

117. Supplyline - wholesale pricing. 2010, Electricity Commission: Wellington, NZ (Date of access: 6 May 2010), http://supplyline.electricitycommission.govt.nz/Home/CurrentOutlook/Wholesalepricing.aspx.

118. Quarterly residential electricity prices to 15 February 2010. 2010, Ministry of Economic Development: Wellington, NZ.

119. Elias, A.A., Energy efficiency in New Zealand's residential sector: A systemic analysis. Energy Policy, 2008. 36: p. 3278-3285.

120. Electricity Commission summary New Zealand electric energy-efficiency potential study. 2007, Electricity Commission: Wellington, NZ.

121. Poletti, S., Government procurement of peak capacity in the New Zealand electricity market. Energy Policy, 2009. 37(9): p. 3409-3417.

122. Explanatory paper and conclusion on: mandatory use of extended water heating cuts as an emergency measure 2005, Electricity Commission: Wellington, NZ.

123. Smart electricity meters: how households and the environment can benefit. 2009, Parliamentary Commissioner for the Environment: Wellington, NZ.

124. DEUN/SEF joint statement on smart meters. 2009, Domestic Energy User's Network/Sustainable Energy Forum: Wellington, NZ.

125. Energy sector transformation to benefit consumers. 2009, New Zealand Government: Wellington, NZ (Date of access: 4 May 2010),

http://www.beehive.govt.nz/release/energy+sector+transformation+benefit+consumers.

126. Electricity security of supply: policy settings: regulatory impact statement/business compliance cost statement. 2003, Ministry of Economic Development: Wellington, NZ.

127. Security of supply. 2010, Electricity Commission: Wellington, NZ (Date of access: 10 March 2010), http://www.electricitycommission.govt.nz/opdev/secsupply.

128. Security of supply policy - explanatory paper 2008, Electricity Commission: Wellington, NZ.

129. Security of supply policy. 2008, Electricity Commission: Wellington, NZ.

130. Summarised flows. 2010, Electricity Commission: Wellington, NZ (Date of access: 11 May 2010), http://www.electricitycommission.govt.nz/opdev/modelling/centraliseddata/inflows.

131. Summary of main decisions - ministerial review into electricity market performance. 2009, Ministry of Economic Development: Wellington, NZ.

132. Layton, B., Improving electricity market performance. in EFNZ Seminar. 2010. Wellington, NZ: Energy Federation of New Zealand.

133. Electricity in New Zealand. 2010, Electricity Authority: Wellington, NZ.

134. The Kyoto Protocol to the United Nations Framework convention on Climate Change. 1998, United Nations: Berlin, Germany. 
135. Estimate of possible value of capped price of $\mathrm{CO}_{2}$ under a New Zealand emissions trading scheme. 2009, Victoria University of Wellington: Wellington, NZ.

136. Emission myths that threaten NZ. 2009, Dominion Post: Wellington, NZ (Date of access: 11 October 2009), http://www.stuff.co.nz/dominion-post/opinion/2876850/Emission-myths-that-threaten-NZ/.

137. Press Release. Taxpayers face $\$ 1.1$ billion Kyoto liability. 2010, Sustainability Council of New Zealand: Wellington, NZ (Date of access: 20 October 2010),

http://www.scoop.co.nz/stories/print.html?path=PO1006/S00231.htm.

138. Order Paper and questions - questions for oral answer 10. Clean, Green Image-Guardian Article [Volume:659;Page:7771]. 2009, New Zealand Parliament: Wellington, NZ (Date of access: 9 May 2010), http://www.parliament.nz/en-NZ/PB/Business/QOA/d/a/7/49HansQ_20091118_00000010-10Clean-Green-Image-Guardian-Article.htm.

139. The travel \& tourism competitiveness report 2009 - managing in a time of turbulence. 2009, World Economic Forum: Geneva, Switzerland.

140. New Zealand was a friend to Middle Earth, but it's no friend of the earth. 2009, Guardian News and Media Limited: London, UK (Date of access: 8 May 2010), http://www.guardian.co.uk/environment/cif-green/2009/nov/12/new-zealand-greenwash.

141. New Zealand: 100 per cent pure hype. 2010, APN Holdings NZ Limited (New Zealand Herald): Auckland, NZ (Date of access: 8 May 2010), http://www.nzherald.co.nz/nz/news/article.cfm?c_id=1\&objectid=10618678\&pnum=0.

142. 2020 target balances economy \& environment. 2009, New Zealand Government: Wellington, NZ (Date of access: 3 September 2009),

http://www.beehive.govt.nz/release/2020+target+balances+economy+amp+environment.

143. Chapman, R., Do the climate change goals and policies of New Zealand and the UK measure up? in ANZSEE Conference 2009. 2009. Darwin, Australia: Australia New Zealand Society of Ecological Economics.

144. NOW - Facing the climate change challenge (March 2008, Issue 14). 2008, AgResearch: Hamilton, NZ.

145. Labour shelves emissions scheme. 2010, ABC News: Sydney, Australia (Date of access: 8 May 2010), http://www.abc.net.au/news/stories/2010/04/27/2883282.htm.

146. New Zealand's energy outlook 2009 - emissions pricing sensitivity. 2009, Ministry of Economic Development: Wellington, NZ.

147. Barrera-Godinez, J.A. and T. Campos-Gonzalez, Vanadium extraction from a Mexican power plant residue, in Vanadium - geology, processing and applications. 2002, MetSoc: Montreal, Canada.

148. Resources - conversion factors. 2009, Carbon Trust: London, UK (Date of access: 9 February 2011), http://www.carbontrust.co.uk/cut-carbon-reduce-costs/calculate/carbon-footprinting/pages/conversionfactors.aspx\#' $\mathrm{kWh}$ ' into ' $\mathrm{kg}$ of carbon dioxide'.

149. Economic modelling of New Zealand climate change policy. 2009, New Zealand Institute of Economic Research and Infometrics: Wellington, NZ.

150. Bertram, G., Assessing the costs of climate change policy in New Zealand. in The Countdown to Copenhagen: Key Climate Change Policy Issues for New Zealand. 2009. Wellington, NZ: Institute of Policy Studies.

151. New Zealand energy strategy to 2050 - powering our future. 2007, Ministry of Economic Development: Wellington, NZ.

152. Energy [R]evolution: a sustainable global energy outlook. 2008, Greenpeace and European Renewable Energy Council: Amsterdam, The Netherlands. 
153. Bertram, G. and S. Terry, The Carbon Challenge: New Zealand's Emissions Trading Scheme. 2010, Bridget Williams Books: Wellington, NZ.

154. The Carbon Challenge. Response, responsibility, and the emissions trading scheme. Main point summary. 2010, Sustainability Council of New Zealand: Wellington, NZ.

155. Energy in the emissions trading scheme. 2010, Ministry for the Environment: Wellington, NZ (Date of access: 21 October 2010), http://www.climatechange.govt.nz/emissions-tradingscheme/participating/energy/.

156. About emissions trading. 2010, Ministry for the Environment: Wellington, NZ (Date of access: 21 October 2010), http://www.climatechange.govt.nz/emissions-trading-scheme/about/.

157. The New Zealand Emissions Trading Scheme. Stationary energy and industrial processes and liquid fossil fuels regulations - 2010 guidance update. 2010, Ministry for the Environment: Wellington, NZ.

158. The implications of higher proportions of renewable electricity by 2030. 2007, Ministry of Economic Development/Energy Efficiency and Conservation Authority/Electricity Commission: Wellington, NZ.

159. Proposed national policy statement for renewable electricity generation. 2008, Ministry for the Environment: Wellington, NZ.

160. Resource Management Act. 2010, Ministry for the Environment: Wellington, NZ (Date of access: 2 November 2010), http://www.mfe.govt.nz/rma/index.html.

161. Wind integration project (WIP) - project plan. 2008, Electricity Commission: Wellington, NZ.

162. Wind generation investigation project (WGIP). 2009, Electricity Commission: Wellington, NZ (Date of access: 2 September 2009),

http://www.electricitycommission.govt.nz/opdev/comqual/windgen/wgip\#scenarios.

163. Verwijs, H., Europe turns a blind eye to big battery. European Energy Review, 2009. March/April: p. 72-75.

164. Leyland, B., New Zealand Energy Strategy to 2050 - Part 3. Transmission and Distribution, 2008. August/September: p. 8-10.

165. Transformational research science and technology - making renewable energy work for New Zealand. 2007, Ministry for Research Science and Technology: Wellington, NZ.

166. Summary report. Effect of large scale wind generation on the operation of the New Zealand Power System and Electricity Market. 2007, Electricity Commission: Wellington, NZ.

167. Wind generation investigation project (WGIP). 2009, Electricity Commission: Wellington, NZ (Date of access: 2 September 2009), http://www.electricitycommission.govt.nz/opdev/comqual/windgen/wgip\#scenarios.

168. How much wind energy can be integrated into the grid? 2009, New Zealand Wind Energy Association: Wellington, NZ (Date of access: 24 December 2009), http://windenergy.org.nz/wind-energy/gridintegration.

169. Archer, C.L. and M.Z. Jacobson, Supplying baseload power and reducing transmission requirements by interconnecting wind farms. Journal of Applied Meteorology and Climatology, 2007. 46(11): p. 17011717.

170. Grubb, M., L. Butler, and P. Twomey, Diversity and security in UK electricity generation: The influence of low-carbon objectives. Energy Policy, 2006. 34(18): p. 4050-4062.

171. How much wind energy can be integrated into the grid? . 2009, New Zealand Wind Energy Association: Wellington, NZ (Date of access: 8 August 2009), http://windenergy.org.nz/windenergy/grid-integration. 
172. Expert talks about economic virtues of future wind generation for New Zealand. 2009, Meridian Energy Ltd.: Wellington, NZ (Date of access: 8 August 2009),

http://www.meridianenergy.co.nz/AboutUs/News/Economic+virtues+of+future+wind+generation.htm.

173. Wind energy resources in New Zealand 2009, New Zealand Wind Energy Association: Wellington, NZ (Date of access: 24 December 2009), http://windenergy.org.nz/nz-wind-farms/wind-resource.

174. Security of supply and wind energy. 2009, New Zealand Wind Energy Association: Wellington, NZ (Date of access: 24 December 2009), http://windenergy.org.nz/wind-energy/energy-security.

175. Iijima, Y., Y. Sakanaka, N. Kawakami, M. Fukuhara, K. Ogawa, M. Bando, and T. Matsuda, Development and field experiences of NAS battery inverter for power stabilization of a $51 \mathrm{MW}$ wind farm. in 2010 International Power Electronics Conference. 2010. Sapporo, Japan: IEEE.

176. Benitez, L., P. Benitez, and G. van Kooten, The economics of wind power with energy storage. Energy Economics, 2008. 30(4): p. 1973-1989.

177. Shakib, A.D. and G. Balzer, Energy storage design and optimization for power system with wind feeding. in 2010 IEEE 11th International Conference on Probabilistic Methods Applied to Power Systems (PMAPS). 2010. Singapore: IEEE.

178. Energy storage system for Irish windfarm increased based on study 2007, Contact Renewable Energy World Website: Peterborough, USA (Date of access: 12 July 2009), http://www.renewableenergyworld.com/rea/news/article/2007/03/energy-storage-system-for-irish-windfarm-increased-based-on-study-47956.

179. Remote area power systems: King Island. 2007, VRB Power Systems Inc.: Vancouver, Canada.

180. Ireland windfarm inks VRB energy storage system purchase agreement. 2006, Wind Energy Investing (Reid, Brown \& Co., LLC): Houston, USA (Date of access: 24 May 2009),

http://www.windenergyinvesting.com/2006/08/30/ireland-windfarm-inks-vrb-energy-storage-systempurchase-agreement/.

181. Size of VRB-ESS for Sorne Hill increased to $2 M W x$ 6hr and completion of Sustainable Energy Ireland / Tapbury feasibility study. 2009, PR Newswire Europe Limited: London, UK (Date of access: 3 July 2009), http://www.prnewswire.co.uk/cgi/news/release?id=193830.

182. Technologies - NaS. 2010, Electricity Storage Association Morgan Hill, California, USA (Date of access: 9 November 2010), http://electricitystorage.org/tech/technologies_technologies_nas.htm.

183. Hydro spill. 2010, Mighty River Power Limited: Auckland, NZ (Date of access: 29 November 2010), http://www.mightyriverpower.co.nz/Generation/LakeLevels/HydroSpill/SpillTables/SpillTerms.aspx.

184. Prices watched as hydro lakes spill. 2009, Fairfax New Zealand Limited: Auckland, NZ (Date of access: 29 November 2010), http://www.stuff.co.nz/dominion-post/archive/national-news/791092.

185. Tiwai woes force lake spill. 2008, Fairfax New Zealand Limited: Auckland, NZ (Date of access: 13 December 2010), http://www.stuff.co.nz/southland-times/news/761319.

186. Contact's profit diluted. 2009, Allied Press Limited: Dunedin, NZ (Date of access: 13 December 2010), http://www.odt.co.nz/news/business/60322/contact039s-profit-diluted.

187. Sustainability: Contact Energy's sustainability report for 2009. 2009, Contact Energy Limited: Wellington, NZ.

188. Decision C103/2009 Re: Project Hayes. 2009, Environment Court of New Zealand: Wellington, NZ.

189. Capital cost. 2010, Electricity Storage Association Morgan Hill, California, USA (Date of access: 9 November 2010), http://electricitystorage.org/tech/technologies_comparisons_capitalcost.htm.

190. Life efficiency. 2010, Electricity Storage Association Morgan Hill, California, USA (Date of access: 9 November 2010), http://electricitystorage.org/tech/photo_capitalcost.htm. 
191. Prudent Energy - technology applications: material. 2009, Prudent Energy Inc.: Beijing, People's Republic of China (Date of access: 22 May 2009), http://www.pdenergy.com/enmaterial.html.

192. Skyllas-Kazacos, M., C. Peng, and M. Cheng, Evaluation of precipitation inhibitors for supersaturated vanadyl electrolytes for the vanadium redox battery. Electrochemical and Solid-State Letters, 1999. 2(3): p. 121-122.

193. Skyllas-Kazacos, M., Stabilised electrolyte solutions, methods of preparation thereof and redox cells and batteries containing stabilised electrolyte solutions. 2000, Patent: 6,143,443, USA.

194. Skyllas-Kazacos, M., Vanadium redox battery electrolyte process. 2002, Patent: PCT/AU02/00613, Australia.

195. Tanaka, Y., K. Mita, K. Horikawa, N. Tokuda, M. Furuya, and M. Kubata, Modified vanadium compound, producing method thereof, redox flow battery electrolyte composite and redox flow battery electrolyte producing method. 2002, Patent: 2364 550, Canada.

196. Broman, B.M., Vanadium electrolyte preparation using asymmetric vanadium reduction cells and use of an asymmetric vanadium reduction cell for rebalancing the state of charge of the electrolytes of an operating vanadium redox battery. 2002, Patent: WO/2002/015317, Switzerland.

197. Chakrabarti, M.H., R.A.W. Dryfe, and E.P.L. Roberts, Evaluation of electrolytes for redox flow battery applications. Electrochimica Acta, 2007. 52(5): p. 2189-2195.

198. Rahman, F. and M. Skyllas-Kazacos, Solubility of vanadyl sulfate in concentrated sulfuric acid solutions. Journal of Power Sources, 1998. 72(2): p. 105-110.

199. Sukkar, T. and M. Skyllas-Kazacos, Membrane stability studies for vanadium redox cell applications. Journal of Applied Electrochemistry, 2004. 34(2): p. 137-145.

200. Sukkar, T. and M. Skyllas-Kazacos, Modification of membranes using polyelectrolytes to improve water transfer properties in the vanadium redox battery. Journal of Membrane Science, 2003. 222(1-2): p. 249-264.

201. Oei, D.G., Permeation of vanadium cations through anionic and cationic membranes. Journal of Applied Electrochemistry, 1985. 15(2): p. 231-235.

202. Mohammadi, T. and M.S. Kazacos, Evaluation of the chemical stability of some membranes in vanadium solution. Journal of Applied Electrochemistry, 1997. 27(2): p. 153-160.

203. Lu, Z.-Z., S.-L. Hu, X.-L. Luo, Z.-H. Wu, L.-Q. Chen, and X.-P. Qiu, Effects of proton exchange membranes on performance of vanadium redox flow battery. Chemical Journal of Chinese UniversitiesChinese, 2007. 28(1): p. 145-148.

204. Qiu, J.-Y., M.-Y. Li, J.-F. Ni, M.-L. Zhai, J. Peng, L. Xu, H.-H. Zhou, J.-Q. Li, and G.-S. Wei, Preparation of PTFE-based anion exchange membrane to reduce permeability of vanadium ions in vanadium redox battery. Journal of Membrane Science, 2007. 297(1-2): p. 174-180.

205. Tian, B., C.W. Yan, and F.-H. Wang, Modification and evaluation of membranes for vanadium redox battery applications. Journal of Applied Electrochemistry, 2004. 34: p. 1205-1210.

206. The VRB energy storage system (VRB-ESSTM) - an introduction to wind \& the integration of a VRBESS. 2007, VRB Power Inc.: Vancouver, Canada.

207. Pumped hydro - to date, the only significant bulk electricity storage technology that is common in the market. 2010, Neutral Energy: El Cerrito, USA (Date of access: 17 November 2010), http://neuralenergy.blogspot.com/2009/06/pumped-hydro.html.

208. B.Sc. Thesis. Wind and pumped-hydro power storage: determining optimal commitment policies with knowledge gradient non-parametric estimation. 2010, Princeton University: USA. 
209. Ripple Control Electricity: Pumped Storage (SEF News, email, June 16, 2010). 2010, Sustainable Energy Forum: Auckland, NZ.

210. Carnegie Mellon Electricity Industry Center Working Paper CEIC-06-04. Economics of electric energy storage for energy arbitrage and regulation in New York. 2006, Carnegie Mellon Electricity Industry Center: Pittsburgh, USA.

211. Energy technology perspectives 2008: strategies and scenarios to 2050, executive summary. 2008, International Energy Agency: Paris, France.

212. Experience curves for energy technology policy. 2000, International Energy Agency: Paris, France.

213. Electric energy storage. 2009, PEW Centre on Global Climate Change: Arlington, USA.

214. Kazunogawa hydroelectric power plant, Japan. 2010, Power-Technology.com: London, UK (Date of access: 17 November 2010), http://www.power-technology.com/projects/kazunogawa/.

215. Hydropower. 2010, International Energy Agency - Energy Technology Systems Analysis Programme: Ottawa, Canada.

216. Renewable energy essentials - hydropower. 2010, International Energy Agency: Paris, France.

217. US Inflation Calculator 2010, Coin News Media Group LLC: USA (Date of access: 23 November 2010), http://www.usinflationcalculator.com/.

218. Bueno, C. and J.A. Carta, Technical-economic analysis of wind-powered pumped hydrostorage systems. Part II: model application to the island of El Hierro. Solar Energy, 2005. 78(3): p. 396-405.

219. Contact discussion board. Onslow-Manorburn pumped hydro storage proposal impact. 2010, Contact Energy Limited: Wellington, NZ (Date of access: 31 March 2010), http://www.contactenergy.co.nz/web/forum/posts/list/3818.page.

220. Cost of pumped hydro storage. 2009, National Wind Watch Inc.: Rowe, USA (Date of access: 9 August 2009), http://www.wind-watch.org/documents/cost-of-pumped-hydro-storage/.

221. Economic analysis of wind plant and battery storage operation using supply chain management techniques. 2010, IEEE: Minneapolis, USA.

222. Bardsley, W.E., Note on the pumped storage potential of the Onslow-Manorburn depression. New Zealand Journal of Hydrology, 2005. 44(2): p. 131-135.

223. Bardsley, E., Submission on the draft New Zealand Energy Strategy. 2007, University of Waikato: Hamilton, NZ.

224. Hydrological evaluation of pumped storage in the Onslow Manorburn basin. 2005, University of Waikato: Waikato, NZ.

225. The economic infeasibility of the proposed Onslow pumped storage scheme (Board Meeting: 13/14 September 2006). 2006, Electricity Commission: Wellington, NZ.

226. Report to the Electricity Commission: proposed Manorburn-Onslow pumped storage scheme. 2006, Parsons Brinkerhoff Associates Limited: Wellington, NZ.

227. Proposed Onslow-Manorburn seasonal pumped storage scheme - preliminary cost estimate (MS Excel spreadsheet). 2006, Electricity Commission: Wellington, NZ.

228. Kear, G. Interview with Kevin Hackwell, Forest and Bird, regarding potential environmental impact of Manorburn-Onslow pumped hydro proposal (15 December 2010). 2010, Victoria University of Wellington: Wellington, NZ.

229. Ludwig, D., B. Walker, and C.S. Holling, Sustainability, stability, and resilience. Conservation Ecology, 1997. 1(1): p. 7-7. 
230. What is resilience? 2009, Stockholm Resilience Centre: Stockholm, Sweden (Date of access: 5 April 2009),

http://www.stockholmresilience.org/research/whatisresilience.4.aeea46911a3127427980004249.html.

231. Contact discussion Board. Possibility of pumped storage. 2010, Contact Energy Limited: Wellington, NZ (Date of access: 31 March 2010), http://www.contactenergy.co.nz/web/forum/posts/list/3819.page.

232. Hydroelectricity. 2007, Contact Energy Limited: Wellington, NZ.

233. Hawea generation scheme still in planning. 2009, Otago Daily Times: Otago, NZ (Date of access: 30 December 2010), http://www.odt.co.nz/your-town/hawea/67447/generation-scheme-still-planning.

234. New Zealand's Energy Outlook 2009 - electricity generation and capacity. 2009, Ministry of Economic Development: Wellington, NZ (Date of access: 20 November 2009), http://www.med.govt.nz/templates/MultipageDocumentTOC__41969.aspx.

235. Ministerial review of the electricity market - improving electricity market performance discussion documents - Submission to the ministry of economic development 16 September 2009. 2009, Sustainable Energy Forum: Wellington, NZ.

236. Dry years 'chance to make a profit'. 2009, Fairfax New Zealand Limited: Auckland, NZ (Date of access: 11 May 2010), http://www.stuff.co.nz/business/2431445/Dry-years-chance-to-make-profit.

237. New generation stacking up. 2006, The Beehive: Wellington, NZ (Date of access: 11 May 2010), http://www.beehive.govt.nz/release/new+electricity+generation+stacking.

238. Is price gouging really the problem? 2001, Stanford University: Stanford, USA (Date of access: 28 February 2011), http://www.stanford.edu/group/fwolak/cgi-

bin/sites/default/files/files/Is\%20price\%20gouging\%20really\%20the\%20problem_July\%202001_Wola k.pdf.

239. Electricity Industry Act 2010. 2010, Parliamentary Council Office: Wellington, NZ (Date of access: 7 November 2010), http://www.legislation.govt.nz/act/public/2010/0116/latest/DLM2634233.html.

240. Authority functions. 2010, Electricity Authority: Wellington, NZ (Date of access: 7 November 2010), http://www.ea.govt.nz/about-us/functions/.

241. Kicking the fossil-fuel habit: New Zealand's ninety percent renewable target for electricity. 2009, Ministry of Economic Development: Wellington, New Zealand (Date of access: 21 November 2009), http://www.mfe.govt.nz/rma/central/nps/hearing-proceeding/53-geoff-bertram-kicking-fossil-habit.pdf.

242. Summary of main decisions - Ministerial review into Electricity Market Performance. 2009, Ministry of Economic Development: Wellington, NZ.

243. Risk management in power markets: The hedging value of production flexibility. 2008, Institute for Operations Research: Zürich, Switzerland (Date of access: 8 February 2011), http://www.ifor.math.ethz.ch/staff/maxfehr/PowerRisk.pdf.

244. Parliamentary Library research paper: the next oil shock. 2010, Parliamentary Library: Wellington, NZ.

245. New Zealand's energy outlook 2009 - oil price sensitivity. 2009, Ministry of Economic Development: Wellington, New Zealand.

246. New Zealand's energy outlook 2010 - changing gear scenario. 2010, Ministry of Economic Development: Wellington, NZ.

247. Shigematsu, T., T. Kumamoto, H. Deguchi, and T. Hara, Application of a vanadium redox-flow battery to maintain power quality. in Transmission and Distribution Conference and Exhibition 2002: Asia Pacific. 2002. Yokohama, Japan: IEEE/PES. 
248. VRB Power Systems - power quality \& energy storage solutions. 2006, VRB Power Systems Inc.: Vancouver, Canada (Date of access: 7 November 2008 (Historical - company web site superseded)), http://www.vrbpower.com/.

249. Submission on Mighty River Power Ltd applications for resource consent. 2009, Ministry for the Environment: Wellington, NZ (Date of access: 8 August 2009), http://www.mfe.govt.nz/rma/call-inturitea/submissions/683-lovejohnbandkathrynj.pdf.

250. Correlation between wind and hydro (Energy Federation of New Zealand Presentation, 18 August 2010). 2010, Electricity Commission: Wellington, NZ.

251. Contact Energy annual report 2009. 2009, Contact Energy Limited: Wellington, NZ.

252. New Zealand's energy outlook 2010 - hydrocarbon harvest scenario. 2010, Ministry of Economic Development: Wellington, NZ.

253. Jalal Kazempour, S. and M.P. Moghaddam, Economic viability of NaS battery plant in a competitive electricity market. in 2009 International Conference on Clean Electrical Power (ICCEP). 2009. Capri, Italy: IEEE.

254. Electricity generation : New Zealand and selected OECD countries. 2004, Parliamentary Library: Wellington, NZ.

255. Utah Power cuts ribbon at pilot battery storage project. 2009, AllBusiness.com, Inc.: San Francisco, USA (Date of access: 3 July 2009), http://www.allbusiness.com/energy-utilities/utilities-industryelectric-power/5585509-1.html.

256. Electricity price debate ignores impact of rising gas prices. 2009, New Zealand Wind Energy Association: Wellington, NZ (Date of access: 24 December 2009), http://windenergy.org.nz/mediacentre/2008-media-releases/73-electricity-price-debate-ignores-impact-of-rising-gas-prices-.

257. Supplementary statement of evidence of James Truesdale. A submission to the Board of Inquiry concerning the Proposed National Policy Statement for Renewable Electricity Generation. 2009, Meridian Energy Limited: Wellington, NZ.

258. Engineer slams hydro split plan. 2009, Fairfax New Zealand Limited: Auckland, NZ (Date of access: 25 November 2010), http://www.stuff.co.nz/timaru-herald/news/3145468/Engineer-slams-hydro-splitplan.

259. External costs - research results on socio-environmental damages due to electricity and transport. 2003, European Commission: Brussels, Belgium.

260. Fradette, M. and K.M. Zhang, Energy storage for a sustainable development. in Proceedings Of The ASME 3rd International Conference On Energy Sustainability, Vol 1. 2009. San Francisco, USA: American Society of Mechanical Engineers.

261. Material safety data sheet vanadium pentoxide MSDS. 2010, ScienceLab: Houston, USA.

262. Teng, Y., S. Ni, C. Zhang, J. Wang, X. Lin, and Y. Huang, Environmental geochemistry and ecological risk of vanadium pollution in Panzhihua mining and smelting area, Sichuan, China. Chinese Journal of Geochemistry, 2006. 25(4): p. 379-385.

263. Oshima, T., M. Kajita, and A. Okuno, Development of sodium-sulfur batteries. International Journal of Applied Ceramic Technology, 2004. 1(3): p. 269-276.

264. Specifications of Okinawa seawater pumped storage power plant operator - Electric Power Development Co., Limited (J-POWER). 2009, International Energy Agency Hydropower Agreement: Paris, France (Date of access: 9 October 2009), http://www.ieahydro.org/01-Okinawa-Seawater-PSPPlg.htm. 
265. Hadjipaschalis, I., A. Poullikkas, and V. Efthimiou, Overview of current and future energy storage technologies for electric power applications. Renewable and Sustainable Energy Reviews, 2009. 13(67): p. 1513-1522.

266. Jaeger, C., Peak load and pumped storage power stations. English Electric Journal, 1964. 19(3): p. 8-9.

267. Friedlander, G.D., Pumped storage-an answer to peaking power. IEEE Spectrum, 1964. 1(10): p. 5875 .

268. Cuenod, M. and D. Greindl, Aspects of planning and operation of pumped storage hydroelectric systems in U.S.A. Bulletin de la Societe Royale Belge des Electriciens, 1967. 83(4): p. 313-323.

269. Kear, G., A. Shah, and F.C. Walsh, The all-vanadium redox flow battery: commercialisation, cost analysis and incentives. International Journal of Energy Research, 2011: p. (In press).

270. Linden, D., Handbook of batteries. 2001, McGraw-Hill: London.

271. An historical overview of the vanadium redox flow battery development at the University of New South Wales, Australia 2002, University of New South Wales: Sydney, Australia (Date of access: 21 June 2009), http://www.vrb.unsw.edu.au/.

272. Menictas, C., D.R. Hong, Z.-H. Yan, M. Wilson, M. Kazacos, and M. Skyllas-kazacos, Status of the vanadium battery development program. in Electrical Engineering Congress - EEC 94. 1994. Sydney, Australia: Institution of Engineers, Australia.

273. Fabjan, C., J. Garche, B. Harrer, L. Jorissen, C. Kolbeck, F. Philippi, G. Tomazic, and F. Wagner, The vanadium redox-battery: an efficient storage unit for photovoltaic systems. Electrochimica Acta, 2001. 47(5): p. 825-831.

274. Vanteck granted rights to the vanadium redox battery technology (VRB) for the Americas. 2001, Vanteck (VRB) Technology Corporation: Vancouver, Canada.

275. Joerissen, L., J. Garche, C. Fabjan, and G. Tomazic, Possible use of vanadium redox-flow batteries for energy storage in small grids and stand-alone photovoltaic systems. Journal of Power Sources, 2004. 127(1-2): p. 98-104.

276. Huang, K.-L., X.-G. Li, S.-Q. Liu, N. Tan, and L.-Q. Chen, Research progress of vanadium redox flow battery for energy storage in China. Renewable Energy, 2008. 33(2): p. 186-192.

277. Sustainable Energy Ireland (SEI). 2009, Sustainable Energy Ireland: Dublin, Ireland (Date of access: 7 July 2009), http://www.sei.ie/.

278. Vanteck's $250 \mathrm{~kW}-520 \mathrm{kWH}$ VRB-ESS successfully installed and commissioned in South Africa. 2001, Vanteck (VRB) Technology Corporation: Vancouver, Canada.

279. Hawkins, J.M. and T. Robbins, A vanadium energy storage field trial. in Electrical Energy Storage Applications and Technologies (EESAT). 2002. San Francisco, USA: The Electricity Storage Association.

280. Menictas, C., D.R. Hong, M. Kazacos, and M. Skyllas-Kazacos, Vanadium battery solar demonstration house. in Solar 94. 1994. Sydney, Australia: American Solar Energy Society.

281. Largent, R.L., M. Skyllas-Kazacos, and J. Chieng, Improved PV system performance using vanadium batteries. in Twenty Third IEEE Photovoltaic Specialists Conference. 1993. Louisville, KY, USA: IEEE.

282. Utah Power cuts ribbon at pilot battery storage project. 2009, AllBusiness.com, Inc.: San Francisco, USA (Date of access: 3 July 2009), http://www.allbusiness.com/energy-utilities/utilities-industryelectric-power/5585509-1.html. 
283. Nakayama, Y., S. Takahashi, K. Hirakawa, and Y. Yamaguchi, Development of a long life 35 Ah capacity VRLA battery for load-leveling applications. Journal of Power Sources, 2004. 125(1): p. 135140.

284. Fang, B., Y. Wei, T. Arai, S. Iwasa, and M. Kumagai, Development of a novel redox flow battery for electricity storage system. Journal of Applied Electrochemistry, 2003. 33(2): p. 197-203.

285. Shibata, A. and K. Sato, Development of vanadium redox flow battery for electricity storage. Power Engineering Journal, 1999. 13(3): p. 130-135.

286. Nakajima, M., M. Sawahata, S. Yoshida, K. Sato, H. Kaneko, A. Negishi, and K. Nozaki, Vanadium redox flow battery with resources saving recycle ability I. Production of electrolytic solution for vanadium redox flow battery from boiler soot. Denki Kagaku, 1998. 66(6): p. 600-608.

287. Toshio, S. and H. Yutaka, Redox battery. 1985, Patent: JP60047373, Japan.

288. Vanadium redox-flow battery (VRB) for a variety of applications. 2001, Sumitomo Electric Industries Limited: Osaka, Japan (Date of access: 10 July 2009), http://www.electricitystorage.org/pubs/2001/IEEE_PES_Summer2001/Miyake.pdf.

289. Tokuda, N., T. Kanno, T. Hara, T. Shigematsu, Y. Tsutsui, A. Ikeuchi, T. Itou, and T. Kumamoto, Development of a redox flow battery system. Sumitomo Electric Industries Limited Technical Review, 2000. 50: p. 88-94.

290. The vanadium battery: the ultimate energy storage solution. 2005, Discovery Communications, LLC: Silverspring, Maryland, USA (Date of access: 05 September 2008), http://www.treehugger.com/files/2005/04/the_vanadium_ba.php.

291. Vanadium battery technology makes commercial progress as a storage solution for renewable energy. 2008, Triple Pundit: USA (Date of access: 24 May 2004),

http://www.triplepundit.com/pages/vanadium-battery-technology-makes-commer.php.

292. The Energy Blog: vanadium redox flow batteries. 2009, Fraiser, J. (Date of access: 6 July 2009), http://thefraserdomain.typepad.com/energy/2006/01/vandium_reflux_.html.

293. Itoh, T., T. Kanno, A. Ikeuchi, K. Kawai, and T. Hara, Development of vanadium redox flow battery system. in 34th Intersociety Energy Conversion Engineering Conference 1999. Vancouver, Canada: Society of Automotive Engineers, Inc.

294. Shinzato, T., K. Emura, K. Yamanishi, H. Deguchi, S. Miyake, T. Hara, and K. Suzuki, Vanadium redox-flow battery for voltage sag. in Electrical Energy Storage Applications and Technologies (EESAT). 2002. San Francisco, USA: The Electricity Storage Association.

295. VRB Power Systems Inc. VRB-EES sales brochure: the wind doesn't always blow when you need it. 2007, VRB Power Systems Inc.: Vancouver, Canada.

296. Remote area power systems: King Island 2007, VRB Power Systems Inc.: Vancouver, Canada.

297. VRB Power Systems - case studies. 2006, VRB Power Systems Inc.: Vancouver, Canada (Date of access: 21 September 2007 (Historical - company web site superseded)), http://www.vrbpower.com/publications/casestudies.html.

298. Size of VRB-ESS for Sorne Hill increased to 2MW $x$ 6hr and completion of Sustainable Energy Ireland / Tapbury feasibility study. 2009, PR Newswire Europe Ltd.: London, UK (Date of access: 3 July 2009), http://www.prnewswire.co.uk/cgi/news/release?id=193830.

299. Ireland windfarm inks VRB energy storage system purchase agreement. 2006, Wind Energy Investing (Reid, Brown \& Co., LLC): Houston, USA (Date of access: 24 May 2009), http://www.windenergyinvesting.com/2006/08/30/ireland-windfarm-inks-vrb-energy-storage-systempurchase-agreement/. 
300. Energy storage system for Irish windfarm increased based on study 2007, Contact Renewable Energy World Website: Peterborough, USA (Date of access: 12 July 2009),

http://www.renewableenergyworld.com/rea/news/article/2007/03/energy-storage-system-for-irish-windfarm-increased-based-on-study-47956.

301. Lim, H.-S., A.M. Lackner, and R.C. Knechtli, Zinc-bromine secondary battery. Journal of the Electrochemical Society, 1977. 124(8): p. 1154-1157.

302. ZBB (brochure). 2008, ZBB Energy Corporation: Wisconsin, USA.

303. ZBB project highlights. 2009, ZBB Energy Corporation: Wisconsin, USA (Date of access: 11 July 2009), http://zbbenergy.com/products/projecthighlights.htm.

304. 2008 update to the EPRI DOE handbook supplement of energy storage for grid connected wind generation applications. 2008, Sandia National Laboratories: Albuquerque, USA (Date of access: 15 November 2010), http://www.sandia.gov/ess/docs/pr_conferences/2008/gotschall_techins.pdf.

305. BOB, America's biggest sodium sulfur battery, powers a Texas town. 2010, Inhabitat: Los Angeles (Date of access: 9 November 2010), http://www.inhabitat.com/2010/04/06/bob-americas-biggestsodium-sulfur-battery-powers-a-texas-town/.

306. Texas pioneers energy storage in giant battery. 2010, National Geographic News: Washington D.C., USA (Date of access: 9 November 2010), http://news.nationalgeographic.com/news/2010/03/100325presidio-texas-battery/.

307. Grid energy storage: big market, tough to tackle. 2009, GreenTech Media Inc.: Cambridge, USA (Date of access: 15 November 2010), http://www.greentechmedia.com/articles/read/grid-energy-storage-bigmarket-tough-to-tackle/.

308. GE Enters the grid-based energy storage business. 2009, ALT Energy Stocks: New Haven, USA (Date of access: 15 November 2010),

http://www.altenergystocks.com/archives/2009/05/ge_enters_the_gridbased_energy_storage_business.h tml.

309. Wind farms operating and under construction. 2009, New Zealand Wind Energy Association: Wellington, NZ (Date of access: 26 November 2010), http://windenergy.org.nz/nz-windfarms/operating-wind-farms.

310. Project Hayes. 2009, Meridian Energy Limited: Wellington, NZ (Date of access: 14 December 2009), http://www.meridianenergy.co.nz/OurProjects/ProjectHayes/.

311. Project Hayes. 2009, New Zealand Wind Energy Association: Wellington, NZ (Date of access: 14 December 2009), http://www.windenergy.org.nz/nz-wind-farms/proposed-wind-farms/project-hayes.

312. Proposed wind farms. 2009, New Zealand Wind Energy Association: Wellington, NZ (Date of access: 26 November 2010), http://windenergy.org.nz/nz-wind-farms/proposed-wind-farms.

313. Report No DOE/EIA-0383(2010). Annual energy outlook 2010 with projection to 2030. 2010, Energy Information Administration: USA (Date of access: 19 November 2010), http://www.eia.doe.gov/oiaf/aeo. 


\section{Appendices}

Appendix A Method of calculation of cost of energy storage per kWh

This appendix describes the use of the LCCA model of Poonpun and Jewell (2008) [93], as applied in this research. Poonpun and Jewell noted that the overall total capital cost (TCC) of a storage system is equal to the cumulative costs of:

1 capital cost of the power capacity $(P)$, used for charge/discharge processes, in units of $\$$, as calculated from the cost per unit of power capacity $\left(\$ \mathrm{~kW}^{-1}\right)$,

2 total capital cost of on-site power quality management systems, rectifiers/transformers, etc., in units of $\$$, as calculated from the cost per unit of the power handling capacity $(\$$ $\mathrm{kW}^{-1}$ ),

3 the total capital cost for the energy storage units $(S U C)$, in units of \$. SUC is calculated from the cost per unit of installed energy storage $\left(S U C U, \$ \mathrm{kWh}^{-1}\right)$, the power rating $(\mathrm{kW})$ and the length of discharge time $\left(H_{0}\right.$, in units of $\left.\mathrm{h}\right)$ and the ac-to-ac roundtrip energy storage efficiency:

$$
S U C=S U C U \cdot P \cdot H_{0} / \eta_{\mathrm{ac}-\mathrm{ac}}
$$

4. balance of plant $(B O P, \$)$, which is the sum of the costs of all the remaining ancillary systems, components and structures not included above. BOP is estimated by multiplying the balance of plant per unit of energy storage (BOPU, $\$ \mathrm{kWh}^{-1}$ ) by $P$ and $H_{0}$, i.e.:

$$
B O P=B O P U \cdot P \cdot H_{0} .
$$

When combined, points 1 and 2 are known as the power electronics (PCS), the total cost of which is:

$$
P C S=P C S U \cdot P
$$

where the $P C S U$ is the unit cost of the power electronics per $\mathrm{kW}$. In this research, the time of discharge is estimated both from the literature limits of the different systems examined (from maximum time of discharge) and also from the expected capacity factor that may be used in NZ. Efficiency is assumed to be equal to $70 \%$, unless stated to the contrary. The total capital cost, therefore, is equal to:

$$
T C C=P C S+S U C+B O P .
$$

In most cases, the capital costs provided within the literature are not delineated to the extent given in points 1-4 (above). Here, it is assumed that the calculations used in the literature were based on maximum cost efficiency of use of the available storage.

The annualised capital cost $(A C)$ is:

$$
A C=T C C \cdot C R F
$$


and the capital recovery factor $(\mathrm{CRF})$ is given by:

$$
C R F=\left(i_{\mathrm{r}}\left[1+i_{\mathrm{r}}\right]^{r}\right) /\left(\left[1+i_{\mathrm{r}}\right]^{r}-1\right)
$$

where, $i_{\mathrm{r}}$ is the annual interest rate $(\%)$ and $r$ is the number of years of operation (replacement period).

Poonpun and Jewel also specifically considered the cost of replacement of batteries, which may occur every 10 to 15 years at current longevity rates. This factor can be included in the annual storage unit replacement cost, A:

$$
A=F \cdot\left[\left(1+i_{\mathrm{r}}\right)^{-r}+\left(1+i_{\mathrm{r}}\right)^{-2 r}+\cdots\right] \cdot C R F .
$$

$F$ is the future value replacement cost of the storage units. This replacement cost is not used in the calculations used in this research other than when the long-term costs of storage are quoted directly in the literature. An end of life condition, therefore, is generally assumed once the storage units have reached time to replacement, which will significantly reduce longterm cost-effectiveness. The relationship between replacement period (years) and lifetime (total charge-discharge cycles) of the storage units $(C D)$ is:

$$
r=C D /(n \cdot D)
$$

The annual storage replacement cost $(A R C)$ is:

$$
A R C=\left(A \cdot P \cdot H_{0}\right) / \eta
$$

The total annual fixed O\&M costs $\left(\$ \mathrm{y}^{-1}\right)$ are estimated via:

$$
\mathrm{O} \& \mathrm{M}={\mathrm{O} \& \mathrm{M}_{\mathrm{f}} P} P
$$

$O \& \mathrm{M}_{\mathrm{f} \mathrm{y}}$ represents the annual units cost per $\mathrm{kW}\left(\$ \mathrm{KW}^{-1} \mathrm{y}^{-1}\right)$.

Where, $\mathrm{E}_{\text {annual }}$ is the total installed energy capacity. Poonpun and Jewel then calculated $S$ :

$$
S=(A C+\mathrm{O} \& \mathrm{M}+A R C) /\left(P \cdot n \cdot H_{0} \cdot D\right)
$$

In the literature, $\mathrm{O} \& \mathrm{M}$ costs are noted in regard to $\$ \mathrm{kWh}^{-1}$ of energy discharged $\left(\mathrm{O} \& \mathrm{M}_{\mathrm{f} \mathrm{E}}\right)$. In this thesis, therefore, the annual fixed O\&M costs are simply added to the final cost of generation per kWh. Other assumptions used in this research for the calculation of $S$ include:

- 1 charge/storage cycle per day for 250 days of each year (includes days of peak demand only),

- time of discharge is dictated by either nominal plant rating or a plant CF of $0.05,0.20$ and 0.26 , and

- an interest rate of $5 \%$ (the average annual rate projected by the EIA reference case in 2010 for the period 2008 to 2035 [313] - excluding inflation and escalation rates).

The cost of primary generation is then added to the energy storage costs along with infrastructure and grid connection costs in order to give a total combined cost of electricity storage/generation. 


\section{Appendix B. Survey information sheet}

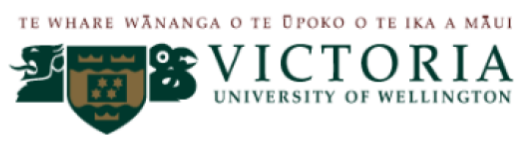

INFORMATION SHEET FOR RESEARCH PARTICIPANTS (Questionnaire \& interview)

\section{Research Project: \\ "Energy storage for electricity generation in New Zealand"}

This research is conducted by:

Gareth Kear

Master of Environmental Studies - Student

gareth.kear@vuw.ac.nz
This research is supervised by:

\section{Ralph Chapman}

\section{Associate Professor}

ralph.chapman@vuw.ac.nz

School of Geography, Environment and Earth Sciences (SGEES)

Victoria University of Wellington

PO BOX 600

Wellington 6140

Dear Project Participant,

You are being asked to complete a questionnaire and to take part in an interview for a research study. The project is investigating the feasibility of introducing new forms of utility-scale energy storage technologies to the New Zealand electricity sector.

\section{Purpose of the study}

The primary aim of the study is:

the determination of the feasibility and costs of introducing non-standard, utilityscale energy storage technologies to the New Zealand electricity sector for enhanced (1) dry-year security of supply, (2) hydroelectricity spillage mitigation, (3) support of intermittent renewable energy-based generation and (4) non-thermal, peak demandbased generation.

This survey (questionnaire and interview) is one part of the study; the other part is an analysis of the existing literature. The study is seeking informed views from a range of policy advisers and experts.

\section{Use of results from the interviews}

The results collected will be reported in papers submitted for publication in academic journals and presented at conferences. The overall findings will also form part of a Masters thesis that will be submitted for assessment.

What is involved if you agree to participate?

- You will be asked to respond to various questions relating to the theme of this research.

- You will also have an opportunity to provide additional comment.

- I expect that the time requirement will be around forty five minutes (sixty minutes maximum). 
Timing and location of interviews

It is expected that the interviews for this research project will take place during the December 2010/January 2011 period, in Wellington, New Zealand. The location would be your office or an interview room at Victoria University of Wellington

Privacy and confidentiality

- The Informed Consent Form (attached) asks you whether you require confidentiality or not. Depending on whether or not you require confidentiality, please select and indicate the relevant statement by ticking the appropriate box on the Consent Form.

- If you request not to be identified personally, you will not be identified in the research project or in any other presentation or publication. The information you provide will be coded by number only.

- In accordance with the requirements of some scientific journals and organisations, the coded and confidential data, but not your identity, may be shared with other competent researchers.

- Your coded data may be used in other, related studies.

\section{Storage and disposal of data}

You will be asked whether you are content for your remarks to be digitally recorded. Access to the written and any electronic material will be restricted to Gareth Kear and Associate Professor Ralph Chapman. The data will remain in the custody of Gareth Kear. All written material will be kept in a locked file, and all electronic material will be password protected. After a maximum of five years, all collected written materials will be destroyed and the audio recordings will be electronically wiped.

\section{Right of withdrawal}

You will have the right to refuse to answer any question(s) and to withdraw any information you have supplied within three weeks of completing the survey.

\section{Provision of feedback}

You have the right to ask to check the interview transcript, and will be able to provide any corrections within three weeks of completing the survey.

Community access to research results

A summary of the completed research output will be available. You may request it by indicating so on the 'Informed Consent Form' (attached), or on later request (email to: gareth.kear@vuw.ac.nz).

Ethics approval

The Victoria University of Wellington Human Ethics Committee has granted ethical approval for this research

If you have any other questions about this project, please feel free to ask me now, or contact me later, from the contact details provided on this information sheet. Thank you for participating.

Sincerely,

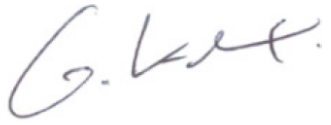

Gareth Kear

Master of Environmental Studies - Student

School of Geography, Environment and Earth Sciences

SCHOOL OF GEOGRAPHY, ENVIRONMENT AND EARTH SCIENCES

PO Box 600, Wellington, New Zealand

Phone +64-4-463 5337 Fax +64-4-463 5186 Website www.geo.vuw.ac.nz
Te Kura Tatai Aro Whenua 


\title{
Appendix C Consent to participation forms ('organisation' and 'individual' versions)
}

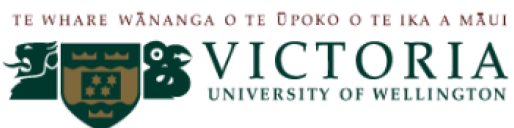

\section{CONSENT TO PARTICIPATION IN RESEARCH (Questionnaire \& Interview - organisation) Energy storage and electricity generation in New Zealand}

1 I have been given adequate information relating to the nature and objectives of this research project, and I have understood that information. I have been given the contact details of both Gareth Kear and Associate Professor Ralph Chapman so I can ask questions about any aspect of the project if I wish. I understand that my remarks could be digitally recorded (see Point 3, below) and the transcript of my remarks will be available to me should I wish to check it. I understand that I may choose to withdraw myself (or any information I have provided) within three weeks after the date given below. I understand that if I withdraw from the project, any data I have provided will be destroyed.

Please tick the box which you prefer:

(a) I consent to the answers I give being attributed to $\boldsymbol{m} \boldsymbol{e}$, as an employee of the organisation I work<smiles>C1CC2CC12</smiles>

Or (b) I consent to the answers I give being attributed only to the organisation I work for, but not attributed to me personally

3 Please tick the box which you prefer:

(a) I consent to the interview being digitally recorded

(b) I agree to the interview but I do not consent to the interview being digitally recorded

Please tick the box which you prefer:

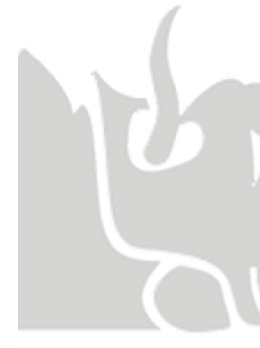

(a) I want to receive a copy of any comments attributed to me, before the research is published

(b) I want to receive a summary of the results of the research and any published article, after completion of the project

(c) I do not need to receive a summary of the results of the research or published articles

If you checked either (a) or (b), above, please provide additional contact details here:

5 I understand that the information I have provided will be used for this research project and that a summary report and any article published in a journal will be sent to me, if requested. I understand that the questionnaires will be destroyed within five years of the completion of the project. I also understand that the data I provide will not be used for any other purpose or released to others without my written consent.

I agree to take part in this research.

Signed:

Date:

Name of participant:

(Please print clearly)

\author{
SCHOOL OF GEOGRAPHY, ENVIRONMENT AND EARTH SCIENCES \\ PO Box 600, Wellington, New Zealand \\ Phone +64-4-463 5337 Fax +64-4-463 5186 Website www.geo.vuw.ac.nz
}

Te Kura Tatai Aro Whenua 


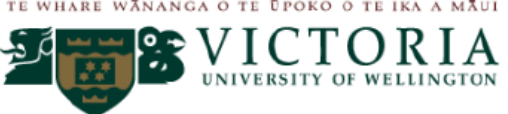

CONSENT TO PARTICIPATION IN RESEARCH (Questionnaire \& Interview - individual)
Energy storage and electricity generation in New Zealand

1 I have been given adequate information relating to the nature and objectives of this research project, and I have understood that information. I have been given the contact details of both Gareth Kear and Associate Professor Ralph Chapman so I can ask questions about any aspect of the project if I wish. I understand that my remarks could be digitally recorded (see Point 3 , below) and the transcript of my remarks will be available to me should I wish to check it. I understand that I may choose to withdraw myself (or any information I have provided) within three weeks after the date given below. I understand that if I withdraw from the project, any data I have provided will be destroyed.

2 Please tick the box which you prefer:

(a) I consent to the answers I give being attributed to $m e$, as an individual person $L$

(b) The answers that I give shall not be attributed to me

(a) I consent to the interview being digitally recorded

Or (b) I agree to the interview but I do not consent to the interview being digitally recorded

Please tick the box which you prefer:

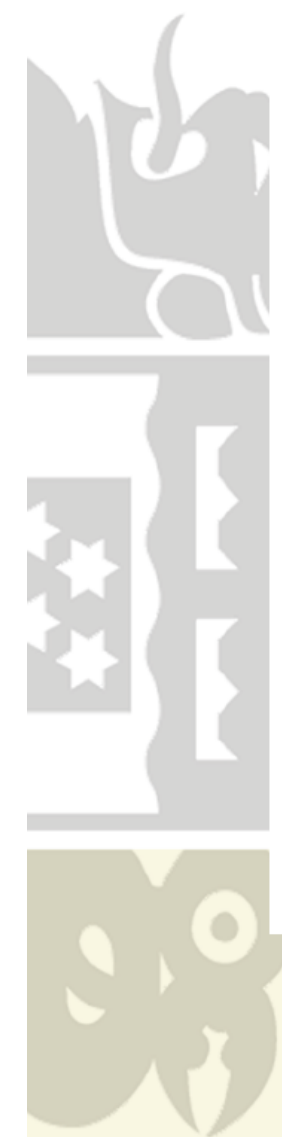

(a) I want to receive a copy of any comments attributed to me, before the research is published

Or (b) I want to receive a summary of the results of the research and any published article, after completion of the project

Or

(c) I do not need to receive a summary of the results of the research or published articles $\square$.

If you checked either (a) or (b), above, please provide additional contact details here:

5 I understand that the information I have provided will be used for this research project and that a summary report and any article published in a journal will be sent to me, if requested. I understand that the questionnaires will be destroyed within five years of the completion of the project. I also understand that the data I provide will not be used for any other purpose or released to others without my written consent.

\section{I agree to take part in this research.}

Signed:

Date:

Name of participant:

(Please print clearly) 


\section{Appendix D Survey ethics approval}

TE WHARE WĀNANGA O TE UPOKO O TE IKA A MĀUI

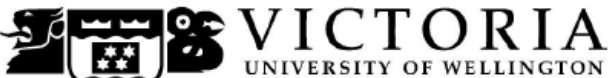

\section{MEMORANDUM}

$\begin{array}{ll}\text { Phone } & 0-4-4635676 \\ \text { Fax } & 0-4-4635209 \\ \text { Email } & \text { Allison.kirkman@vuw.ac.nz }\end{array}$

\begin{tabular}{l|l}
\hline TO & Gareth Kear \\
\hline COPY TO & Ralph Chapman \\
\hline FROM & Dr Allison Kirkman, Convener, Human Ethics Committee \\
\hline
\end{tabular}

\begin{tabular}{l|l}
\hline DATE & 30 November 2010 \\
\hline PAGES & 1 \\
\hline
\end{tabular}

SUBJECT Ethics Approval: No 18131 Utility-scale energy storage for backup electricity generation in New Zealand

Thank you for your application for ethical approval, which have now been considered by the Standing Committee of the Human Ethics Committee.

Your application has been approved from the above date and this approval continues until 28 February 2011. If your data collection is not completed by this date you should apply to the Human Ethics Committee for an extension to this approval.

Best wishes with the research.

Allison Kirkman

Human Ethics Committee 
Appendix E Questionnaire

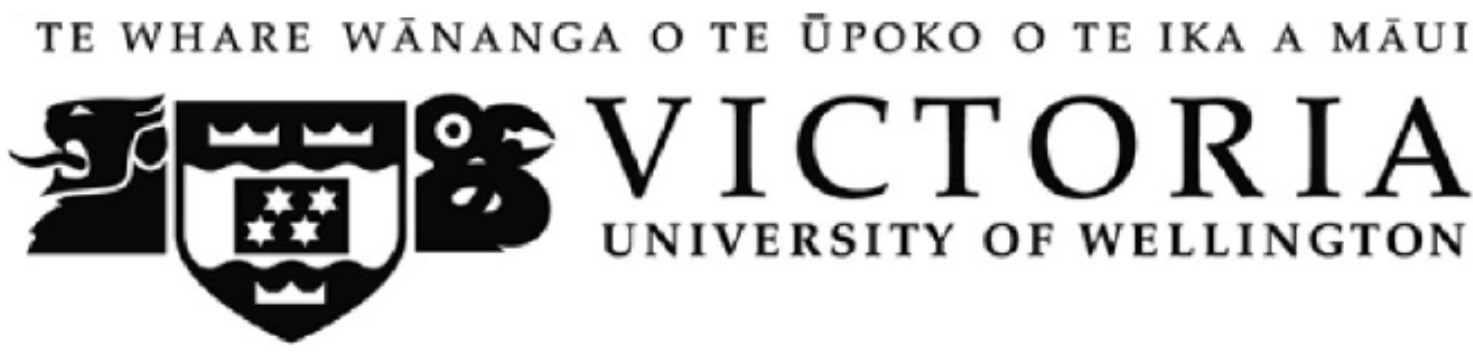

Energy storage - questionnaire for key informants

Name:

Date:

Organisation (if applicable):

Please return to:

\section{Gareth Kear}

Phone: +6444635337

Fax: +64 44635186

C/O School of Geography, Environment and Earth Sciences (SGEES)

Victoria University of Wellington

PO BOX 600

Wellington 6140

For a rapid response please scan this document and send via email to:

Gareth.Kear@vuw.ac.nz / garethkear@hotmail.com 


\section{Introduction}

You are being asked to complete a questionnaire for a research study based at Victoria University of Wellington. The project is investigating the feasibility of introducing new forms of renewable utilityscale energy storage technologies to the New Zealand electricity sector.

I am seeking informed views from a range of policy advisers and experts with knowledge of the New Zealand electricity sector. I am interested in summarising both the extent of current knowledge and identifying gaps in existing data.

\section{The questionnaire}

Please answer the 'rating scale-based' questions in one of the following three ways:

1. mark an ' $X$ ' anywhere on the answer line to indicate an exact value, or encircle a range of values, i.e.,

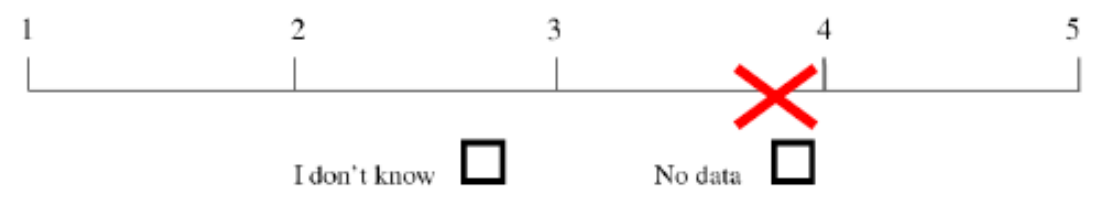

or

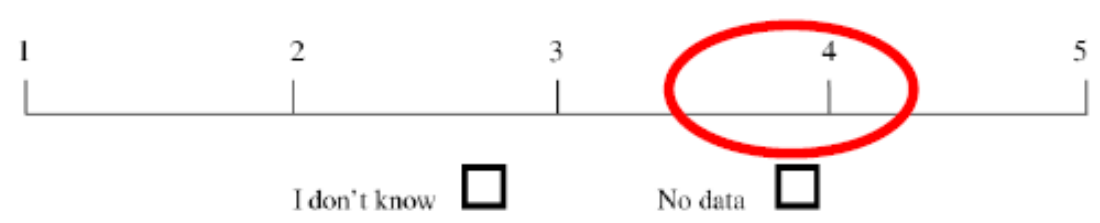

2. check the 'I don't know' box if you are personally unaware of the answer, or

3. check the 'No data' box if it is your understanding that there is insufficient information available and it is likely that the question cannot be answered by anyone.

\section{General assumptions}

'Backup electricity generators' is a term used in this research for generators that ensure (1) peak adequacy, (2) intermittency adequacy and (3) dry-year security of supply under emergency conditions.

All introduced energy storage will be charged using either wind- or hydro-based renewable resources, and will only be charged when this energy is available in significant excess, i.e., when it would otherwise have a low value (e.g., hydro-spillage and/or wind excess).

Until directed by the questioning, please consider that there will be no new discoveries of large-scale and easily accessible natural gas fields in New Zealand prior to 2025. In all other cases, please adopt the most likely developmental pathways. 
1. What is likely to be the growth rate of average electricity demand from now until 2025 ?

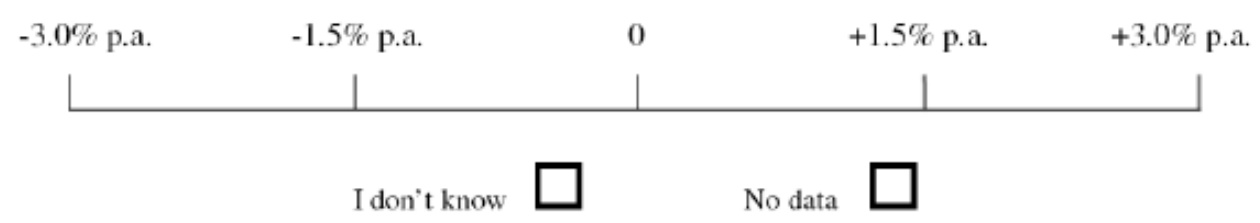

2. If growth in demand does occur, at what scale of individual power station is most of the new supply likely to be realised? (Please note: logarithmic scale.)

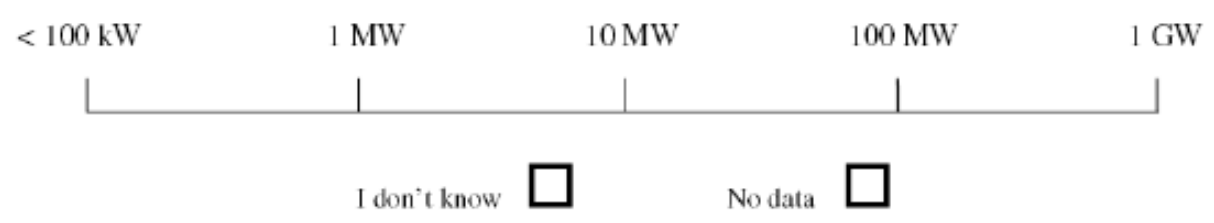

3. In approximate terms, what will be the growth rate of peak electricity demand from now until 2025 ?

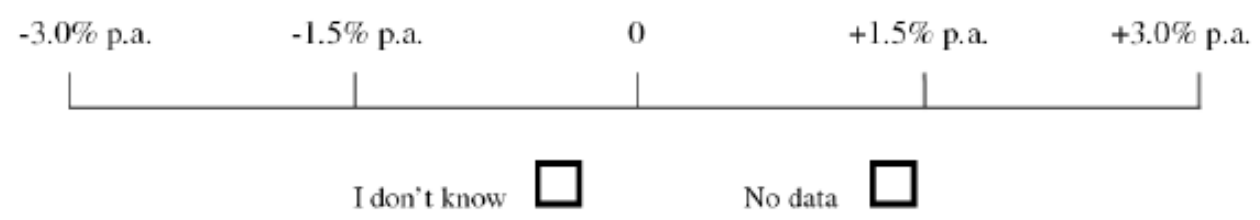

4. How much of any growth in peak demand to 2025 will be met with the construction of thermal capacity based on natural gas and/or diesel fuels?

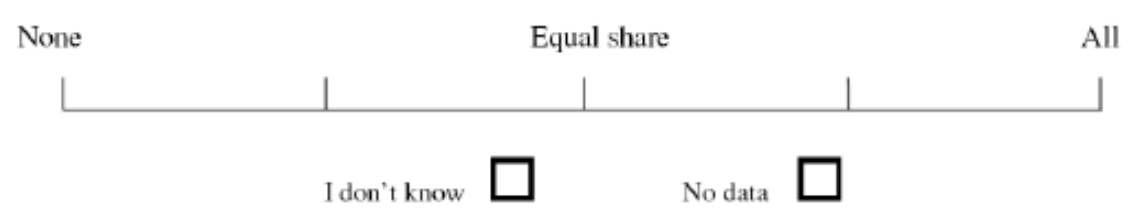

5. Will fast-start backup power capacity be necessary for the successful introduction of a $20 \%$ share of wind power by 2025 ?

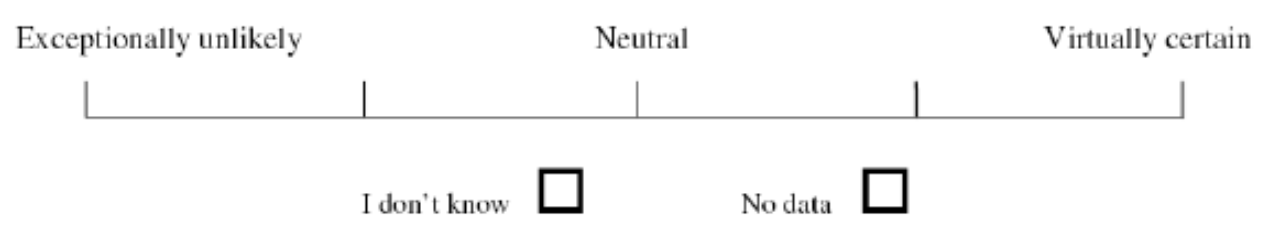


6. Is it likely that a $20 \%$ share of intermittent power capacity (wind) can be integrated into the national grid by 2025 using standard, non-pumped hydro storage without the introduction of any new thermal fast-start capacity?

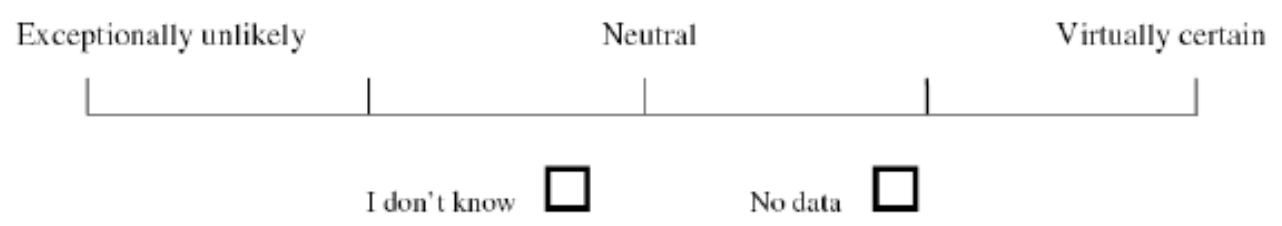

7. If all four coal units at Huntly are decommissioned prior to 2025 and no new thermal is built, do you consider it likely that enough renewables power and standard hydro storage could be consented and built to prevent emergency dry-year events?

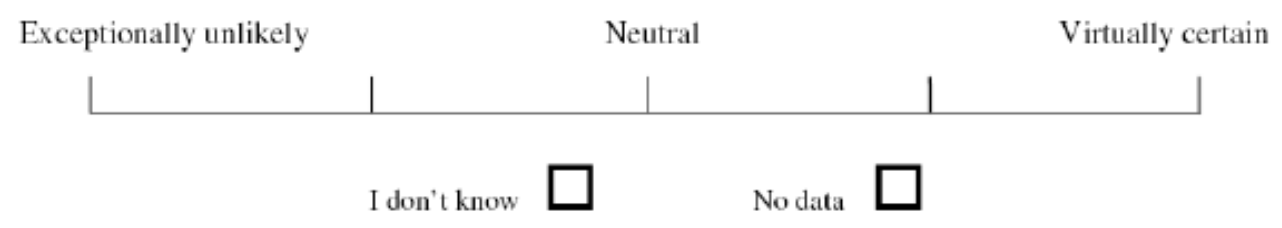

Please proceed to the next page. 
8. Excluding environmental and economic considerations, do you consider that it is technically feasible for pumped hydroelectricity-based energy storage systems to be introduced by 2025 for the management of:

(a) Peak electricity demand?

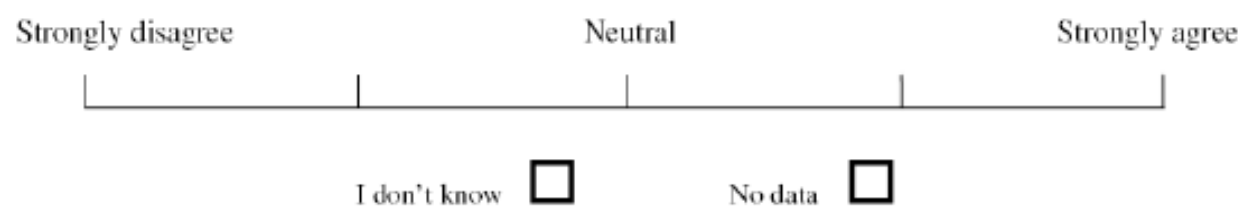

(b) Grid integration of intermittent renewables?

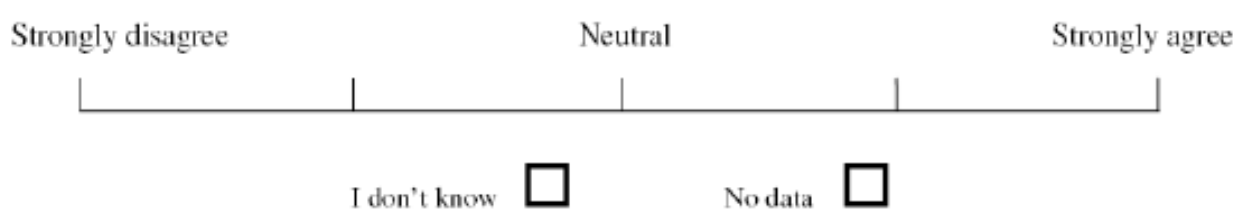

(c) Emergency dry-year reserve generation?

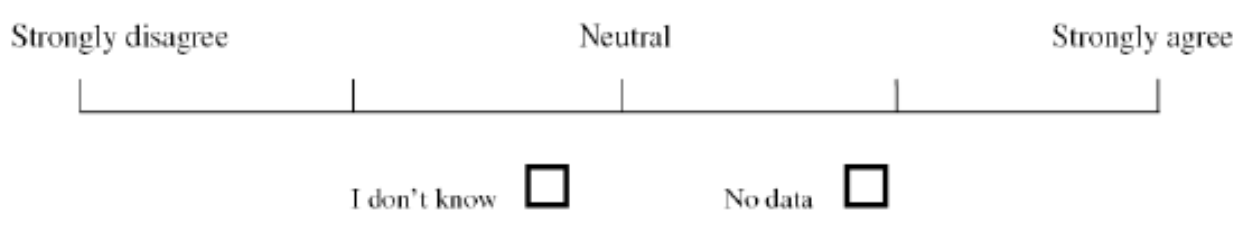

(d) Reduction of hydroelectricity spillage losses or wind excess issues?

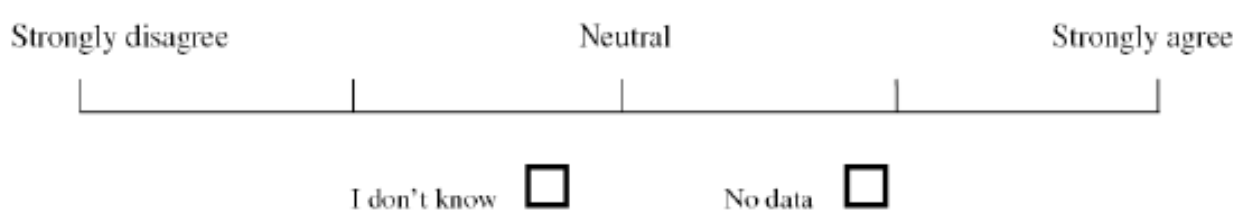

Please proceed to the next page. 
9. Excluding environmental and economic considerations, do you consider that it is technically feasible for battery-based energy storage systems to be introduced by 2025 for the management of:

(a) Peak electricity demand?

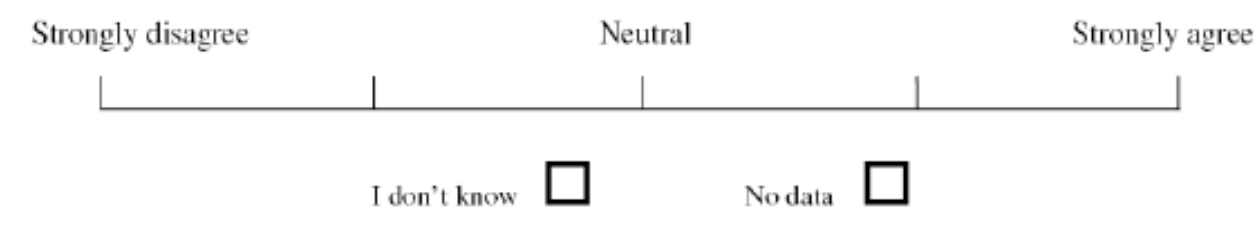

(b) Grid integration of intermittent renewables?

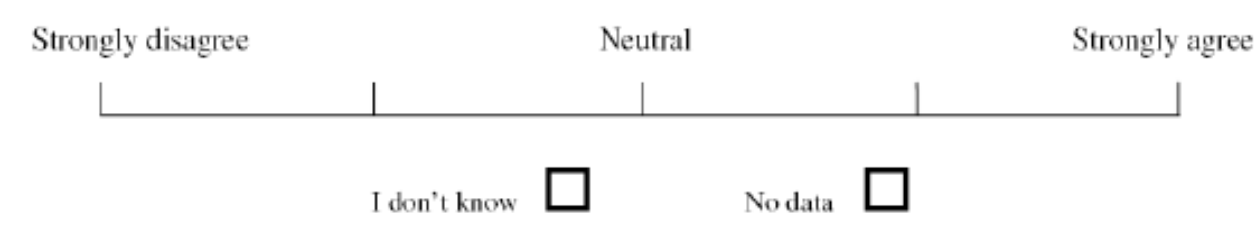

(c) Emergency dry-year reserve generation?

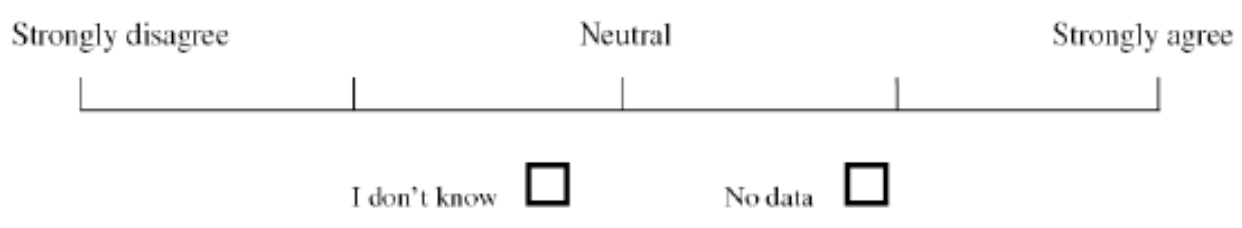

(d) Reduction of hydroelectricity spillage losses or wind excess issues?

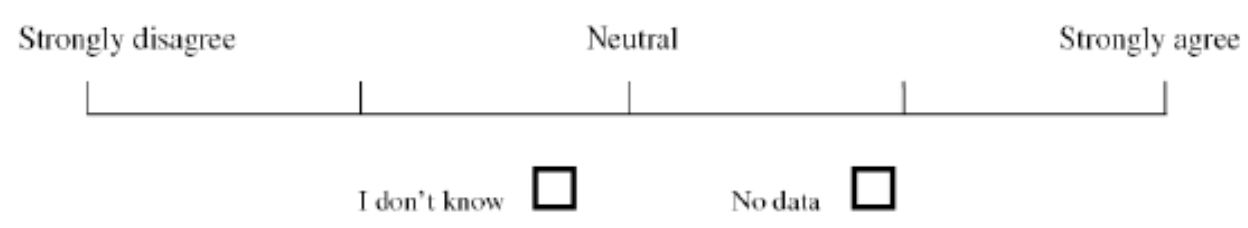

Please proceed to the next page. 
10. Please rank the following in regard to what you would consider to be the most cost-effective investment for fast-start, backup power generation in New Zealand at $\mathrm{NZ} \$ 30\left[\mathrm{CO}_{2}\right.$-e] per tonne, $\mathrm{NZ} \$ 10$ [gas] per GJ and NZ\$50 [diesel] per GJ.

Assume that each power station has a power rating is $200 \mathrm{MW}$ and will operate at a power capacity factor of $0.05(5 \%)$.

Please use a scale of 1 to 5 , where 1 is the most cost-effective.

Pumped hydroelectricity system (hydro-spillage and/or wind powered)

Diesel system (open cycle gas turbine)

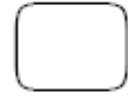

Natural gas system with dedicated gas storage (open cycle gas turbine)

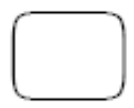

Utility-scale battery system (hydro-spillage and/or wind powered)

Natural gas system (open cycle gas turbine)

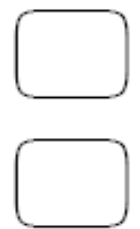

Please proceed to the next page. 
11. Assuming $\mathrm{NZ} \$ 30\left[\mathrm{CO}_{2}\right.$-e] per tonne, $\mathrm{NZ} \$ 10$ [gas] per GJ and $\mathrm{NZ} \$ 50$ [diesel] per GJ, what is likely to be the approximate long run marginal cost (LRMC) of backup generation from the following? Please assume a power rating of $200 \mathrm{MW}$ operating at a capacity factor of $0.05(5 \%)$.

(a) A natural gas generator?

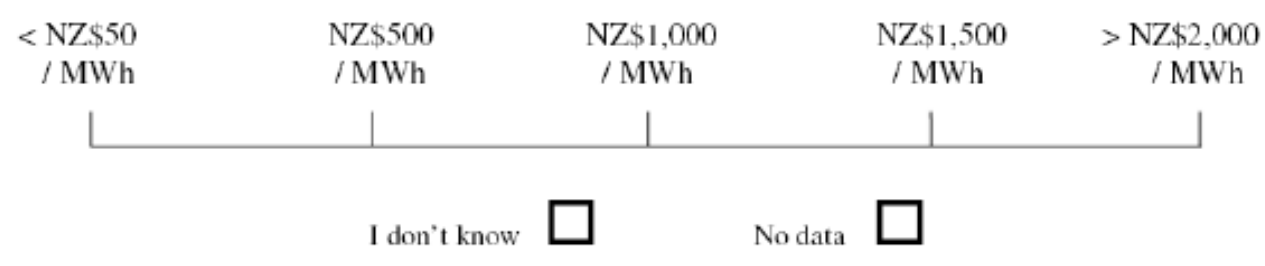

(b) A diesel generator?

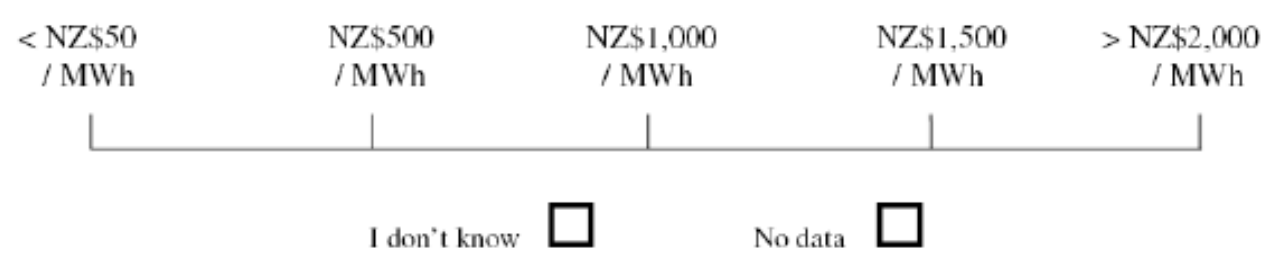

(c) A gas generator run on stored natural gas?

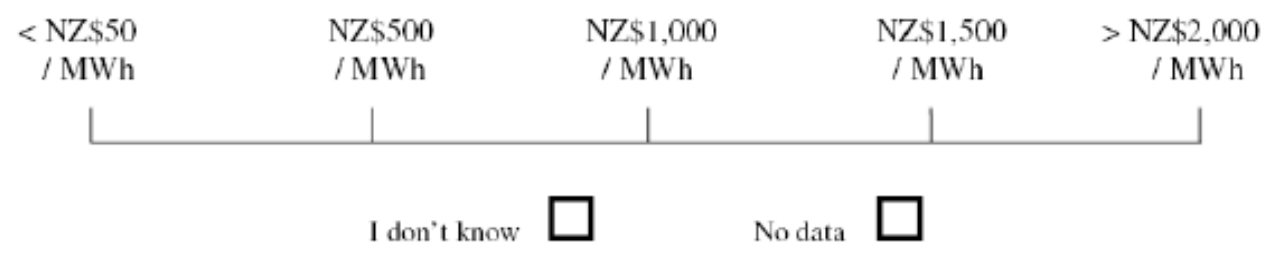

(d)A pumped hydroelectricity generator, where spillage and/or wind power is used for pumping?

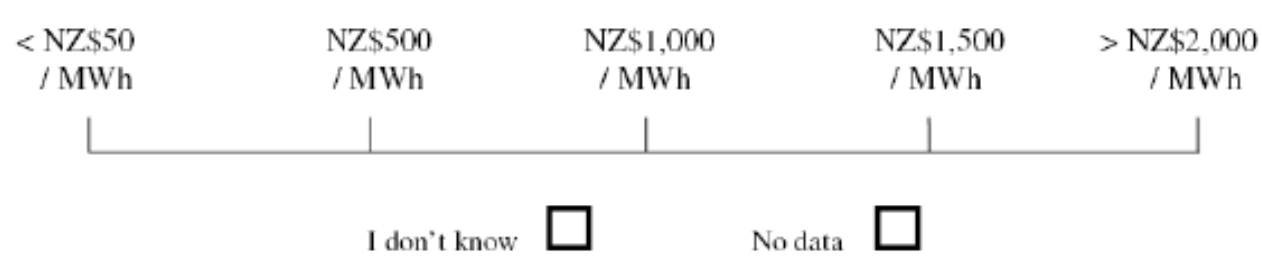

(e) A battery-based generator, where spillage and/or wind power is used to charge the system?

\begin{tabular}{|c|c|c|c|c|}
\hline $\begin{array}{r}<\mathrm{NZ \$ 50} \\
/ \mathrm{MWh}\end{array}$ & $\begin{array}{l}\mathrm{NZ} \$ 500 \\
/ \mathrm{MWh}\end{array}$ & $\begin{array}{l}\mathrm{NZ} \$ 1,000 \\
/ \mathrm{MWh}\end{array}$ & $\begin{array}{l}\mathrm{NZ} \$ 1,500 \\
/ \mathrm{MWh}\end{array}$ & $\begin{array}{c}>\mathrm{NZ} \$ 2,000 \\
/ \mathrm{MWh}\end{array}$ \\
\hline & & $\mid$ & 1 & \\
\hline
\end{tabular}


12. Do you consider that the introduction of pumped hydro and/or batteries prior to 2025 is likely at $\mathrm{NZ} \$ 30\left[\mathrm{CO}_{2}\right.$-e $]$ per tonne, $\mathrm{NZ} \$ 10$ [gas] per GJ and $\mathrm{NZ} \$ 50$ [diesel] per GJ?

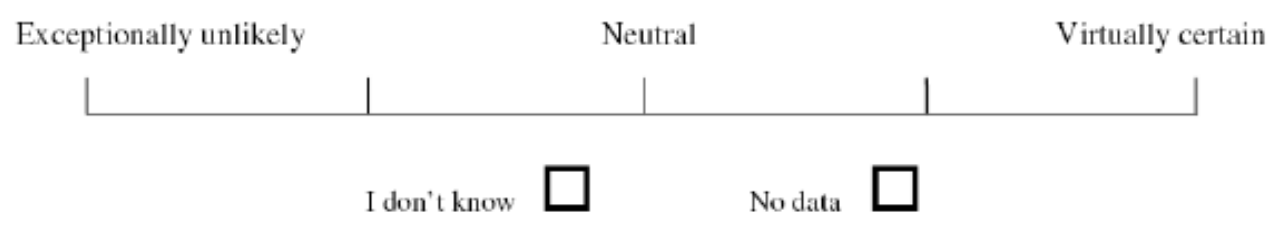

13. Do you consider that a price on carbon of $\underline{\mathrm{NZ} \$ 100}\left(\mathrm{CO}_{2}\right.$-e) per tonne would significantly improve the likelihood of pumped hydro and/or batteries being introduced by 2025 (at NZ $\$ 10$ [gas] per GJ and NZ\$50 [diesel] per GJ)?

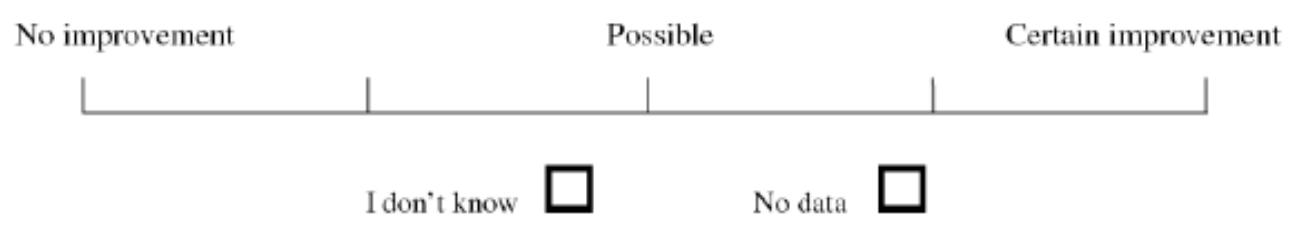

14. If there are discoveries enabling the price of natural gas to $\varliminf$ imit at NZ $\$ 5$ per GJ by 2025 , would you consider that the introduction of pumped hydro and/or batteries to New Zealand prior to 2025 is likely at $\underline{\mathrm{NZ} \$ 100}\left(\mathrm{CO}_{2}\right.$-e $)$ per tonne?

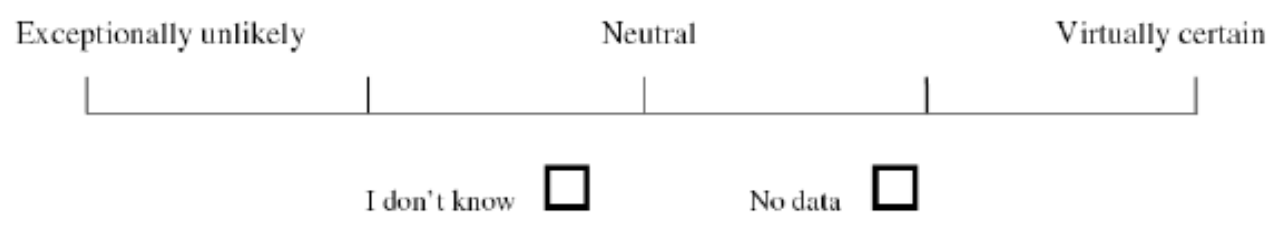

15. If the global economy experiences a series of 'oil shocks' (intermittent periods of high oil prices) prior to 2025 could this significantly improve the likelihood of pumped hydro and/or batteries being introduced by 2025 at $\underline{\mathrm{NZ} \$ 30}\left[\mathrm{CO}_{2}\right.$-e] per tonne and $\mathrm{NZ} \$ 10$ [gas] per GJ?

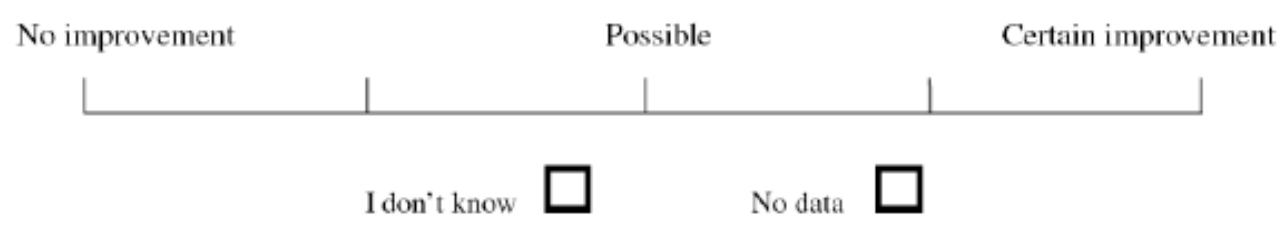

Please proceed to the next page. 
16. While independently considering both pumped hydro- and battery-based energy storage, please rank the following as either a disadvantage (negative) or an advantage (positive) with respect to the promotion of these systems.

Please assign any one of the following: $-2,-1,0,+1,+2$.

Leave the box blank if you 'don't know'.

Pumped hydroelectricity Utility-scale batteries

(a) A preference to maintain the current framework of the electricity market

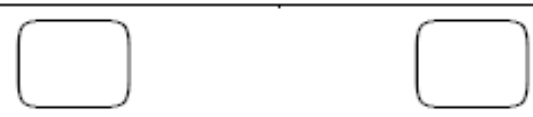

(b) The need to reduce local environmental impact
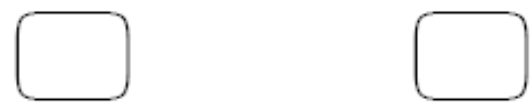

(c) The adequacy of existing skills and knowledge
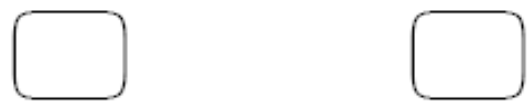

(d) The need for ease of integration with large-scale, centralised generation sources
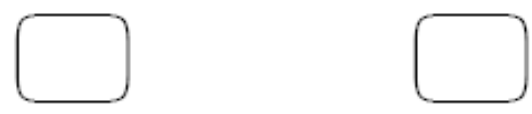

(e) The need for flexibility in site selection
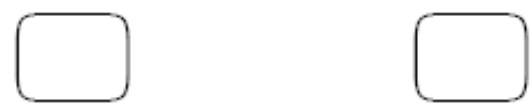

(f) An investor requirement for a costeffective solution
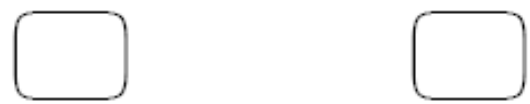

(g) The need for a technically effective solution
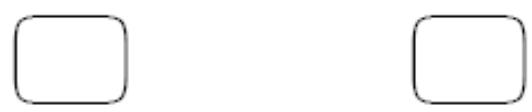

(h) The need for limited modification of existing transmission infrastructure
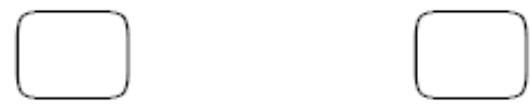

(i) A future requirement for significant climate change adaptation
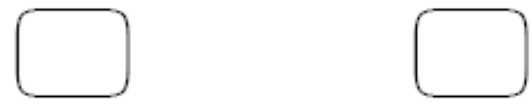

(j) A preference for internationally adopted and fully commercialised technology
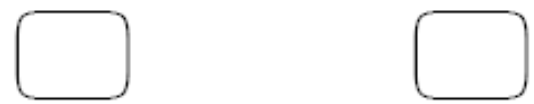

(k) The need for adequate power capacity
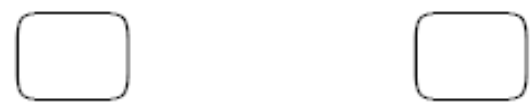

(1) The need for adequate energy capacity
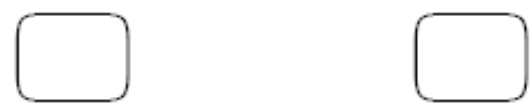

(m) The need for climate change mitigation
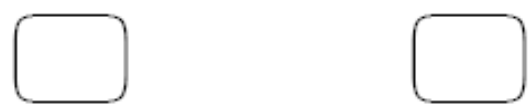
17. Please rank the following with respect to their potential to contribute towards the general promotion of new forms of renewables-based energy storage in NZ.

Please use a scale of 1 to 5 , where 1 as the most potential.

Leave the box blank if you 'don't know'.

Introduced energy storage (renewables based)

The need to reduce $\mathrm{CO}_{2}$-e emissions

The need for reliable security of supply

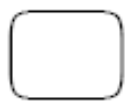

A need for congruence with current investment pathways

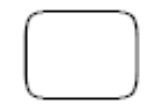

A need to reduce the impact of fossil-fuelbased uncertainties

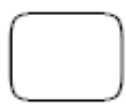

A need for national energy independence

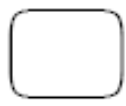

Please proceed to the next page. 
18. Please rank the following in regard to which technology is most likely to make the biggest contribution towards new-build backup power capacity in New Zealand up to 2025 .

Please use a scale of 1 to 4 , where 1 has the greatest potential.

Please continue to assume that there will be no new discoveries of large-scale and easily accessible natural gas fields prior to this date.

Pumped hydroelectricity power

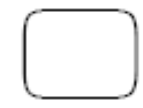

Thermal power

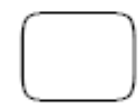

Battery power

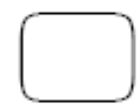

Non-pumped, standard hydropower

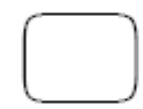

19. Is there another new form of utility-scale energy storage that could be examined for application to the New Zealand electricity sector? If so, please specify.

Please feel free to add further comments over the page. 


\section{Additional comments}

Thank you for your input. 


\section{Appendix F Hydro-spillage definitions}

Table AF1. Typical definitions of the terms and categories used by the NZ generators for the justification of hydro spillage in NZ, after Mighty River Power [183]. Those terms that are included in the calculation of avoidable spillage in this work, as shown in Figure 3.4, are indicated with a tick. (The absence of a tick does not necessarily indicate that this term cannot at some point be used with a form of energy storage.)

\begin{tabular}{|c|c|c|}
\hline Term & Definition & $\begin{array}{l}\text { Energy } \\
\text { Storage }\end{array}$ \\
\hline Plant & $\begin{array}{l}\text { Hydro-spill was due to a plant malfunction including plant owned by a third } \\
\text { party, or from plant testing, or from planned or unplanned outages. }\end{array}$ & - \\
\hline Obstructions & $\begin{array}{l}\text { Hydro-spill was due to physical obstructions preventing normal operation of } \\
\text { generating plant. Such obstructions include weed, logs, silt, public, etc. }\end{array}$ & - \\
\hline High inflow & $\begin{array}{l}\text { Hydro-spill was due to high inflow events. This code applies when the flows } \\
\text { exceed the ability of the generation scheme to generate at that level. This code } \\
\text { only applies when the operator has no discretion over avoiding the release. }\end{array}$ & $\sqrt{ }$ \\
\hline Regulatory & $\begin{array}{l}\text { Hydro-spill was due to regulatory obligations. It includes statutes, resource } \\
\text { consents, use permits, bylaws, etc. This code only applies when the operator has } \\
\text { no discretion over avoiding the release. }\end{array}$ & - \\
\hline Contractual & $\begin{array}{l}\text { Hydro-spill was due to contractual obligations. This code only applies when the } \\
\text { operator has no discretion over avoiding the release. }\end{array}$ & - \\
\hline Recreational & $\begin{array}{l}\text { Hydro-spill was for recreational use. That is where recreational, social or cultural } \\
\text { interests have negotiated hydraulic profiles; and hydro-release has occurred as a } \\
\text { result. }\end{array}$ & - \\
\hline Cost & Hydro-spill was due to the cost of generation exceeding the spot price. & $\nabla$ \\
\hline Economic & Hydro-spill was for other commercial reasons such as price support in the market. & - \\
\hline $\begin{array}{l}\text { Transmission } \\
\text { constraint }\end{array}$ & Hydro spill was due to transmission or distribution constraints. & - \\
\hline $\begin{array}{l}\text { Hydraulic } \\
\text { constraint }\end{array}$ & $\begin{array}{l}\text { Hydro-spill was due to capacity differences within some hydraulically coupled } \\
\text { schemes, requiring additional water bypass to maintain output. }\end{array}$ & - \\
\hline Other & $\begin{array}{l}\text { Hydro-spill was due to any other reason. When this code is used, an appropriate } \\
\text { description and explanation must also be included. }\end{array}$ & - \\
\hline
\end{tabular}




\section{Appendix G Tabulated summaries of interview responses}

Table AG1. Summary of responses obtained during the interview for Question A1 on the current benefits of energy storage: "Please describe 2 or 3 of the main benefits that utility-scale energy storage currently provides to the electricity system."

\begin{tabular}{|c|c|c|}
\hline Q.A1 & Benefits of existing ES & Summary of respondent's deductive reasoning \\
\hline $\mathrm{GO} 2$ & $\begin{array}{l}\text { (1) Security of supply } \\
\text { (2) Economic } \\
\text { (3) Ancillary services }\end{array}$ & $\begin{array}{l}\text { (1) Provides peaking capacity for North Island and buffers monthly \& seasonal } \\
\text { variability } \\
\text { (2) Reduces the requirement for importing large amounts of thermal peaking } \\
\text { plant (also provided jobs during construction phase) } \\
\text { (3) - }\end{array}$ \\
\hline GO3 & $\begin{array}{l}\text { (1) Economic } \\
\text { (2) Security of supply }\end{array}$ & $\begin{array}{l}\text { (1) Enables elec. prices to stay low \& limits large thermal fuel stock piles } \\
\text { (2) From existing hydro storage capacity }\end{array}$ \\
\hline NGO2 & (1) Security of supply & (1) Dry year resilience (but only in conjunction with coal) \\
\hline INDIV1 & $\begin{array}{l}\text { (1) Security of supply } \\
\text { (2) Economic } \\
\text { (3) Low } \mathrm{CO}_{2} \text {-e emissions }\end{array}$ & $\begin{array}{l}\text { (1) Hydro storage capacity used to meet demand } \\
\text { (2) Reduces market volatility } \\
\text { (3) Hydro displaces thermal generation }\end{array}$ \\
\hline INDIV2 & $\begin{array}{l}\text { (1) Security of supply } \\
\text { (2) Economic } \\
\text { (3) Low } \mathrm{CO}_{2} \text {-e emissions } \\
\text { (4) Ancillary services }\end{array}$ & $\begin{array}{l}\text { (1) Enables supply to be varied to meet demand, rather than vice versa } \\
\text { (2) Enormous economic benefit to the industrial sector } \\
\text { (3) Hydro displaces thermal generation } \\
\text { (4) - }\end{array}$ \\
\hline INDIV3 & $\begin{array}{l}\text { (1) Security of supply } \\
\text { (2) Economic } \\
\text { (3) Low } \mathrm{CO}_{2} \text {-e emissions }\end{array}$ & $\begin{array}{l}\text { (1) Hydro storage capacity (to meet peak and average demand) } \\
\text { (2) - } \\
\text { (3) Hydro displaces thermal generation }\end{array}$ \\
\hline INDIV4 & $\begin{array}{l}\text { (1) Security of supply } \\
\text { (2) Wind integration } \\
\text { (3) Economic } \\
\text { (4) Low } \mathrm{CO}_{2} \text {-e emissions } \\
\text { (5) Fuel independence }\end{array}$ & $\begin{array}{l}\text { (1) Hydro provides baseload, voltage regulation, peaking, etc. } \\
\text { (2) Hydro is already supporting variable renewables, to some extent } \\
\text { (3) Whole electricity system relies on hydro-based energy storage (although } \\
\text { would have otherwise have built more coal-based capacity) } \\
\text { (4 \& 5) See (3) }\end{array}$ \\
\hline INDIV5 & (1) Security of supply & (1) But, need to plan effectively for dry-years, peaking capacity, etc. \\
\hline INDIV6 & $\begin{array}{l}\text { (1) Security of supply } \\
\text { (2) Ancillary services } \\
\text { (3) Economic }\end{array}$ & $\begin{array}{l}(1 \& \text { 2) The lake-based system is operated for short-run security of supply \& } \\
\text { ancillary services } \\
\text { (3) NZ is electricity-supply dependent }\end{array}$ \\
\hline INDIV8 & $\begin{array}{l}\text { (1) Security of supply } \\
\text { (2) Ancillary services } \\
\text { (3) Economic }\end{array}$ & $\begin{array}{l}\text { (1) Management of peak demand } \\
\text { (2) Stabilising load on thermal stations \& management of frequency } \\
\text { (3) Minimising price spikes }\end{array}$ \\
\hline
\end{tabular}


Table AG2. Summary of responses obtained during the interview for Question A2 on the future benefits of energy storage: "If the capacity of energy storage could be greatly expanded to meet all of the needs of the system, what could be the main benefits to the electricity sector?"

\begin{tabular}{|c|c|c|}
\hline Q.A2 & Potential benefits of future ES & Summary of respondent's deductive reasoning \\
\hline GO2 & $\begin{array}{l}\text { (1) A significant increase proportion of } \\
\text { variable/intermittent renewables * }\end{array}$ & $\begin{array}{l}\text { (1) However, the system would initially years to use up existing } \\
\text { hydro capacity that will soon be freed-up for use in the North } \\
\text { Island (via the upgraded HVDC link in 2012) }\end{array}$ \\
\hline GO3 & $\begin{array}{l}\text { (1) Improved security of supply } \\
\text { (2) Economic - increased flexibility }\end{array}$ & $\begin{array}{l}\text { (1) During dry winters \& backup for unexpected loss of gas-based } \\
\text { plant } \\
\text { (2) Flexibility has monetary value, but hard to quantify }\end{array}$ \\
\hline NGO2 & $\begin{array}{l}\text { (1) Improved system reliability } \\
\text { (2) Improved security of supply }\end{array}$ & $\begin{array}{l}(1 \& 2) \text { Will significantly improve the likelihood of achieving } \\
\text { complete adequacy in both cases }\end{array}$ \\
\hline INDIV1 & $\begin{array}{l}\text { (1) Eliminate market volatility } \\
\text { (2) Possible } 90-100 \% \text { renewables }\end{array}$ & $\begin{array}{l}\text { (1) Dry seasons increase volatility due to inflexibility of existing } \\
\text { hydro } \\
\text { (2) Removes the requirement for thermal backup }\end{array}$ \\
\hline INDIV2 & (1) Complete security of supply & $\begin{array}{l}\text { (1) "A whole-lot of problems would go away", dry-year supply } \\
\text { issues, supply failures, etc. This is because NZ's current energy } \\
\text { storage capacity is relatively limited. }\end{array}$ \\
\hline INDIV3 & $\begin{array}{l}\text { (1) } \mathrm{CO}_{2} \text {-e emissions mitigation } \\
\text { (2) Conservation of petrochemical } \\
\text { resources for future generations } \\
\text { (3) Improved security of supply }\end{array}$ & $\begin{array}{l}\text { (1 \& 2) Displaces gas/diesel-based fossil fuel combustion } \\
\text { (3) E.g., during dry winters }\end{array}$ \\
\hline INDIV4 & $\begin{array}{l}\text { (1) Increases renewable share } \\
\text { (2) Avoided costs of transmission } \\
\text { upgrades } \\
\text { (3) Improved local air quality }\end{array}$ & $\begin{array}{l}\text { (1) Fast start energy storage allows for displacement of fast-start } \\
\text { peaking plant } \\
\text { (2) Through improved flexibility } \\
\text { (3) Displacement of thermal plant at population centres }\end{array}$ \\
\hline INDIV5 & $\begin{array}{l}\text { (1) Improved security of supply } \\
\text { (2) Increases renewable share } \\
\text { (3) } \mathrm{CO}_{2} \text {-e emissions mitigation } \\
\text { (4) Increased longevity of plant } \\
\text { (5) Buffer fuel uncertainties }\end{array}$ & $\begin{array}{l}\text { (1) More power \& energy capacity available } \\
\text { (2 \& 3) Removes the requirement for thermal backup } \\
\text { (4) For pumped hydro only (relative to thermal plant) } \\
\text { (5) Future prices of fossil fuels are highly uncertain }\end{array}$ \\
\hline INDIV6 & (1) Improved security of supply & (1) Long-run security of supply could be achieved \\
\hline INDIV8 & $\begin{array}{l}\text { (1) Reduce market volatility } \\
\text { (2) Avoided cost of reserves } \\
\text { (3) Improved ancillary services }\end{array}$ & $\begin{array}{l}\text { (1) Managing price spikes } \\
\text { (2) Minimises the need for reserve generators } \\
\text { (3) Improved frequency keeping }\end{array}$ \\
\hline
\end{tabular}

* The decommissioning of Huntly coal units was also noted to be a likely result, although this was not directly presented by the respondent as a 'potential benefit'. 


\section{Gareth Kear (garethkear@hotmail.com)}

Table AG3. Summary of responses obtained during the interview for Questions B1 on the likely future contribution of thermal reserves: "Do you respond in the questionnaire that more thermal backup power (such as peaker capacity) is more likely to be to be introduced than new forms of renewable energy storage such as pumped hydro? If so, why. Or if not, why not?"

\begin{tabular}{|c|c|c|}
\hline Q.B1 & Ans. & Summary of respondent's deductive reasoning \\
\hline GO2 & Yes & (1) Thermal is likely to be the most cost effective option \\
\hline \multirow[t]{3}{*}{ GO3 } & Yes & (1) Thermal is likely to be the most cost effective option \\
\hline & & (2) RMA consent processes are quick \& cheap $\&$ receive very little public opposition \\
\hline & & (4) There are long term fuel-supply contracts in place that need to be honoured \\
\hline \multirow[t]{3}{*}{ NGO2 } & Yes & $\begin{array}{l}\text { (1) There will be a role for thermal peaking under the scenario presented (although wind can } \\
\text { displace hydro used for baseload and 'free-up' capacity for peaking applications) }\end{array}$ \\
\hline & & (2) Thermal is flexible and has more value when used for backup rather than baseload \\
\hline & & (3) Only considers gas (excludes diesel due to projected oil-price volatility) \\
\hline \multirow[t]{3}{*}{ INDIV1 } & Yes & (1) Thermal is likely to be the most cost effective option \\
\hline & & $\begin{array}{l}\text { (2) RMA consent processes are quick \& cheap \& receive very little public opposition (local } \\
\text { environmental impact more important to public opinion than global impact) }\end{array}$ \\
\hline & & (3) Low visual impact \\
\hline \multirow[t]{2}{*}{ INDIV2 } & No & (1) Wind can displace hydro used for baseload \& 'free-up' hydro capacity for peaking \\
\hline & & $\begin{array}{l}\text { However, positive aspects of thermal capacity are: small local environmental impact physical } \\
\text { footprint (including visual impact, modest local environmental impacts and "trivial" air quality } \\
\text { issues [applies to "clean fuels" only]) }\end{array}$ \\
\hline \multirow[t]{5}{*}{ INDIV3 } & Yes & (1) Local environmental impact more important to majority of public than global impact \\
\hline & & (2) Politicians prefer to avoid of public backlash associated with wind \& hydro \\
\hline & & (3) Thermal can be installed "under the radar" (low visual impact \& media coverage). \\
\hline & & (4) Flexible site selection and there are gas resources within range of Auckland \\
\hline & & (5) Hydro generally requires longer transmission lines \\
\hline \multirow[t]{3}{*}{ INDIV4 } & Yes & (1) Thermal is well understood and generators are familiar with this approach \\
\hline & & (2) Industry is risk averse (unlikely to favour long-term returns \& new investment types) \\
\hline & & $\begin{array}{l}\text { (3) Thermal is perceived to be the most likely cost effective option, but may be the case only when } \\
\text { the assessment is based on a short-term investment-based approach }\end{array}$ \\
\hline \multirow[t]{4}{*}{ INDIV5 } & Yes & (1) Thermal is likely to be the most cost effective option \\
\hline & & (2) Favoured by "political and bureaucratic processes" \\
\hline & & (3) Shorter timescales associated with RMA consent \& construction process \\
\hline & & (4) Fast-start technology (of the order of minutes) \\
\hline \multirow[t]{4}{*}{ INDIV6 } & Yes & (1) Mature, reliable \& well established technology \\
\hline & & (2) Thermal is well understood and will benefit from the "Sheer inertia of familiarity" \\
\hline & & (3) Thermal is likely to be the most cost effective option \\
\hline & & (4) Thermal would have to be banned through regulation or be economically undesirable \\
\hline INDIV8 & No & (1) Caveat: if capacity factor is high (0.1-0.2). At 0.05 thermal likely more cost-effective \\
\hline
\end{tabular}


Table AG4. Summary of the perceived negative aspects of increasing the capacity of thermal generation for backup applications. (The respondent's perceived benefits and drivers of thermal capacity are described in Table AE3.)

\begin{tabular}{|c|c|}
\hline Code & Primary negative aspects of thermal capacity \\
\hline GO2 & (1) $\mathrm{CO}_{2}$-e emissions \\
\hline GO3 & (1) $\mathrm{CO}_{2}$-e emissions (a very significant drawback) \\
\hline $\mathrm{NGO} 2$ & $\begin{array}{l}\text { (1) Fuel supply and fuel price uncertainties (20-25-year lifetime expected) } \\
\text { (2) } \mathrm{CO}_{2} \text {-e emissions and carbon pricing }\end{array}$ \\
\hline INDIV1 & (1) $\mathrm{CO}_{2}$-e emissions \\
\hline INDIV2 & $\begin{array}{l}\text { (1) } \mathrm{CO}_{2} \text {-e emissions } \\
\text { (2) Requires stable fuel supplies }\end{array}$ \\
\hline INDIV3 & $\begin{array}{l}\text { (1) } \mathrm{CO}_{2} \text {-e emissions (non-renewable technologies) } \\
\text { (2) Can use/value petrochemicals at as feedstock rather than just as combustion reactants }\end{array}$ \\
\hline INDIV4 & $\begin{array}{l}\text { (1) Thermal capacity will not viable when fossil fuels are likely to be restricted } \\
\text { (2) } \mathrm{CO}_{2} \text {-e emissions } \\
\text { (3) Internationally, the combustion of carbon may soon be viewed as a "moral crime" }\end{array}$ \\
\hline INDIV5 & $\begin{array}{l}\text { (1) } \mathrm{CO}_{2} \text {-e emissions (contrary to climate change mitigation policy) } \\
\text { (2) Security of supply [fuel supply] } \\
\text { (3) Limited longevity relative to hydroelectricity-based technologies }\end{array}$ \\
\hline INDIV6 & $\begin{array}{l}\text { (1) } \mathrm{CO}_{2} \text {-e emissions (contrary to climate change mitigation policy) } \\
\text { (2) Can use/value petrochemicals as a chemical feedstock rather than just as combustion reactants }\end{array}$ \\
\hline INDIV8 & - \\
\hline
\end{tabular}




\section{Gareth Kear (garethkear@hotmail.com)}

Table AG5. Summary of responses obtained during the interview for Questions B2 on the likely impact of the prices of carbon and petroleum: "Do you think that the price of $\mathrm{CO}_{2}$-e and oil-price uncertainty have the potential to stop investment in thermal backup generation by 2025?"

\begin{tabular}{|c|c|c|}
\hline Q.B2 & Answer & Summary of respondent's deductive reasoning \\
\hline \multirow[t]{2}{*}{$\mathrm{GO} 2$} & \multirow[t]{2}{*}{ No } & (1) This answer excludes dry-year reserve, i.e., coal is likely to be influenced \\
\hline & & $\begin{array}{l}\text { (2) Peaking/fast reserve LRMCs will be high because the capacity factor is very low. } \\
\text { Emissions will be of a low volume, therefore an this type of plant will run only at extremely } \\
\text { high wholesale electricity prices.. Carbon pricing, therefore, is likely to be small by } \\
\text { comparison to the wholesale electricity price }\end{array}$ \\
\hline GO3 & I don’t know & - \\
\hline \multirow[t]{6}{*}{ NGO2 } & \multirow{2}{*}{$\begin{array}{l}\text { Yes (diesel } \\
\text { peakers) }\end{array}$} & (1) ETS has already influenced how fossil fuels are viewed within the industry \\
\hline & & (2) Certain to have some influence in the future, especially on gas baseload \\
\hline & $\begin{array}{l}\text { Yes (gas } \\
\text { baseload) }\end{array}$ & $\begin{array}{l}\text { (3) Contact is now storing gas for generation when whole sale electricity prices are high } \\
\text { (more profitable). }\end{array}$ \\
\hline & \multirow{3}{*}{$\begin{array}{l}\text { I don't know } \\
\text { (gas peakers) }\end{array}$} & (4) Peakers less likely to be influenced by the price of $\mathrm{CO}_{2}$-e, as Point (2), above \\
\hline & & (4) MED modelling indicates that thermal peaking capacity will still be present \\
\hline & & (5) If diesel is the only option, will certainty have a significant impact on peakers \\
\hline \multirow[t]{5}{*}{ INDIV1 } & \multirow[t]{5}{*}{ Possible } & (1) Considerable uncertainty \\
\hline & & (2) The price of $\mathrm{CO}_{2}$-e is the most significant issue \\
\hline & & $\begin{array}{l}\text { (3) At a significantly high oil price, consumers will transition to electric vehicles, which may } \\
\text { encourage thermal if this happens very rapidly }\end{array}$ \\
\hline & & (4) With a supply of gas, $\mathrm{NZ} \$ 200-300 \mathrm{CO}_{2}-\mathrm{e}$ tonne ${ }^{-1}$ will be required. \\
\hline & & $\begin{array}{l}\text { (5) If diesel is the only option, will certainty have a significant impact on peakers, but only if } \\
\text { capacity factor increases beyond current utility (i.e., Whirinaki) }\end{array}$ \\
\hline \multirow[t]{2}{*}{ INDIV2 } & \multirow[t]{2}{*}{ No } & $\begin{array}{l}\text { (1) Thermal backup may be limited by fuel supply constraints for both gas and diesel (not the } \\
\text { price of } \mathrm{CO}_{2}-\mathrm{e} \text {, in the case of the former) }\end{array}$ \\
\hline & & $\begin{array}{l}\text { (2) Peakers will have low capacity factors, thus enabling wholesale electricity prices to be } \\
\text { very high prior to the cut-off point }\end{array}$ \\
\hline \multirow[t]{3}{*}{ INDIV3 } & \multirow[t]{3}{*}{ Yes } & (1) Gas \& diesel will both be affected (although OCGTs can use both fuels) \\
\hline & & (2) We are close to realising peak oil \\
\hline & & (3) $\mathrm{CO}_{2}$-e pricing introduces uncertainty for investors adopting thermal capacity \\
\hline \multirow[t]{3}{*}{ INDIV4 } & \multirow[t]{3}{*}{ Possible } & (1) Industry will not be ready for change and will have to catch-up \\
\hline & & (2) Diesel is likely to be affected first \\
\hline & & (3) It is likely that a price of $\sim \mathrm{US} \$ 200(\mathrm{NZ} \$ 260) \mathrm{CO}_{2}$-e tonne ${ }^{-1}$ will be required. \\
\hline \multirow[t]{2}{*}{ INDIV5 } & Yes (diesel) & (1) Limited security of supply of oil (Diesel is likely to be affected first) \\
\hline & No (gas) & $\begin{array}{l}\text { (5) "The ETS is useless at the moment". It is likely that a price of } \sim \mathrm{US} \$ 200(\mathrm{NZ} \$ 260) \mathrm{CO}_{2^{-}} \\
\text {e tonne }{ }^{-1} \text { will be required for real change to occur }\end{array}$ \\
\hline \multirow[t]{3}{*}{ INDIV6 } & \multirow[t]{3}{*}{ Yes } & (1) But $>\mathrm{NZ} \$ 100 \mathrm{CO}_{2}$-e tonne $\mathrm{e}^{-1}$ will be required \\
\hline & & (2) $\$ 12.50$ to $\$ 25$ tonne $^{-1}$ will not be effective \\
\hline & & $\begin{array}{l}\text { (3) Oil price uncertainty less of an issue (assuming little new diesel constructed. Only } \\
\text { Whirinaki will be affected, which has a low capacity factor }\end{array}$ \\
\hline \multirow[t]{2}{*}{ INDIV8 } & \multirow[t]{2}{*}{ No } & (1) Electricity market is primary problem \\
\hline & & $\begin{array}{l}\text { (2) "[T] he chances are that the world will continue to cool thus disproving the hypothesis of } \\
\text { dangerous man made global warming" }\end{array}$ \\
\hline
\end{tabular}




\section{Gareth Kear (garethkear@hotmail.com)}

Table AG6. Summary of responses obtained during the semi-structured interview for Questions C1 on past performance in regard to dry-year security of supply: "In the past, have the institutional arrangements for security of supply during extremely dry years been wholly adequate?"

\begin{tabular}{|c|c|c|}
\hline Q.C1 & Ans. & Summary of respondent's deductive reasoning \\
\hline GO2 & No & (1) Ministerial Review was required and was implemented to improve situation \\
\hline \multirow[t]{3}{*}{ GO3 } & No & (1) Market pricing works, but only to an extent \\
\hline & & (2) Conservation cut-backs every 3-4 years have not been good for the economy \\
\hline & & (3) Investment and management incentives needed to prevent future scarcity prices \\
\hline \multirow[t]{2}{*}{ NGO2 } & No & (1) No black-outs, but economic activity been attenuated \\
\hline & & $\begin{array}{l}\text { (2) Whirinaki operated previously in a manner whereby the true costs of security of supply have not } \\
\text { been realised through the market }\end{array}$ \\
\hline INDIV1 & No & (1) Perception of the issue in NZ was negative, thus, Ministerial Review initiated \\
\hline INDIV2 & No & (1) Dry-year impacts are themselves evidence of inadequate management \\
\hline \multirow[t]{2}{*}{ INDIV3 } & No & $\begin{array}{l}\text { (1) Modelling has been inadequate, although the hydro resource is part of a complex system. E.g., } \\
\text { Geographical spread of hydro inflows between North and South Island is not symmetrical (e.g., full } \\
\text { lakes in north, draught in south) }\end{array}$ \\
\hline & & (2) Inability to consider 'security of supply' before 'efficiency' \\
\hline \multirow[t]{2}{*}{ INDIV4 } & No & (1) Improper use of Whirinaki Power Station \\
\hline & & (2) Demand side not included \\
\hline \multirow[t]{2}{*}{ INDIV5 } & No & (1) No disasters, but three dry-year evens over 10 years has not been ideal \\
\hline & & $\begin{array}{l}\text { (3) Repeated requests for conservation will result in public demand for improvements in physical } \\
\text { infrastructure }\end{array}$ \\
\hline \multirow[t]{3}{*}{ INDIV6 } & No & (1) “Utterly inadequate" \\
\hline & & (2) The system is driven by short-term economic efficiency not 'security of supply' \\
\hline & & $\begin{array}{l}\text { (3) More corporate responsibility is needed along with medium to long-term thinking regarding } \\
\text { infrastructure and institutional arrangements }\end{array}$ \\
\hline INDIV8 & No & (1) The NZ electricity market cannot manage dry-year problem effectively \\
\hline
\end{tabular}




\section{Gareth Kear (garethkear@hotmail.com)}

Table AG7. Summary of responses obtained during the semi-structured interview for Questions C2 on pumped hydro and future dry-year security of supply: "Do you think that most, if not all, of the negative aspects of dry year events could be mitigated through the use of large-scale pumped hydro, for example?"

\begin{tabular}{|c|c|c|}
\hline Q.C2 & Answer & Summary of respondent's deductive reasoning \\
\hline \multirow[t]{2}{*}{ GO2 } & No & (1) Not economically feasible \\
\hline & & (2) Uncertainty of a reasonable rate of return on the investment \\
\hline \multirow[t]{5}{*}{ GO3 } & Possible & Technically possible, but: \\
\hline & & (1) New generation is being built to accommodate this, such as geothermal and wind \\
\hline & & (2) Relatively poor economics of pumped hydro is a barrier \\
\hline & & (3) No incentives for 'security of supply' over 'efficiency' (see Section XX) \\
\hline & & (4) However, this is not a free-market issue \\
\hline \multirow[t]{5}{*}{ NGO2 } & No & (1) Historically, energy storage has moved from hydro towards gas and coal \\
\hline & & (2) New generation is being built to accommodate this, such as geothermal and wind \\
\hline & & (3) Ministerial review should promote 'security of supply' ("still evolving") \\
\hline & & (5) However, this is not a free-market issue \\
\hline & & (6) Pumped hydro is the last step in the security of supply risk management process \\
\hline \multirow[t]{3}{*}{ INDIV1 } & Possible & Technically possible, but: \\
\hline & & (1) Unfavourable economics, RMA consenting processes and scale of energy needed \\
\hline & & (2) However, this is not a free-market issue \\
\hline \multirow[t]{4}{*}{ INDIV2 } & Yes & $\begin{array}{l}\text { (1) A very large, standalone system such as the Manorburn-Onslow proposal would be required } \\
\text { (although this particular proposal was noted to be uneconomic) }\end{array}$ \\
\hline & & (2) Should review the consent limitations of Lake Hawea prior to pumped hydro \\
\hline & & (3) No incentives for 'security of supply' over 'efficiency' (see Section XX) \\
\hline & & (4) This is a free market problem \\
\hline \multirow[t]{6}{*}{ INDIV3 } & Yes & (1) Would benefit from a large pumped hydro facilities in South and North Islands \\
\hline & & (2) A low cost pumped hydro solution required (i.e., utility of existing lakes) \\
\hline & & (3) Long term thinking is required (may only be economical at a $>30$-year return \\
\hline & & (4) Long-term thinking is not fashionable (year-by-year, short-term thinking is) \\
\hline & & $\begin{array}{l}\text { (6) This is a free market problem. There are counter incentives in place (generators can increase } \\
\text { profits during dry years when prices increase. 'Security of supply' is not the priority. Making } \\
\text { money efficiently is the primary goal }\end{array}$ \\
\hline & & (8) Need to plan for the 100-year dry-year event \\
\hline \multirow[t]{4}{*}{ INDIV4 } & Possible & Technically possible, but: \\
\hline & & (1) Large uncertainties associated with RMA consenting processes and social issues \\
\hline & & $\begin{array}{l}\text { (2) This is a free market problem and the government has to step in to control the market if } \\
\text { emissions reduction is taken seriously }\end{array}$ \\
\hline & & (3) Environmental issues associated with hydro are not mitigated by pumped hydro \\
\hline \multirow[t]{7}{*}{ INDIV5 } & Possible & Technically possible, but: \\
\hline & & (1) $10,000 \mathrm{GWh}$ storage will be effective, but will be too expensive to keep in reserve \\
\hline & & (2) Multiple smaller pumped hydro schemes are more likely than large schemes \\
\hline & & (5) Local environmental issues and public opposition \\
\hline & & (6) No incentives for 'security of supply' over 'efficiency' (see Section XX) \\
\hline & & (7) Would probably need to be funded a government source, or directly regulated for \\
\hline & & (8) However, this is not a free-market issue \\
\hline \multirow[t]{4}{*}{ INDIV6 } & Possible & Technically possible, but: \\
\hline & & (1) Probably not economically viable (especially marine pumped hydro) \\
\hline & & (2) More efficient management of existing hydro more cost-effective and responsible \\
\hline & & (3) It is a free market problem, especially as the level of corporate responsibility is low \\
\hline \multirow[t]{2}{*}{ INDIV8 } & No & $\begin{array}{l}\text { (1) Not a long-term storage solution (other than the Manorburn-Onslow proposal, which is not } \\
\text { economically viable) }\end{array}$ \\
\hline & & (2) Other generators/investors may increase electricity prices when pumping occurs \\
\hline
\end{tabular}


Table AG8. Summary of responses obtained during the semi-structured interview for Questions D1 on the extent of hydro spillage in NZ: "Is hydro spillage a serious issue in terms of energy losses from the system?" and D2: "How much money (or energy) can be saved from the sector (or individual hydro lakes) through spillage mitigation?"

\begin{tabular}{|c|c|c|c|}
\hline Code & $\begin{array}{l}\text { Ans. } \\
\text { Q.D1 }\end{array}$ & $\begin{array}{l}\text { Ans. } \\
\text { Q.D2 }\end{array}$ & Summary of respondents deductive reasoning \\
\hline \multirow[t]{2}{*}{$\mathrm{GO} 2$} & No & None & $\begin{array}{l}\text { (1) Unusual events will happen. Early } 2009 \text { combination of high inflows, Tiwai Point } \\
\text { Smelter offline and the currently limited HVDC transmission capacity }\end{array}$ \\
\hline & & & (2) New HVDC pole to be commissioned 2012 will limit impacts of such events \\
\hline GO3 & No & $\begin{array}{l}\text { Very } \\
\text { little }\end{array}$ & $\begin{array}{l}\text { (1) But, the Ministerial Review result is likely to promote hydro-based 'security of supply' } \\
\text { over 'economic efficiency'. This will result in increased spillage. }\end{array}$ \\
\hline \multirow[t]{4}{*}{ NGO2 } & No & None & (1) Spillage involves low volumes when averaged over the long term \\
\hline & & & $\begin{array}{l}\text { (2) Early } 2009 \text { was result of combination of high inflows, Tiwai Point Smelter being } \\
\text { offline and limited DC transmission capacity }\end{array}$ \\
\hline & & & (3) "Don't need a huge investment in pumped storage just for a one-off scenario" \\
\hline & & & (4) Long-term hydrology trends may differ from short-term indicators \\
\hline \multirow[t]{2}{*}{ INDIV1 } & Yes & I don't & (1) However, if an economic method available, it would have been applied \\
\hline & & know & (3) Access to the resource would also be highly variable \\
\hline INDIV2 & No & $\begin{array}{l}\text { Very } \\
\text { little }\end{array}$ & $\begin{array}{l}\text { (1) Most years 100s GWh are spilled, not 1,000s GWh. The late } 2008 / 2009 \text { was simply a } \\
\text { one-off result of the Tiwai Point Smelter being offline }\end{array}$ \\
\hline \multirow[t]{3}{*}{ INDIV3 } & No & $\begin{array}{l}\text { I don't } \\
\text { know }\end{array}$ & $\begin{array}{l}\text { (1) Not an issue with the existing utility of system based on economic 'efficiency', } \\
\text { although pumped hydro could save spillage from any Tiwai Point smelter down time }\end{array}$ \\
\hline & & & $\begin{array}{l}\text { (2) Generally, only of significance only to generators in regard to financial losses, but this } \\
\text { could contribute to the capital costs of energy storage }\end{array}$ \\
\hline & & & $\begin{array}{l}\text { (3) But, highly uncertain income source with events occurring every 5-10 years - needs a } \\
\text { long-run approach to investment (missing in NZ at the moment) }\end{array}$ \\
\hline \multirow[t]{3}{*}{ INDIV4 } & Yes & $\begin{array}{l}\text { I don't } \\
\text { know }\end{array}$ & $\begin{array}{l}\text { (1) Generators would like to increase economic efficiency by mitigating all spillage, but } \\
\text { the cost effectiveness of saving spillage is unknown }\end{array}$ \\
\hline & & & (2) Savings are probably not likely to contribute to capital costs of storage \\
\hline & & & $\begin{array}{l}\text { (2) But ideally, the system should utilising all available water resources to offset the need } \\
\text { for the equivalent amount of generation elsewhere at a later time }\end{array}$ \\
\hline \multirow[t]{2}{*}{ INDIV5 } & Don't & I don't & (1) Uncertain if at a significant level to warrant introduction of energy storage \\
\hline & know & know & (2) Timing of spillage events important, but difficult to manage \\
\hline \multirow[t]{2}{*}{ INDIV6 } & No & $\begin{array}{l}\text { Very } \\
\text { little }\end{array}$ & $\begin{array}{l}\text { (1) Since 1998/1999“Generators are not allowed to spill...they have to give notification”. } \\
\text { This maximises the efficiency of water use and reduces spillage. }\end{array}$ \\
\hline & & & $\begin{array}{l}\text { (2) "Using water to pump water" is not viable. Pumped hydro could not be used to } \\
\text { mitigate spillage under conditions of high inflow rates, as hydro turbines are likely to be } \\
\text { operating at maximum capacity to minimize spillage (offsetting generation elsewhere). A } \\
\text { proportion of this power would be used for pumping (more efficient to transmit directly to } \\
\text { point of demand). }\end{array}$ \\
\hline \multirow[t]{2}{*}{ INDIV8 } & No & $\begin{array}{l}\text { Very } \\
\text { little }\end{array}$ & $\begin{array}{l}\text { (1) Very little at the moment }(\sim 2 \%) \text {, but will increase significantly at } 20 \% \text { wind (hydro } \\
\text { inflow-wind intensity correlation, i.e., security of supply > efficiency. }\end{array}$ \\
\hline & & & (2) Could increase regulation of unregulated lakes to save spillage \\
\hline
\end{tabular}


Table AG9. Summary of responses obtained during the semi-structured interview for Questions E1 on the current status of introduced energy storage: "Do you know if your organization/the electricity sector has considered introducing renewable energy storage such as pumped hydro and batteries?" and the sub-question: "What was the result?"

\begin{tabular}{|c|c|c|}
\hline Q.E1 & Ans. & Summary of respondents deductive reasoning \\
\hline \multirow[t]{2}{*}{ GO2 } & $\begin{array}{l}\text { Feasibility } \\
\text { study }\end{array}$ & $\begin{array}{l}\text { (1) The EC conducted an economic analysis of the Manorburn-Onslow proposal. Result: not } \\
\text { economically feasible }\end{array}$ \\
\hline & & (2) Genesis may have examined pumped hydro \\
\hline \multirow[t]{3}{*}{ GO3 } & Feasibility & (1) Meridian funded an energy storage study that was conducted offshore in the USA \\
\hline & & $\begin{array}{l}\text { (2) Not economic relative to maximising the effectiveness of existing hydro capacity. Also, } \\
\text { issues in the market regarding 'security of supply' } v s \text {. 'economic efficiency' }\end{array}$ \\
\hline & & (3) Pumped hydro discussed (Manorburn-Onslow proposal), but not seriously considered \\
\hline NGO2 & I don't know & (1) Energy storage is "on the radar of the gentailers" \\
\hline INDIV1 & $\begin{array}{l}\text { Feasibility } \\
\text { study }\end{array}$ & (1) Did not note the name of the organisation, or the result of the analysis \\
\hline \multirow[t]{2}{*}{ INDIV2 } & No & (1) Batteries - definitely not \\
\hline & & (2) Pumped hydro discussed (Manorburn-Onslow proposal), but not seriously considered \\
\hline \multirow[t]{2}{*}{ INDIV3 } & No & (1) Pumped hydro discussed (Manorburn-Onslow proposal), but not seriously considered \\
\hline & & $\begin{array}{l}\text { (2) Manorburn-Onslow proposal probably is not economic due to: lack of bottom lake, } \\
\text { lengthy tunnel and net evaporation. Cheaper alternatives are available for development } \\
\text { using existing lakes (e.g., a Tekapo scheme \& modification of the Hawea consent limits) }\end{array}$ \\
\hline INDIV4 & No & (1) Has only been seriously considered at the micro, mini and community scales \\
\hline INDIV5 & No & - \\
\hline INDIV6 & I don't know & - \\
\hline INDIV8 & $\begin{array}{l}\text { Feasibility } \\
\text { studies }\end{array}$ & $\begin{array}{l}\text { (1) "I have worked on several proposals for pumped storage. But, the way the electricity } \\
\text { market works, they are not viable". [Projects were not described] }\end{array}$ \\
\hline
\end{tabular}

Table AE10. "Do NZ-new types of utility-scale energy storage technologies have a future in NZ?”

\begin{tabular}{|c|c|c|}
\hline Code & Answer & Time scales \& notes \\
\hline $\mathrm{GO} 2$ & Likely & $\begin{array}{l}\text { Short to medium term. There is a considerable opportunity for batteries in regard to supply of } \\
\text { ancillary services, such as } 6 \mathrm{~s} \text { fast reserves at the } 6 \mathrm{~s} \text { response scale. For example, batteries } \\
\text { can be deployed with wind turbines to store dc energy for release as fast reserve, when } \\
\text { required. }\end{array}$ \\
\hline GO3 & Likely & $\begin{array}{l}\text { Medium to long term (> } 10 \text { years from the present). Economic viability could improve, } \\
\text { especially for ancillary services and as a result of EVs. Respondent could not predict the rate } \\
\text { of development of utility-scale batteries, but the lead-in time will also depend on the dominant } \\
\text { political paradigm. New forms of energy storage, for example will be essential to achieve a } \\
100 \% \text { renewables target. }\end{array}$ \\
\hline NGO2 & Likely & $\begin{array}{l}\text { Long term (probably). NZ should utilise both existing hydro capacity for peaking and weather } \\
\text { forecasting more effectively first. This approach is likely to be most cost effective that the } \\
\text { introduction of new forms of energy storage. }\end{array}$ \\
\hline INDIV1 & Likely & Long term. The sector is following developments in energy storage. \\
\hline INDIV2 & Possible & $\begin{array}{l}\text { Long term (pumped hydro only). NZ should utilise both existing hydro capacity for peaking } \\
\text { more effectively first. Batteries are unlikely to be introduced within the foreseeable future, } \\
\text { especially where pumped hydro is an alternative. }\end{array}$ \\
\hline INDIV3 & Likely & $\begin{array}{l}\text { Short to medium term (pumped hydro only). Only if natural lakes are used (for example, } \\
\text { pumping via canals). Pumped hydro has the potential to be "cheaper than thermal". A } \\
\text { "serious" study is required, although, "no one is taking responsibility" }\end{array}$ \\
\hline INDIV4 & Likely & $\begin{array}{l}\text { Unknown timescale. The sector is not particularly "agile" in terms of the adoption of new } \\
\text { technologies. Government may need to step-in during the initiation phase. }\end{array}$ \\
\hline INDIV5 & Possible & Will depend on the development of the economic viability of the technologies. \\
\hline INDIV6 & Likely & $\begin{array}{l}\text { Medium to long term ( } 2025 \text {, batteries only). "[I] don't see immediate prospects of either } \\
\text { batteries or pumped storage. " [However,] the situation will change radically once EVs are } \\
\text { integrated with the grid". Second hand car batteries from EVs could also lower the capital } \\
\text { cost of large utility-scale battery banks. }\end{array}$ \\
\hline INDIV8 & - & - \\
\hline
\end{tabular}




\section{Gareth Kear (garethkear@hotmail.com)}

Table AG11. Summary of responses obtained during the semi-structured interview for Questions E2 on the potential for rational decision making in the sector: "If the long run marginal cost of electricity from pumped hydro or batteries can be proven (by a number of sources) to be similar to thermal backup, would your organization/the sector consider investigating further?"

\begin{tabular}{|c|c|c|}
\hline Q.E2 & Answer & Summary of respondent's deductive reasoning \\
\hline GO2 & Yes & (1) Decision making is simply based on economic considerations \\
\hline GO3 & Yes & (1) Energy storage has niche applications that may be economic \\
\hline NGO2 & Yes & $\begin{array}{l}\text { (1) Decision making is simply based on economic considerations. "If it can make money at the } \\
\text { required rate of return, It will be on the agenda" }\end{array}$ \\
\hline INDIV 1 & Yes & $\begin{array}{l}\text { (1) Sector makes a rational decisions, that are not be based on ideology } \\
\text { (2) At least one of the generator consider themselves to be "fuel agnostic" } \\
\text { (3) The most economic solution may be not to introduce new solutions }\end{array}$ \\
\hline INDIV2 & Yes & (1) Decision making is simply based on economic considerations \\
\hline INDIV3 & Yes & $\begin{array}{l}\text { (1) Caveat: only if public/political aversion to thermal generation appears } \\
\text { (2) Investors "need to be brave enough to do something different" }\end{array}$ \\
\hline INDIV4 & Yes & $\begin{array}{l}\text { (1) Decision making will be based on economic considerations, but may depend on individuals } \\
\text { within the sector to guide investors into innovation } \\
\text { (2) Need to "kick-start" a trend in the industry }\end{array}$ \\
\hline INDIV5 & Yes & (1) Decision making is simply based on economic considerations \\
\hline INDIV6 & Possible & $\begin{array}{l}\text { (1) Decision making will be based on economic considerations, but will also depend on the } \\
\text { format of the market, cartels and other vested interests. } \\
\text { (2) In regard to the introduction of sustainable solutions: "The sector is planning to obstruct } \\
\text { change, not to create it" } \\
\text { (3) Government intervention (e.g., regulation) may be required to legitimise future decision } \\
\text { making processes }\end{array}$ \\
\hline INDIV8 & - & Declined to respond \\
\hline
\end{tabular}




\section{Appendix H Thermal reserve capacity under EC and MED scenarios to 2040}

Table AH1. Review of EC-derived [20], 2008 SOO-projected new-build schedule of peaking plant (diesel-, gas-, standard hydroand pumped hydro-based) and introduced dry year reserve (Huntly Units 1-4 only) from 2009 to 2038 for scenarios MDS1 to MDS5. Non-peaking hydro is excluded and the individual Huntly unit transitions to dry-year reserve are each associated with the decommissioning of $226 \mathrm{MW}$ of existing coal-based capacity (see also Table AH2 for further details of the Huntly coal-based unit decommissioning schedules). The early 'Gas (fast start)' capacity can be assumed for the purposes of this work to include the newly commissioned Stratford peaking plant.

\begin{tabular}{|c|c|c|c|c|c|c|c|c|c|c|}
\hline & MDS1 & $\begin{array}{l}\text { Power } \\
\text { / MW }\end{array}$ & MDS2 & $\begin{array}{l}\text { Power / } \\
\text { MW }\end{array}$ & MDS3 & $\begin{array}{l}\text { Power / } \\
\text { MW }\end{array}$ & MDS4 & $\begin{array}{l}\text { Power/ } \\
\text { MW }\end{array}$ & MDS5 & $\begin{array}{l}\text { Power / } \\
\text { MW }\end{array}$ \\
\hline 2009 & Diesel & 150 & & & & & Diesel & 150 & & \\
\hline 2010 & & & Gas (fast start) & 200 & Hydro peaking & 17 & Gas (fast start) & 200 & Gas (fast start) & 200 \\
\hline 2011 & Hydro peaking & 17 & Hydro peaking & 17 & & & & & & \\
\hline 2012 & & & & & Diesel & 150 & Hydro peaking & 17 & & \\
\hline \multirow[t]{2}{*}{2013} & Diesel (x2) & 300 & Diesel (x2) & 300 & Gas (fast start) & 200 & & & Diesel & 150 \\
\hline & & & & & Huntly Unit 1 & 245 & & & & \\
\hline 2014 & & & Diesel & 150 & & & Diesel & 150 & Diesel & 150 \\
\hline 2015 & & & Huntly Unit 2 & 245 & Huntly Unit 2 & 245 & & & Diesel & 150 \\
\hline 2016 & & & Hydro peaking & 100 & & & & & & \\
\hline \multirow[t]{2}{*}{2017} & Gas (fast start) & 200 & & & Diesel & 150 & & & & \\
\hline & Hydro peaking & 100 & & & & & & & & \\
\hline \multirow[t]{2}{*}{2018} & Hydro peaking & 180 & Huntly Unit 3 & 245 & Huntly Unit 3 & 245 & & & Hydro peaking & 180 \\
\hline & & & Hydro peaking & 180 & Hydro peaking & 180 & & & & \\
\hline 2019 & Diesel & 150 & Gas & 200 & & & Hydro peaking & 100 & & \\
\hline 2020 & Hydro peaking & 190 & Hydro peaking & 190 & Huntly Unit 4 & 245 & Diesel & 150 & & \\
\hline 2021 & & & & & & & & & Hydro peaking & 100 \\
\hline 2022 & Gas (fast start) & 200 & & & & & & & & \\
\hline 2023 & Diesel & 150 & & & & & & & & \\
\hline
\end{tabular}

Table AH1 is continued over the page. 
Gareth Kear (garethkear@hotmail.com)

\begin{tabular}{|c|c|c|c|c|c|c|c|c|c|c|}
\hline & MDS1 & $\begin{array}{l}\text { Power } \\
\text { / MW }\end{array}$ & MDS2 & $\begin{array}{l}\text { Power / } \\
\text { MW }\end{array}$ & MDS3 & $\begin{array}{l}\text { Power / } \\
\text { MW }\end{array}$ & MDS4 & $\begin{array}{l}\text { Power / } \\
\text { MW }\end{array}$ & MDS5 & $\begin{array}{l}\text { Power / } \\
\text { MW }\end{array}$ \\
\hline 2024 & Diesel & 150 & Diesel & 150 & & & & & & \\
\hline 2025 & Hydro peaking & 150 & Hydro peaking & 150 & & & & & & \\
\hline \multirow[t]{2}{*}{2026} & & & & & Diesel (x2) & 300 & & & & \\
\hline & & & & & $\begin{array}{l}\text { (Huntly } \\
\text { Unit 1) }\end{array}$ & $(-245)$ & & & & \\
\hline 2027 & & & & & Diesel (x2) & 300 & & & & \\
\hline \multirow[t]{2}{*}{2028} & & & Diesel (x2) & 300 & Gas (fast start) & 200 & & & Diesel & 150 \\
\hline & & & $\begin{array}{l}\text { (Huntly } \\
\text { Unit 2) }\end{array}$ & $(-245)$ & $\begin{array}{l}\text { (Huntly } \\
\text { Unit 2) }\end{array}$ & $(-245)$ & & & & \\
\hline \multicolumn{11}{|l|}{2029} \\
\hline \multirow[t]{2}{*}{2030} & Pumped hydro & 300 & $\begin{array}{l}\text { (Huntly } \\
\text { Unit 3) }\end{array}$ & $(-245)$ & Pumped hydro & 300 & & & & \\
\hline & & & & & $\begin{array}{l}\text { (Huntly } \\
\text { Unit 3) }\end{array}$ & $(-245)$ & & & & \\
\hline 2031 & & & & & & & & & Diesel & 150 \\
\hline 2032 & & & & & $\begin{array}{l}\text { (Huntly } \\
\text { Unit 3) }\end{array}$ & $(-245)$ & & & & \\
\hline \multicolumn{11}{|l|}{2033} \\
\hline \multicolumn{11}{|l|}{2034} \\
\hline 2035 & Pumped hydro & 300 & & & & & & & & \\
\hline \multicolumn{11}{|l|}{2036} \\
\hline \multicolumn{11}{|l|}{2037} \\
\hline 2038 & & & Diesel & 150 & Diesel & 150 & & & & \\
\hline
\end{tabular}


Table AH2. EC-derived cumulative sums of total peaking and dedicated Huntly dry-year reserve power capacity expected to be installed from each type of peaking generator from 2009 to 2025, 2030 and 2040 for 2008 SOO scenarios MDS1 to MDS5 [20].

\begin{tabular}{|c|c|c|c|c|c|}
\hline \multirow[b]{3}{*}{ Net 2009-2025 } & \multicolumn{5}{|c|}{ Installed power capacity / MW } \\
\hline & MDS1 & MDS2 & MDS3 & MDS4 & MDS5 \\
\hline & \multirow[b]{2}{*}{900} & \multirow[b]{2}{*}{600} & \multirow[b]{2}{*}{300} & \multirow[b]{2}{*}{450} & \multirow[b]{2}{*}{450} \\
\hline Diesel peaking & & & & & \\
\hline Gas peaking & 400 & 400 & 200 & 200 & 200 \\
\hline Hydro peaking & 637 & 637 & 197 & 117 & 280 \\
\hline Pumped hydro peaking & 0 & - & 0 & - & - \\
\hline Total peaking & 1,937 & 1,637 & 697 & 767 & 930 \\
\hline Huntly dry-year reserve & - & 490 & 980 & - & - \\
\hline \multicolumn{6}{|l|}{ Net 2009-2030 } \\
\hline Diesel peaking & 900 & 900 & 900 & 450 & 600 \\
\hline Gas peaking & 400 & 400 & 400 & 200 & 200 \\
\hline Hydro peaking & 637 & 637 & 197 & 117 & 280 \\
\hline Pumped hydro peaking & 300 & - & 300 & - & - \\
\hline Total peaking & 2,237 & 1,937 & 1,797 & 7,67 & 1,080 \\
\hline Huntly dry-year reserve & - & 0 & 245 & - & - \\
\hline \multicolumn{6}{|l|}{ Net 2009-2040 } \\
\hline Diesel peaking & 900 & 1,050 & 1050 & 450 & 750 \\
\hline Gas peaking & 400 & 400 & 400 & 200 & 200 \\
\hline Hydro peaking & 637 & 637 & 197 & 117 & 280 \\
\hline Pumped hydro peaking & 600 & - & 300 & - & - \\
\hline Total peaking & 2,537 & 2,087 & 1,947 & 767 & 1,230 \\
\hline Huntly dry-year reserve & - & 0 & 0 & - & - \\
\hline
\end{tabular}


Table AH3. Review of MED-derived [234], 2009 energy outlook-projected new-build schedule of peaking plant (diesel-, gas- and hydro peaking) and introduced dry year reserve (Huntly, coal-gas based Units 1-4 only) from 2009 to 2040 for the reference scenario and the economic, oil price and emissions pricing growth sensitivities. Both the case of zero and very high (NZ\$100 tonne

$\left.{ }^{1}\right)$ emissions price is shown, but for brevity, only 'very high' rates of growth in terms of GDP $\left(+1.5 \% \mathrm{y}^{-1} v s\right.$. reference forecast) and oil price $(+50 \%$ vs. reference forecast) are shown (scenario conditions are defined in Section 3.1). Peaking plant were identified from the power capacity values presented in the list of projects given in the MED's interactive electricity model: cost of generation [234]. The MED Huntly unit transitions to dry-year reserve are each associated with the re-commissioning of $226 \mathrm{MW}^{-1} \mathrm{of}^{-1}$ existing coal-based capacity (in contrast, the EC assumed 245 MW [20]).

\begin{tabular}{|c|c|c|c|c|c|c|c|c|c|c|}
\hline & Reference & $\begin{array}{l}\text { Power } \\
\text { / MW }\end{array}$ & $\begin{array}{l}\text { Very high } \\
\text { GDP Growth }\end{array}$ & $\begin{array}{l}\text { Power/ } \\
\text { MW }\end{array}$ & $\begin{array}{l}\text { Very high oil } \\
\text { price growth }\end{array}$ & $\begin{array}{l}\text { Power/ } \\
\text { MW }\end{array}$ & $\begin{array}{l}\text { Zero emissions } \\
\text { price }\end{array}$ & $\begin{array}{l}\text { Power/ } \\
\text { MW }\end{array}$ & $\begin{array}{l}\text { Very high } \\
\text { emissions } \\
\text { price }\end{array}$ & $\begin{array}{l}\text { Power / } \\
\text { MW }\end{array}$ \\
\hline \multicolumn{11}{|l|}{2009} \\
\hline \multirow[t]{2}{*}{2010} & Gas & 200 & Gas & 200 & Gas & 200 & Gas & 200 & Gas & 200 \\
\hline & Diesel & 150 & Diesel & 150 & Diesel & 150 & Diesel & 150 & Diesel & 150 \\
\hline \multicolumn{11}{|l|}{2011} \\
\hline \multirow[t]{2}{*}{2012} & & & & & & & & & Hydro peaking & 17 \\
\hline & & & & & & & & & Huntly Unit & 226 \\
\hline \multirow[t]{2}{*}{2013} & & & Diesel & 150 & & & & & & \\
\hline & & & Hydro peaking & 17 & & & & & & \\
\hline 2014 & Diesel & 150 & Diesel & 150 & & & & & Huntly Unit & 226 \\
\hline \multirow[t]{2}{*}{2015} & Hydro peaking & 17 & & & Hydro peaking & 17 & & & & \\
\hline & Huntly Unit & 226 & Huntly Unit & 226 & Huntly Unit & 226 & Huntly Unit & 226 & & \\
\hline \multirow[t]{2}{*}{2016} & & & & & & & Diesel & 150 & & \\
\hline & & & & & & & Hydro Peaking & 17 & & \\
\hline 2017 & Huntly Unit & 226 & Huntly Unit & 226 & Huntly Unit & 226 & Huntly Unit & 226 & & \\
\hline 2018 & & & Hydro peaking & 180 & & & & & & \\
\hline
\end{tabular}

Table AH3 is continued over the page. 
Table AH3 continued

\begin{tabular}{|c|c|c|c|c|c|c|c|c|c|c|}
\hline & Reference & $\begin{array}{l}\text { Power } \\
\text { / MW }\end{array}$ & $\begin{array}{l}\text { Very high } \\
\text { GDP Growth }\end{array}$ & $\begin{array}{l}\text { Power / } \\
\text { MW }\end{array}$ & $\begin{array}{l}\text { Very high oil } \\
\text { price growth }\end{array}$ & $\begin{array}{l}\text { Power/ } \\
\text { MW }\end{array}$ & $\begin{array}{l}\text { Zero } \\
\text { emissions } \\
\text { price }\end{array}$ & $\begin{array}{l}\text { Power / } \\
\text { MW }\end{array}$ & $\begin{array}{l}\text { Very high } \\
\text { emissions } \\
\text { price }\end{array}$ & $\begin{array}{l}\text { Power/ } \\
\text { MW }\end{array}$ \\
\hline 2020 & Hydro peaking & 190 & Hydro peaking & 190 & Hydro peaking & 190 & & & Hydro peaking & 190 \\
\hline \multicolumn{11}{|l|}{2021} \\
\hline 2022 & & & & & & & Hydro peaking & 190 & & \\
\hline 2023 & Gas & 200 & & & Gas & 200 & & & & \\
\hline 2024 & & & Diesel & 300 & & & & & Gas & 200 \\
\hline \multicolumn{11}{|l|}{2025} \\
\hline \multicolumn{11}{|l|}{2026} \\
\hline 2027 & & & & & & & Gas & 200 & & \\
\hline 2028 & & & Diesel & 150 & Diesel & 150 & & & & \\
\hline 2029 & & & Gas & 200 & & & Gas & 200 & & \\
\hline 2030 & Gas & 200 & & & Gas & 200 & & & & \\
\hline 2031 & & & Diesel & 150 & & & Gas & 200 & & \\
\hline \multicolumn{11}{|l|}{2032} \\
\hline 2033 & & & Diesel & 150 & & & & & & \\
\hline 2034 & & & Diesel & 150 & & & & & & \\
\hline \multicolumn{11}{|l|}{2035} \\
\hline 2036 & Gas & 200 & & & Gas & 200 & & & & \\
\hline \multicolumn{11}{|l|}{2037} \\
\hline \multicolumn{11}{|l|}{2038} \\
\hline 2039 & & & Gas & 200 & & & & & & \\
\hline 2040 & & & & & & & & & & \\
\hline
\end{tabular}


Table AH4. Summary of MED-derived [234] cumulative sums of total peaking and dedicated Huntly Units 1-4 dry-year reserve power capacity expected to be installed from each type of peaking generator from 2009 to 2025, 2030 and 2040 for an number of selected MED 2009 energy outlook scenarios. Hydro peaking capacities are estimates only, as the 2009 outlook did not specifically distinguish the role of hydroelectricity-based capacity (the hydro peaking capacity, as shown, was identified using the power capacity data published in the . MED's interactive electricity model: cost of generation.

\begin{tabular}{|c|c|c|c|c|c|}
\hline \multirow[b]{3}{*}{ Net 2009-2025 } & \multicolumn{5}{|c|}{ Installed power capacity / MW } \\
\hline & Reference & $\begin{array}{l}\text { Very high } \\
\text { GDP } \\
\text { Growth }\end{array}$ & $\begin{array}{l}\text { Very high } \\
\text { oil price } \\
\text { growth }\end{array}$ & $\begin{array}{l}\text { Zero } \\
\text { emissions } \\
\text { price }\end{array}$ & $\begin{array}{l}\text { Very high } \\
\text { emissions } \\
\text { price }\end{array}$ \\
\hline & \multirow[b]{2}{*}{300} & & \multirow[b]{2}{*}{150} & \multirow[b]{2}{*}{300} & \multirow[b]{2}{*}{150} \\
\hline Diesel peaking & & 750 & & & \\
\hline Gas peaking & 400 & 200 & 400 & 200 & 400 \\
\hline Hydro peaking & 207 & 387 & 207 & 207 & 207 \\
\hline Pumped hydro peaking & - & - & - & - & - \\
\hline Total peaking & 907 & 1337 & 757 & 707 & 757 \\
\hline $\begin{array}{l}\text { Huntly Units 1-4 dry-year } \\
\text { reserve }\end{array}$ & 452 & 452 & 452 & 452 & 452 \\
\hline Net 2009-2030 & & & & & \\
\hline Diesel peaking & 300 & 900 & 300 & 300 & 150 \\
\hline Gas peaking & 600 & 400 & 600 & 600 & 400 \\
\hline Hydro peaking & 207 & 387 & 207 & 207 & 207 \\
\hline Pumped hydro peaking & - & - & 0 & - & - \\
\hline Total peaking & 1107 & 1687 & 1107 & 1107 & 757 \\
\hline $\begin{array}{l}\text { Huntly Units 1-4 dry-year } \\
\text { reserve }\end{array}$ & 452 & 452 & 452 & 452 & 452 \\
\hline Net 2009-2040 & & & & & \\
\hline Diesel peaking & 300 & 1350 & 300 & 300 & 150 \\
\hline Gas peaking & 800 & 600 & 800 & 800 & 207 \\
\hline Hydro peaking & 207 & 387 & 207 & 207 & 400 \\
\hline Pumped hydro peaking & - & - & 0 & - & - \\
\hline Total peaking & 1307 & 2337 & 1307 & 1307 & 757 \\
\hline $\begin{array}{l}\text { Huntly Units 1-4 dry-year } \\
\text { reserve }\end{array}$ & 452 & 452 & 452 & 452 & 452 \\
\hline
\end{tabular}

